Copyright

by

Jonathan Louis Gaspredes

2011 
The Thesis committee for Jonathan Louis Gaspredes Certifies that this is the approved version of the following thesis:

\title{
Development of an Integrated Building Load-Ground Source Heat Pump Model as a Test Bed to Assess Short- and Long-Term Heat Pump and Ground Loop Performance
}

\author{
APPROVED BY \\ SUPERVISING COMMITTEE:
}

Glenn Y. Masada, Supervisor

Tess J. Moon, Co-Supervisor 


\title{
Development of an Integrated Building Load-Ground Source Heat Pump Model as a Test Bed to Assess Short- and Long-Term Heat Pump and Ground Loop Performance
}

\author{
by
}

Jonathan Louis Gaspredes, B.S.M.E.

\author{
THESIS \\ Presented to the Faculty of the Graduate School of \\ The University of Texas at Austin \\ in Partial Fulfillment \\ of the Requirements \\ for the Degree of
}

MASTER OF SCIENCE IN ENGINEERING

THE UNIVERSITY OF TEXAS AT AUSTIN

December 2011 
Dedicated to everyone that has encouraged me along my path through life, especially my parents. 


\section{Acknowledgments}

First, I would like to thank my advisor Dr. Glenn Y. Masada for his continued support and leadership over the last two years. His guidance over the course of this project was invaluable. I am grateful that he offered me the opportunity to work on this project.

I would also like to thank my co-advisor Dr. Tess J. Moon for her valuable input over the duration of the project.

My mother, Betty Smith, deserves an incredible amount of thanks for not only her moral support, but also instilling in me the confidence to face challenges.

I would like to thank my father, Edward Gaspredes, for his continued support and for pushing me to attend graduate school.

My better half, Amanda Rawlinson, deserves special appreciation for providing moral support and for reminding me what is really important in life.

I would like to thank Sid Bala, Jacob Blair, and Sid Shah for their help and input through the project.

I would also like to acknowledge financial support from the U.S. Department of Energy Office of Energy Efficiency and Renewable Energy, Recovery Act-Geothermal Technologies Program: Ground Source Heat Pump Award 
No. DE-EE0002803.

I would like to acknowledge ClimateMaster, Inc. for their in-kind project support. I would especially like to thank Mike Hammond for all of his valuable input. Paul Bony and Dee Brower deserve appreciation as well.

Additional recognition goes to Paul Ballentine of Solennium, Chris Winland of Good Company Associates and Mel Riser of ToolWerks for their expert inputs into the project and in-kind support. The technical support Austin Energy, Austin Technology Incubator and Texas is Hot is also appreciated. 


\title{
Development of an Integrated Building Load-Ground Source Heat Pump Model as a Test Bed to Assess Short- and Long-Term Heat Pump and Ground Loop Performance
}

\author{
Jonathan Louis Gaspredes, M.S.E. \\ The University of Texas at Austin, 2011 \\ Supervisors: Glenn Y. Masada \\ Tess J. Moon
}

Ground source heat pumps (GSHP) have the ability to significantly reduce the energy required to heat and cool buildings. Historically, deployment of GSHP's in the cooling-dominated Texas and Southwest region has been significantly less than in other regions of the United States. The long term technical and economic viability of GSHPs in arid regions such as Texas has been questioned due to failures of ground loop heat pump systems by early adopters. A proposed solution is to include a supplemental heat rejection (SHR) device to help offset the unbalanced ground loads.

An integrated building load-ground source heat pump model is developed in this thesis and is designed to be a test bed for potential SHR devices. The model consists of discrete component models that can be mixed and matched to represent various types of buildings and ground source heat 
pumps. One of the unique features of the integrated model is the use of the Simulink ${ }^{\circledR} /$ Matlab $^{\circledR}$ environment. This environment allows the user to develop component models that take advantage of the built-in functionality of Matlab ${ }^{\circledR}$ and Simulink ${ }^{\circledR}$. Another unique feature is the full coupling of the building load, heat pump, and ground loop at every time step. The building load, heat pump, and ground loop models were chosen to allow for short time step simulations, which allows for a range of dynamic response times to be modeled and for different heat pump/SHR control methods to be explored. The integrated model can be used on any computer that has the Matlab ${ }^{\circledR}$ and Simulink ${ }^{\circledR}$ software.

The building load model used, called HAMBASE, can model both residential and commercial buildings. HAMBASE was validated using the ASHRAE 140-2007 standard. The heat pump model uses readily available data provided by GSHP manufacturers to accurately model operation across a wide range of input conditions. The vertical borehole ground loop model, developed at Oklahoma State University, is based on Eskillson's g-function model, but included a one-dimensional numerical model to calculate the short term thermal response of the borehole and ground. The ground loop model utilizes GLHEPRO, a ground loop sizing and simulation tool, to create the required parameter files.

Using the integrated building load-ground source heat pump model, a model of a single family house with a ground source heat pump was developed. The house model was validated by the results from eQuest and GELHPRO. 
A series of sensitivity studies were completed to determine dominant factors affecting the use of GSHPs in Texas and the Southwest regions of the United States. The results show that the life of a vertical borehole can be significantly extended/cut short if the ground parameters are properly/not properly designed prior to ground loop sizing. 


\section{Table of Contents}

Acknowledgments $\quad$ v

Abstract vii

List of Tables $\quad$ xiv

List of Figures xviii

Chapter 1. Introduction 1

1.1 What Is GSHP? . . . . . . . . . . . . . . . . . . 2

1.2 What Are The Issues? . . . . . . . . . . . . . . . 6

1.3 Objectives ...................... 8

$\begin{array}{lll}\text { Chapter 2. Building Load Model } & 10\end{array}$

2.1 Model Requirements . . . . . . . . . . . . . . . . . . . . . 10

2.1.1 Environment Requirements . . . . . . . . . . . . . . 11

2.1.2 Building Load Model Requirements . . . . . . . . . . 13

2.2 Literature Review . . . . . . . . . . . . . . . . . 15

2.2 .1 eQuest/DOE-2.2 . . . . . . . . . . . . . . 15

2.2.2 Energy Plus . . . . . . . . . . . . . . . . . . . 18

2.2 .3 TRNSYS . . . . . . . . . . . . . . . . . . 19

2.2.4 HAMBASE . . . . . . . . . . . . . . . 20

2.2.5 Model and Environment Selection . . . . . . . . . 23

2.3 Validation of HAMBASE Building Load Model . . . . . . . . . 25

2.3.1 Case 600 - Model Details . . . . . . . . . . . . 26

2.3.2 Case 600 - Selected Results . . . . . . . . . . . . 30

2.3.3 Sensitivity Study . . . . . . . . . . . . . . . 35

2.3.4 Validation Conclusions . . . . . . . . . . . . 36 
Chapter 3. Water Source Heat Pump Model 38

3.1 Literature Review . . . . . . . . . . . . . . . . . . . . . 41

3.1 .1 Component Models . . . . . . . . . . . . . . . . . 42

3.1.2 Complete Heat Pump Models . . . . . . . . . . . . . . . 46

3.2 Performance Maps . . . . . . . . . . . . . . . . . . . . . . . 48

3.2 .1 Assumptions . . . . . . . . . . . . . . . . . . 49

3.3 Model Calculations . . . . . . . . . . . . . . . . . 51

3.3 .1 Interpolation . . . . . . . . . . . . . . 51

3.3.2 Correction Factors . . . . . . . . . . . . . . . 52

3.3.2.1 Curve Fitting Method . . . . . . . . . . . 55

3.3.2.2 Wet Bulb Corrections for Cooling . . . . . . . 57

3.3.3 Wet-Bulb Calculations . . . . . . . . . . . . . . 58

3.3.4 Condensation Calculations _. . . . . . . . . . . 60

3.3.5 Leaving Water Temperature Calculations . . . . . . . 62

3.3.6 Transient Model Approximation . . . . . . . . . . . 62

Chapter 4. Ground Loop Heat Exchanger Model 66

4.1 Literature Review . . . . . . . . . . . . . . . . . . 67

4.1.1 Borehole Models . . . . . . . . . . . . . . . . . . . 68

4.1.1.1 Hellström's Two-dimensional Model . . . . . . . 68

4.1.1.2 Multipole Model . . . . . . . . . . . . . . 70

4.1 .2 Bulk Ground Models . . . . . . . . . . . . . . . . . . . . 72

4.1.2.1 Kelvin's Line Source Theory . . . . . . . . . . . 72

4.1.2.2 Cylindrical Source Solution . . . . . . . . . 73

4.1.2.3 Finite Line Source . . . . . . . . . . . . . . . 74

4.1.2.4 Eskillson's G-function Model . . . . . . . . . . . 75

4.1.2.5 Finite Difference/Volume/Element Models . . . 80

4.2 Implemented Models . . . . . . . . . . . . . . . . . . 82

4.2.1 Short Time Step Response Factor Model . . . . . . . . . 82

4.2 .2 Xu's Model . . . . . . . . . . . . . . . . . . . . . 88

4.2 .3 Finite Difference Model . . . . . . . . . . . . . . . . 92 
$\begin{array}{lll}\text { Chapter 5. } & \text { Integrated Building Load-GSHP Model } & 96\end{array}$

5.1 Simulink $^{\circledR}$ Model . . . . . . . . . . . . . . . . . . . . 96

5.1.1 Heat Pump Model Implementation . . . . . . . . . . . . 99

5.1.2 Building Load Model Implementation . . . . . . . . . . 102

5.1.3 Ground Loop Model Implementation . . . . . . . . . . . 104

5.1 .4 Additional Model Notes . . . . . . . . . . . . . . . 106

5.2 Model Details . . . . . . . . . . . . . . . . . . . . 108

5.2.1 Residential Building Load Model . . . . . . . . . . . . 108

5.2 .2 Ground Source Heat Pump . . . . . . . . . . . . . . . . 114

5.3 Model Validation . . . . . . . . . . . . . . . . . . . 117

5.3.1 Building Load Model Validation . . . . . . . . . . . . 118

5.3.2 Ground Loop Validation . . . . . . . . . . . . . . . . . 122

5.3 .3 Validation Conclusions . . . . . . . . . . . . . . . . 126

Chapter 6. Base Model Results $\quad 128$

6.1 Time Step Results . . . . . . . . . . . . . . . . . . . . . . 128

6.2 Hourly Results . . . . . . . . . . . . . . . . . . . . . . . 133

6.3 Monthly Results . . . . . . . . . . . . . . . . . . . . 138

6.4 Yearly Results . . . . . . . . . . . . . . . . . . . . . . . 143

$\begin{array}{lll}\text { Chapter 7. } & \text { Sensitivity Studies } & 149\end{array}$

7.1 Borehole Length . . . . . . . . . . . . . . . . . 150

7.2 Borehole Configuration and Spacing . . . . . . . . . . . 156

7.3 Ground Temperature . . . . . . . . . . . . . . . . . . 164

7.4 Grout Conductivity . . . . . . . . . . . . . . . . . 171

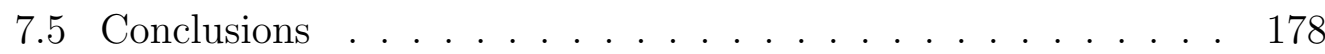

$\begin{array}{lll}\text { Chapter 8. Conclusions } & 179\end{array}$

$\begin{array}{ll}\text { Appendices } & 183\end{array}$

Appendix A. HAMBASE Validation 184

$\begin{array}{lll}\text { Appendix B. } & \text { Integrated Model Validation } & 198\end{array}$ 
Appendix C. Ground Loop Properties and GLHEPRO Use 205

C.1 GLHEPRO Inputs for Base Model . . . . . . . . . . . . . . 205

C.2 Use of GLHEPRO . . . . . . . . . . . . . . . . . . . 206

$\begin{array}{lll}\text { Appendix D. Base Results } & 211\end{array}$

Appendix E. Sensitivity Study Data 214

E.1 Borehole Length . . . . . . . . . . . . . . . . . . . . . . . 214

E.2 Borehole Layout and Spacing . . . . . . . . . . . . . 217

E.3 Ground Temperature . . . . . . . . . . . . . . . . . . 220

E.4 Grout Conductivity . . . . . . . . . . . . . . . . . . 224 


\section{List of Tables}

2.1 Comparison of models based on stated requirements . . . . . . 24

2.2 Building material properties for case 600 - Exterior wall, recreated from ASHRAE 140-2007 [ASH, 2007] . . . . . . . . . 27

2.3 Angular dependance of solar heat gain factor, recreated from ASHRAE 140-2007 [ASH, 2007] . . . . . . . . . . . . 28

2.4 Annual solar radiation loads on case 600 . . . . . . . . . . 31

2.5 Summary of sensitivity study cases . . . . . . . . . . . . . 37

3.1 Model inputs and outputs . . . . . . . . . . . . . . . . 41

3.2 Performance map model assumptions . . . . . . . . . . . . . . 50

3.3 Example calculations - Interpolation and correction factors . . 53

3.4 Correction factors for airflow [ClimateMaster, 2010] . . . . . . 55

3.5 Correction factors for wet bulb temperature [ClimateMaster, 2010] . . . . . . . . . . . . . . . 57

5.1 Envelope constructions and material properties . . . . . . . . 111

5.2 Glazing properties used in HAMBASE model . . . . . . . . . 112

5.3 Building loads used to size ground loop using GLHEPRO . . . 118

5.4 Range of the reported values for annual building loads for ASHRAE 140-2007, cases 600 and 900 . . . . . . . . . . . 119

5.5 Comparison between Simulink ${ }^{\circledR}$ model and eQuest building load results .................... . . 120

5.6 Comparison of maximum and minimum entering water temperatures to the heat pump . . . . . . . . . . . . .

6.1 Summary building loads and heat pump operation time over 15 years . . . . . . . . . . . . . . . . 145

6.2 Summary total energy use, ground loop temperatures and heat pump efficiencies over 15 years . . . . . . . . . . . . . . 145

7.1 Borehole length sensitivity study summary and installation cost 150 
7.2 Comparison of initial borehole costs for different borehole lengths and the resulting energy costs over ten years, assuming 0.1133 $\$ / k W h$ (Texas residential price August 2011) [U.S. Dept. of Energy, 2011a] . . . . . . . . . . . . . . . .

7.3 Comparison of EER for years five and ten based on the different configurations and spacing simulated . . . . . . . .

7.4 Comparison of EER for years five and ten based on the different configurations and spacing simulated . . . . . . . .

7.5 Comparison of operating costs and savings over ten years for the different configurations tested, assuming $0.1133 \$ / k W h$ (Texas residential price August 2011) [U.S. Dept. of Energy, 2011a] . 162

7.6 Simulated ground temperatures . . . . . . . . . . . . . . . . . 164

7.7 Comparison of operating costs and savings over ten years for the different ground temperatures tested, assuming $0.1133 \$ / k W h$ (Texas residential price August 2011) [U.S. Dept. of Energy,

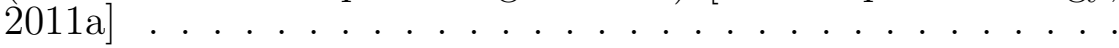

7.8 Comparison of maximum and mean heat pump water temperatures in ${ }^{\circ} \mathrm{C}$ for years five and ten . . . . . . . . . .

7.9 Comparison of operating costs and savings over ten years for the different grout conductivities tested, assuming $0.1133 \$ / k W h$ (Texas residential price August 2011) [U.S. Dept. of Energy, 2011a] . . . . . . . . . . . . . . .

A.1 Summary of sensitivity study cases . . . . . . . . . . .

B.1 Comparison between Simulink ${ }^{\circledR}$ model and eQuest building load results for full internal load case . . . . . . . . . . . . .

B.2 Comparison between Simulink ${ }^{\circledR}$ model and eQuest building load results for no internal load case . . . . . . . . . . . . . 200

B.3 Comparison between Simulink ${ }^{\circledR}$ model and eQuest ground loop heat rejection results for full internal loads . . . . . . . . . .

B.4 Comparison between Simulink ${ }^{\circledR}$ model and eQuest ground loop heat rejection results for no internal loads . . . . . . . . . . . 202

B.5 Ground loop validation results - full eQuest internal loads . . 203

B.6 Ground loop validation results - no internal loads . . . . . . . 204

C.1 Ground loop properties used in GLHEPRO . . . . . . . . . . . 205

D.1 Heat pump operation time and output for base case, basis for Figures 6.16 and $6.17 \ldots \ldots . \ldots . \ldots 211$ 
D.2 Annual and monthly peak electricity usage of the heat pump, basis for Figure 6.20 . . . . . . . . . . . . .

D.3 Annual heat pump temperatures and efficiency ratings, basis for Figures 6.18 and 6.19 . . . . . . . . . . . .

E.1 Maximum yearly heat pump entrance temperature in ${ }^{\circ} C$, based on hourly averages, basis for Figure 7.1 . . . . . . . . .

E.2 Total annual cooling in $M W h$ for borehole lengths tested over 15 years, basis for Figure $7.2 \ldots \ldots$. . . . . . .

E.3 Total annual time in hours that zone 1 air temperature is above cooling set point for the bore lengths tested, basis for Figure 7.3 215

E.4 Average annual energy efficiency ratio (EER) in Btu/Wh for the bore lengths tested, basis for Figure 7.4 . . . . . . . . . .

E.5 Total annual electricity use in $k W h$ for the bore lengths tested, basis for Figure 7.5 . . . . . . . . . . . . . . . . . . . . 216

E.6 Total annual cooling in $M W h$ for the borehole configurations tested over 15 years, basis for Figure 7.7 . . . . . . . . . .

E.7 Total annual time in hours that zone 1 air temperature is above cooling set point for the borehole configurations tested, basis for Figure 7.8 . . . . . . . . . . . . . . . . . .

E.8 Average annual energy efficiency ratio (EER) in $B t u / W h$ for the borehole configurations tested, basis for Figure 7.9 . . . .

E.9 Total annual electricity use in $k W h$ for the borehole configurations tested, basis for Figure 7.10 . . . . . . . . . .

E.10 Mean yearly heat pump entrance temperature in ${ }^{\circ} C$, based on hourly averages, basis for Figure 7.13 . . . . . . . . .

E.11 Maximum yearly heat pump entrance temperature in ${ }^{\circ} C$, based on hourly averages, basis for Figure 7.14 . . . . . . . .

E.12 Total annual cooling in $M W h$ for the ground temperatures tested over 15 years, basis for Figure $7.15 \ldots . . . . .$.

E.13 Total annual time in hours that zone 1 air temperature is above cooling set point for the ground temperatures tested, basis for Figure $7.16 \ldots \ldots \ldots \ldots$

E.14 Average annual energy efficiency ratio (EER) in Btu/Wh for the ground temperatures tested, basis for Figure 7.17 . . . .

E.15 Total annual electricity use in $k W h$ for the ground temperatures tested, basis for Figure 7.18 . . . . . . . . . . .

E.16 Mean yearly heat pump entrance temperature in ${ }^{\circ} C$, based on hourly averages, basis for Figure 7.19 . . . . . . . . . 
E.17 Maximum yearly heat pump entrance temperature in ${ }^{\circ} C$, based on hourly averages, basis for Figure 7.20 . . . . . . . . . 225

E.18 Total annual cooling in $M W h$ for the grout conductivities tested over 15 years, basis for Figure 7.21 . . . . . . . . . . . 225

E.19 Total annual time in hours that zone 1 air temperature is above cooling set point for the grout conductivities tested, basis for Figure 7.22 . . . . . . . . . . . . . . . . . . . . . 226

E.20 Average annual energy efficiency ratio (EER) in Btu/Wh for the grout conductivities tested, basis for Figure 7.23 . . . . . . 226

E.21 Total annual electricity use in $k W h$ for the grout conductivities tested, basis for Figure 7.24 . . . . . . . . . . . . . . . . 227 


\section{List of Figures}

1.1 Schematic of ground source heat pump system [Yavuzturk, 1999] 4

1.2 Example of typical ground loop configurations [U.S. Dept. of Energy, 2011b] . . . . . . . . . . . . . . 5

2.1 Summer and winter comfort zones [ASH, 2009] . . . . . . . . . 14

2.2 Case 600 building dimensions $[\mathrm{ASH}, 2007] \ldots$. . . . . . . . . 27

2.3 Hourly incident radiation on west wall for July 27 . . . . . . . 31

2.4 Hourly HVAC load for January 4th . . . . . . . . . . . . . . . 33

2.5 Hourly air temperature values for the $600 \mathrm{FF}$ case . . . . . . . 33

2.6 Annual and peak heating and cooling loads . . . . . . . . . . . 34

2.7 Changes in building loads from case 600 to case 610 , addition of shading over south facing windows . . . . . . . . . 36

3.1 Ideal vapor compression cycle diagrams . . . . . . . . . . . . . 39

3.2 Operation of heat pump during cooling with model variables (Source: Oklahoma State University) . . . . . . . . . . . . 40

3.3 Black box of performance map model . . . . . . . . . . . . . . 49

3.4 Example of data provided by the manufacturer [ClimateMaster, 2010] . . . . . . . . . . . . . . . 54

3.5 Plot of correction factors for airflow fraction during heating . . 56

3.6 Absolute error for relative humidity to wet bulb temperature calculations based on Clausius-Clapeyron equation . . . . . . 59

3.7 Absolute error for relative humidity to wet bulb temperature calculations based on curve-fitted equations . . . . . . . . 60

3.8 Transient response of a heat pump during start-up [Fu et al.,

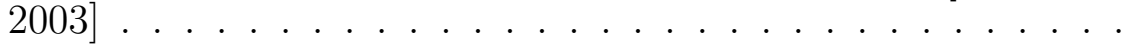

4.1 Drawing of vertical borehole ground loop with approximate dimensions . . . . . . . . . . . . . . .

4.2 Diagram of Hellström's approximation of the heat transfer inside of the borehole [Young, 2004] . . . . . . . . . . .

xviii 
4.3 Example source and sink for the multipole method [Young, 2004] 71

4.4 G-functions for typical borehole configurations, data from GLHEPRO 4.0 [Spitler, 2000] . . . . . . . . . . . . . . 78

4.5 Piecewise approximation of $q(t)$ and resulting temporal superposition . . . . . . . . . . . . . . . . 79

4.6 Details of the finite volume model [Yavuzturk, 1999] . . . . . . 84

4.7 Short time step and Eskillson's g-functions for typical borehole configurations, data from GLHEPRO 4.0 [Spitler, 2000] . . . . 85

4.8 Borehole simplification for Xu's one-dimensional model . . . . 89

4.9 Grid method used in one-dimensional numerical model [Xu, 2007] 89

4.10 Modified version of Hellström's borehole model . . . . . . . . 94

5.1 Top level Simulink ${ }^{\circledR}$ model . . . . . . . . . . . . . . . . . . . 97

5.2 Heat pump sub-model . . . . . . . . . . . . . . . . 100

5.3 Performance map options menu . . . . . . . . . . . . . . . . . 101

5.4 Thermostat sub-model . . . . . . . . . . . . . . . . 102

5.5 Building load sub-model . . . . . . . . . . . . . . . . 103

5.6 Ground loop sub-model . . . . . . . . . . . . . . . 105

5.7 Ground loop pump sub-model . . . . . . . . . . . . . . . 107

5.8 Images of the modeled house . . . . . . . . . . . . . . . . . 109

5.9 eQuest rendering of the house . . . . . . . . . . . . . . . . 110

5.10 Internal load profiles . . . . . . . . . . . . . . . . . . 113

5.11 Undisturbed ground temperatures $\left({ }^{\circ} F\right)$ at depths greater than $9.1 \mathrm{~m}(30 \mathrm{ft})$ [American Society of Petroleum Geologists, 1974] 116

5.12 Average ground conductivity from 0-300 ft [American Society of Petroleum Geologists, 1974] . . . . . . . . . .

5.13 Monthly average heat rejected/extracted in the borehole, comparison between GLHEPRO and Simulink ${ }^{\circledR}$ ground loop models - Jan. to Dec., data can be found in Tables B.5 and B.6 . . .

5.14 Monthly average water temperatures entering the borehole and heat pump, comparison between GLHEPRO and Simulink ${ }^{\circledR}$ ground loop models,- Jan. to Dec.- full internal load, data can be found in Tables B.5 and B.6 . . . . . . . . . . .

5.15 Monthly average water temperatures entering the borehole and heat pump, comparison between GLHEPRO and Simulink ${ }^{\circledR}$ ground loop models,-- Jan. to Dec.- no internal load, data can be found in Tables B.5 and B.6 . . . . . . . . . . . . . 
6.1 Building air and wall temperatures by zone for June 30, 12:00$15: 00$. . . . . . . . . . . . . . . .

6.2 Zone 1 air temperature, thermostat limits, and thermostat response for June 30, 12:00-15:00 . . . . . . . . . . . . . . .

6.3 Building air relative humidity by zone for June 30, 12:00-15:00

6.4 Heat extracted from the conditioned space, heat rejected to the ground loop water, and electricity used by the heat pump for June 30, 12:00-15:00 . . . . . . . . . . . . . . . . . .

6.5 Ground loop water temperatures at the entrance to the heat pump and ground loop . . . . . . . . . . . . .

6.6 Hourly mean values of conditioned zone 1 temperatures and thermostat set points for the first year of simulation, Jan.-Dec.

6.7 Hourly mean values of heat pump output to the conditioned zone (heating is positive), Jan.-Dec. . . . . . . . . . . . .

6.8 Hourly mean values of heat rejected to ground loop water by the heat pump (positive heat rejection is associated with cooling) Jan.-Dec. . . . . . . . . . . . . . . . . .

6.9 Hourly mean values of heat pump entrance temperature and temperature change, Jan.-Dec. . . . . . . . . . . . . .

6.10 Hourly mean values of ground loop entrance temperature and temperature change, Jan.-Dec. . . . . . . . . . .

6.11 Monthly total values of heat pump output to the conditioned zone 1,15 years . . . . . . . . . . . . . . . 140

6.12 Monthly total values of heat pump operation time, 15 years . 140

6.13 Monthly total values of electricity used to provide cooling and heating, and to operate the ground loop water pump, 15 years

6.14 Monthly values of mean, maximum and minimum heat pump entering water temperatures (maximum and minimum based on hourly averages), 15 years . . . . . . . . . .

6.15 Monthly values for efficiency ratings for the heat pump opera-

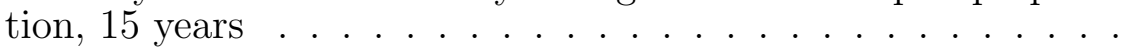

6.16 Annual total building loads for heating and cooling, 15 years, data can be found in Table D.1 . . . . . . . . . . . . . . 144

6.17 Annual total heat pump operation time for heating and cooling, 15 years, data can be found in Table D.1 . . . . . . . .

6.18 Annual mean, maximum, and minimum ground loop water temperatures at the entrance of the heat pump (maximum and minimum based on hourly averages) 15 years, data can be found in Table D.3 . . . . . . . . . . . . . . . . . . . . . . 
6.19 Annual mean efficiency ratings for the heat pump, 15 years, data can be found in Table D.3 . . . . . . . . . . . . . . . 146

6.20 Annual and peak electricity used by the heat pump, 15 years, data can be found in Table D.2 . . . . . . . . . . . 148

7.1 Maximum yearly heat pump entrance temperatures for different borehole lenghts, based on hourly averages, data can be found in Table E.1 . . . . . . . . . . . . . . . . . . . . . .

7.2 Total annual cooling for the different borehole lengths tested, data can be found in Table E. 2 .

7.3 Total annual time that zone 1 air temperature exceeded the cooling set point for different borehole lengths tested, based on hourly averages, data can be found in Table E.3 . . . . . . . .

7.4 Average annual energy efficiency ratio (EER) for the different borehole lengths tested, data can be found in Table E.4 . . . .

7.5 Total annual electricity use for the different borehole lengths tested, data can be found in Table E.5 . . . . . . . . . . . . 155

7.6 Borehole configurations tested, figure not to scale . . . . . . . 157

7.7 Total annual cooling for the different borehole configurations tested, data can be found in Table E.6 . . . . . . . . . .

7.8 Total annual time that zone 1 air temperature exceeded the cooling set point for the different borehole configurations tested, based on hourly averages, data can be found in Table E.7 . . .

7.9 Average annual energy efficiency ratio (EER) for the different borehole configurations tested, data can be found in Table E.8

7.10 Total annual electricity use for the different borehole configurations tested, data can be found in Table E.9 . . . . . . . . . .

7.11 Total annual time that zone 1 air temperature exceeded cooling set point for the improved borehole configurations tested, based on hourly averages, data can be found in Table E.7 . . . . . .

7.12 Undisturbed ground temperatures $\left({ }^{\circ} F\right)$ at depths greater than $9.1 m(30 \mathrm{ft})$ [American Society of Petroleum Geologists, 1974]

7.13 Yearly mean water temperature entering the heat pump for the different ground temperatures tested, data can be found in Table E.10 . . . . . . . . . . . . . . . . . . .

7.14 Yearly maximum water temperature entering the heat pump for the different ground temperatures tested, data can be found in Table E.11 . . . . . . . . . . . . . . . 
7.15 Total annual cooling for the different ground temperatures tested, data can be found in Table E.12 . . . . . . . . . . . . . . . . 168

7.16 Total annual time that zone 1 air temperature exceeds cooling set point for the different ground temperatures tested, based on hourly averages, data can be found in Table E.13 . . . . . . .

7.17 Average annual energy efficiency ratio (EER) for the different ground temperatures tested, data can be found in Table E.14 .

7.18 Total annual electricity use for the different ground temperatures tested, data can be found in Table E.15 . . . . . . .

7.19 Yearly mean water temperature at the heat pump entrance for the different grout conductivities tested, data can be found in Table E.16 . . . . . . . . . . . . . .

7.20 Yearly maximum water temperature at the heat pump entrance for the different grout conductivities tested, data can be found in Table E.17 . . . . . . . . . . . . . . . .

7.21 Total annual cooling for the different grout conductivities tested, data can be found in Table E.18 . . . . . . . . . . . .

7.22 Total annual time that zone 1 air temperature exceeds cooling set point for the different grout conductivities tested, based on hourly averages, data can be found in Table E.19 . . . . . . .

7.23 Average annual energy efficiency ratio (EER) for the different grout conductivities tested, data can be found in Table E.20 .

7.24 Total annual electricity use for the different grout conductivities tested, data can be found in Table E.21 . . . . . . . .

A.1 Comparison of hourly incident radiation on the south wall for March 5th . . . . . . . . . . . . . .

A.2 Comparison of hourly incident radiation on the west wall for March 5th . . . . . . . . . . . . . .

A.3 Comparison of hourly incident radiation on the south wall for July 27th . . . . . . . . . . . . . . . . . . .

A.4 Comparison of hourly incident radiation on the west wall for July 27th . . . . . . . . . . . . . . . 186

A.5 Comparison of hourly HVAC system loads for case 600 on January 4 th . . . . . . . . . . . . . . . . . 187

A.6 Comparison of total annual and peak load for case 600 . . . . 187

A.7 Comparison of total annual and peak load differences between case 610 and 600 . Includes the addition of shading over the south windows. . . . . . . . . . . . 
A.8 Comparison of total annual and peak load differences between case 620 and 600 . Moves the windows from the south wall to the east and west walls. . . . . . . . . . . . . . . . . . . . . . 188

A.9 Comparison of total annual and peak load differences between case 630 and 620 . Includes the addition of shading around the windows on the east and west walls . . . . . . . . . . .

A.10 Comparison of total annual and peak load differences between case 640 and 600 . Heater thermostat is setback to $10^{\circ} \mathrm{C}$ at night 189

A.11 Comparison of total annual and peak load differences between case 650 and 600. Adds night time ventilation . . . . . . . . . 190

A.12 Comparison of total annual and peak load for case 900 . . . . 190

A.13 Comparison of total annual and peak load differences between case 900 and 600 . The construction materials properties are changed to have higher volumetric heat capacities . . . . . . .

A.14 Comparison of hourly HVAC system loads for case 900 on January 4 th . . . . . . . . . . . . . . . .

A.15 Comparison of total annual and peak load differences between case 910 and 900 . Includes the addition of shading over the south windows . . . . . . . . . . . . . . .

A.16 Comparison of total annual and peak load differences between case 920 and 900. Moves the windows from the south wall to the east and west walls. . . . . . . . . . . .

A.17 Comparison of total annual and peak load differences between case 930 and 920 . Includes the addition of shading around the windows on the east and west walls . . . . . . . . . .

A.18 Comparison of total annual and peak load differences between case 940 and 900 . Heater thermostat is setback to $10^{\circ} \mathrm{C}$ at night 193

A.19 Comparison of total annual and peak load differences between case 950 and 900. Adds night time ventilation . . . . . . .

A.20 Comparison of total annual and peak load differences between case 960 and 900 . Addition of unconditioned solar space on the south side of the building . . . . . . . . . . . . . . . . . 194

A.21 Hourly temperatures on January 4th for the 600FF case . . . 195

A.22 Hourly temperatures on July 27th for the 650FF case . . . . . 195

A.23 Hourly temperatures on January 4th for the 900FF case . . . 196

A.24 Histogram of the hourly temperatures for the 900FF case . . . 196

A.25 Hourly temperatures on July 27th for the 950FF case . . . . . 197

xxiii 
C.1 Main screen of GLHEPRO . . . . . . . . . . . . . . . 206

C.2 G-function and borehole resistance calculation screen . . . . 208 


\section{Chapter 1}

\section{Introduction}

In 2010, 13.71 quads (14.46 EJ) of primary energy was used to provided space heating and cooling for buildings in the United States, accounting for $33.9 \%$ of the total primary energy consumed by buildings and $14.0 \%$ of the total primary energy consumed [U.S. Dept. of Energy, 2011c,d]. Ground source heat pumps offer the ability to significantly reduce the energy required to condition buildings when compared to traditional heating and cooling systems. Reductions in total electricity consumption can be as high as $40 \%$ for residential buildings [Fisher and Rees, 2005]. If both residential and commercial applications are considered it has been estimated that the installation of ground source heat pumps could reduce the use of non-renewable energy consumption of buildings by 3.4 to 3.9 quads (3.6 to 4.1 EJ) [Hughes, 2008]. This quantity corresponds to offsetting $30-40 \%$ of the projected growth of building energy consumption by 2030. If ground source heat pumps were installed throughout Texas, they could reduce the peak demand in the summer months by $20 \%$, which would reduce the forecasted peak electrical load growth in the state of Texas by 80\% [Optimal Energy, Inc, 2007, U.S. Dept. of Energy, 2008].

In 2010, an estimated 2.76 million ground source heat pump units were 
installed worldwide with a total capacity of $33,134 M W$. This number of installed units is twice the number of installed in 2005 and four times the number in 2000 [Lund et al., 2011]. The majority of this growth occurred in North America, Europe, and China. In 2010, it is estimated that 100,000 to 120,000 heat pump units were sold in the United States, representing a $\$ 2-3$ billion per year industry. Seventy percent of the units were installed in residences and the remaining $30 \%$ were installed in commercial and institutional buildings [Lund et al., 2011].

\subsection{What Is GSHP?}

A ground source heat pump (GSHP) consists of a vapor compression cycle cycle that is coupled to the ground using a water loop. A schematic of a ground loop heat pump system with the major components labels is shown in Figure 1.1. The cycle and the function of the components, assuming that the heat pump is providing cooling, are as follows:

Compressor Saturated, low pressure refrigerant from the evaporator is compressed to a high pressure and temperature vapor.

Condenser The high temperature vapor from the compressor rejects heat via a concentric tube heat exchanger into the ground loop water heating the water. The vapor condenses and becomes a saturated liquid.

Expansion Device The saturated liquid refrigerant from the condenser is 
throttled through an expansion valve reducing the pressure and temperature, which results in a low quality liquid-vapor mixture.

Evaporator The low temperature mixture from the expansion device extracts heat via a fin and tube heat exchanger from the air in the conditioned space reducing the temperature of the air. The liquid portion of the mixture evaporates until the refrigerant is a saturated vapor or superheated vapor. The refrigerant then enters into the compressor

Ground Loop After the ground loop water passes through the condenser it is pumped into the ground. While passing through the ground the water rejects heat, lowering its temperature. The cooled water is then return back to the condenser.

For heating to occur the flow is reversed with an electronic value. This causes the fin and tube heat exchanger that interfaces with the air to become the condenser and the concentric tube heat exchanger to become the evaporator. In contrast to a GSHP, a conventional air source heat pump rejected/extracts heat to/from the outside air via a second fin and tube heat exchanger to $\mathrm{cool} /$ heat the building.

Ground source heat pumps are more efficient than air source heat pumps because the heat that is rejected/extracted by the unit occurs at the relatively constant temperatures of the ground. During the months when cooling is required, an air source heat pump rejects heat to the high temperature (summer) outside air while a GSHP rejects heat to the typically cooler ground. 


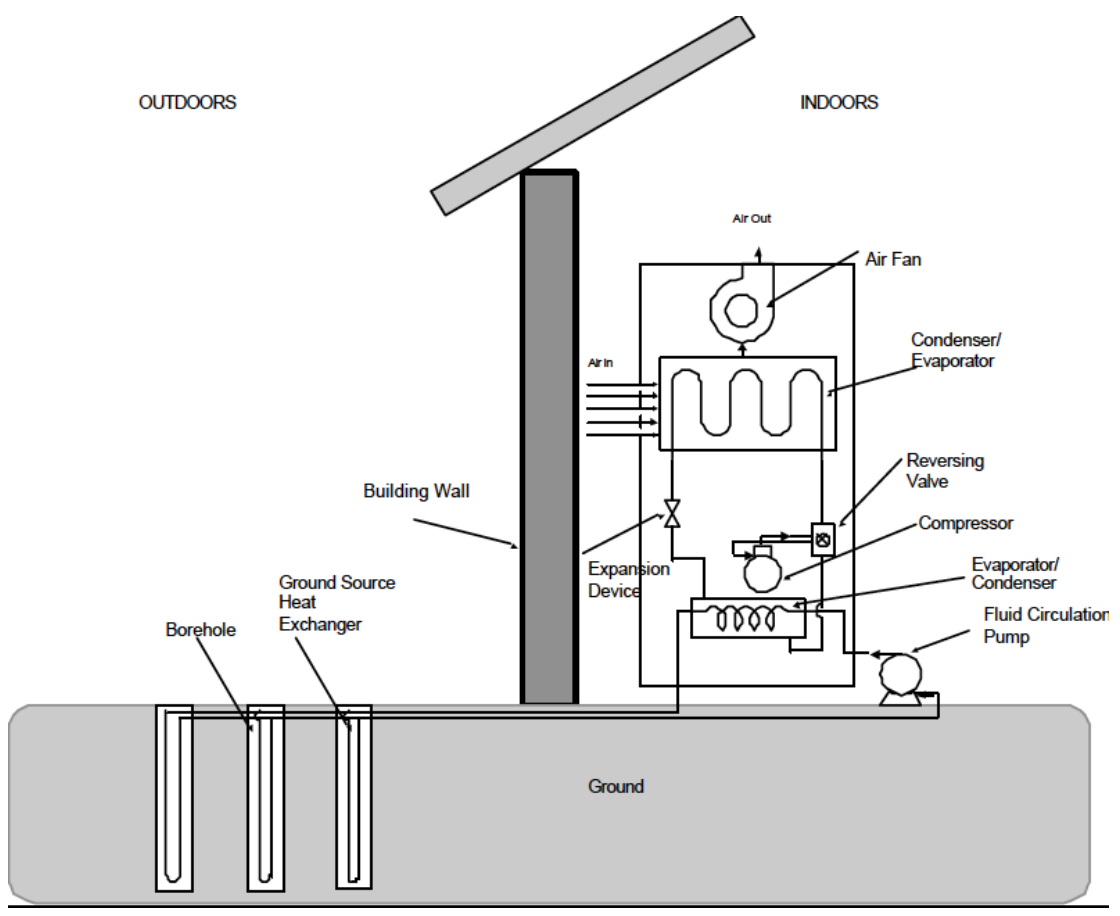

Figure 1.1: Schematic of ground source heat pump system [Yavuzturk, 1999]

By decreasing the temperature of the heat sink the cycle operates more efficiently since the compressor needs to work less to provide the same cooling capacity. The same ideas apply to the heating mode, where the ground temperature is typically higher than the cold air temperature, so more heat can be extracted from the ground to heat the conditioned space.

Ground source heat pumps are coupled to the ground in several ways as shown in Figure 1.2. The system can either be a closed system, in which the same water circulates continuously through the system, or an open system that only cycles water through the system once. Open systems takes water out of a water source (pond, well) and return it back to a different sink. Open 
systems are rarely used due to potential water contamination and fouling in the water pipes. These units are typically found in areas with significant bodies of water or with high ground water tables, such as in Florida.
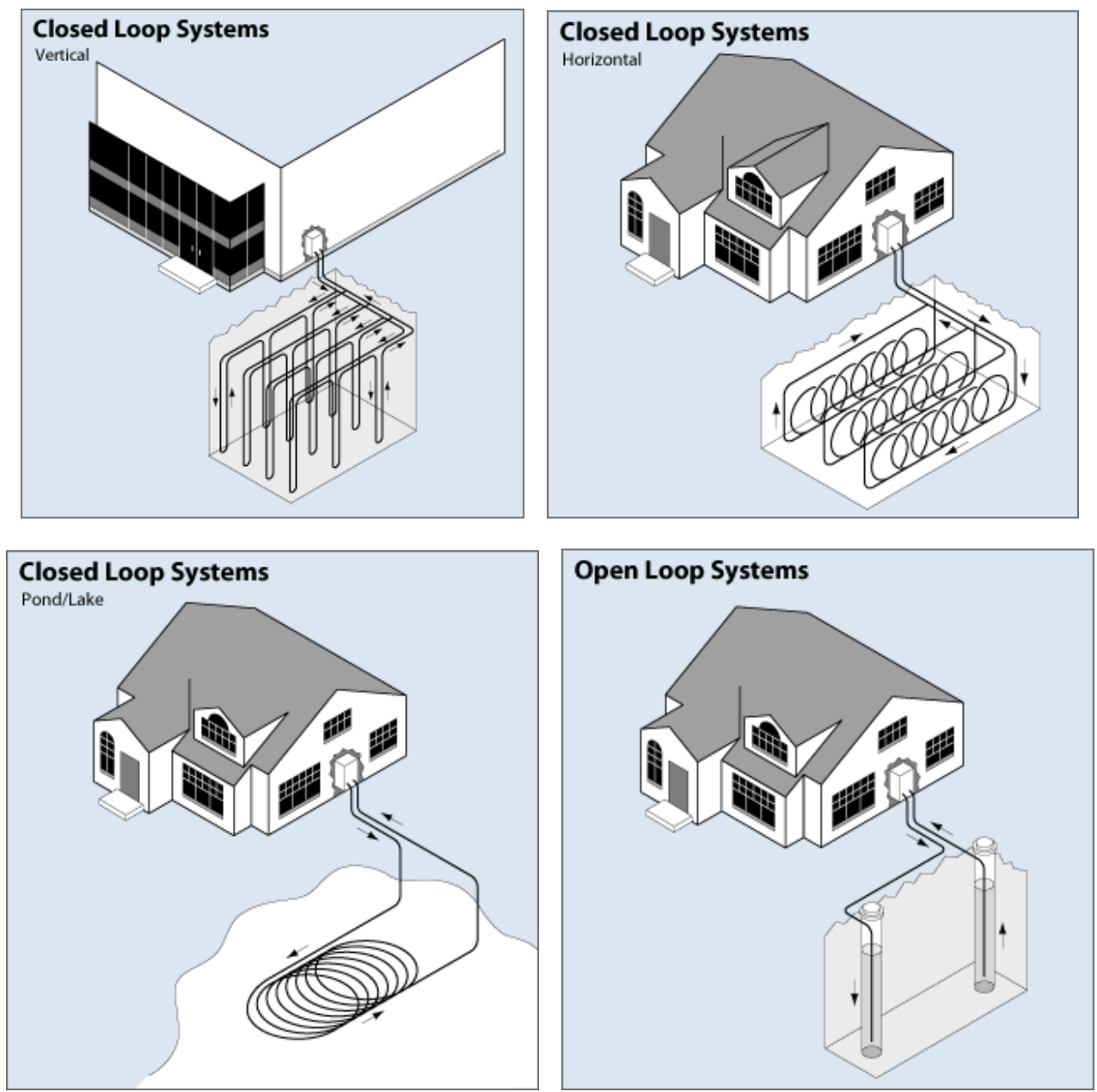

Figure 1.2: Example of typical ground loop configurations [U.S. Dept. of Energy, 2011b]

Closed systems have water loops installed in three possible forms; a field of vertical boreholes, a field of horizontal trenches, or a large coil in a body of 
water. The field of vertical boreholes consists of a number of deep, typically $90 m(300 \mathrm{ft})$, vertical boreholes each containing a "u-tube". The "u-tube" is a pair of high density polyethylene pipes that are connected with a u-shaped joint at the bottom, which allows the water to flow down and then back up through the pipe in the borehole. Typically, there are multiple boreholes that are connected in parallel through a series of connecting headers. The vertical boreholes take advantage of the relatively constant yearly ground temperatures below approximately $10 \mathrm{~m}(33 \mathrm{ft})$. Vertical boreholes are typically used in residential applications in the south and those that do not have the space for horizontal loops, as well as most commercial installations.

Horizontal, closed loop systems have multiple runs of looped pipes that are buried in horizontal trenches. The trenches are dug below the frost line and the fluid in the loops may contain antifreeze. Horizontal fields require significantly more surface area than vertical boreholes. Horizontal loops are typically found in the Midwest and Northeast portions of the Uniter States.

If the GSHP is installed near a large body of water, a pond loop can be installed in the pond. The pond water serves as the heat source and sink.

\subsection{What Are The Issues?}

According to Hughes [2008], some of the key barriers to the growth of the ground source heat pump industry include the large initial investment and the lack of new technologies and methods to reduce the high initial cost and the long payback period. The initial investment includes the cost of the heat pump 
unit, which currently costs 50-100\% more than a comparable air source heat pump unit, and the cost of drilling and installing the ground loops [Hughes, 2008]. In Texas a single $90 m(300 \mathrm{ft})$ borehole costs approximately $\$ 3000$ to install (includes drilling) and typically there is one $90 \mathrm{~m}$ borehole installed for each $3.5 \mathrm{~kW}$ (1 refrigeration ton) of cooling needed [Hammond, 2011]. Both components of the initial cost can be reduced. The cost of the ground source heat pump could be reduced to at least the price of a comparable air source heat pump if the economies of scale approached those of air source heat pump manufactures. Currently the largest air source heat pump manufacturer out sells the largest ground source heat pump manufacturer by a factor of ten [Hughes, 2008].

The development of new technologies, such supplemental heat rejectors, could reduce the initial cost of the ground loop installation by reducing the total length of ground loops and the associated drilling/trenching costs. Currently, it is common to find cooling towers used as supplemental heat rejectors for large commercial installations, but no equivalent technology is currently deployed in residential applications.

In Texas and other semi-arid regions the deployment of GSHPs has been limited. Of the total GSHP installations in the United States over $50 \%$ were installed in only ten states; Florida, Illinois, Indiana, Iowa, Michigan, Minnesota, Nebraska, New York, Ohio and Pennsylvania [Lund et al., 2011]. Deployment in semi-arid regions is limited not only by the initial cost, but also due to questions about their long-term technical viability [Fisher and 
Rees, 2005]. Some GSHP installations have seen significant decreases in operational effectiveness after 7-10 years due to excessively high ground loop water temperatures. High water temperatures are caused by unbalanced heat loads on the ground due to the cooling dominated climates, mild winter temperatures, and unfavorable soil conditions, including soils with low conductivities, the lack of moisture and ground water flow to remove heat, and higher annual ground temperatures.

\section{$1.3 \quad$ Objectives}

The objective of this research is to develop a GSHP system model that can be used to investigate new technologies and methods that will improve the implementation and long-term viability of GSHPs in Texas and the Southwest portion of the United States. The model must have the following capabilities:

- Multi-year simulations, with a reasonable simulation time

- Ability to add user defined components (SHRs)

- Capable of modeling a wide range of component responses

- Full coupling of building load, heat pump and ground loop models

- Accurately model:

- Building loads of residential and commercial buildings

- Commercially available ground source heat pumps 
- Thermal response of the ground loop including temperatures

- Designed for research use with minimal assumptions about configurations, layouts, parameters, etc.

The model has three major components - the building load model, heat pump model and the ground loop model. Each model is described in its own chapter that contains a literature review, model selection process, and model description. Chapters 2, 3, and 4, describe the building load, heat pump and ground loop model, respectively. The resulting integrated building load-GSHP model, discussed in Chapter 5 couples all three models together. Chapter 6 shows detailed simulation results for a test case and Chapter 7 shows the results of a sensitivity study performed on selected parameters.

For an example of the model used to investigate SHR devices see Balasubramanian [2011]. 


\section{Chapter 2}

\section{Building Load Model}

The creation of the integrated building load-GSHP model began with the selection of the building load model since this model would dictate the modeling environment that would be used for the rest of the project. The complexity of building load models in combination with the large number of models available led to the decision to use an existing model as opposed to creating a new one. To reduce implementation time and reduce possible errors the building load model would be used in its developed environment. For example, if Energy Plus was chosen for the building load model, the rest of the integrated model would be implemented using the Energy Plus format. This constraint increases the complexity of the model selection processes because different formats of the other sub models must be considered, as well as the benefits (computation, coupling, flexibility) of the modeling environment.

\subsection{Model Requirements}

For clarity the building load model requirements are divided into environment requirements and building load requirements. Understanding and satisfying these requirements allows for the selection of the models and envi- 
ronments that are best suited for the project.

\subsubsection{Environment Requirements}

One key goal of the overall project is to evaluate possible methods to reject heat to reduce the net yearly load on the ground loop. Various methods are being evaluated such as cooling towers and desuperheaters [Balasubramanian, 2011]. Evaluating these Supplemental Heat Rejection (SHR) devices requires modeling their operation and control in the chosen environment. This implies two requirements. First, the environment must support the addition of user definable components. Second, the components will be created in the environment, therefore it is preferred that the programming language of the environment be known by the research group prior to the start of the project. These include Matlab ${ }^{\circledR}$, Simulink ${ }^{\circledR}, \mathrm{C}$, and $\mathrm{C}++$. The computing resources available to team dictate that the model be able to run on Windows based operating systems at least, but it would be preferable for the modeling environment to run on Macintosh and Linux operating systems as well.

The goal of the research project is to show the effect of ground heating on the conditioning provided to the house. Therefore, the building load model must interface with the a Ground Source Heat Pump (GSHP) model. The simplest case would be to use the calculated building load as an input into

the GSHP model, without any feedback to the building load model, but the scenario would not be satisfactory. It is more desirable to be able to model the response of the building load and internal conditioned air temperatures 
to reductions in heat pump capacity due to long term ground heating. This requires some coupling between the GSHP model and the building load model. As the ground temperatures rise the temperature of the water returning to the heat pump increases, which in turn reduces the cooling capacity and efficiency of the heat pump. If the capacity is reduce significantly the heat pump will not be able to maintain the set point temperature in the conditioned space of the building. Therefore, the integrated model must couple the building model with the heat pump and ground loop at every time step [Crawley et al., 2001].

Localized ground heating due to GSHPs manifests itself over many years, so the model must be able simulate many years of operation (10-20 years) in a reasonable amount of computation time. The model must also handle the different dynamic responses of the various components that make up the integrated model.

The model must be able to perform parametric studies such as the effects of the undisturbed ground temperature, ground conductivity, building materials, internal building loads, and SHR capacity. The model also must be easily reconfigurable to compare the placement, type, and capacities of the SHRs. The ability to add/move/change/remove components without significant reprogramming of the model would be very beneficial. The implementation and development of various SHR models must be completed independently from the integrated model to simplify development and validation as well as allow for parallel model development.

A summary of the environment requirements are: 
- Ability to add user defined components (SHRs)

- Preference to programming languages already known by the research group (Matlab ${ }^{\circledR}$, Simulink ${ }^{\circledR}, \mathrm{C}, \mathrm{C}++$ )

- Full coupling of building load, heat pump and ground loop models

- Multi-year simulations, with a reasonable simulation time

- Ability to make significant model configuration changes without significant reprogramming

- Independent component model development

- Run off different computer platforms and operating systems

- Simulate the range of dynamic response characteristics of the many components

\subsubsection{Building Load Model Requirements}

A key goal of the research is to determine cost-effective methods to reduce the energy rejected into the ground while cooling/heating across a range of building types. The cooling/heating profiles of commercial facilities and residential structures differ greatly, which present different opportunities for possible SHR methods. This requires that the model be accurate for a wide range of buildings from large multi-zone commercial buildings to single family residences. 
The building load model must not only account for the temperature of the air in the structure, it also must account for the moisture in the structure. In climates with high levels of outdoor humidity the ability of the air conditioning portion of an HVAC system to remove moisture from the air plays a large role in the overall comfort in the occupants of the structure. Figure 2.1 shows the zones of perceived comfort for occupants wearing summer (0.5 clo) and winter (1.0 clo) clothing. For both zones the lower the humidity, the higher the air temperature can be to keep the occupants comfortable. Therefore,

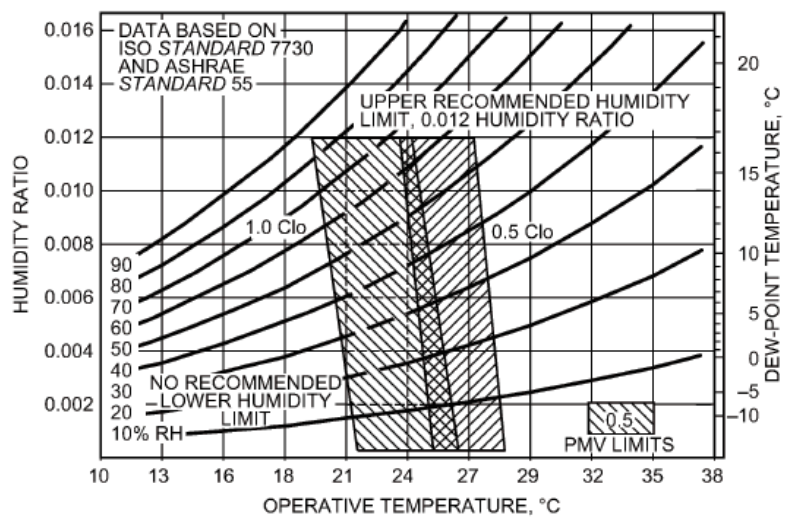

Figure 2.1: Summer and winter comfort zones [ASH, 2009]

if the HVAC system can reduce the amount of moisture during cooling, the thermostat can be set at a higher temperature, which reduces the cooling energy needed. To account for the perceived comfort level of the occupants, the building load must account for both the moisture and the temperature of the air [Crawley et al., 2008, de Wit, 2006]. The model must also use industryaccepted weather data such the Typical Metrological Year (TMY) data. 
Due to the time required to develop and validate a new building load model, an existing model that has been validated would be preferred. This strategy will reduce the model implementation time and allow for more time to be spent modeling the heat pump and/or ground loop.

A summary of the building load model requirements are:

- Accurately model building loads of the residential and commercial buildings

- Model the relative humidity in the building

- Perform hourly or sub-hourly load calculations for the entire year

- Previously validated

\subsection{Literature Review}

Based on the requirements listed in the previous sections a series of building load models/modeling environments were reviewed. EQuest, Energy Plus, TRANSYS, and HAMBASE/Simulink ${ }^{\circledR}$ where all considered and are discussed in the following sections. Table 2.1 shows a comparison of how the models/environments compare with regards to the model requirements.

\subsection{1 eQuest/DOE-2.2}

EQuest is a building energy model that can determine the complete energy usage of buildings. It combines a graphical interface, eQuest, with 
the building simulation engine, DOE 2.2 [Crawley et al., 2008, Hirsch, 2009]. eQuest provides a user-friendly interface to create building models and analyze results. The models can be created using a built-in wizard to assign various parameters to the model based on simple questions. eQuest takes advantage of DOE 2.2's large library of material properties, construction types and fenestration types to reduce the number of user inputs. The user interface also uses "Dynamic Defaults" to ensure the default values given by the wizard are appropriate for the type of building being modeled. The wizard is designed to be used with commercial buildings, but with modifications, residential buildings models can be created. EQuest provides the ability to easily run parametric studies on the building model. EQuest is only available on Windows operating systems.

The DOE 2.2 building simulation engine models the energy usage of the HVAC system, including the compressors, fans, chillers, boilers, and any other devices that consume energy. This is accomplished in three stages first the hourly building load is determined for each hour of the year using a heat balance engine. The heat balance engine quantifies the sensible and latent heating or cooling loads for each defined space based on weather conditions, solar loads, internal gains and infiltration. The loads are calculated by assuming that the space is held at a constant temperature. Second, DOE 2.2 then calculates the required HVAC system performance required to meet the building load demands. Third, a cost analysis is performed to determine the cost of operations [Law, 2004]. This three step method does not provided 
coupling between the HVAC systems simulation and the building load, which is critical for accurate space temperature predictions [Crawley et al., 2001]. For this project, accurate temperature predictions are crucial for determining when a GSHP system cannot provided the required cooling. The hourly time steps also prevent component response dynamics that occur in less than an hour from being modeled.

eQuest/DOE 2.2 already contain many different HVAC components, including a ground source heat pump model that is based on Eskillson's gfunctions and effective borehole resistances (More information in Chapter 4). With the variety of built in components it would be very easy to run studies on different types of HVAC systems or change the type of ground loop. Unfortunately, these components are programed into the DOE 2.2 simulation engine. If the user wants to create his/her own SHR components it would require making changes to the underlying engine, which would be very difficult. The DOE 2.2 engine also has predefined templates for the configuration of the components, which prevents the user from changing how the components are connected.

eQuest/DOE 2.2 simulates a single year in less than 30 seconds on a $2.4 \mathrm{GHz}$ Intel processor which would allow for many parametric studies to be quickly completed. Multi-year simulations are not supported in eQuest. eQuest has been previously shown to be accurate using ASHRAE's 140-2007 standard, discussed in Section 2.3 [ASH, 2007]. 


\subsubsection{Energy Plus}

Energy Plus is a building load simulation engine, similar to DOE 2.2. It doesn't include a graphical user interface like eQuest, but there are commercial software packages such as CYPE-Building Services, Design Builder, and EFEN that are available for purchase as well as free options such as the OpenStudio plug-in for Google Sketch Up and Results Viewer [U.S. Dept. of Energy, 2011e]. Each of these interfaces has strengths and weaknesses and a thorough review

of available software packages would be needed if Energy Plus was selected as the building load modeling software. Energy Plus is available on Windows, Mac, and Linux.

Energy Plus was derived from the DOE 2 and Blast building load models. The best parts of each of these models where chosen to be part of Energy Plus. The Energy Plus model uses the same heat balance engine as DOE 2.2 and includes an additional model for the mass transfer. Energy Plus couples the HVAC and Building model at every time step. The model solves for the total heat gain/loss in the building on 15 minute time steps, then it simulates the HAVC system using smaller time steps for that 15 minutes to determine the response. By simulating in this manner the building load and HVAC models are fully coupled to allow for the model to include realistic system controls that are a function of the room temperature, model the effects of inter-zone airflows and calculated accurate space temperatures. The short time steps also allow the dynamics of any additional components to model as well. The results of Energy Plus have been previously validated with the ASHRAE's 140-2007 
Standard [Crawley et al., 2008, 2001].

Energy Plus was programmed to be user expandable. The program utilizes modules that fit together to create the complete building load and HVAC system. These modulus include a ground loop model that is based on Eskillson's g-functions, which are discussed in Chapter 4. The user can program additional modulus for Energy Plus in Fortran 90. This would allow for the creation of custom SHRs that could be placed at different points in the ground loop. Since the modules are only functional in Energy Plus, multiple copies of each model would need to be developed to perform independent SHR analysis. The order of the modules is not predefined, which allows the user to compare different equipment set ups [Crawley et al., 2008, 2001]. Modifications to the way Energy Plus creates weather files would have to be completed in order for the model to run for longer than a single year [Murugappan, 2002].

\subsubsection{TRNSYS}

TRNSYS (TRaNsient SYstem Simulation) is a software package that is designed to model large energy systems. The package focuses on coupling individual, modular components that can represent simple devices such as pumps or complex models of multi-zone buildings. TRNSYS comes with a large library of components, including a ground loop model. The components are connected and configured in a graphical user interface called the TRNSYS Simulation Studio. The included building load model includes a preprocessor, called TRNBuild, to create the building model files that also has a graphical 
user interface. The TRNSYS solver solves the system of algebraic and dif-

ferential equations that are defined in the Simulation Studio [Crawley et al., 2008, Duffy et al., 2009].

The building load model is simultaneously solved with all of the HVAC system components resulting in a fully coupled model. The temperature and humidity level of the each building zone is modeled using two differential equations, each subject to infiltration, ventilation, conduction through the envelope, internal gains, and inter-zone heat and mass transfer. The building load model of TRNSYS has previously be validated using the ASHRAE 140-2007 standard.

The user can developed his/her own component models in any programming language, and models developed for other software packages can be included. The ability of TRNSYS to model any configuration of components and its graphical interface make running configuration based parametric studies very simple. This allows for the development of SHRs that fit into the TRNSYS model very easily. TRNSYS also features the ability to turn an entire model into a stand alone application that can be used by non-expert users to run parameter studies [Crawley et al., 2008]. One draw back is that it is only available on Windows.

\subsubsection{HAMBASE}

HAMBASE (Heat Air and Moisture model for Building And Systems Evaluation) is a building load model that was developed at the Eindhoven Uni- 
versity of Technology. The version of the model that is being considered for the integrated building load-GSHP model is implemented as a Simulink ${ }^{\circledR}$ function block. The Simulink ${ }^{\circledR}$ environment is excellent for multi-domain simulation of dynamic systems. It incorporates a graphical interface, Matlab functionality and built-in solvers. Using the Simulink ${ }^{\circledR}$ environment to develop the integrated model will allow for easy creation of different model components due to the built-in functions of the Matlab programming language as well as the prior familiarity of the research group with it. Simulink ${ }^{\circledR}$ also allows for independent component model development, which allow the custom component model to be tested and evaluated independently from the integrated model. The graphical interface allows for changes to be made to the model such as adding a SHR device to the ground loop with just a few clicks [de Wit, 2006, Mathworks, 2011].

HAMBASE does not include a graphical user interface and there are no commercially available interfaces, so the creation of the building model must be completed in a text file. This is more difficult than using a graphical user interface such as eQuest, however user knows exactly what is being modeled. HAMBASE has not had a complete third-party validation study preformed on it, but the developers performed the first test of the ASHRAE 140-2007 standard (discussed in Section 2.3) with good results. The lack of a full validation requires that the HAMBASE be validated before use.

HAMBASE utilizes a modeling procedure based on zones. A zone is the smallest simulated volume of the structure. Each zone represent a single room 
or a group of rooms that have similar thermal and moisture conditions. The Simulink ${ }^{\circledR}$ implementation of HAMBASE defines two differential equations for each zone, one for the heat transfer and the other for the mass transfer. Each differential equation equates the rate of change of the state variable to the total gains and losses in each zone. These two equations are coupled because the saturation vapor pressure needed for the hydric model is dependent on air temperature and the amount of heat that is released by condensation. During the simulation, the radiant wall temperature, air temperature, and the humidity are calculated for each zone. Using the Simulink ${ }^{\circledR}$ environment allows for each zone to have its own HVAC system or share a common system with the other zones. Using zones allows accurate modeling of areas of the structure with very different climates. For example, a large uncooled/unheated warehouse with a small cooled/heated office inside would have a different cooling/heating profile than if the office was modeled without the warehouse or if the whole warehouse was cooled/heated. The zones also allows for the internal heat and moisture gains to be placed in the proper area of the structure, such as the zone associated with the kitchen in a residential house [de Wit, 2006].

The Simulink ${ }^{\circledR}$ environment allows for full coupling between all of the different components. Since the model is based on differential equations the Simulink ${ }^{\circledR}$ implementation of HAMBASE can take advantage of user-defined controllers and HVAC system components. The HVAC system components can then be coupled to a ground loop model, allowing for the ground loop water temperature to effect to provided cooling and efficiency of the HVAC 
system. The Simulink ${ }^{\circledR}$ environment has built-in solvers to determine the time step which can either be a variable time step that is used to reduce error or a user defined fixed time step. Having control of the time steps allows for the user to trade accuracy for speed, or vise versa, when needed. Simulink ${ }^{\circledR}$ also allows for multi-rate simulations, i.e. part of the model can be simulated at one time step and a different part of the model can be simulated at a different time step. The Simulink ${ }^{\circledR}$ environment also allow for running simulations of any desired length. Simulink ${ }^{\circledR} /$ Matlab $^{\circledR}$ is available on Windows, Mac, and Linux [Mathworks, 2011].

\subsubsection{Model and Environment Selection}

To compare the models side-by-side, the requirements were scored on a scale of ' $\{-1,0,1\}$ ', as shown in Table 2.1. A ' -1 ' was given if the model or environment did not meet the requirement. For example, eQuest received

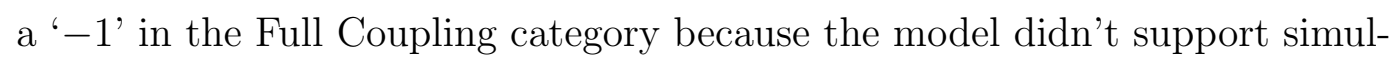
taneous simulation of the building load and HVAC system. A '0' was given if the model did not meet the stated requirement but the issue could fixed without much additional effort, or the requirement was met but would require significantly more effort than other models. Energy Plus received a ' 0 ' in the New Components category because it would be significantly more effort to develop new components for Energy Plus than it would be to develop them for TRNSYS or Simulink ${ }^{\circledR}$. Energy Plus also received a '0' in the Multiyear Simulations category since it does not support multiyear simulation directly, 
but there does exist a work around. Finally, a ' 1 ' was given if the model met the requirement.

Table 2.1: Comparison of models based on stated requirements

\begin{tabular}{lrrrr}
\hline & eQuest & Energy Plus & TRNSYS & Simulink $^{\circledR}$ \\
\hline Environment & & & & \\
Multiyear Simulations & -1 & 0 & 1 & 1 \\
Simulation Times & 1 & 1 & -1 & -1 \\
Full Coupling & -1 & 1 & 1 & 1 \\
Parametric Studies: & & & & \\
Parameter & 1 & 1 & 1 & 1 \\
Configuration & -1 & 1 & 1 & 1 \\
Programming Language & 0 & -1 & 0 & 1 \\
New Components & -1 & 0 & 1 & 1 \\
Model Development & -1 & -1 & 0 & 1 \\
Operating System & -1 & 1 & -1 & 1 \\
Dynamic Responses & -1 & 1 & 1 & 1 \\
\hline Subtotal & -5 & 4 & 4 & 8 \\
\hline Building Load & & & & \\
Commercial Buildings & 1 & 1 & 1 & 1 \\
Residential Buildings & 1 & 1 & 1 & 1 \\
Humidity & -1 & 1 & 1 & 1 \\
Hourly Time Steps & 1 & 1 & 1 & 1 \\
Prior Validation & 1 & 1 & 1 & -1 \\
\hline Subtotal & 3 & 5 & 5 & 3 \\
\hline \hline Total & $\mathbf{- 2}$ & $\mathbf{9}$ & $\mathbf{9}$ & $\mathbf{1 1}$ \\
\hline
\end{tabular}

The scores for a given model where totaled, with a higher score being better. Table 2.1 shows that HAMBASE/Simulink ${ }^{\circledR}$, Energy Plus, and TRNSYS scored the highest overall combined scores with 11, 9, and 9, respectively. Looking at the subtotals for each category, Simulink ${ }^{\circledR}$ scored better in terms of the modeling environment, while the TRNSYS and Energy Plus building models scored better than the HAMBASE building model. The main differ- 
ence between the building models was the lack of a complete validation for HAMBASE. The Simulink ${ }^{\circledR}$ environment out-scored the TRNSYS and Energy Plus environments by having a better ability to independently model and verify new components as well as the research team having prior experience with Simulink ${ }^{\circledR}$. This led the team to choose HAMBASE and Simulink ${ }^{\circledR}$.

\subsection{Validation of HAMBASE Building Load Model}

To ensure that HAMBASE is an accurate model, a method of validation needed to be found. The validation of building models such as HAMBASE is difficult for two reasons. First, due to the complexity of the building models there does not exist analytical solutions to which one can compare the result of the model. Second, to create an experimental validation would be costly and time consuming to perform. The ASHRAE (American Society of Heating, Refrigeration and Air-Conditioning Engineers) 140-2007 standard is used to validate building load models based on comparisons between many different models. It uses a series of standardized building, load and weather parameters that are modeled using eight common building models. The results of the models are tabulated and reported as part of the standard. This standard allows for the results of different models to be quickly compared to the results of the reported models. The advantages of a method of this nature is that there is no ambiguity in the program inputs; it provides many different cases to allow for many different comparisons; and it is relativity fast and inexpensive to complete. The main disadvantage is that no exact solution exists for each 
case which leaves the user to interpret the results and determine if the model is sufficiently accurate [ASH, 2007].

The 140-2007 standard is divided into several cases that vary specific building parameters. The basis for all of the test cases is case 600 . The rest of the tests use modified versions of this case. The inputs and results of case 600 will be discussed in detail here for illustrative purposes. Appendix A contains the results of the rest of the cases.

\subsubsection{Case 600 - Model Details}

Case 600 is a rectangular building with a flat roof and south facing windows as depicted in Figure 2.2. The building is oriented so that each exterior wall faces a cardinal direction. The building is composed of materials with low thermal masses. The specific material properties of the external walls, roof, and floor are provided in detail as part of the standard. The specific material properties that were used for the exterior walls in HAMBASE are given in Table 2.2 as an example of the supplied properties. The standard also

provides more general values for the heat transfer properties of the building materials, such as the overall heat transfer coefficient for each exterior surface. These values, shown at the bottom of Table 2.2, can be used for models that treat the wall as a uniform body instead of the treating it as separate materials.

The standard states that even though heat loss into the ground through the foundation can have a significant effect on the total building load building load models do not model this type of heat transfer very well. To reduce 


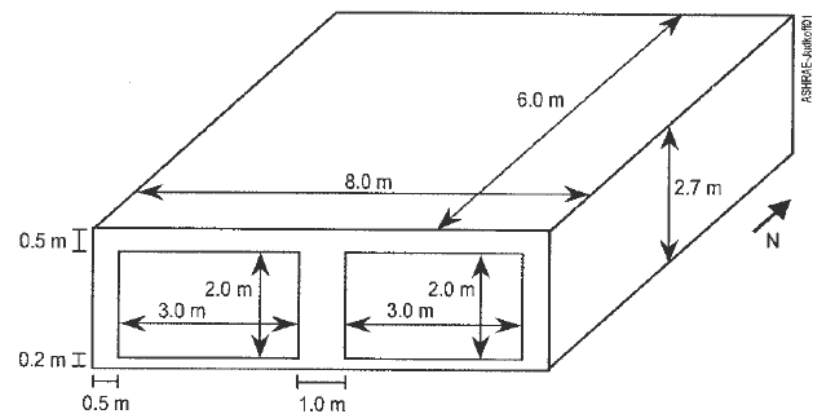

Figure 2.2: Case 600 building dimensions [ASH, 2007]

the error caused by this effect, the foundation includes thick insulation to thermally decouple the floor from the ground. For example, the 600 case included 1.003 meters of insulation with the same conductivity $(0.04 \mathrm{~W} / \mathrm{m} / \mathrm{K})$ as the fiberglass quilt insulation used in the walls. The density and specific heat are specified to be as small as the model will allow, but not less than zero.

Table 2.2: Building material properties for case 600 - Exterior wall, recreated from ASHRAE 140-2007 [ASH, 2007]

\begin{tabular}{lrrrrrr}
\hline Element & $\mathrm{k}$ & Thickness & $\mathrm{U}$ & $\mathrm{R}$ & Density \\
& $W / m / K$ & $m$ & $W / m^{2} / K$ & $\begin{array}{r}\mathrm{Cp} \\
m^{2} K / W\end{array}$ & \multicolumn{1}{l}{$\mathrm{kg} / \mathrm{m}^{3}$} & $\mathrm{~J} / \mathrm{kg} / K$ \\
\hline Exterior Wall (inside to outside) & & & & & \\
Int Surf Coef & & & 8.290 & 0.121 & & \\
Plasterboard & 0.160 & 0.012 & 13.333 & 0.075 & 950.0 & 840.0 \\
Fiberglass quilt & 0.040 & 0.066 & 0.606 & 1.650 & 12.0 & 840.0 \\
Wood Siding & 0.140 & 0.009 & 15.556 & 0.064 & 530.0 & 900.0 \\
Ext Surf Coef & & & 29.300 & 0.034 & & \\
& & & & & & \\
Total air-air & & & & $\mathbf{0 . 5 1 4}$ & $\mathbf{1 . 9 4 4}$ & \\
Total air-surf & & & & $\mathbf{0 . 5 5 9}$ & $\mathbf{1 . 7 8 0}$ & \\
\hline
\end{tabular}


Table 2.3: Angular dependance of solar heat gain factor, recreated from ASHRAE 140-2007 [ASH, 2007]

\begin{tabular}{lrrrrrrrrr}
\hline Angle (deg.) & 0 & 10 & 20 & 30 & 40 & 50 & 60 & 70 & 80 \\
SHG & 0.789 & 0.789 & 0.787 & 0.784 & 0.775 & 0.754 & 0.700 & 0.563 & 0.302 \\
\hline
\end{tabular}

As illustrated in Figure 2.2 the building has $12 \mathrm{~m}^{2}\left(129 \mathrm{ft}^{2}\right)$ of glazing (windows) on the south facing exterior wall of the house. The windows are defined in many different ways since there are many different ways to treat the heat transfer through the windows. HAMBASE uses the overall heat transfer coefficient $(U)$, the convection factor $\left(h_{c}\right)$, the normal solar gain factor (SHG) and the angular dependance of the solar heat gain factor to completely define the heat transfer properties of the glazing. The windows specified have a overall heat transfer coefficient, $U$, of $3.0 \mathrm{~W} / \mathrm{m}^{2} / K$ and a convection factor, $h_{c}$, of $0.04 \mathrm{~W} / \mathrm{m}^{2} / K$. The angular dependance of the solar heat gain factor is given is Table 2.3. Since other models such as Energy Plus and DOE 2.2 define the windows in a different manner, ASHRAE provides a table of different properties for the windows. Not all of the properties are used in any single building model.

The standard locates the building in Denver, Colorado. This dictates the weather for the simulation and how the solar radiation lands on the house. The weather file is specified as TMY (Typical Meteorological Year) data, which gives the temperature, humidity, diffuse and normal solar radiation, wind speed and wind direction for every hour of the year. The weather was 
intentionally chosen to be in a dry climate to reduce the effect of moisture on the results. Some building models, including HAMBASE, model the moisture levels in the building to determine the relative humidity while other do not model the moisture. Since high values of relative humidity can effect the total loads on the building the weather was intentionally chosen to be very dry.

The standard specifies that the infiltration rate of the building be 0.5 ACH (Air Changes per Hour). Since the building is hypothetically in Denver, which is at an altitude of $1609 \mathrm{~m}$ (5544 ft) above sea level, the density of the air must be adjusted to approximately $80 \%$ of the value at sea level. This brings reduces mass flow of the infiltration to the proper level. For buildings that do not have the ability to adjust the density of air, the standard specifies that the infiltration rate be reduce to $0.41 \mathrm{ACH}$. The standard also specifies that the total internal load be $200 \mathrm{~W}(341 \mathrm{Btu} / \mathrm{hr})$ which corresponds to 4.17 $W / m^{2}\left(1.32 B t u / h r / f t^{2}\right)$. This load is on 24 hours a day, for the entire year and is specified as $100 \%$ sensible.

The HVAC system is specified to have a heating and cooling capacity of $1000 \mathrm{~kW}$ (284 refrigeration tons). This effectively gives the system an infinite capacity, which was done to prevent the specified capacities from effecting the peak heating and cooling loads that are reported. The HVAC system provides $100 \%$ convective heating or cooling and does not provide any latent heat extraction. The thermostat is set so that if the conditioned zone air temperature is greater than $27^{\circ} \mathrm{C}\left(80.6{ }^{\circ} \mathrm{F}\right)$ the building is cooled and if the conditioned zone air temperature is less than $20^{\circ} \mathrm{C}\left(68^{\circ} \mathrm{F}\right)$ the building is 
heated.

\subsubsection{Case 600 - Selected Results}

ASHRAE 140-2007 provides a variety of data sets that characterize the building load for the 600 case. Each data set is designed to test and troubleshoot different parts of the building load model. The standard suggests that when validating a model the user should get good agreement for all of the case 600 data sets and then move on to the additional tests.

The validation begins by looking at the solar load on the surfaces of the building. Figure 2.3 compares the incident radiation on the west wall of the building for every hour on July 27th. The line represents the results from HAMBASE and diamonds is the mean of the eight values reported by 140-2007. The error bars indicate the maximum and minimum values reported by the standard. This format is used for all plots of this type. The results show that there is good agreement between HAMBASE and the reported values. Similar plots for the south wall, as well as, for March 5th are available in Appendix A as Figures A.1, A.3, and A.4. These figures also show good agreement between HAMBASE and the 140-2007 standard.

Next, the total annual loads on each surface of the building as well as the radiation transmitted through the glazing are compared. Table 2.4 shows annual incident radiation values for each of the surfaces of the building. The values for HAMBASE are within the reported range for the north, east and west walls, while the south wall and the roof (horizontal) are just outside 


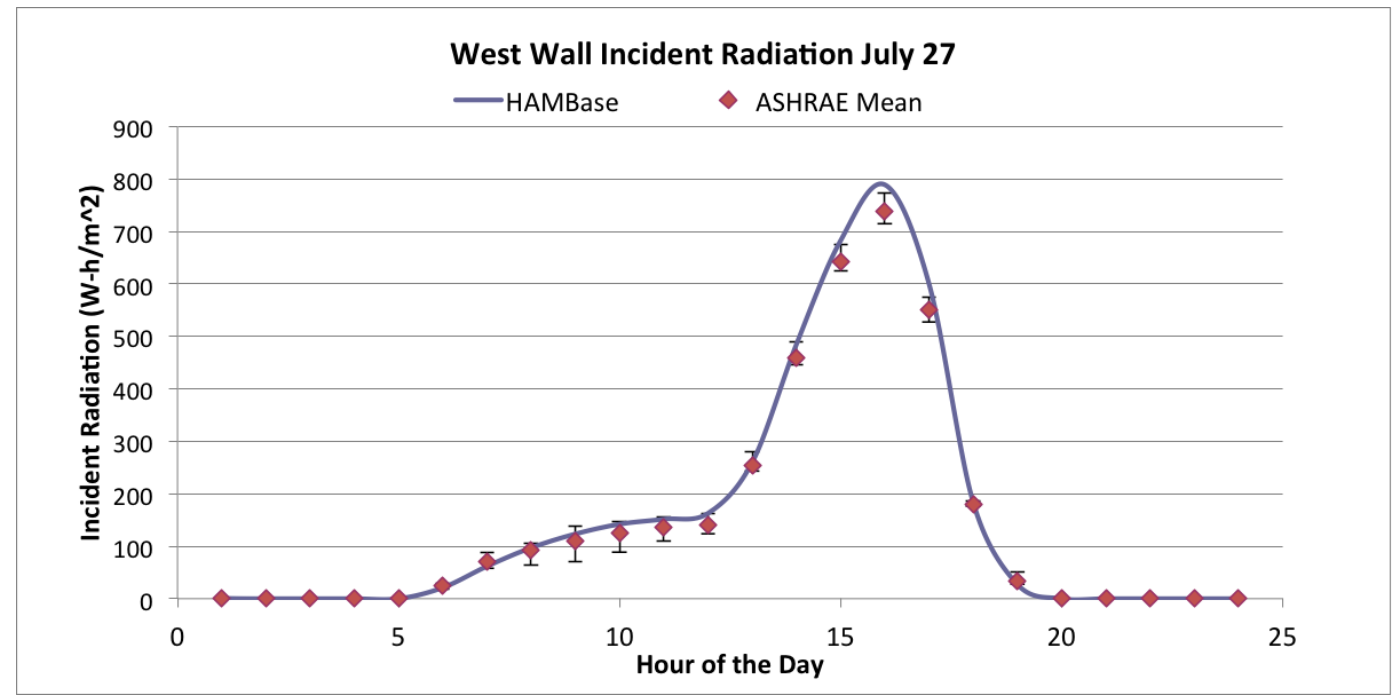

Figure 2.3: Hourly incident radiation on west wall for July 27

Table 2.4: Annual solar radiation loads on case 600

\begin{tabular}{|c|c|c|c|c|}
\hline & \multicolumn{3}{|c|}{ 140-2007 Reported Values } & \multirow[t]{2}{*}{ HAMBASE } \\
\hline & \multicolumn{3}{|c|}{ Minimum Average Maximum } & \\
\hline \multicolumn{5}{|c|}{ Annual Incident Radiation $\left(k W h / m^{2}\right)$} \\
\hline North & 367.4 & 428.8 & 457 & 441.8 \\
\hline East & 959 & 1079.9 & 1217.3 & 1156.2 \\
\hline West & 856.5 & 1018.4 & 1090 & 1084.2 \\
\hline South & 1456 & 1490.0 & 1566 & 1590.8 \\
\hline Horizontal & 1797 & 1826.8 & 1832 & 1839.4 \\
\hline \multicolumn{5}{|c|}{ Annual Transmitted Radiation $\left(\mathrm{kWh} / \mathrm{m}^{2}\right)$} \\
\hline & 914 & 962.5 & 1051 & 1001.5 \\
\hline \multicolumn{5}{|c|}{ Annual Transmissivity Coefficient } \\
\hline & 0.623 & 0.646 & 0.671 & 0.629 \\
\hline
\end{tabular}


of the reported range. All of HAMBASE's values are higher than the mean reported values. Table 2.4 also compares the annual radiation that is transmitted through the glass and the annual transmissivity coefficient. The annual transmissivity coefficient is the fraction of the incident radiation on the south wall that is transmitted through the glazing on the south wall. Both of these values fall within the reported ranges.

The hourly HVAC system loads and the hourly interior air temperatures are compared. The hourly HVAC system results for January 4th are shown in Figure 2.4. The heating loads are represented as positive loads (adding energy to the building) while cooling loads are represented as negative (removing energy from the building). The figure shows that HAMBASE is predicting more system load for both heating and cooling period than the mean reported values. In addition, HAMBASE is predicting more cooling requirements than the maximum reported value during the hours $11,12,13$ and 14 . It is also predicting more heating requirements than the maximum reported value for hours 19, 20, and 21. For all of these times HAMBASE is just outside of the reported range. Figure 2.5 shows the hourly "free floating" temperature for January 4th. The free floating temperature is the air temperature in the building with the heating and cooling capacity of the HVAC system set to zero. This case, $600 \mathrm{FF}$, is an example of the additional cases that are tested as part of 140-2007. The plot shows that HAMBASE is accurately predicting the interior air temperatures of the building, all of HAMBASE's values are within the range of reported values. 


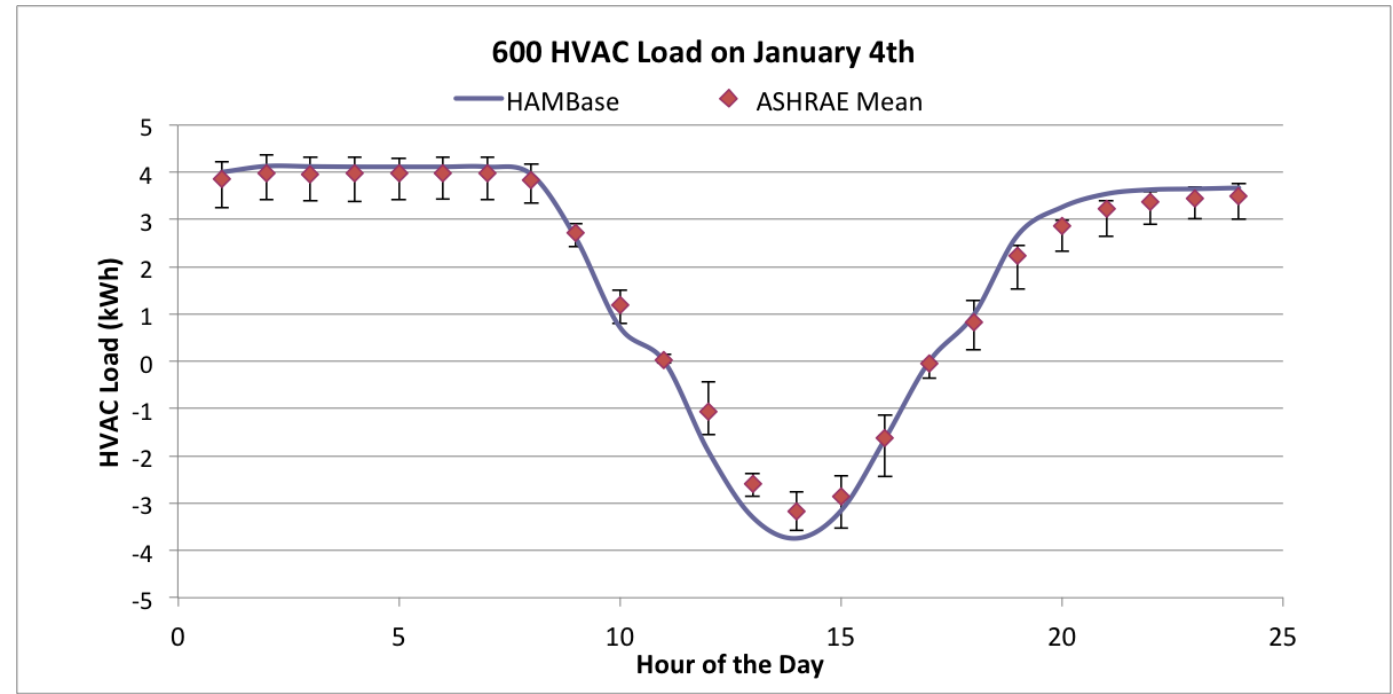

Figure 2.4: Hourly HVAC load for January 4th

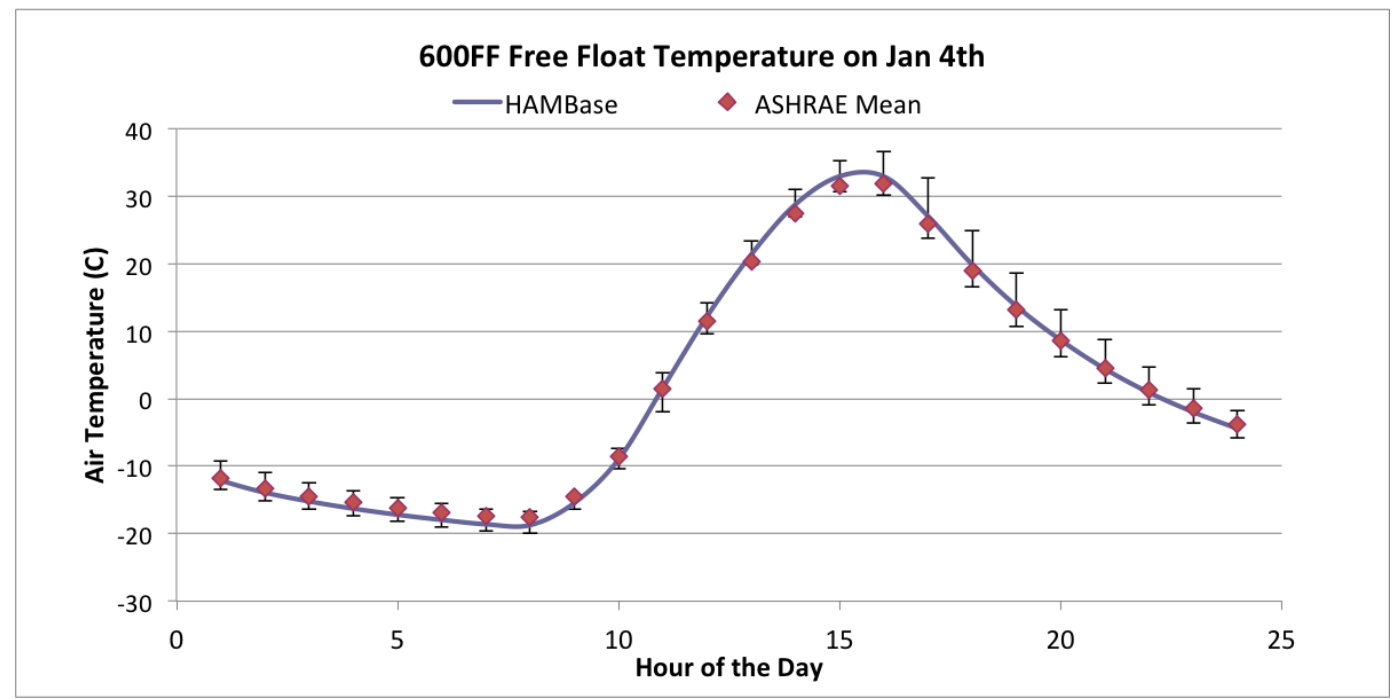

Figure 2.5: Hourly air temperature values for the $600 \mathrm{FF}$ case 
The final comparison for case 600 is shown in Figure 2.6. This chart compares the total annual heating and cooling loads as well as the peak heating and cooling loads for all eight of the reported models and HAMBASE. HAMBASE is on the far right of each section. The vertical scale is in MW-h for the total annual loads and $\mathrm{kW}$ for the peak loads. The empty bars in the peak load comparisons for SERIRES, correspond to unreported values. From this we see the HAMBASE predicts values within the range of the reported values.

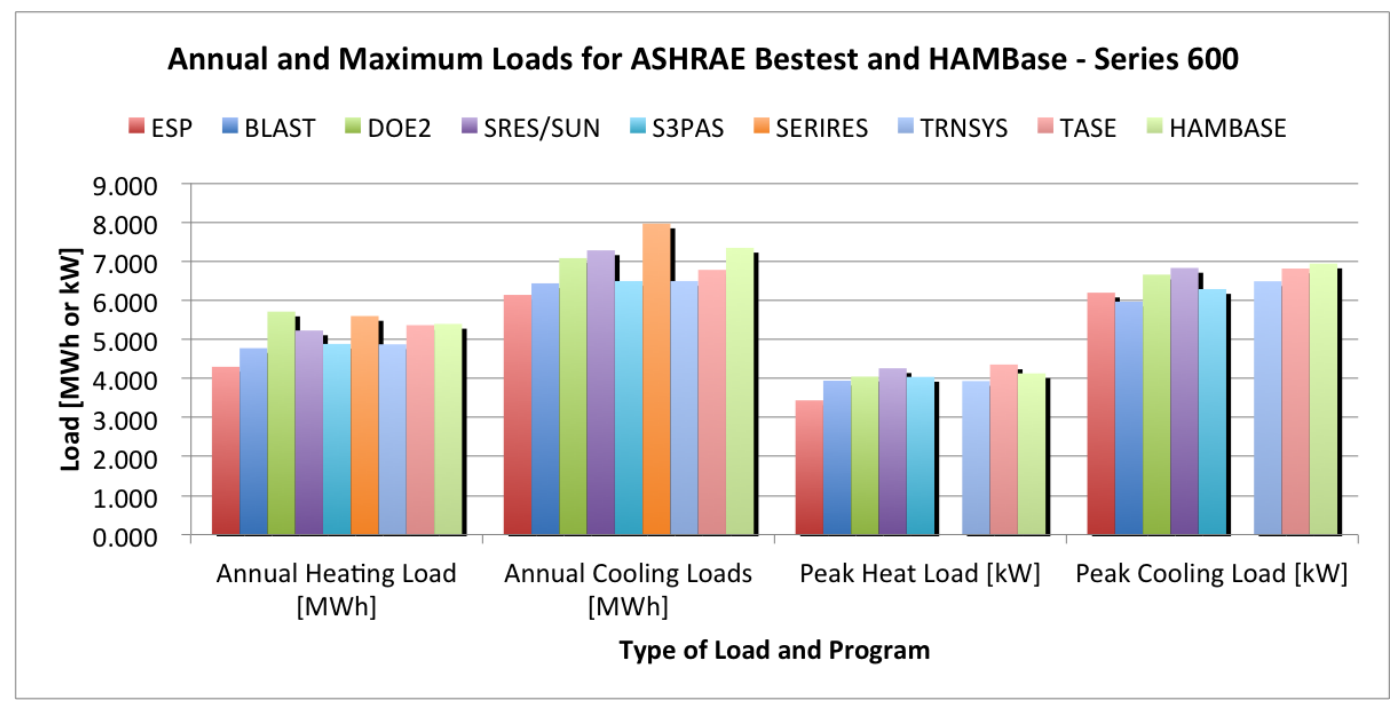

Figure 2.6: Annual and peak heating and cooling loads

Based on the results presented, it was determined that HAMBASE was in good agreement with the reported values for case 600. Therefore, additional cases of the 140-2007 standard where completed to further validate HAMBASE. 


\subsubsection{Sensitivity Study}

The additional cases specified by ASHRAE 140-2007 are used to determine the sensitivity of the model to various changes. Each additional case has a single change from its base case as summarized in Table 2.5. For example, case 620 moves the south facing windows of case 600 to the east and west faces of the building, while all other parameters are exactly the same. In addition, case 630 then adds shading around the east and west facing windows of its base case 620 . In total, 16 additional cases where simulated.

The results of all of the additional cases except for the free floating temperature cases $(600 \mathrm{FF}, 900 \mathrm{FF}, 650 \mathrm{FF}$, and $950 \mathrm{FF})$ were compared to the reported values by determining the change in annual heating and cooling and peak loads between the case and it's basis. For example, Figure 2.7 shows that HAMBASE predicted for Case 610, which adds shading over the south facing windows of the 600 case, 1.6 MW-h less annual cooling than case 600, while the annual heating and peak loads did not change much. Comparing these results to the reported values it is seen that the heating load changes were very small for all of the models and the annual cooling value changes agree. The change in the peak cooling load for the HAMBASE model was less that the reported range of values for the models, but was close to the minimum value. The results for the rest of the additional cases are shown in Figures A.6 - A.25 in Appendix A. 


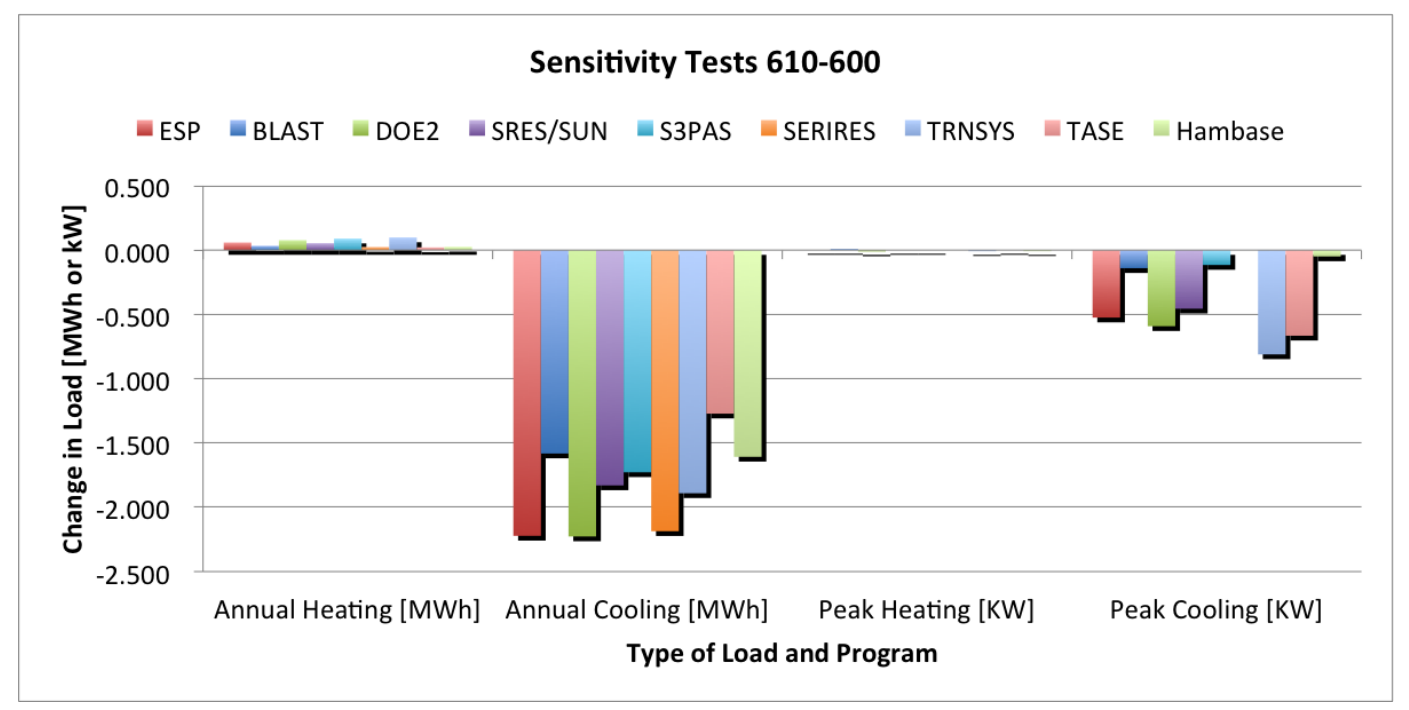

Figure 2.7: Changes in building loads from case 600 to case 610, addition of shading over south facing windows

\subsubsection{Validation Conclusions}

ASHRAE 140-2007 does not provide criteria to determine if the simulation results are in agreement or not. The standard provides a set of guidelines for comparing the results and leaves up to the user to determine whether not the model is accurate. Based on the results of the case 600 model presented in Section 2.3.2, it was determined that HAMBASE was modeling case 600 with sufficient accuracy. Reviewing the results of the sensitivity studies presented in Appendix A indicates that the HAMBASE adequately models the tested cases. Based on these results HAMBASE was determined to be accurate enough for the research group to use as the building load model. 
Table 2.5: Summary of sensitivity study cases

\begin{tabular}{|c|c|c|}
\hline Case & Base Case & Changes \\
\hline 610 & 600 & Addition of shading over south facing windows \\
\hline 620 & 600 & $\begin{array}{l}\text { Removes the } 12 \mathrm{~m}^{2} \text { of windows from the south wall } \\
\text { and adds } 6 \mathrm{~m}^{2} \text { of shading to the east and west walls }\end{array}$ \\
\hline 630 & 620 & $\begin{array}{l}\text { Addition of shading above and around the widows on } \\
\text { the east and west walls }\end{array}$ \\
\hline 640 & 600 & $\begin{array}{l}\text { The heater thermostat is setback to } 10{ }^{\circ} \mathrm{C} \\
\text { between the } 2300 \text { and } 0700 \text { hours and left at } 20{ }^{\circ} \mathrm{C} \\
\text { between } 0700 \text { and } 2300 \text { hours }\end{array}$ \\
\hline 650 & 600 & $\begin{array}{l}\text { Night time ventilation is added between } 1800 \\
\text { and } 0700 \text { hours, the heat is always off and cooling is } \\
\text { only provided between } 0700 \text { and } 1800 \text {. }\end{array}$ \\
\hline 900 & 600 & $\begin{array}{l}\text { Construction materials changed to materials } \\
\text { with higher heat capacities }\end{array}$ \\
\hline 910 & 610 & Same as 900 \\
\hline 920 & 620 & Same as 900 \\
\hline 930 & 630 & Same as 900 \\
\hline 940 & 640 & Same as 900 \\
\hline 950 & 650 & Same as 900 \\
\hline 960 & 900 & $\begin{array}{l}\text { Addition of unconditioned sunspace on the } \\
\text { south side of the house }\end{array}$ \\
\hline $600 \mathrm{FF}$ & 600 & No heating or cooling provided to the building \\
\hline $650 \mathrm{FF}$ & 650 & Same as $600 \mathrm{FF}$, still has night time ventilation \\
\hline $900 \mathrm{FF}$ & 900 & Same as $600 \mathrm{FF}$ \\
\hline $950 \mathrm{FF}$ & 950 & Same as $600 \mathrm{FF}$, still has night time ventilation \\
\hline
\end{tabular}




\section{Chapter 3}

\section{Water Source Heat Pump Model}

A water source heat pump ${ }^{1}$ model is an integral part of the integrated building-GSHP model. The water source heat pump contains the refrigerant loop that extracts/rejects heat from/to the conditioned air space and rejects/extracts heat into/from the water circulating though the ground loop for cooling/heating, respectively. Figure 3.1 shows the T-s and P-h diagrams for a ideal vapor compression model. The following process form the ideal vapor compression cycle:

Process 1-2 Saturated, low pressure refrigerant is compressed via isentropic compression to a high pressure and temperature vapor.

Process 2-3 Constant pressure heat rejection occurs from the high temperature refrigerant to the high temperature reservoir. The vapor condenses and becomes a saturated liquid.

Process 3-4 The refrigerant is throttled through an expansion valve via an enthalpic process to reduce the pressure and temperature. At state 4 the

\footnotetext{
${ }^{1}$ In this Thesis, Water Source Heat Pump refers to the vapor compression unit that interfaces the ground loop and the conditioned air, while Ground Source Heat Pump refers to the combination of a water source heat pump and a ground loop.
} 


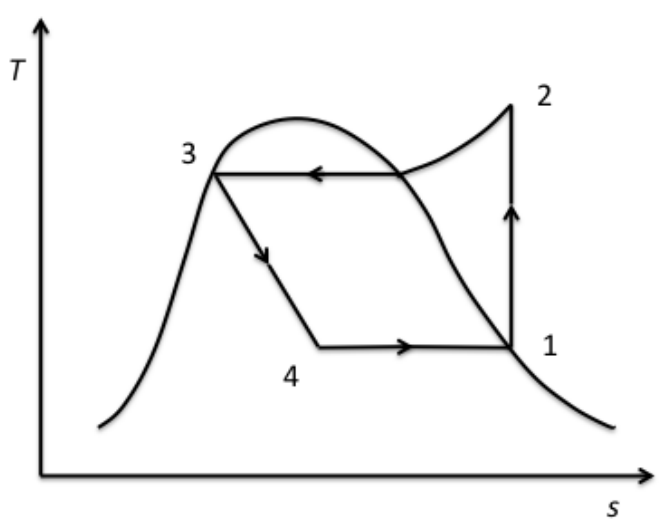

(a) T-s Diagram

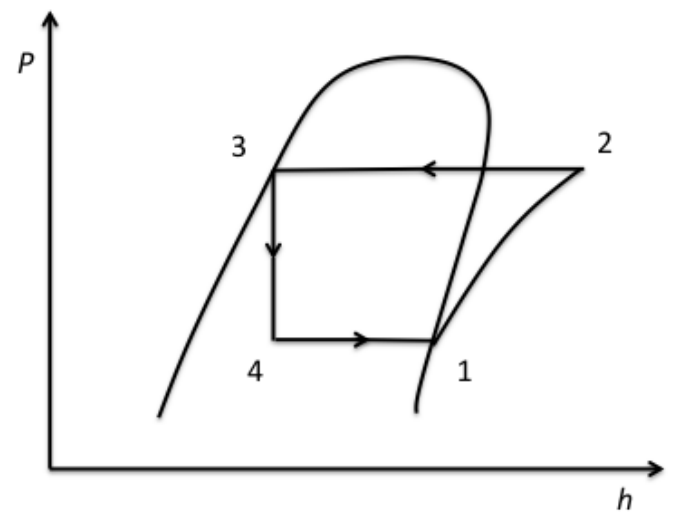

(b) P-h Diagram

Figure 3.1: Ideal vapor compression cycle diagrams

refrigerant is a low quality liquid-vapor mixture.

Process 4-1 Constant pressure heat transfer occurs from the low temperature reservoir to the lower temperature refrigerant. The liquid portion of the mixture evaporates until the refrigerant is a saturated vapor.

The actual vapor compression cycle varies slightly from the ideal case. At state 3 the saturated liquid is actually subcooled which prevents vapor from entering the throttling device and at state 1 the saturated vapor is superheated to prevent liquid from entering the compressor. Figure 3.2 is a schematic of a water source heat pump in the cooling mode with the inputs and outputs of the model labeled. Table 3.1 lists the inputs and outputs of the model as well as the associated units. The model inputs are: temperatures of the air, $T_{D B, A I R}$, and water, $T_{W A T E R, I N}$ at the inlet to the heat pump unit; the volumetric flow 


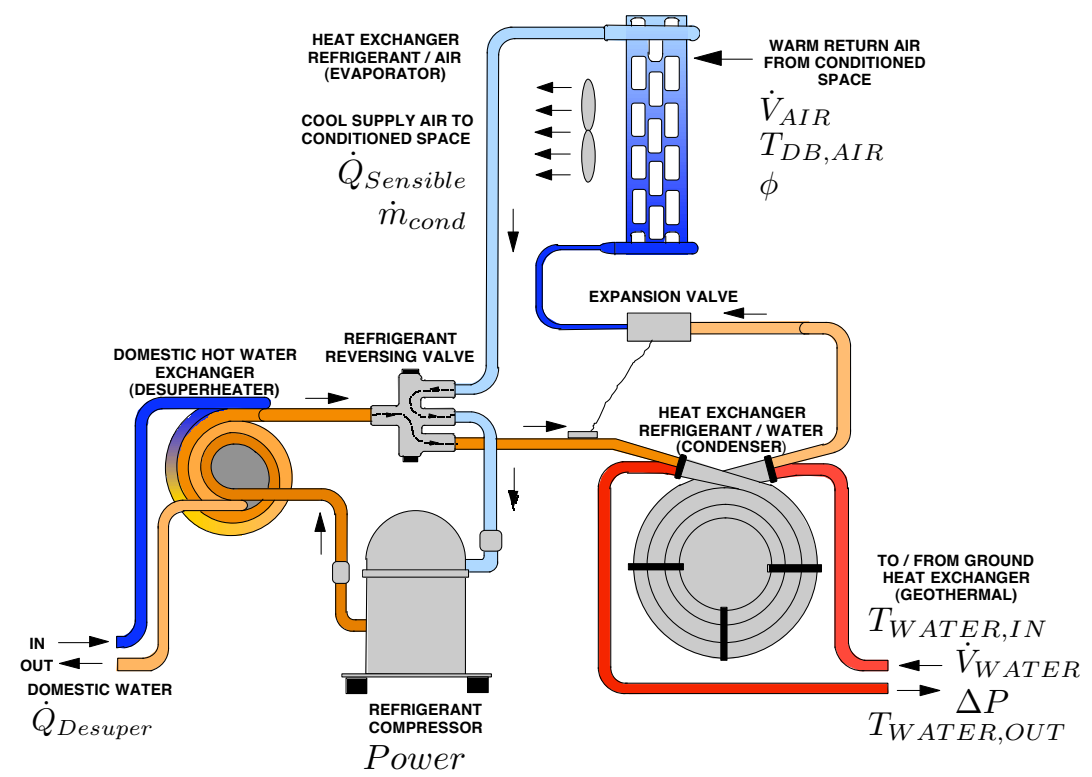

Figure 3.2: Operation of heat pump during cooling with model variables (Source: Oklahoma State University)

rates of air, $\dot{V}_{A I R}$, and water, $\dot{V}_{W A T E R}$, through the unit; the heat removed by a SHR device, $\dot{Q}_{\text {Desuper }}$; and the water content of the entering air in terms of the relative humidity, $\phi$. The model needs to calculate: the sensible, $\dot{Q}_{\text {Sensible }}$, and latent, $\dot{m}_{\text {cond }}$, output of the heat pump; the electrical power consumed by the unit, Power; the water outlet temperature, $T_{W A T E R, O U T} ;$ and the pressure drop of the water as it flows through the refrigerant to water heat exchanger, $\Delta P$.

After comparing multiple methods of modeling the heat pump, including first-principles based models and various empirical models, the performance map method was chosen because it was based on actual performance data, was computationally inexpensive and could be quickly implemented. 
Table 3.1: Model inputs and outputs

\begin{tabular}{lr|lr}
\hline \multicolumn{2}{c|}{ Inputs } & \multicolumn{2}{c}{ Outputs } \\
\hline$\dot{V}_{\text {AIR }}$ & {$\left[\mathrm{m}^{3} / \mathrm{s}\right]$} & $\dot{Q}_{\text {Sensible }}$ & {$[\mathrm{W}]$} \\
$T_{\text {DB,AIR }}$ & {$\left[{ }^{\circ} \mathrm{C}\right]$} & $\dot{m}_{\text {cond }}$ & {$[\mathrm{kg} / \mathrm{s}]$} \\
$\phi$ & {$[-]$} & Power & {$[\mathrm{W}]$} \\
$\dot{V}_{W A T E R}$ & {$[L / s]$} & $T_{W A T E R, O U T}$ & {$\left[{ }^{\circ} \mathrm{C}\right]$} \\
$T_{W A T E R, I N}$ & {$\left[{ }^{\circ} \mathrm{C}\right]$} & $\Delta P$ & {$[k P a]$} \\
$\dot{Q}_{\text {Desuper }}$ & {$[\mathrm{W}]$} & & \\
\hline
\end{tabular}

One of the benefits of the performance map model is that the heat pump data required to create an accurate model is widely distributed by the ground loop heat pump manufacturers. An issue that arises with models that require detailed geometric, material, or construction about particular system components is that manufacturers of heat pumps components do not divulge this information. It is considered proprietary, so an individual or research group will have difficulty obtain this information.

\subsection{Literature Review}

During the development of the heat pump model implemented in the integrated GSHP model, several different modeling approaches where considered and are reviewed below. Each approach had its advantages and disadvantages that were considered. 


\subsubsection{Component Models}

As explained above, a water source heat pump unit consists of four major components: Compressor, Expansion Value, Refrigerant to Air Heat Exchanger (fin and tube), and Refrigerant to Water Heat Exchanger (concentric tube). Each component can be modeled in a first-principles fashion or using empirical data. The first-principle models rely on very detailed geometric, material, and construction data about each component of the heat pump system. For example, Chen et al. [2002a] developed a model of a scroll compressor that includes the multiple stages of compression in the scroll, the leakage from one compression stage to the next, and the heat transfer through the vanes of the scroll. Chen et al. [2002b] completes the scroll compressor model by adding the heat transfer between nine different nodes of the compressor housing and refrigerant. The resulting combined model has 26 nonlinear equations that must be solved simultaneously. This model requires very specific geometry data of the scroll, accurate motor characteristics and material properties of multiple internal components. A model this complex would be useful for an engineer designing compressors, but is too complex and computationally demanding to be of use to this study. [Chen et al., 2002b,a]

Wang et al. [2005] also developed a first principles based model of a scroll compressor. The model uses detailed geometric data about the scroll profile to determine an expression for the volume of the working compression chamber. He also uses the data to model the leakage out of each working compression chamber. The combination of theses two models and the addition of 
a thermodynamic model of the suction, compression, and discharge processes allows the model to accurately predict the pressure and temperature of refrigerant during the compression process as well as the the refrigerant mass flow rate and required motor power [Wang et al., 2005].

Detailed first-principles based models also exist for the two types of heat exchangers. Judge and Radermacher [1997] developed a model of a fin and tube heat exchanger for use in refrigerant cycle simulations. The model discretizes the heat exchanger into 100 nodes, then calculates a heat transfer coefficient for each node based on the refrigerant states, refrigerant flow type [single state, condensing two phase, evaporating two phase, annulus], the geometry and material of the tubes and fins and the state of the air. The resulting equations must be solved simultaneously [Judge and Radermacher, 1997]. Garca-Valladaresa et al. [2004] provide a similar method for modeling the concentric tube heat exchanger used in water source heat pumps. Both of these models require detailed construction and geometry data. This information is considered proprietary by heat pump manufactures, therefore getting accurate data about a variety of different heat exchangers is very difficult to accomplish. These models are also computationally demanding.

Due to the large number of inputs needed for a first-principles model semi-empirical compressor and heat exchanger models have been developed. These models are based on a simplified physical representation of the process with a reduced number of inputs and a reduced computation time compared to the first-principle models. 
Winandy et al. [2002] developed a semi-empirical model of a scroll compressor that calculates the mass flow rate, electric power and discharge temperature based on seven parameters. To simplify the model, the change of the refrigerant state through the compressor is divided into inlet heating, isentropic compression, constant volume compression and exit cooling. Each step represents a different thermodynamic process that occurs in the compressor. The seven input parameters are determined empirically by minimizing the error between experimental data and the model results [Winandy et al., 2002]. This approach allows for the creation of a model based on the published performance data that is available from the compressor manufacturers. After determining the input parameters the model has less that a $\pm 4 \%$ error on the mass rate and shaft power and the discharge temperature was within $\pm 5 K$.

Fischer and Rice [1983] developed an air source heat pump model (discussed in detail in Section 3.1.2) that uses the NTU-effectiveness method to determine the performance of fin and tube heat exchangers. The NTUeffectiveness method calculates the theoretical maximum amount of heat transfer, $q_{\max }$, that can take place based on the inlet conditions and heat capacities of the fluids. The actual heat transferred, $q$, is determined based on the effectiveness, which is defined as:

$$
E\left(N T U, \frac{C_{\min }}{C_{\max }}\right)=\frac{q}{q_{\max }}
$$

The effectiveness, $E$, is a function of the number of transfer units, $N T U$, and the ratio of the heat capacities of the fluids in the heat exchanger. The exact function for the effectiveness is determined by the specific type of heat 
exchanger. For example, Fischer and Rice [1983] used Equation 3.2 to calculate the effectiveness, $E$, for a fin and tube heat exchanger with two phase refrigerant flow.

$$
E=1-e^{-N T U}
$$

$N T U$ is determined by the overall heat transfer coefficient, $U$, which is determined by various correlations depending on the states of the refrigerant and geometry of the heat exchanger. The heat exchanger is divided into three regions, each representing a state of the refrigerant. The heat transfer is calculated for a given region and then summed to determine the total [Fischer and Rice, 1983]. The advantage of this model over the model developed by Judge and Radermacher [1997], is a reduction in the computation time due to the reduction in the number of calculation nodes (3 vs. 100). Lee and Jones [1997] present a model for the concentric tube heat exchangers that is also based on the NTU-effectiveness method. This model was developed to model a desuperheater and is therefore only valid for single phase flow. Even though the basis for semi-empirical models are simpler than the first-principle models they still require geometric and material data for the heat exchangers in order to calculate the heat transfer coefficients.

On the opposite end of the spectrum from first-principle models are completely empirical models, that map the inputs of the model to the outputs using a series of simple equations that are curve fit to experimental data. Models of this form reduce computation time due to their simplicity, but there is a loss of physical details about the modeled process. One of the two compres- 
sor models used by Fischer and Rice [1983] is based on an empirical method. They use manufacturer published compressor maps to curve fit a series of biquadratic functions based on the compressor inlet and outlet temperatures to calculate the power input and mass flow rate. The output refrigerant enthalpy is determined based on the power input, mass flow rate, input enthalpy and an environmental heat loss factor. An advantage of models based on empirical data is that when the model is operating in the provided data range the results are very accurate. In contrast operating points outside of the provided data set can result in large errors since the equations are not based on the physical process.

Pacheco-Vega et al. [2001] implemented a feed forward artificial neural network to model the heat transfer in a fin and tube heat exchanger. The neural network has 11 inputs which includes seven basic geometric measurements of the heat exchanger and four fluid inlet properties. After training the model on 38 experimental runs the trained network was able to predict the heat transfer with $1.5 \%$ over a variety of different sized heat exchangers. One of the novel features of this model is its ability to estimate the error of it calculations, which aids in the identification of areas of the input manifold that require additional training.

\subsubsection{Complete Heat Pump Models}

Fischer and Rice [1983] developed a complete model of an air source heat pump. The model utilizes individual models for each of the components 
in the cycle. The fin and tube heat exchangers are modeled using the NTUeffectiveness method and the compressor is modeled using an empirical model, which are both discussed in the Section 3.1.1. The model was published in 1983 and is outdated in terms of components. For example, the model uses reciprocating compressor instead of a modern scroll compressor. The model also does not support modern refrigerants such as R-410A. Even though the individual component models do not meet the project needs the computation algorithm is of interest for developing a water source heat pump model. The model groups the compressor, condenser and the thermal expansion value into a "high-side" section and the evaporator into a "low-side" section. The amount of superheat at the exit of the evaporator and the air temperatures at the inlets of the evaporator and condenser must be specified as inputs to the model, along with estimates of the refrigerant mass flow rate and saturation temperatures at the exit of the evaporator and the inlet of the condenser. The model algorithm starts at the exit of the evaporator and calculates the properties of the refrigerant and mass flow rates through the compressor, condenser and thermal expansion valve. The model then iterates the estimated properties until the mass flow rates through the components agree within a specific tolerance. The model then iterates the "low-side" inlet properties until the outlet of the evaporator has reached the specified superheat level. At this point the model calculates the required evaporator inlet air temperature and compares it to the ambient air temperature. If these agree within a given tolerance the model calculations are finished, otherwise the estimated satura- 
tion temperature at the evaporator exit is adjusted and the calculations are repeated. An advantage of a model like this is that the components can be changed out to model a different heat pump configuration, or a supplemental heat rejector could be added to the to the heat pump. The trade off is this model requires detailed information about the components of the system. The model requires a significant amount of simulation time due to the two iteration loops required to solve system as a whole in addition to any iterations required by the component models.

Spitler and Cullin [2008] use a model of a water source heat pump that is based on data available in manufacturer's catalogues. The models fits a set of equations to the provided data and uses the equations to calculate the output values of the heat pump based on the inlet conditions. The advantage of this approach is the results are very accurate within the published operating range, the resulting model is computationally efficient, and the data is readily available for a wide range of heat pumps. A disadvantage of this approach is that the model does not calculate any internal variables, such as the refrigerant states. These internal variables are needed when looking at possible supplemental heat rejection devices, such as desuperheaters, that are part of the vapor compression cycle.

\subsection{Performance Maps}

The performance map model is based on data published by heat pump manufacturers, such as ClimateMaster [ClimateMaster, 2010] and Water Fur- 
nace [WaterFurnace, 2010]. The data that is provided by the manufacturers is collected based on the ANSI/ASHRAE/ARI/ISO 13256-1 standard for rating and testing water source heat pumps [ClimateMaster, 2010]. The data relates the inlet conditions of the heat pumps to the exit conditions and operating parameters, an example performance map can be found in Figure 3.4. Figure 3.3 shows the inputs and outputs of the performance maps. Comparing the

\begin{tabular}{|c|c|c|}
\hline Entering Water Temperature & \multirow{4}{*}{$\begin{array}{c}\text { Performance } \\
\text { Map }\end{array}$} & Heating/Cooling Capacity \\
\hline \multirow{3}{*}{$\begin{array}{l}\text { Entering Air Dry-Bulb and } \\
\text { Wet-Bulb Temperature } \\
\text { Flow Rates of Water and Air }\end{array}$} & & $\begin{array}{l}\text { Desuperheater Capacity } \\
\text { Heat Rejected/Extracted }\end{array}$ \\
\hline & & $\begin{array}{l}\text { from Water } \\
\text { Power Consumption }\end{array}$ \\
\hline & & Water Pressure Drop \\
\hline
\end{tabular}

Figure 3.3: Black box of performance map model

inputs and outputs of the model shown in Table 3.1 to those shown in the black box diagram shows that the desired inputs and outputs of the overall model do not completely match the inputs and outputs of the performance maps. For example, the integrated model uses $\phi$, relative humidity, to represent the moisture content of the air and the performance maps uses $T_{W B, A I R}$, the wet bulb temperature of the air.

\subsubsection{Assumptions}

The completed performance map model make some assumptions about the heat pump. The assumptions are divided into two categories, operational and computational assumptions. The latter category of assumptions are as- 
sociated with model calculations and are discussed throughout the document where applicable as well as listed in Table 3.2. The operational assumptions are based on the operation of the heat pump. For example, the model assumes that the heat pump is operating without faults. Consideration of faults is currently beyond the scope of the project. The model also assumes that the heat pump has a single speed fan and a single stage compressor. Multi-speed fans and two stage compressors are available on ultra efficient residential units and have been shown to reduce energy consumption and increase occupant comfort. They were not considered due to the increase in the complexity of the control algorithms. The addition of multi-speed fans and two-stage compressors represents a desirable improvement to the integrated model. The model currently assumes that the air flow rate, $\dot{V}_{A I R}$, is constant throughout the simulation. Constant air flow was assumed due to the lack of model information associated with pressure drops due in the distribution systems of the conditioned air. This assumption could be relaxed by implementing a resistance model of the air ducts.

Table 3.2: Performance map model assumptions

\begin{tabular}{lr}
\hline Assumption & Related Section \\
\hline Linear interpolation for performance map data & Section 3.3.1 \\
Calculate $T_{W B}$ based on empirical equations & Section 3.3.3 \\
$\begin{array}{l}\text { Air and water vapor are ideal gases for } \\
\quad \text { condensation calculations }\end{array}$ & Section 3.3.4 \\
$\begin{array}{l}\text { Condensation and leaving water temperature calculations } \\
\quad \text { assume that the processes are steady state, steady flow }\end{array}$ & Section 3.3.4 \\
Transient responces & Section 3.3.6 \\
\hline
\end{tabular}




\subsection{Model Calculations}

The performance map calculations are divided into two steps. The first step uses interpolation to determine the operating conditions based on the inlet water temperature, $T_{W A T E R, I N}$, and the volumetric water flow rate, $\dot{V}_{W A T E R}$, based on nominal volumetric air flow rates and inlet air conditions. The second step then uses correction factors to account for the actual volumetric air

flow rate, $\dot{V}_{A I R}$, the inlet air dry bulb and wet bulb temperatures, $T_{D B, A I R}$ and $T_{W B, A I R}$ and the concentration and type of antifreeze. A set of example performance map calculations can be found in Table 3.3. As previously mentioned the performance map model inputs are different than the inputs from the integrated model. In order for the models to work together the inputs to the performance map model need to be calculated. Since the performance map model is a steady state model a method has been implemented to represent the transient response of the system.

\subsubsection{Interpolation}

To determine the operating conditions based on the inlet water temperature, $T_{W A T E R, I N}$, and the volumetric water flow rate, $\dot{V}_{W A T E R}$, a double interpolation method is used. The performance map provides data over a range of inlet water temperatures from $20-120^{\circ} \mathrm{F}$ and for each inlet water temperature three different volumetric water flow rates are given. The data is provided for a set of nominal airflow rates that vary by the capacity of the heat pump and the nominal inlet air conditions set at $68^{\circ} \mathrm{F}$ dry bulb for heating 
and $80^{\circ} \mathrm{F}$ dry bulb and $67^{\circ} \mathrm{F}$ wet bulb for cooling. An example performance map can be found in Figure 3.4.

The model uses linear interpolation to determine the values of operating conditions between the reported operating conditions. The linear interpolation assumes that the relationship between the independent, $x$, and dependent, $y$, values are linear with a slope determined by the closest known operating conditions. The formula used for this calculation is given in Equation 3.3.

$$
y=y_{1}+\left(x-x_{2}\right) \frac{y_{2}-y_{1}}{x_{2}-x_{1}} \text { where } y_{1}=f\left(x_{1}\right) \& y_{2}=f\left(x_{2}\right)
$$

The model first interpolates based on the inlet water temperature and then interpolates based on the volumetric water flow rate. Since each reported inlet water temperature has multiple reported volumetric water and air flow rates associated with it the model interpolates over the range of reported volumetric water and air flow rates values. An example of this is shown in Table 3.3 under Step 1. The next step is to interpolate the values based on the volumetric flow rate of water, which is performed similarly to previous step and show in Table 3.3 under Step 2. The result of completing the interpolation is a complete set of operating conditions for the specified inlet water temperature and flow rate and the nominal inlet air conditions and flow rates.

\subsubsection{Correction Factors}

To account for conditions other than the nominal inlet air conditions and flow rates a set of correction factors are used to scale the operating conditions. The correction factors are valid for all of the GSHPs in a single model 
Table 3.3: Example calculations - Interpolation and correction factors

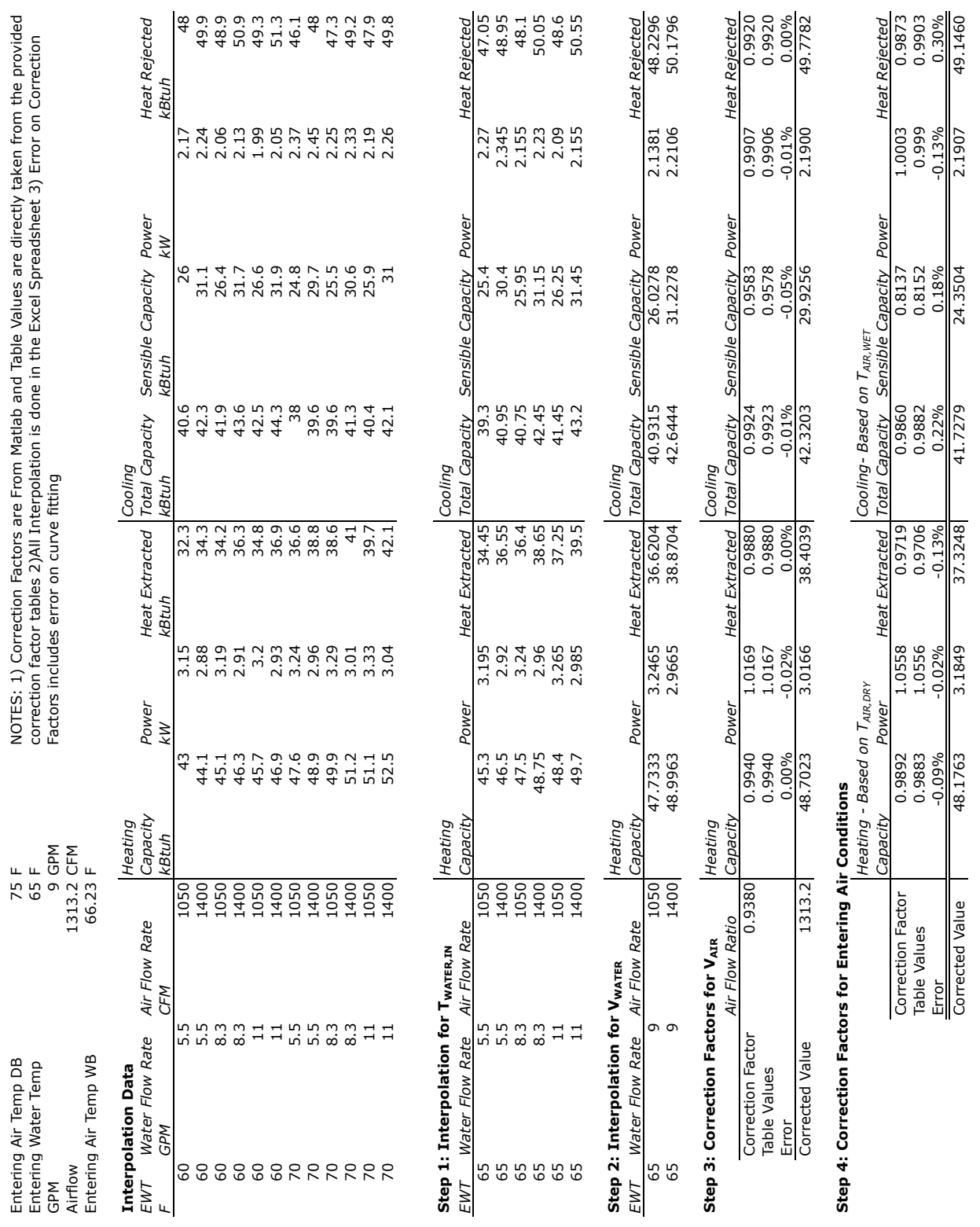


TS SERIES 6DHZ - HFC-41 DA SUBMITTAL DATA ENG/I-P

Performance Data TS H/V/D 048 (PSC Blower)
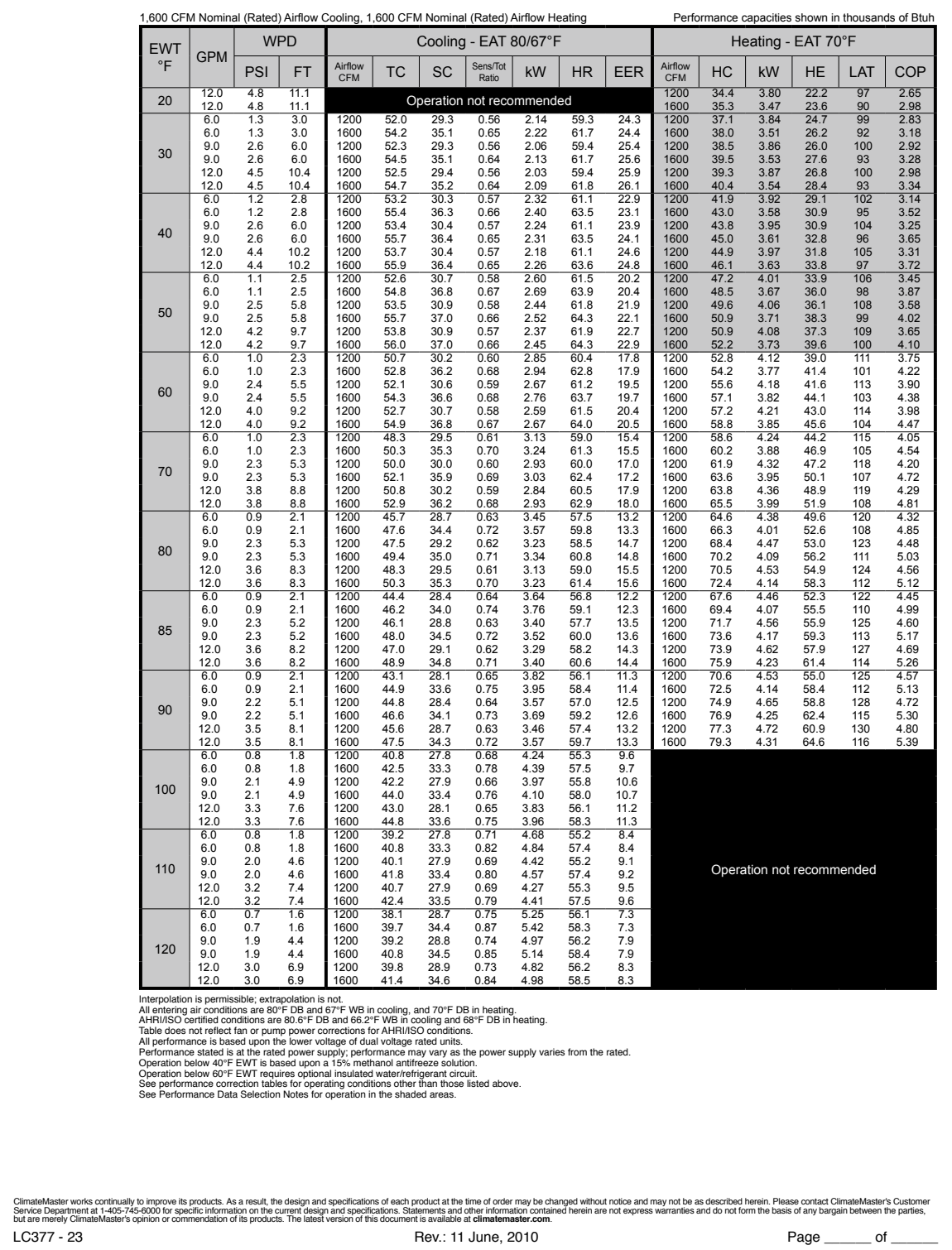

Figure 3.4: Example of data provided by the manufacturer [ClimateMaster, 2010] 
line, i.e the correction factors are valid for all Tranquility 20 heat pump, regardless of the capacity. The corrections factors are provided in tabular form as shown in Tables 3.4 and 3.5. The correction factors were implemented using two different methods, one based on curve fitting and the other was specifically designed for the sensible capacity correction factors in Table 3.5.

\subsubsection{Curve Fitting Method}

All correction factors, except the sensible cooling correction factor, are a function of a single variable. For example, in Table 3.4 the correction factors are based on the $\%$ of rated airflow. To implement these correction factors in the model an equation was fit to each set of values. Figure 3.5 shows a plot of the airflow correction factors for heating that are in Table 3.4 with the curve fits and the resulting equations. All of curve fits are based on

Table 3.4: Correction factors for airflow [ClimateMaster, 2010]

\begin{tabular}{|c|c|c|c|c|c|c|c|c|}
\hline \multirow{2}{*}{$\begin{array}{c}\text { Airflow } \\
\text { \% of } \\
\text { Rated }\end{array}$} & \multicolumn{5}{|c|}{ Cooling } & \multicolumn{3}{|c|}{ Heating } \\
\hline & $\begin{array}{c}\text { Total } \\
\text { Capacity }\end{array}$ & $\begin{array}{l}\text { Sensible } \\
\text { Capacity }\end{array}$ & $S / T$ & Power & $\begin{array}{l}\text { Heat of } \\
\text { Rejection }\end{array}$ & $\begin{array}{l}\text { Heating } \\
\text { Capacity }\end{array}$ & Power & $\begin{array}{l}\text { Heat of } \\
\text { Extraction }\end{array}$ \\
\hline $68.75 \%$ & 0.9465 & 0.8019 & 0.8472 & 0.9614 & 0.9496 & & & \\
\hline $75 \%$ & 0.9602 & 0.8350 & 0.8696 & 0.9675 & 0.9617 & 0.9740 & 1.0936 & 0.9425 \\
\hline $81.25 \%$ & 0.9724 & 0.8733 & 0.8981 & 0.9744 & 0.9728 & 0.9810 & 1.0635 & 0.9592 \\
\hline $87.50 \%$ & 0.9831 & 0.9149 & 0.9306 & 0.9821 & 0.9829 & 0.9876 & 1.0379 & 0.9744 \\
\hline $93.75 \%$ & 0.9923 & 0.9578 & 0.9653 & 0.9906 & 0.9920 & 0.9940 & 1.0167 & 0.9880 \\
\hline $100 \%$ & 1.0000 & 1.0000 & 1.0000 & 1.0000 & 1.0000 & 1.0000 & 1.0000 & 1.0000 \\
\hline $106.25 \%$ & 1.0062 & 1.0392 & 1.0328 & 1.0102 & 1.0070 & 1.0057 & 0.9878 & 1.0105 \\
\hline $112.50 \%$ & 1.0109 & 1.0733 & 1.0617 & 1.0211 & 1.0130 & 1.0112 & 0.9800 & 1.0194 \\
\hline $118.75 \%$ & 1.0141 & 1.1001 & 1.0848 & 1.0329 & 1.0180 & 1.0163 & 0.9705 & 1.0284 \\
\hline $125 \%$ & 1.0159 & 1.1174 & 1.0999 & 1.0455 & 1.0220 & 1.0211 & 0.9614 & 1.0368 \\
\hline $130 \%$ & 1.0161 & 1.1229 & 1.1050 & 1.0562 & 1.0244 & 1.0247 & 0.9554 & 1.0430 \\
\hline
\end{tabular}

Black area denotes where operation is not recommended. 


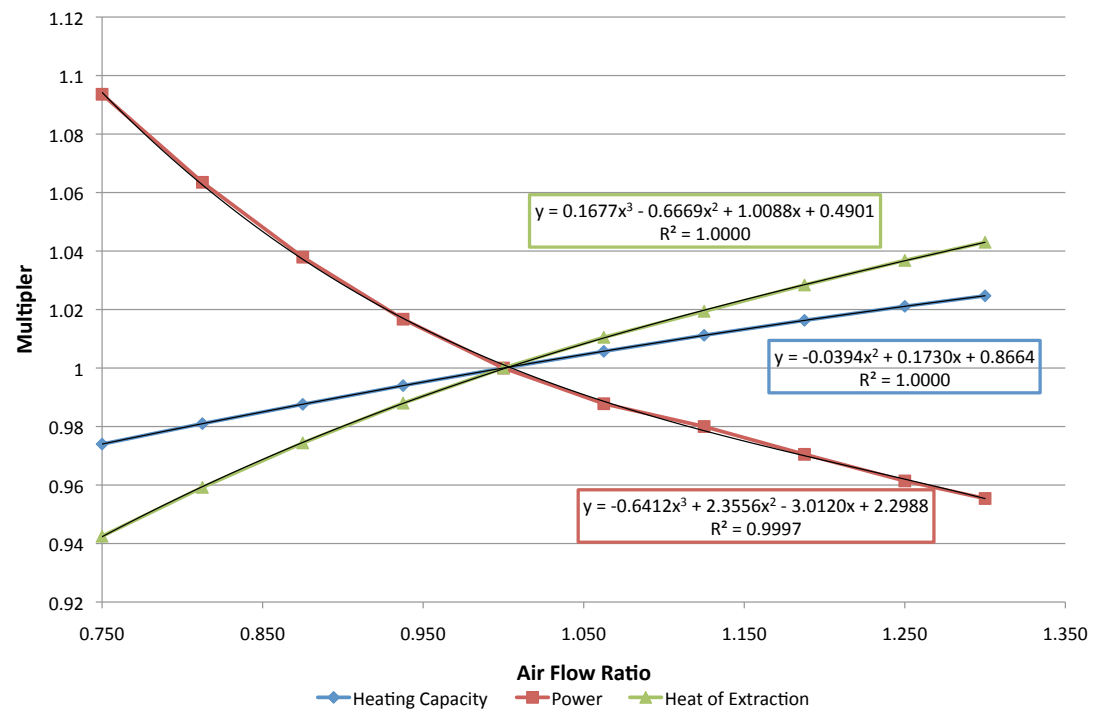

Figure 3.5: Plot of correction factors for airflow fraction during heating

polynomials and achieved good agreement with the data as represented by the $R^{2}$ value in the plot. Table 3.3 was used to verify the accuracy of the curve fits and that the model was calculating the correction factors correctly. The test inlet conditions were chosen to correspond to values reported in the correction factor tables. For example, the volumetric air flow was chosen to be 1313.2 CFM which is $93.75 \%$ of the rated airflow. This allows for the correction factor to be calculated in the model and compared directly with the values in the table, and based on these two values an error was calculated. Table 3.3 shows that the error is significantly less that $1 \%$ for all correction factors. 


\subsubsection{Wet Bulb Corrections for Cooling}

The correction factors for the sensible cooling capacity are based on both the wet bulb and dry bulb temperatures as shown in Table 3.5. To implement this into the model MATLAB's built-in interpolation command, interp2(Z, XI, YI), was used. Since the correction factors are not defined for every wet bulb and dry bulb temperature combination in the table two boundary functions were determined based on the table. These allow for the model to determine if the particular combination of inlet conditions is not recommended, blacked out in Table 3.5, or if it is to dry for any latent cooling to occur, starred in Table 3.5.

Table 3.5: Correction factors for wet bulb temperature [ClimateMaster, 2010]

\begin{tabular}{|c|c|c|c|c|c|c|c|c|c|c|c|c|}
\hline \multicolumn{13}{|c|}{ Cooling } \\
\hline \multirow{2}{*}{$\begin{array}{c}\text { Entering } \\
\text { Air } \\
\text { WB }^{\circ} \mathrm{F}\end{array}$} & \multirow{2}{*}{$\begin{array}{l}\text { Total } \\
\text { Capacity }\end{array}$} & \multicolumn{9}{|c|}{$\begin{array}{c}\text { Sensible Cooling Capacity Multiplier - } \\
\text { Entering DB }{ }^{\circ} \mathrm{F}\end{array}$} & \multirow{2}{*}{ Power } & \multirow{2}{*}{$\begin{array}{l}\text { Heat of } \\
\text { Rejection }\end{array}$} \\
\hline & & 60 & 65 & 70 & 75 & 80 & 80.6 & 85 & 90 & 95 & & \\
\hline 50 & 0.7432 & 0.9111 & * & * & * & * & * & * & * & * & 0.9866 & 0.7901 \\
\hline 55 & 0.8202 & 0.7709 & 0.8820 & 1.0192 & * & * & * & * & * & * & 0.9887 & 0.8527 \\
\hline 60 & 0.8960 & & 0.6702 & 0.8540 & 1.0473 & * & * & * & * & * & 0.9924 & 0.9146 \\
\hline 65 & 0.9705 & & & 0.6491 & 0.8657 & 1.0809 & 1.1066 & * & * & * & 0.9975 & 0.9757 \\
\hline 66.2 & 0.9882 & & & 0.5939 & 0.8152 & 1.0333 & 1.0592 & 1.2481 & * & * & 0.9990 & 0.9903 \\
\hline 67 & 1.0000 & & & 0.5559 & 0.7801 & 1.0000 & 1.0261 & 1.2158 & * & * & 1.0000 & 1.0000 \\
\hline 70 & 1.0438 & & & & 0.6377 & 0.8645 & 0.8913 & 1.0847 & 1.2983 & * & 1.0042 & 1.0362 \\
\hline 75 & 1.1159 & Opera & tion not $r$ & ecomme & nded & 0.6008 & 0.6289 & 0.8323 & 1.0578 & 1.2773 & 1.0123 & 1.0959 \\
\hline
\end{tabular}

* = Sensible capacity equals total capacity

AHRI/ISO/ASHRAE $13256-1$ uses entering air conditions of Cooling $-80.6^{\circ} \mathrm{F} \mathrm{DB} / 66.2^{\circ} \mathrm{F} \mathrm{WB}, 1$

and Heating $-68^{\circ} \mathrm{F} \mathrm{DB} / 59^{\circ} \mathrm{F}$ WB entering air temperature 


\subsubsection{Wet-Bulb Calculations}

In order to implement the performance maps the wet bulb temperature of the incoming air is required, and the integrated building-GSHP model provides $\phi$, the relative humidity. During the creation of the model two different methods of calculating the wet bulb temperature where explored. The first method, based on the Clausius-Clapeyron equation, Equation 3.4, used the saturation pressure of water and the volume fraction of water, Equation 3.5, in the air to calculate the relative humidity [Schmidt et al., 2006].

$$
\begin{gathered}
\ln \left(P_{S A T}\right)=\frac{21.4 T+494.41}{T+273.15} \\
y=\frac{\left(T_{D B, A I R}-T_{W B, A I R}\right) c_{p}^{A I R}-L_{V}\left(P_{W B, S A T} / P\right)}{-\left(T_{D B, A I R}-T_{W B, A I R}\right) c_{p}^{V A P O R}-L_{V}}
\end{gathered}
$$

This model was useful since it is valid for any atmosphere pressure.

The second method uses a series of empirically determined curves based on a psychometric chart [U.S. Dept. of Commerce,Weather Bureau]. Equations that relate the dry bulb temperature to the wet bulb temperature of the form shown in Equation 3.6 were found for constant relative humidity values.

$$
T_{W B}=a T_{D B}^{2}+b T_{D B}+c
$$

For a given dry bulb temperature a range of wet bulb temperatures are calculated for the range of relative humidity specified. The actual wet bulb temperature is then interpolated based on the actual relative humidity. A disadvantage of this model is that it is only valid for a given altitude. Therefore the equations need to be updated as the altitude of the simulation changes. 
To ensure the the accuracy of these conversions, the calculated relative humidity values, $\phi$, was compared to a table published by NOAA that converts dry bulb and wet bulb temperatures into relative humidity based on psychometric charts [U.S. Dept. of Commerce,Weather Bureau]. The results are shown in Figures 3.6 and 3.7. From the Figure 3.6 we can see that the error for the Clausius-Clapeyron equation is large at low temperatures and high $\phi$. In comparison Figure 3.7 shows the error based on the curve fit equations, which is significantly less than the Clausius-Clapeyron equation. Based on these results the curve fitting method was chosen.

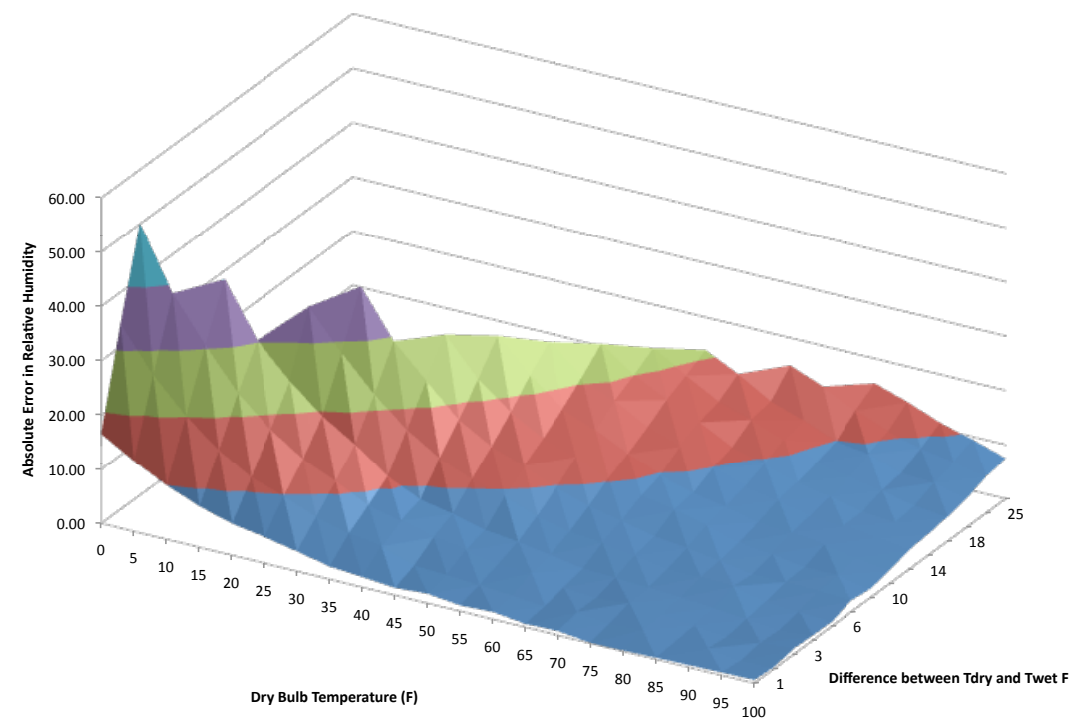

Figure 3.6: Absolute error for relative humidity to wet bulb temperature calculations based on Clausius-Clapeyron equation 


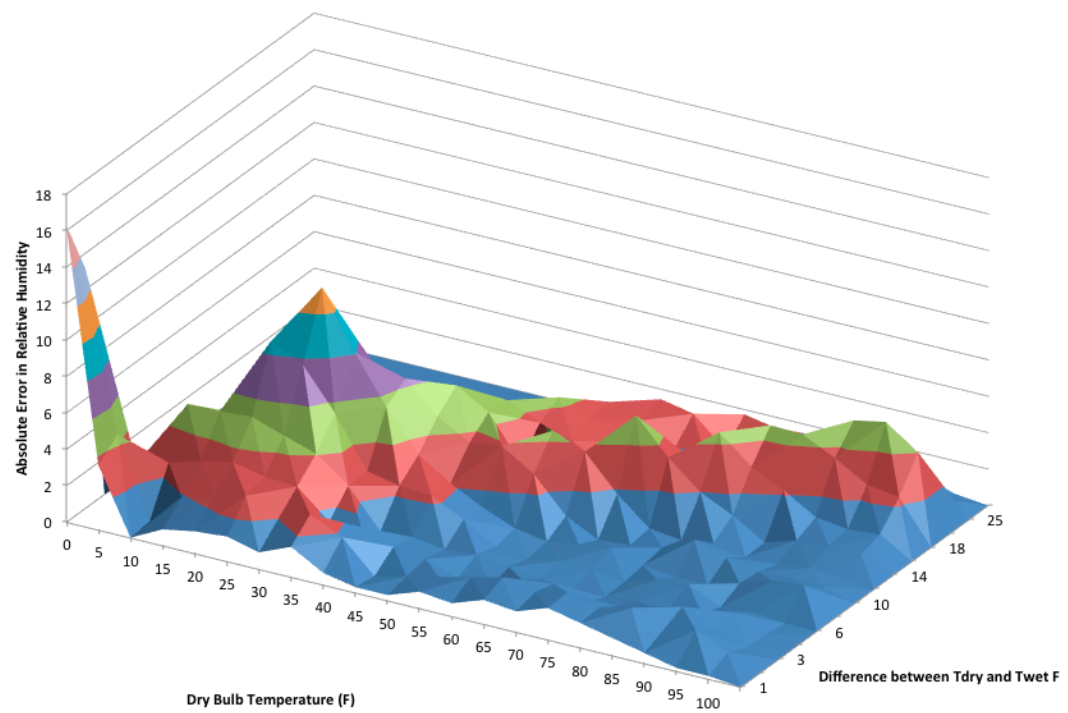

Figure 3.7: Absolute error for relative humidity to wet bulb temperature calculations based on curve-fitted equations

\subsubsection{Condensation Calculations}

The dehumidification of the conditioned air space is important for occupant comfort. The building model accounts for this by allowing the mass flow rate of water removed from the air to be specified. The performance map calculates the latent cooling capacity, which is the amount of cooling associated with water condensing out of the air. Assuming that water vapor and air are ideal gases and that the process is in a steady state, steady flow process an energy balance for the air/water vapor mixture flowing through the heat pump can be written as shown in Equation 3.7 [Schmidt et al., 2006].

$$
h_{D A, I N}+\omega_{I N} h_{W V, I N}+\frac{\dot{Q}}{\dot{m}_{D A}}=h_{D A, O U T}+\omega_{O U T} h_{W V, O U T}
$$


In the equation $h_{D A}$ and $h_{W V}$ are the enthalpies of the dry air and water vapor, $\omega$ is the humidity ratio, $\dot{Q}$ is the energy added to the system, and $\dot{m}_{D A}$ is the mass flow rate of dry air. Realizing that $\dot{Q}$ has been determined from the performance maps in the form of Equation 3.8 the portions of Equation 3.7 associated with the dry air can be removed reducing it to Equation 3.9.

$$
\begin{gathered}
\dot{Q}=-\left(\dot{Q}_{\text {Latent }}+\dot{Q}_{\text {Sensible }}\right) \\
\omega_{I N} h_{W V, I N}+\frac{-\dot{Q}_{\text {Latent }}}{\dot{m}_{D A}}=\omega_{\text {OUT }} h_{W V, \text { OUT }}
\end{gathered}
$$

Assuming that the enthalpy of the water vapor is constant over the process Equation 3.9 reduces to Equation 3.10.

$$
\omega_{O U T}=\omega_{I N}+\frac{-\dot{Q}_{\text {Latent }}}{\dot{m}_{D A} h_{W V}}
$$

Recognizing that $\omega$ is defined as shown in Equation 3.11,the mass balance of the water vapor for the process can be rewritten as shown in Equation 3.12.

$$
\begin{gathered}
\omega=\frac{\dot{m}_{W V}}{\dot{m}_{D A}} \\
\dot{m}_{\text {cond }}=\dot{m}_{D A}\left(\omega_{I N}-\omega_{O U T}\right)
\end{gathered}
$$

Combining Equation 3.10 and Equation 3.12 gives Equation 3.13 which relates the rate of water condensation, $\dot{m}_{\text {cond }}$, to the rate of latent cooling, $\dot{Q}_{\text {Latent }}$, and the enthalpy of the water vapor in the air, $h_{W V}$.

$$
\dot{m}_{\text {cond }}=\frac{\dot{Q}_{\text {Latent }}}{h_{W V}}
$$




\subsubsection{Leaving Water Temperature Calculations}

The performance map calculates the amount of heat rejected/extracted into/from the ground loop water, but does not directly calculate the temperature change of the water. An option would be to assume that all of the heat rejected/extracted into/from the water was then rejected/extracted into/from the ground. This is true most of the time but it does not account for the temperature change in the ground loop water which will affect the efficiency the heat pump and the rate of heat transfer into the ground. Therefore, the temperature rise of the ground loop water as it passes through the heat pump needs to be calculated. Performing a energy balance assuming steady state, steady flow gives Equation 3.14.

$$
\begin{gathered}
u_{I N}+\frac{\dot{Q}}{\dot{m}}=u_{O U T} \\
T_{O U T}=T_{I N}+\frac{\dot{Q}}{\dot{m} c}
\end{gathered}
$$

By assuming that the heat capacity, $c$, is constant and rearranging Equation 3.14 to solve for $T_{O U T}$ in Equation 3.15.

\subsubsection{Transient Model Approximation}

The performance map provides steady state operation data and not transient data. If the model was left this way there could be errors in the amount of power consumed by the heat pump. During the start up of a heat pump system the heating/cooling capacity of the heat pump unit increases rapidly for the first 240 seconds until it reaches a steady state value as shown 
in Figure 3.8 [Fu et al., 2003]. In the figures, the fluctuations in capacity past the initial start up is due to changes in environmental and water loop conditions which are already modeled in the integrated model. To model the

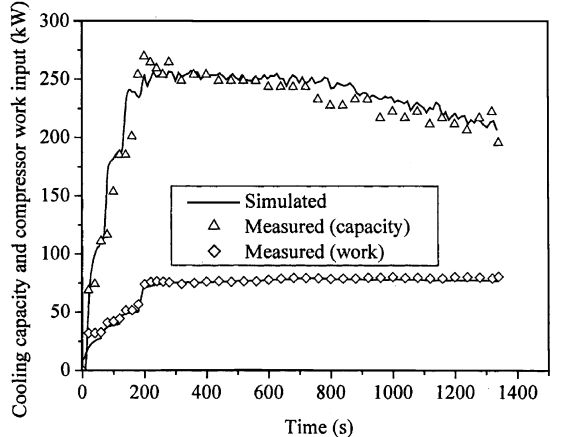

(a) Cooling

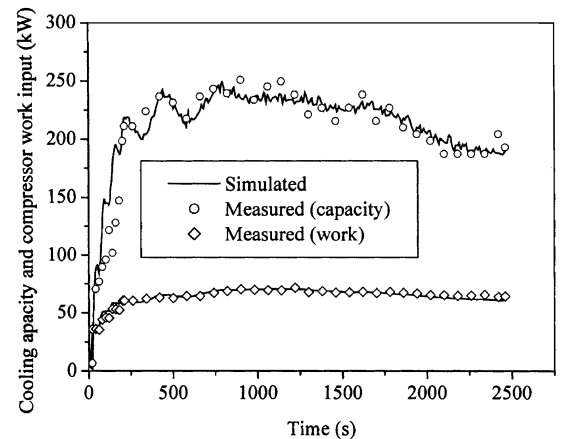

(b) Heating

Figure 3.8: Transient response of a heat pump during start-up [Fu et al., 2003]

transient effects of a heat pump during start up many variations of a first and second order system responses have been suggested in previous literature [Kim and Bullard, 2001, Fu et al., 2003, Tree and Weiss, 1985] but due to the lack of actual data on the modeled system a simple first order system response as shown in Equation 3.16 is used.

$$
\dot{Q}=\dot{Q}_{s s}\left[1-e^{-t / \tau}\right] \text { where } \tau=60 \text { secs }
$$

After the heat pump compressor is turned off, the refrigerant begins to return to ambient temperature and migrates to equalize the pressure in the loop. This process occurs over time, and will affect how long the heat pump takes to reach steady state operating conditions. For a heat pump that is cycling on 
and off very quickly the refrigerant has very little time (i.e. $<\tau$ ) to migrate between cycles and therefore reaches steady state significantly quicker than if the unit is cycling very slowly with a long time (i.e. $>\tau$ ) between cycles. For the purpose of the simulation the migration of the refrigerant is assumed to occur at the same rate after shut-down as during start-up.

The power required by the heat pump will have a transient response in a manner similar to the capacity. The power that is reported in the performance maps includes the power required to operate the compressor and the fan. The work that is shown is Figure 3.8 is the work of the compressor and does not include the work done by the fan. It shows that the compressor work response is similar to the capacity response. Since we are making an assumption about the capacity response of the unit as well as not knowing the exact power response of the fan, the model assumes that the power that is consumed is the same as the steady state power any time the heat pump is on. This power does not include the power required to operate the circulation pumps that move the water through the ground loop.

After completed initial simulations of the integrated building loadGSHP model, the results showed that the heat pump unit was cycling on and off an average of 6 times per hour which is significantly more than expected. The combination of the high cycle rates and the 1st order lag on the heat pump output increased the heat rejected into the ground by $40 \%$ in the summer and increase electricity usage by $41 \%$ over a steady state model of the heat pump. The effect of the transient response was significantly larger than 
expected. Therefore this portion of the model was removed from the model until the high heat pump cycle rates can be corrected.

While considering the results of the model presented in later chapters the removal of the transient effects needs to be considered. The transient response causes the heat pump to operate longer to provide the needed amount of cooling causing it to reject/extract more heat to/from the ground and will consume more electricity. Lowering the amount of heat rejected into the ground will reduce long term ground heating. If any ground heating issues become apparent without the transient response of the heat pump, they will only be increased if the transient effects are included. Based on this, the removal of the transient effects will lead to conservative results when compared to the results the included the transient effects. 


\section{Chapter 4}

\section{Ground Loop Heat Exchanger Model}

The ground loop heat exchanger rejects/extracts heat to/from the ground to provide a heat sink/source for the ground source heat pump. Ground loop heat exchangers can be placed in the ground either in horizontal fields or into vertical boreholes. In horizontal fields, the ground loop is placed near the surface of the ground, just below the frost line, over a large area. Vertical borehole are drilled into the ground up to depths of $90 \mathrm{~m}(300 \mathrm{ft})$ and have a loop of pipe that runs down to the bottom of the borehole and back to the top as shown in Figure 4.1. The loop of high density polyethylene pipe that is placed in the borehole is called a u-tube due to its shape. The borehole is back filled with grout that expands and fills any voids in borehole to enhance the heat conduction. The fluid flowing throught the ground loop is typically water or a water/antifreeze mixture. The ground loop model must properly interface with the rest of the integrated building-GSHP model so must meet the following requirements:

- Calculate the heat transferred into the ground by specifying only the inlet water temperature and flow rate and the previous ground loop loads.

- Be computationally efficient. 


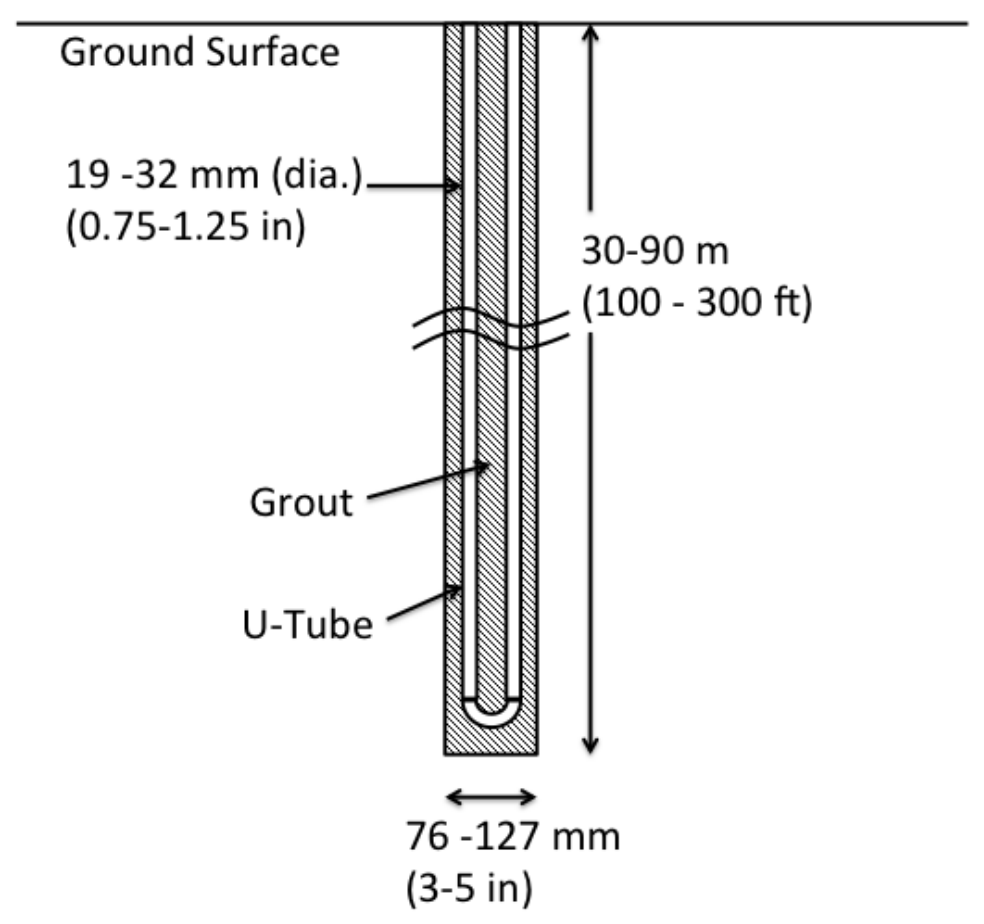

Figure 4.1: Drawing of vertical borehole ground loop with approximate dimensions

- Model the effect of multiple boreholes in close proximity.

- Accommodate time steps at least as small as an hour or possibly smaller.

- Be validated.

\subsection{Literature Review}

The ground loop heat exchangers can be divided into two regions of interest: inside the borehole and the ground outside of the borehole. The heat transfer outside of the borehole, in the bulk ground, is typically treated 
as heat conduction problem with a line or cylindrical source in an infinite or semi-infinite medium. The heat transfer inside of the borehole is a combination of convection between water and u-tube and conduction between the two legs of the u-tube, the grout, and the surrounding ground.

\subsubsection{Borehole Models}

The geometry of the borehole is significantly more complicated than the bulk ground. This complexity leads to many assumptions such as assuming that the heat transfer is steady state [Hellström, 1991] or that the geometry fits into the grids created by a finite difference model [Rottmayer et al., 1997, Yavuzturk, 1999]. These assumptions need to be carefully considered when choosing an appropriate model.

\subsubsection{Hellström's Two-dimensional Model}

Hellström [1991] developed an analytical solution to the heat transfer between the two segments of the $\mathrm{u}$-tube and the ground. The model creates a resistance network that has nodes for each of the bulk fluid temperatures and the borehole perimeter temperature. The borehole perimeter temperature

is assumed to be uniform. Figure 4.2 shows the temperature nodes and the resulting resistance network for Hellström's model.

$$
\left\{\begin{array}{l}
T_{f 1}-T_{b}=R_{1} q_{1}+R_{12} q_{2} \\
T_{f 2}-T_{b}=R_{12} q_{1}+R_{2} q_{2}
\end{array}\right.
$$



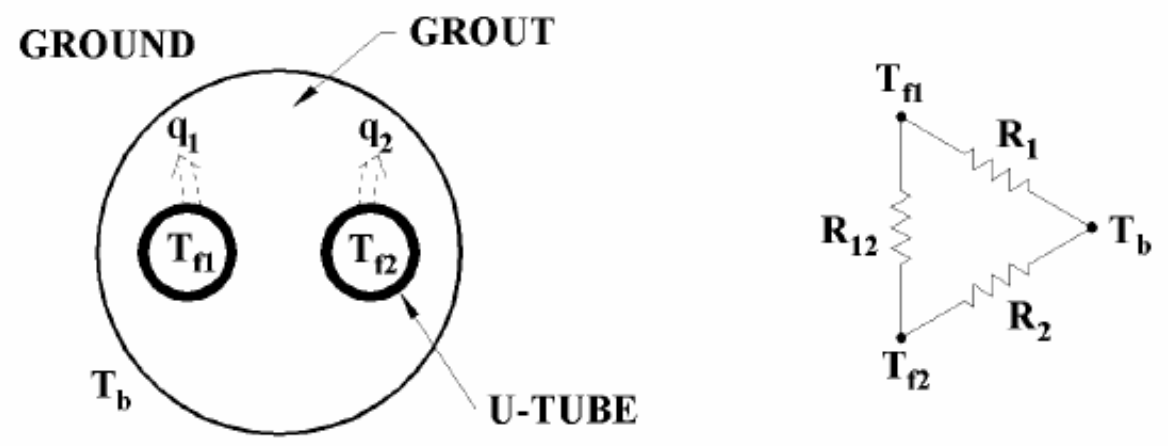

Figure 4.2: Diagram of Hellström's approximation of the heat transfer inside of the borehole [Young, 2004]

The resulting set of linear equations are shown in Equation 4.1, where $q_{1}$ and $T_{f 1}$ is the heat transfer and fluid temperature associated with the downward flowing tube and $q_{2}$ and $T_{f 2}$ is the heat transfer and fluid temperature associated with the upward flowing tube ${ }^{1}$. The resistance values, $R_{1}, R_{2}$, and $R_{12}$ are calculated using shape factors that account for the geometry of the borehole [Hellström, 1991].

Hellström's two-dimensional model was extended by Zeng et al. [2003] to create a quasi three-dimensional model by adding the heat capacity of the fluid into Equation 4.1 and defining it over the total length, $H$, of the borehole. The resulting equations are shown in Equation 4.2 with the two boundary conditions shown in Equation 4.3. $R_{1}^{*}, R_{2}^{*}$, and $R_{12}^{*}$ are the transformed resistance values, $M$ is the mass of the fluid, $c$ is the heat capacity of the fluid and $\mathrm{z}$ is

\footnotetext{
${ }^{1}$ Unless units are explicitly stated all equations are in SI with temperatures given in ${ }^{\circ} C$. Care needs to be taken to ensure that the units used are appropriate.
} 
the axis along the length borehole .

$$
\left\{\begin{array}{c}
-M c \frac{d T_{f 1}}{d z}=\frac{\left(T_{f 1}-T_{b}\right)}{R_{1}^{*}}+\frac{\left(T_{f 1}-T_{f 2}\right)}{R_{12}^{*}} \\
-M c \frac{d T_{f 2}}{d z}=\frac{\left(T_{f 2}-T_{b}\right)}{R_{2}^{*}}+\frac{\left(T_{f 2}-T_{f 2}\right)}{R_{12}^{*}} \\
T_{f 1}(0)=T_{i n} \\
T_{f 1}(H)=T_{f 2}(H)
\end{array}\right.
$$

\subsubsection{Multipole Model}

The multipole model, developed by Bennet et al. [1987], is a steady state, analytical model that can calculate the conductive heat flow between pipes of different radiuses. The model does not require any symmetry along the borehole axis. The model uses multiple sets of line sources with line sinks at mirrored points to solve the general, two-dimensional heat conduction equation:

$$
\frac{\partial 2 T}{\partial x^{2}}+\frac{\partial 2 T}{\partial y^{2}}=0
$$

Figure 4.3 show an example line source and sink for a single pipe in the borehole. Each pipe would have at least one associated source and sink. For more accurate results additional sources and sinks are added. To get a solution to the differential equation the temperatures inside of the pipe walls and at the outer boundary conditions of the are assumed to be constants and the problem is assumed to be in steady state. The outer boundary conditions are defined at, $r_{b}$, the radius of the outer region. For the calculations used this is set to $100 m$ (328 ft). Young [2004] showed that the multipole method with ten 


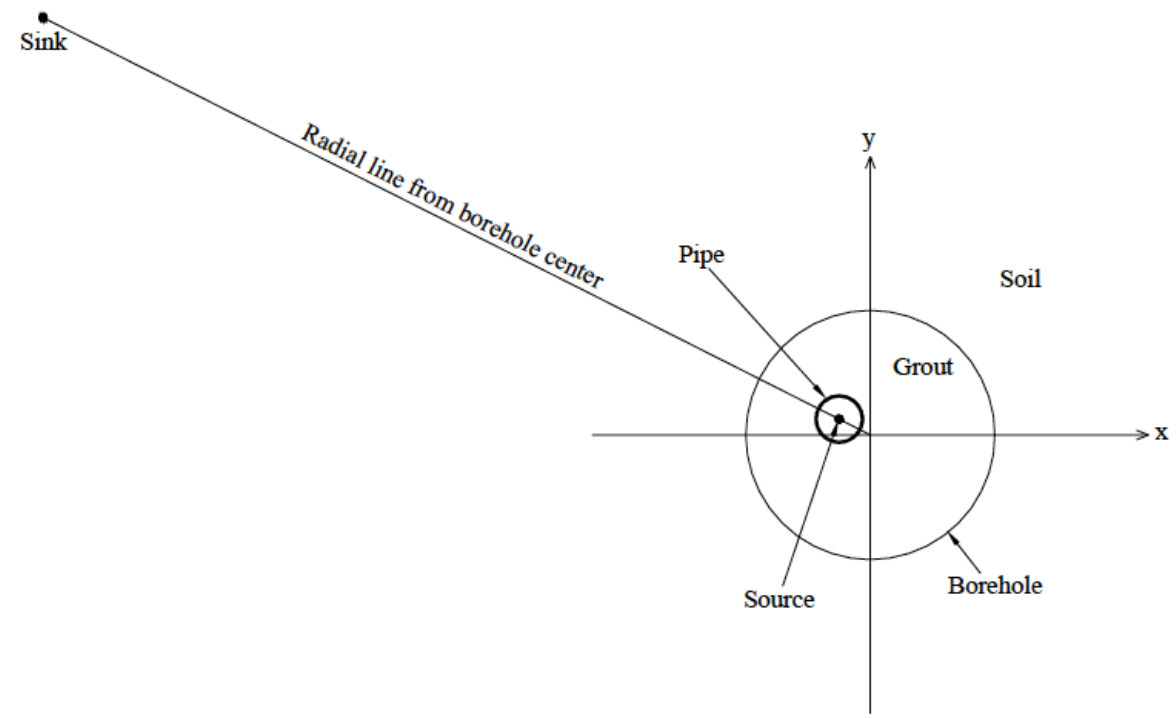

Figure 4.3: Example source and sink for the multipole method [Young, 2004] sources per pipe (10th order) gave results with at least four digits of accuracy. He provides a detailed description of the calculations required for this method.

The multipole model is used by $\mathrm{Xu}$ [2007] to calculate the total thermal resistance of the borehole. This is accomplished by:

$$
R_{B H}=\frac{T_{\text {fluid }}-T_{B H}}{q_{u t u b e, 1}+q_{u t u b e, 2}}
$$

where $T_{B H}$ is the average borehole wall temperature, $T_{\text {fluid }}$ is the average utube pipe temperature, and $q_{u t u b e, 1}$ and $q_{u t u b e, 2}$ are the heat fluxes out of each leg of the u-tube. $\mathrm{Xu}$ [2007] uses the result to calculate equivalent resistances for his one-dimensional borehole model. 


\subsubsection{Bulk Ground Models}

Bulk ground models focus on the effects of the ground loop heat exchangers at distances much greater than the borehole radius. Many models such as the Finite Line Source model and the Cylindrical Source model ignore the effects of the heat transfer at the borehole and assume a uniform source [Ingersoll and Plass, 1948, Carslaw and Jaeger, 1946]. Other models compute the heat transfer near the borehole by using one of the borehole models discussed in Section 4.1.1.

\subsubsection{Kelvin's Line Source Theory}

Kelvin's line source theory assumes that the heat source is an infinite line that is in an uniform, infinite medium [Ingersoll and Plass, 1948]. This assumes that the heat transfer effects at the top and bottom of the ground loop are negligible. The model also assumes that the heat rejected ${ }^{2}$ is constant along the length of the line source (constant heat flux) and that the ground is at constant initial temperature. Ingersoll and Plass's method can calculate the temperature response at any radial distance and time using:

$$
T(r, t)-T(t=0)=\frac{q^{\prime}}{2 \pi k} \int_{X}^{\infty} \frac{e^{-u^{2}}}{u} d u \text { where } X=\frac{r^{2}}{2 \sqrt{\alpha t}}
$$

where $r$ is the distance in meters from the line source, $T$ is the temperature in $K, q^{\prime}$ is the heat flux in $W / m, t$ is time in seconds, $k$ is the conductivity

\footnotetext{
${ }^{2}$ The descriptions of the following models will assume that ground loop is rejecting heat into the ground (e.g. the heat pump is cooling the structure).
} 
of the ground in $W / m / K$ and $\alpha$ is the diffusivity of the ground in $m^{2} / s$. Ingersoll and Plass [1948] estimated that Kelvin's line source model produces significant error when $\frac{\alpha t}{r_{b}^{2}}<20[-]$, where $r_{b}$ is the radius of the bore hole. This indicates that the model can accurately represent heat transfer from small pipes $(<50 \mathrm{~mm})$ after a few hours of operation and larger pipes $(102-203 \mathrm{~mm})$ after a couple of days.

\subsubsection{Cylindrical Source Solution}

Carslaw and Jaeger [1946] first developed an exact solution to a cylindrical source in an infinite medium with constant properties. One of their solutions assumes that the boundary condition on the cylindrical source is either a constant temperature or a constant heat flux. This solution was later improved by Ingersoll et al. [1954]. The solution for a constant heat flux source is:

$$
T(r, t)-T(t=0)=\frac{q^{\prime}}{k} G(z, p) \text { where } z=\frac{\alpha t}{r_{b}}, p=\frac{r}{r_{b}}
$$

where $r$ is the distance from the center of the source, $r_{b}$ is the radius of the source, $T$ is the temperature, $q^{\prime}$ is the heat flux, $t$ is time, $k$ is the conductivity of the ground and $\alpha$ is the diffusivity of the ground. $G(z, p)$ in an integration of a complex function from zero to infinity. The cylindrical source model was first applied to vertical ground loop heat exchangers by Kavanaugh [1985]. Gu and O’Neal [1998] developed a method to determine an equivalent diameter for the u-tube, Dobson et al. [1995] modeled the heat transfer between the two legs of the u-tube ("short-circuiting") and a method for modeling the on-off 
cycling of the ground loop.

Carslaw and Jaeger [1946] developed a second solution for the cylindrical source model where the infinite medium is bounded at $r_{b}$ by an infinite circular cylinder that is a perfect conductor, but has a finite capacitance. This model was extended by Young [2004] by adding a lumped parameter model of the borehole inside of the cylinder source to allow the transient response of the borehole to be modeled.

\subsubsection{Finite Line Source}

Eskillson [1987] developed an analytical solution to a finite line source model for a ground loop heat exchanger. The model assumes that there is a semi-infinite medium with a uniform initial temperature, constant heat flux, and constant surface temperature. The finite line source solution is derived by dividing the borehole into point sources and integrating there contributions to get the temperature response in the ground. The ground temperature in $K$ for a given depth, $z$, radius, $r$ and time, $t$ is given by:

$$
T_{q}(r, z, t)=-\frac{q^{\prime}}{4 \pi k} \int_{D}^{D+H}\left\{\frac{1}{R_{+}} \operatorname{erfc}\left(\frac{R_{+}}{\sqrt{4 \alpha t}}\right)-\frac{1}{R_{-}} \operatorname{erfc}\left(\frac{R_{-}}{\sqrt{4 \alpha t}}\right)\right\} \mathrm{d} s
$$

where $R_{+}=\sqrt{r^{2}+(z-s)^{2}}$ and $R_{-}=\sqrt{r^{2}+(z+s)^{2}}$

where $H$ is the total active depth of the borehole, $D$ is the length of the adiabatic portion of the borehole at the surface of the ground, $z$ is the depth of the calculated temperature, and $s$ is the integration variable. All other variables are the same as previously defined. The adiabatic portion, $D$, of 
the borehole may be cause by a insulating casing or a section of insulating soil. For a given active borehole length, $H$, changes in the adiabatic length do not affect the solution. Due to the constant heat flux assumption the heat transfer must be calculated for the entire length of the borehole. Eskillson [1987] recommends using the integral mean temperature of borehole wall to calculate the heat transfer inside the borehole. This temperature in $K$ is calculated by:

$$
T_{b}=\frac{q^{\prime}}{2 \pi k} g\left(t / t_{s}, r_{b} / H\right)
$$

The function $g\left(t / t_{s}, r_{b} / H\right)$, commonly referred to as a g-function, is determined numerically (discussed in more detail in Section 4.1.2.4) but can be approximated by:

$$
g\left(t / t_{s}, r_{b} / H\right) \approx \begin{cases}\ln \left(\frac{H}{2 R_{b}}\right)+\frac{1}{2} \ln \left(\frac{t}{t_{s}}\right) & \text { for } \frac{5 r_{b}}{\alpha}<t<t_{s} \\ \ln \left(\frac{H}{2 R_{b}}\right) & \text { for } t>t_{s} \text { where } t_{s}=\frac{H^{2}}{9 \alpha}\end{cases}
$$

Using Equation 4.9, the borehole wall temperature, $T_{b}$, can be computed over time for a given heat flux, $q^{\prime}$. Since the model is approximating a borehole that has a finite radius with a line source with no radius the model has a lower time limit of $t=5 r_{b}^{2} / \alpha$ [Eskillson, 1987]. This corresponds to about 1-2 days for a $100 \mathrm{~mm}(4 ")$ borehole in saturated clay, for times less than this the results of the model will not be accurate [Xu, 2007].

\subsubsection{Eskillson's G-function Model}

Eskillson [1987] created a method to determine the temperature response of the ground around a borehole that is a hybrid analytical-numerical 
technique. The method is divided into four steps:

1. Determine the thermal response of the ground around a single borehole to a pulse heat input.

2. Spatially superimpose the thermal responses of individual boreholes to determine the response of a field of boreholes.

3. Convert response into non-dimensional temperature response factors ("gfunctions").

4. Use response factors to determine temperature response of the borehole wall for a $q^{\prime}(t)$ via temporal superposition.

To determine the thermal response of a single borehole Eskillson uses a two-dimensional (radial-axial coordinates) finite volume method with a unit step heat input. The model assumes that the ground is homogenous and has constant boundary conditions. Since the time steps considered are much longer that the transient response of the borehole the thermal capacitance of the borehole is neglected.

Using the results from the cylindrically symmetric response of a single borehole the thermal response of multiple boreholes in a field is determined by spatial superposition. For an arbitrary point in the ground this is represented by:

$$
T(x, y, z, t)=T_{0}(z)+\sum_{i=1}^{N} T_{i}\left(r_{i}, z_{i}, t\right)
$$


where $T_{i}$ is the thermal response of borehole $i, r_{i}$ and $z_{i}$ are the radial distance and depth of the desired point in relation to borehole $i$, and $T_{0}(z)$ is the initial temperature of the ground. This process involves some approximations, but Eskillson [1987] shows the resulting errors have a negligible effect on the final solution.

Next, the thermal response is converted into non-dimensional response factors, which Eskillson calls "g-functions". The g-functions determine the temperature response through Equation 4.12.

$$
T_{b}=T_{0}+\frac{q}{2 \pi k} g\left(\frac{t}{t_{s}}, \frac{r_{b}}{H}\right)
$$

The response is non-dimensionalized with respect to $r_{b} / H$ and $t / t_{s}$ which are the ratios of borehole radius to borehole length and current time to the steady state time, respectively. The steady state time is given by:

$$
t_{s}=\frac{H^{2}}{9 \alpha}
$$

where $\alpha$ is the diffusivity of the ground. By making the response non-dimensional the thermal response of a particular borehole field geometry only needs to be calculated a single time and can be reused for different bulk ground properties by changing $\alpha$ and different borehole geometries by changing $H$ and $r_{b}$.

A selection of the resulting g-functions are plotted in Figure 4.4. The plots are for the same ground properties and borehole geometry, the only difference is the number of boreholes and configuration. As the number of boreholes increases the interaction among them increases causing an increase 


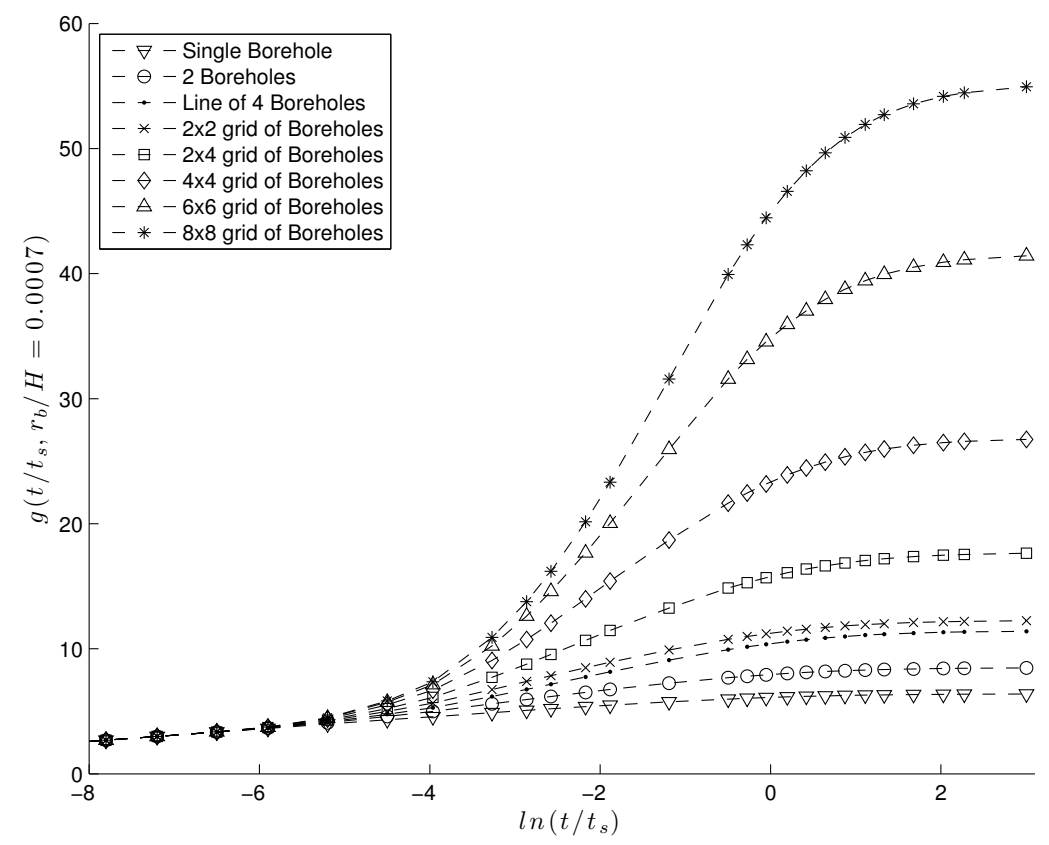

Figure 4.4: G-functions for typical borehole configurations, data from GLHEPRO 4.0 [Spitler, 2000]

in the thermal response of each borehole, especially for values of $\ln \left(t / t_{s}\right)>-4$ which corresponds to approximately 8.5 months.

To determine the thermal response of the borehole to a time varying heat flux, $q(t)$, Eskillson [1987] suggests using a temporal superposition technique. The superposition method begins by approximating $q(t)$ with a piecewise constant function as shown in Figure 4.5a. Next, the piecewise approximation is decomposed into individual heat pulses that are constant in 


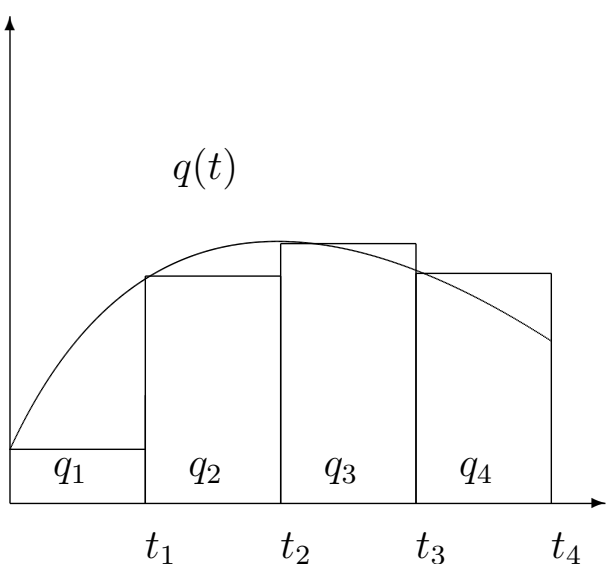

(a) $q(t)$ and piecewise approximation

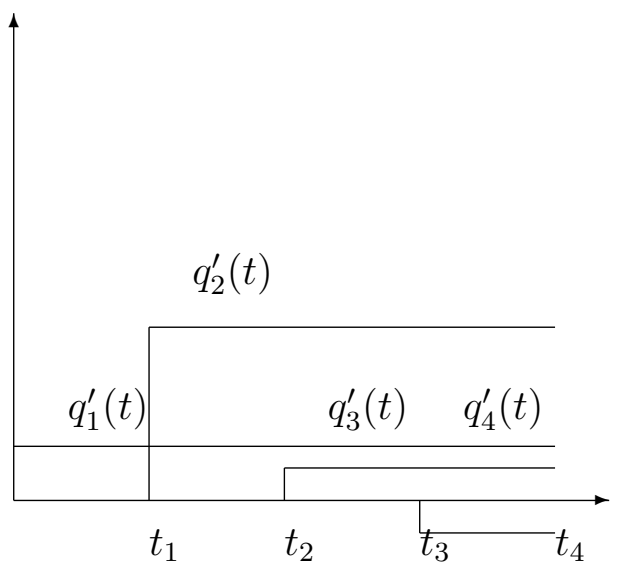

(b) Temporal superposition of $q^{\prime}(t)$

Figure 4.5: Piecewise approximation of $q(t)$ and resulting temporal superposition

time and on until the end of the simulation. Mathematically this becomes:

$$
q(t)=\sum_{i=1}^{n} q_{i}^{\prime}(t) \quad \text { for } \quad \begin{aligned}
q_{2}^{\prime}(t) & =q_{1} \\
\vdots & =\left(q_{2}-q_{1}\right) H\left(t_{1}\right) \\
q_{n}^{\prime}(t) & =\left(q_{n}-q_{n-1}\right) H\left(t_{n}\right)
\end{aligned}
$$

where $H(t)$ is the Heaviside step function and $n$ is the number of time steps. Applying this decomposition to Equation 4.12 gives:

$$
T_{b}=T_{0}+\sum_{i=1}^{n} \frac{q_{i}-q_{i-1}}{2 \pi k} g\left(\frac{t_{n}-t_{i}}{t_{s}}, \frac{r_{b}}{H}\right)
$$

The decomposition results in the superposition of the temperature responses of $n$ different heat fluxes, each of which has a different start time, $t_{i}$, to produce the total response of the borehole [Eskillson, 1987, Xu, 2007]. 
Just like Eskillson's finite line source model the g-function solution has a minimum time step requirement of $\Delta t>5 r_{b}^{2} / \alpha$. Since many building models produce hourly or even sub-hourly loads it is desirable to have a ground loop model that can handle time steps in this range. Both Yavuzturk [1999] and $\mathrm{Xu}$ [2007] extended the g-function model to allow for shorter time steps, these model are discuss in detail in Sections 4.2.1 and 4.2.2.

\subsubsection{Finite Difference/Volume/Element Models}

Finite difference/volume/element models have been used to successfully model ground loop heat exchangers, but due to the computational expense their use in hourly or sub-hourly simulations is limited.

A quasi three-dimensional Finite Difference Model (FDM) was used by Rottmayer et al. [1997] to model the borehole. The model uses a series of two-dimensional, $(r, \theta)$, FDMs that assume no axial conduction to model the borehole at different depths. The model neglects the thermal mass of the utube walls and the grout; for long time step simulations this is acceptable, but for short time steps this negatively affects the thermal response of the borehole. Yavuzturk [1999] developed a two-dimensional FDM that is similar to the Rottmayer et al. [1997] model to determine the thermal response of a horizontal cross section of the borehole. Both of these models make assumptions about the geometry of the u-tube by approximating it as a "pie-sector", shown in Figure 4.6b. More information on Yavuzturk's model can be found in Section 4.2.1. 
Finite Element Models (FEM) have an advantage over other finite methods since they can model the complex geometry of the borehole without simplifying assumptions. Some examples of FEMs include work by Muraya et al. [1996] creating a two-dimensional model which was used to run a parameter study of ground loop heat exchangers and work by Kohl and Hopkirk [1995] creating "FRACTure" a three-dimensional FEM model which was used to study co-axial tube boreholes [Muraya et al., 1996, Kohl and Hopkirk, 1995, Kohl et al., 2002]. Even though these models can be used to better represent the geometry of a ground loop heat exchanger their utility for short time step simulations is diminished due to the extensive computation time.

Young [2004] and Xu [2007] rely on General Elliptical Multi-block Solver (GEMS2D), which is a Finite Volume Model, to validate various aspects of their models. GEMS2D was developed by the Building and Environment Thermal Systems Research Group at Oklahoma State University. Young used the model to determine the accuracy of the Multipole Model discussed in Section 4.1.1.2. Xu implemented a one-dimensional finite volume model to model the short time step response of ground loop heat exchangers. Xu's model is simplified so that there are only $\approx 600$ cells and does not model the entire system. He also uses GEMS2D to validate his one-dimensional finite volume model. More information on Xu's model can be found in Section 4.2.2.

Of the models mentioned only Yavuzturk [1999] and Xu [2007] implement their models in hourly or sub-hourly simulations. Yavuzturk used a FDM to pre-calculate response factors and Xu uses a very simple FVM to cal- 
culate the local thermal response of the borehole. Both of these methods have significantly reduced computation times in comparison to full finite models.

\subsection{Implemented Models}

During the development of the integrated building load-GSHP model three different ground loop models where implemented. Initially, a finite difference model was implemented using a model developed by a group of senior mechanical engineering students as part of their senior design project. Due to long calculation times this model was replaced with two different models based on Eskillson's g-function model (Discussed in Section 4.1.2.4).

\subsubsection{Short Time Step Response Factor Model}

Yavuzturk [1999] extended Eskillson's [1987] work by determining short time step g-functions. These short time step g-functions are used to determine the thermal response of the ground for $\Delta t<5 r_{b}^{2} / \alpha$. This allows for simulations with hourly or sub-hourly time steps. The short time step g-functions were developed in a manner similar to Eskillson's method outlined at the beginning of Section 4.1.2.4.

To model the thermal response of the borehole for short time steps a numerical model of the borehole was developed. The resulting finite volume, 2-D $(r, \theta)$ model assumes that:

- Effects of the surface of the ground and the end of the u-tube are negli- 
gible.

- Bulk ground has uniform properties.

- The temperature profile of the fluid is approximated along the length of the borehole.

- Interaction between neighboring borehole are negligible.

The model is based on the polar coordinate version of transient conduction equation shown in Equation 4.16. The equation is discretized with a fully implicit finite volume approach using first order backwards differencing in time and second order central differencing in space.

$$
\frac{1}{\alpha} \frac{\partial T}{\partial t}=\frac{\partial^{2} T}{\partial r^{2}}+\frac{1}{r} \frac{\partial T}{\partial r}+\frac{1}{r^{2}} \frac{\partial^{2} T}{\partial \theta}
$$

The finite volume model creates a numerical grid over the borehole in order to come up with a solution, as shown in Figure 4.6a. The u-tubes do not fit into the grid very well, therefore they are approximated by a "Pie Sector" as shown in Figure 4.6b which approximates the borehole geometry to fit into the numerical gird. Additional information regarding the numerical model can be found in Yavuzturk's thesis [Yavuzturk, 1999].

The results of the numerical model are non-dimensionalized to create the short time step g-functions. Eskillson's [1987] g-functions did not account for any borehole properties, thus in order to increase the accuracy of the short 


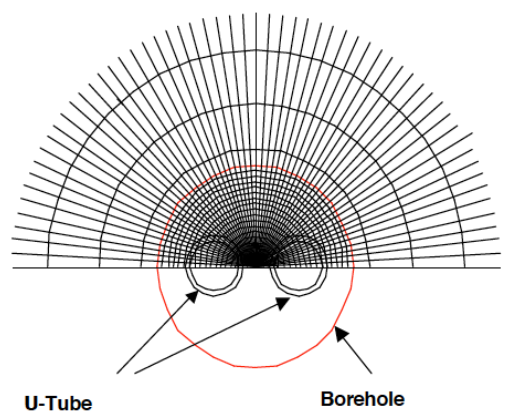

(a) Example numerical grid

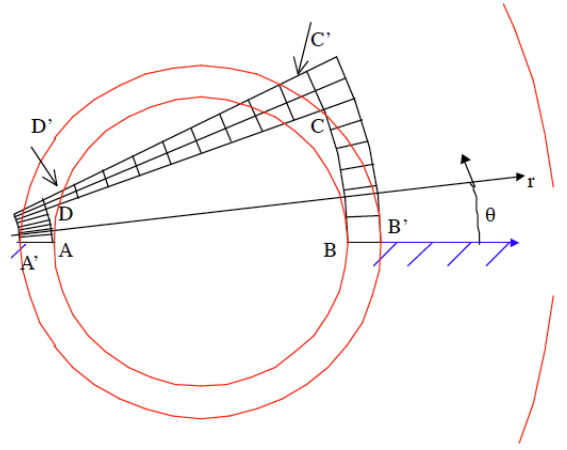

(b) Pie-Sector approximation of borehole

Figure 4.6: Details of the finite volume model [Yavuzturk, 1999]

time step g-functions Yavuzturk includes the resistance of the borehole during the non-dimensionalization process, as shown in Equation 4.17.

$$
g\left(t / t_{s}, r_{b} / H\right)=\frac{2 \pi k\left(T_{\text {borehole }}-R_{\text {total }} Q-T_{\text {ground }}\right)}{Q}
$$

$R_{\text {total }}$ is the total equivalent resistance of the borehole. It is the sum of the fluid convective resistance, pipe conduction resistance and the grout conduction resistance.

The resulting short time step g-functions are shown in Figure 4.7. The short time step g-functions are calculated for $\ln \left(t / t_{s}\right)<-8$. For $\ln \left(t / t_{s}\right)>-8$ the g-functions are still calculated using Eskillson's [1987] model. The addition of the short time step g-functions allows for the model to be calculated on time steps as short as five minutes.

Yavuzturk also developed a method to consolidate previous ground loads to reduce the computation time of the model. At every time step the 


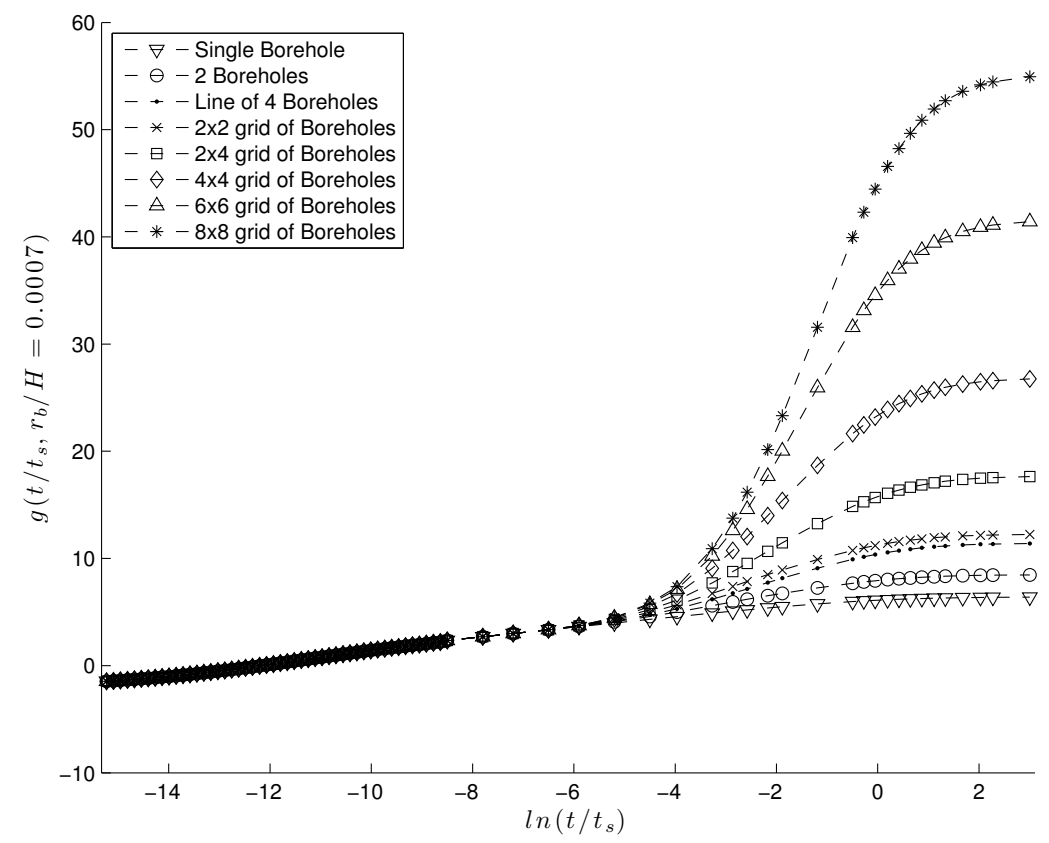

Figure 4.7: Short time step and Eskillson's g-functions for typical borehole configurations, data from GLHEPRO 4.0 [Spitler, 2000]

model must calculate the thermal response of the borehole based on all of the previous ground loads. The is calculating using Equation 4.15 where n equals the number of previous time steps. For an one year simulation, with hourly time steps the model must calculate the thermal response of the borehole for 8760 different loads at every time step. The increase in the number of calculations per time step causes the simulation time per time step to increase. To reduce this effect Yavuzturk created an algorithm to combine previous loads for each time step into blocks representing days, months, and years. The blocks, also called aggregated loads, combine the loads for each time step over a set time interval, such as a day, to create a representative load for that ag- 
gregation period. This reduces the total number of calculations that have to be performed at each time step which in turn decrease the total simulation time. The aggregation procedure turns Equation 4.15 into 4.19.

One of the requirements for the ground loop model was that it calculate the heat rejected into the ground and the water temperature coming out of the ground based on the inlet water temperature. This is accomplished by assuming that the borehole temperature, $T_{\text {borehole }}$, is the average temperature of the borehole. This leads to:

$$
T_{\text {out }}=2 T_{\text {borehole }}-T_{\text {in }}
$$

The temperature of the borehole is determined by:

$$
\begin{aligned}
T_{\text {borehole }}(t)= & T_{\text {ground }}+\sum_{m=1}^{M}\left[\frac{\left(\bar{q}_{m}-\bar{q}_{m-1}\right)}{2 \pi k} g\left(\frac{\left(t-t_{m}\right)}{t_{s}}, \frac{r_{b}}{H}\right)\right] \\
& +\sum_{n=1}^{N}\left[\frac{\left(q_{n}-q_{n-1}\right)}{2 \pi k} g\left(\frac{\left(t-t_{n}\right)}{t_{s}}, \frac{r_{b}}{H}\right)\right]
\end{aligned}
$$

where $M$ is the number of aggregation periods, $\bar{q}_{m}$ is the average heat rejected/extracted over each aggregation period, $t_{m}$ is the start time of each aggregation period, $\mathrm{N}$ is the number of time steps since the last aggregation, $q_{n}$ is the heat rejected/extracted for the $n^{t h}$ time step, and $t_{n}$ is the starting time of the $n^{t h}$ time step. The heat rejected/extracted for each time step is calculated by:

$$
Q(t)=\frac{\left(T_{\text {ground }}-T_{\text {borehole }}\right)}{R_{\text {total }}}
$$

The advantages of this model include the short simulation time. Since the model uses the pre-calculated short time step g-functions, the computation 
time required for the model simulation is minimized. The model was validated, with good agreement, by Yavuzturk using experimental data. The model takes advantage of GLHEPRO's ability to produce a parameter file for the model which allows for modifications to the ground loop to be quickly implemented [Spitler, 2000].

One of the problems with this model is the use of an average borehole temperature to calculate the heat transfer in the borehole. The model calculates the average temperature and the outlet temperature based on the inlet temperature, but the model does not keep track of any other fluid temperatures. This assumption is fine once the fluid in the ground loop reaches a steady-state, but during start up and sudden inlet fluid temperature changes this assumption is violated, resulting in errors in the outlet temperature. If the inlet temperature changes significantly faster than the average borehole temperature can respond the outlet temperature will have to change significantly. This can cause large transient spikes in the outlet temperature that cause the ground loop temperatures to fluctuate over the next time steps. For sufficiently large time steps that allow the fluid in the ground loop to be completely replaced this assumption is never violated; for a $91.4 \mathrm{~m}(300 \mathrm{ft})$ borehole with a $25 \mathrm{~mm}$ (1 in) diameter u-tube and $0.19 \mathrm{~L} / \mathrm{s}(3 \mathrm{GPM})$ of fluid flow, this time-delay corresponds to 8.2 minutes. Another issue with respect to short time steps is that GLHEPRO only provided short time step g-function data down to 5 minute time steps, so running this model at any time step less than 5 minutes in not feasible. 


\subsubsection{Xu's Model}

Xu [2007] developed a model based on Eskillson's [1987] g-functions that used a one-dimensional, finite volume model to allow for small time steps. Unlike Yavuzturk's [1999] model which implements a numerical model to predetermine the short time step response of the ground, Xu's model uses a numerical model during the simulation to calculate the short time step response.

The numerical model is a one-dimensional, finite volume model based on transient conduction equation in cylindrical coordinates, show in Equation 4.21. A fully implicit method is used to discretized the equation.

$$
\frac{1}{\alpha} \frac{\partial T}{\partial t}=\frac{\partial^{2} T}{\partial r^{2}}+\frac{1}{r} \frac{\partial T}{\partial r}
$$

The numerical model assumes that:

- There is a single, centered pipe as shown in Figure 4.8 .

- Effects of the surface of the ground and the end of the u-tube are negligible.

- Bulk ground has uniform properties.

- Interaction between neighboring boreholes are negligible.

The the diameter of the single center pipe is $\sqrt{2}$ times larger than a single leg of the actual u-tube. This maintains the thermal mass of both the grout and water in the pipe. The one-dimensional model is divided into five sections 

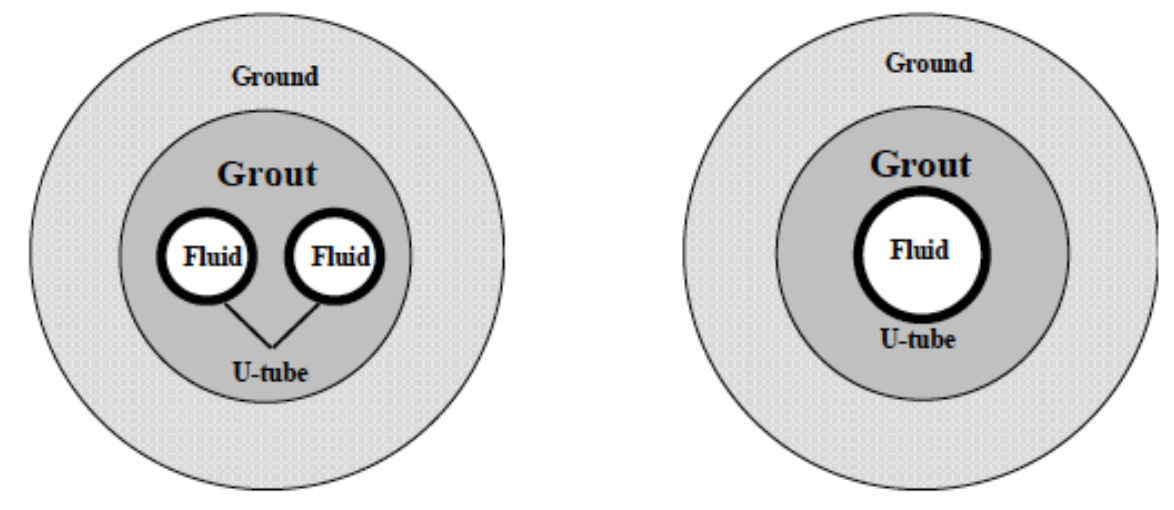

Figure 4.8: Borehole simplification for Xu's one-dimensional model

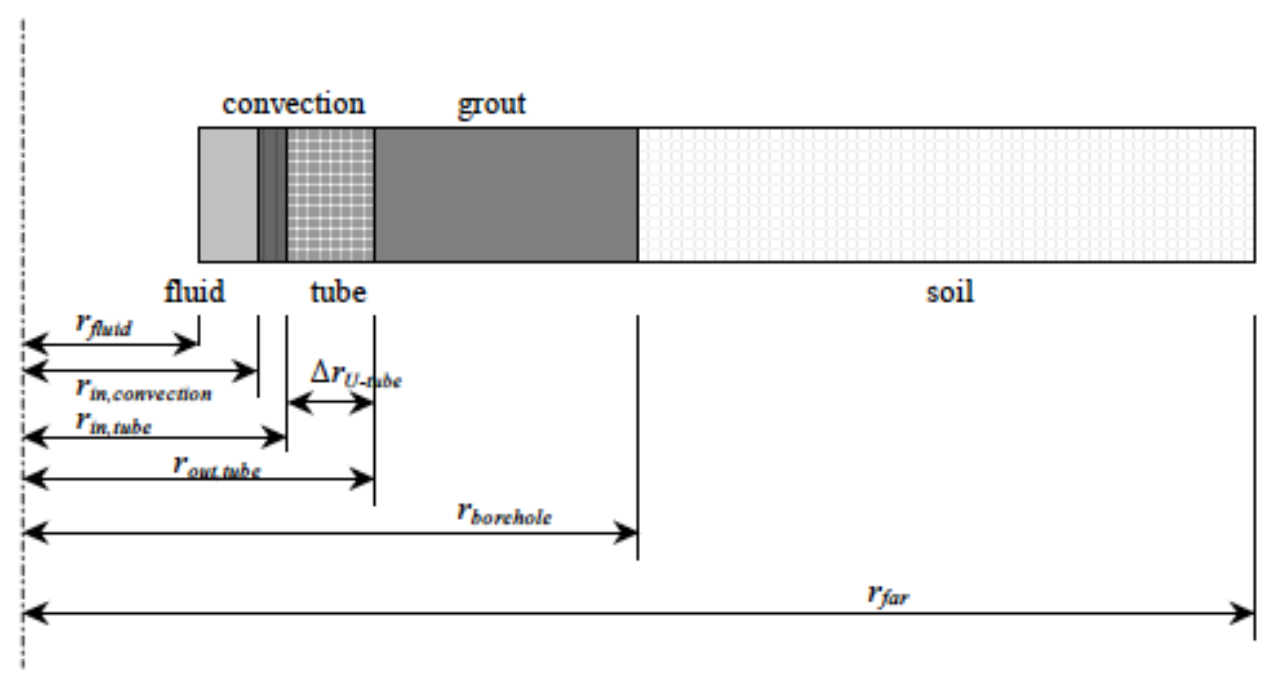

Figure 4.9: Grid method used in one-dimensional numerical model [Xu, 2007] 
as shown in Figure 4.9. This eliminates the dependance of the heat transfer in the $\theta$ direction. Each of the five sections of the grid is represented by multiple individual finite volume cells; for example the far field $\left(r_{\text {borehole }}<r<r_{\text {far }}\right)$ ) is represented by 500 cells. The two grid sections closest to the centerline represent the ground loop fluid and the convection between the fluid and the inside of the u-tube. Since the one-dimensional model is a approximation of the actual geometry each of the sections uses equivalent heat transfer properties. A single conductivity for the grout and the u-tube layers is calculated so that the total resistance of the one-dimensional borehole model matches the resistance of the actual two-dimensional borehole. This is accomplished by calculating the total resistance of the two-dimensional borehole using the Multipole method discussed in Section 4.1.1.2 and then back calculating the equivalent conductivity using:

$$
k_{\text {equiv }}=\frac{\ln \left(r_{b} / r_{\text {tube,in }}\right)}{2 \pi R_{\text {equiv }}}
$$

where $R_{\text {equiv }}$ is the resistance calculated by the Multipole method, and $r_{t u b e, i n}$ is the inner radius of the single tube. The conductivity of the convection layer is calculated in a similar manner. The model performs the calculations each time step since the total borehole resistance changes with temperature.

The model replaces the short time step g-functions of Yavuzturk's [1999] model with a one-dimensional model to determine the short term thermal response of the recent ground loads on the borehole. The model then aggregates the loads in a manner similar to Yavuzturk's model and applies the aggregated 
loads to Eskillson's [1987] g-functions to calculate the long term response. Mathematically this is:

$$
\begin{aligned}
T_{\text {borehole }}(t)= & T_{\text {ground }}+\sum_{m=1}^{M}\left[\frac{\left(\bar{q}_{m}-\bar{q}_{m-1}\right)}{2 \pi k} g\left(\frac{\left(t-t_{m}\right)}{t_{s}}, \frac{r_{b}}{H}\right)\right] \\
& +\Delta T_{\text {oned }}+R_{\text {equiv }} q(t)
\end{aligned}
$$

where $\bar{q}_{m}$ is the aggregated loads, $\Delta T_{\text {oned }}$ is the temperature response of the one-dimensional model, and $q$ is the current ground loop load. $T_{\text {borehole }}$ is assumed to be the average of the inlet and outlet temperatures which is the same as Yavuzturk's model. The outlet temperature is then calculated based on Equation 4.20 .

Xu's [2007] model is computationally more complex then the short time step g-function model presented in Section 4.2.1, but not as computationally demanding as a finite difference model. The additional complexity allows the simulation of an larger range of operating conditions when compared to the short time step g-function model, such as fluid rates that do not cause turbulent flow in the $\mathrm{u}$-tube. This is possible since the borehole resistance, which is a function of water flow rate, borehole temperature, geometry and material properties, is calculated at every time step. This model also takes advantage of GLHEPRO's ability to produce parameter files for the model allowing for easy parameter changes to the ground loop model.

Since this model, like Yavuzturk's [1999] model, calculates the heat transfer based on the average fluid temperature it has the same problem with time steps that violate the average temperature assumption. Time steps less 
than this minimum time are only a problem when there are sudden changes in inlet temperature. An advantage of this model over Yavuzturk's model is that due to the one-dimensional model the time steps can be a small as needed and are not limited by the provided data or steady state assumptions in the borehole model.

\subsubsection{Finite Difference Model}

A team of undergraduate mechanical engineering students developed a Finite Difference Model (FDM) to model a ground loop heat exchanger as part of there Senior Design Project. The team used a two-dimensional FDM to calculate the temperature response of the ground away from the borehole (far-field model) and an extended version of Zeng et al.'s [2003] interpretation of Hellström's [1991] model for the borehole model (near-field model).

The FDM models the heat transfer in $r$ and $z$ directions and assumes that there is symmetry in the $\theta$ direction. The two-dimensional simplification greatly reduces the size and complexity of the model and greatly decreases model run time. The finite difference model has the following boundary conditions: 


$$
\begin{aligned}
-\left.k \frac{\partial T}{\partial r}\right|_{r=r_{b}} & =q_{s}(z) \\
\left.\frac{\partial T}{\partial r}\right|_{r=r_{f a r}} & =0 \\
-\left.k \frac{\partial T}{\partial z}\right|_{z=0} & =h_{\text {surf }}\left(\left.T\right|_{z=0}-T_{\infty}(t)\right) \\
\left.T\right|_{z=z_{f a r}} & =T_{\text {ground }} \\
\left.T\right|_{t=0} & =T_{0}(r, z)
\end{aligned}
$$

In order, they represent the boundary of the borehole with a heat flux term that is a function of depth, the boundary between the field undisturbed ground that is adiabatic at $r=r_{f a r}$, heat transfer from the ambient air to surface of the ground, the boundary between the field undisturbed ground that is adiabatic at $z=z_{\text {far }}$ and the initial conditions.

The borehole model that was implemented is a modified version of Hellström's [1991] model. The team added the convection and conduction resistances for the fluid to the resistance network to better model the heat transfer between the fluid and pipe walls. They also extended the boundary of the borehole model past the outside of the borehole so that it included some of the bulk ground. This was done to reduce variation of the temperature with changes in $\theta$ at the boundary between the two models. In the modified model, shown in Figure 4.10, $T_{1}$ and $T_{2}$ are the fluid temperatures in the two legs of the utube, $T_{1}^{\prime}$ and $T_{2}^{\prime}$ are the wall temperatures of the u-tube, $T_{0}$ is the borehole wall temperature, $R_{\text {conv }}$ and $R_{\text {cond }}$ are the fluid convection and 

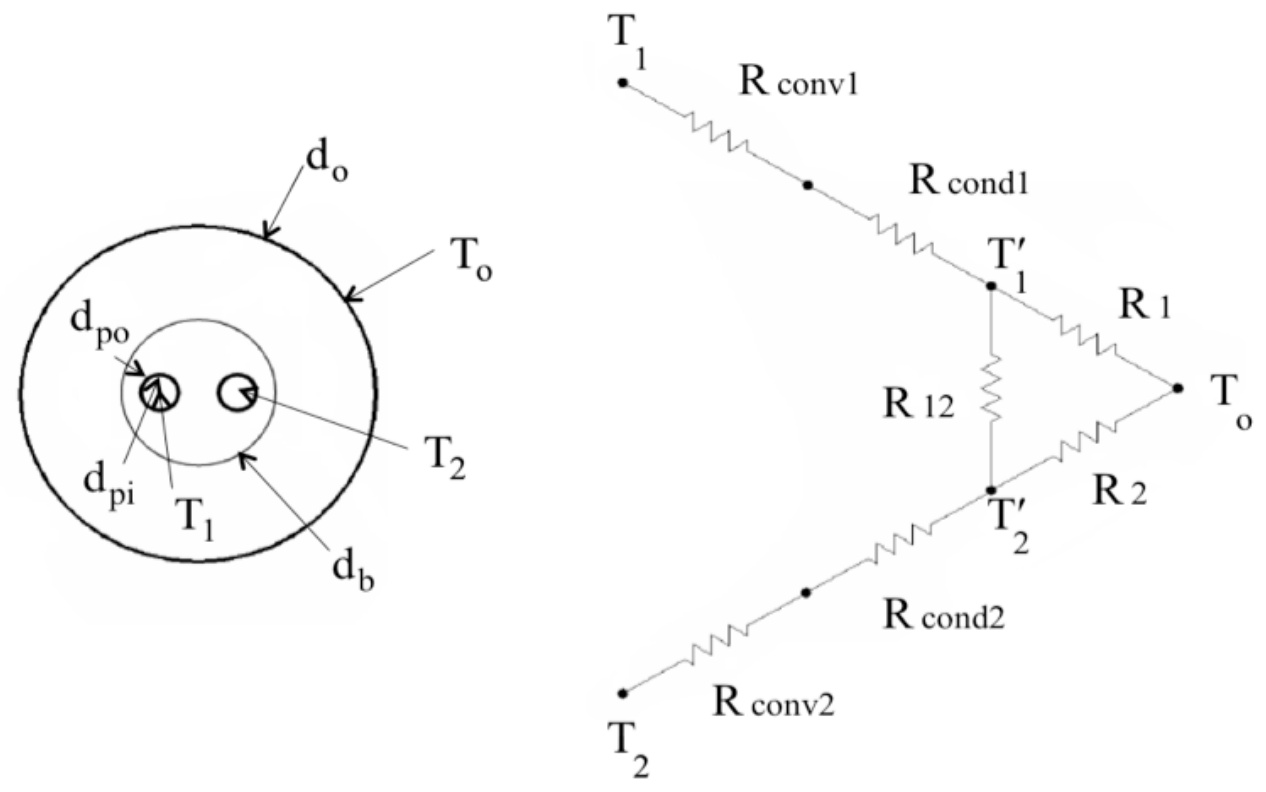

Figure 4.10: Modified version of Hellström's borehole model

conduction resistances, and $R_{1}, R_{2}$ and $R_{12}$ are the conduction resistances in the borehole. The borehole conduction resistances are calculated using shape factors which account for the geometry of the borehole.

The borehole model takes advantage of Zeng et al.'s [2003] modifications of Hellström's [1991] model to model the change in fluid temperatures in the length of the borehole. The borehole length is divided into segments, and each segment calculates the borehole model shown in Figure 4.10 which in turn calculates the fluid temperature change over the segment for each leg. Each of the segments is coupled to a node of the finite difference model of the far-field. The resulting coupled model can calculate the temperature change in the fluid 
over the length of the borehole based on only the inlet temperature and the past load history of the ground loop heat exchanger.

This model has the potential to accurately model the borehole for small time steps. This model does not use an average temperature to calculate the heat transfer into the ground, which prevents the transient temperature spikes that are present in Xu's [2007] and Yavuzturk's [1999] model when simulated for small time steps. Since Hellström's model assumes that the heat transfer is steady state, care must be taken to ensure that the time steps are long enough to allow for the borehole model to reach equilibrium. A drawback of the finite difference model just described is that it cannot model multiple boreholes in a field, which will cause the model to under-estimate the temperature response of the ground in situations where borehole interaction occurs. The largest drawback of this model is the large computation time required. 


\section{Chapter 5}

\section{Integrated Building Load-GSHP Model}

The integrated building load-GSHP model that couples the component models discussed in Chapters 2, 3, and 4 is presented in this chapter. In addition, the details of the residential building model and ground source heat pump system used to simulate the results presented in subsequent chapters are discussed. Finally, the results from a two-part validation are presented, which show that the integrated model is sufficiently accurate to model the long term performance of ground source heat pumps for residential applications.

\subsection{Simulink ${ }^{\circledR}$ Model}

The Simulink ${ }^{\circledR}$ modeling environment is designed for multi-domain simulation of dynamic systems. Simulink ${ }^{\circledR}$ includes a graphical user interface that allows the user to modify the model. The model is presented in a block diagram format, with blocks that perform mathematical functions, data manipulation, or conditional statements. Simulink ${ }^{\circledR}$ includes a large library of blocks for the user, as well as allowing the user to develop user-defined blocks using the functionality of Matlab. Large models can be divided into sub-models that act like sub-functions in traditional text based programming. 
For example, Figure 5.1 shows the main Simulink ${ }^{\circledR}$ model in the graphical editor for the integrated building load-GSHP model. The four largest blocks are sub-models that contain the models for HAMBASE, the performance map based heat pump model, Xu's ground loop model and the water pump model. Each block is a custom block that was created by the research team. The top level model also used some of the included blocks, such as the constant block, which outputs a constant value, and the selector, which selects a subset of an array of values [Mathworks, 2011].

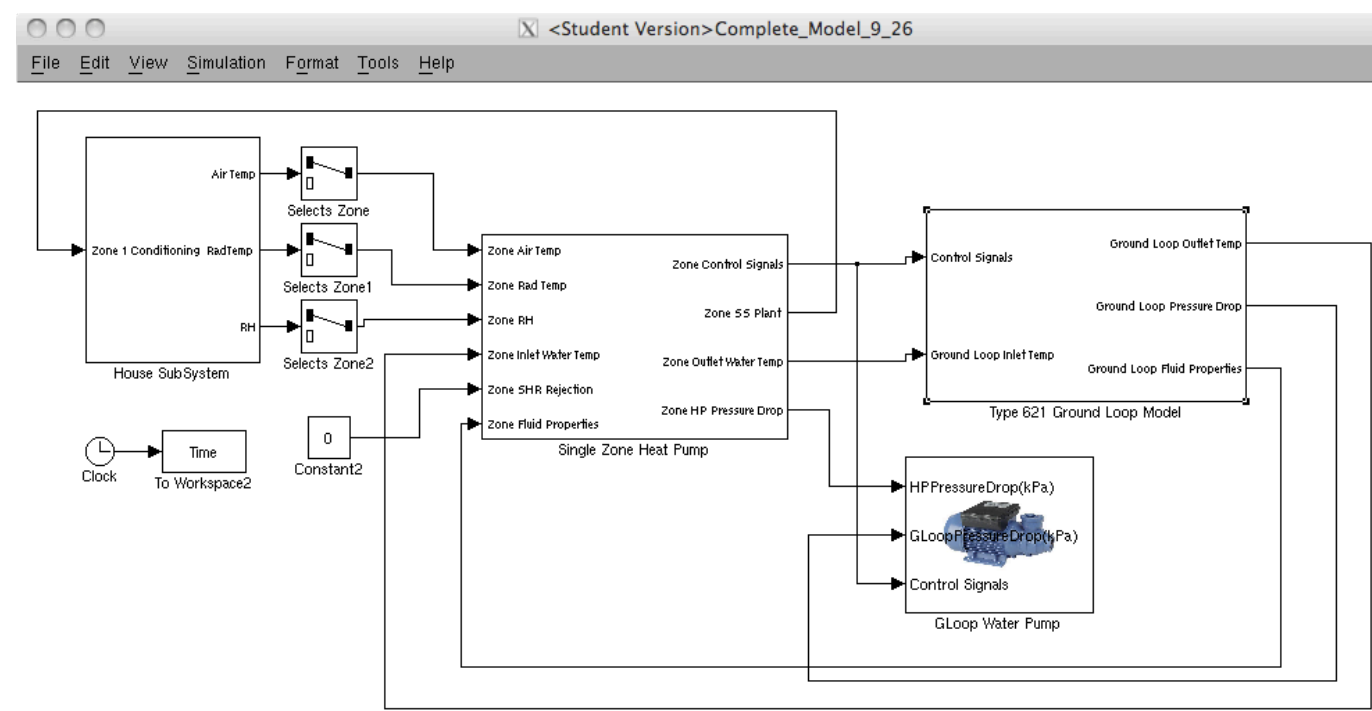

Figure 5.1: Top level Simulink ${ }^{\circledR}$ model

The graphical model editor allows the user to easily make configuration changes to the model without rewriting the underling code. For example, a block that models a cooling tower can easily be dropped into the editor and connected into the ground loop without modifying any text-based code. The 
graphical environment also allows the model to be used by an non-expert user. For example, to change the size of the heat pump the user just double clicks on the heat pump model block and a menu appears that has the size of the heat pump in a drop down menu [Mathworks, 2011].

Simulink ${ }^{\circledR}$ comes with built-in solvers to simulate the model. There are two types of solvers that can be used; variable time step solvers that change the size of the time step based on the integration error and fixed time step solvers. Each solver has multiple options for the order of the numerical solution. The model is solved using a 1st order, fixed step solver. An additional advantage of the Simulink ${ }^{\circledR}$ environment is its ability to handle multi-rate simulations. In the integrated model the ground loop is simulated every five minutes and the rest of the model is simulated every 30 seconds. Simulink ${ }^{\circledR}$ has built-in blocks to handle the required time step transitions and data manipulation [Mathworks, 2011].

The model was developed so that it could be expanded to include multiple heat pump models with a single building load model and a single ground loop model or even a case with multiple buildings and heat pumps with a single ground loop model. Therefore the model is divided into sub-models that are self contained and can be duplicated inside of the model. The Simulink ${ }^{\circledR}$ model is composed of three main sub-models, the building load model, the heat pump model and the ground loop model. The background of each of these models is discussed in Chapters 2, 3, and 4. 


\subsubsection{Heat Pump Model Implementation}

The heat pump sub-model, shown in Figure 5.2, contains the performance map heat pump model discussed in Chapter 3 as well as the thermostat to control the heat pump. As with all of the sub-models the inputs, which are designated by the small numbered ovals, are defined on the left and the outputs on the right. They correspond to the connections in the top level model. For example, the heat pump sub-model has six inputs and four outputs. The large block in the middle of the sub-model contains the performance map code that was discussed previously.

One of the many advantages of the Simulink ${ }^{\circledR}$ environment is the ability for a non-expert user to make changes to the model. A good example is illustrated by how the user changes the size and type of heat pump. Instead of changing hard coded data, the user just double clicks on the heat pump performance map block and is presented with a menu, shown in Figure 5.3. The drop down menu allows the user to select the heat pump size and brand. This approach also prevents a non-expert user from accessing the main code and possibly making changes. Beneath this interface, the code is importing the performance map data as data files so that additional heat pump models can be added.

The heat pump is controlled by the thermostat model shown in Figure 5.4. The model determines the room temperature based on a combination of the zone air temperature, $T_{a i r}$, and the zone radiant wall temperature, $T_{\text {rad }}$ as shown in Equation 5.1. The weighting factor, $\alpha$, determines how the air and 


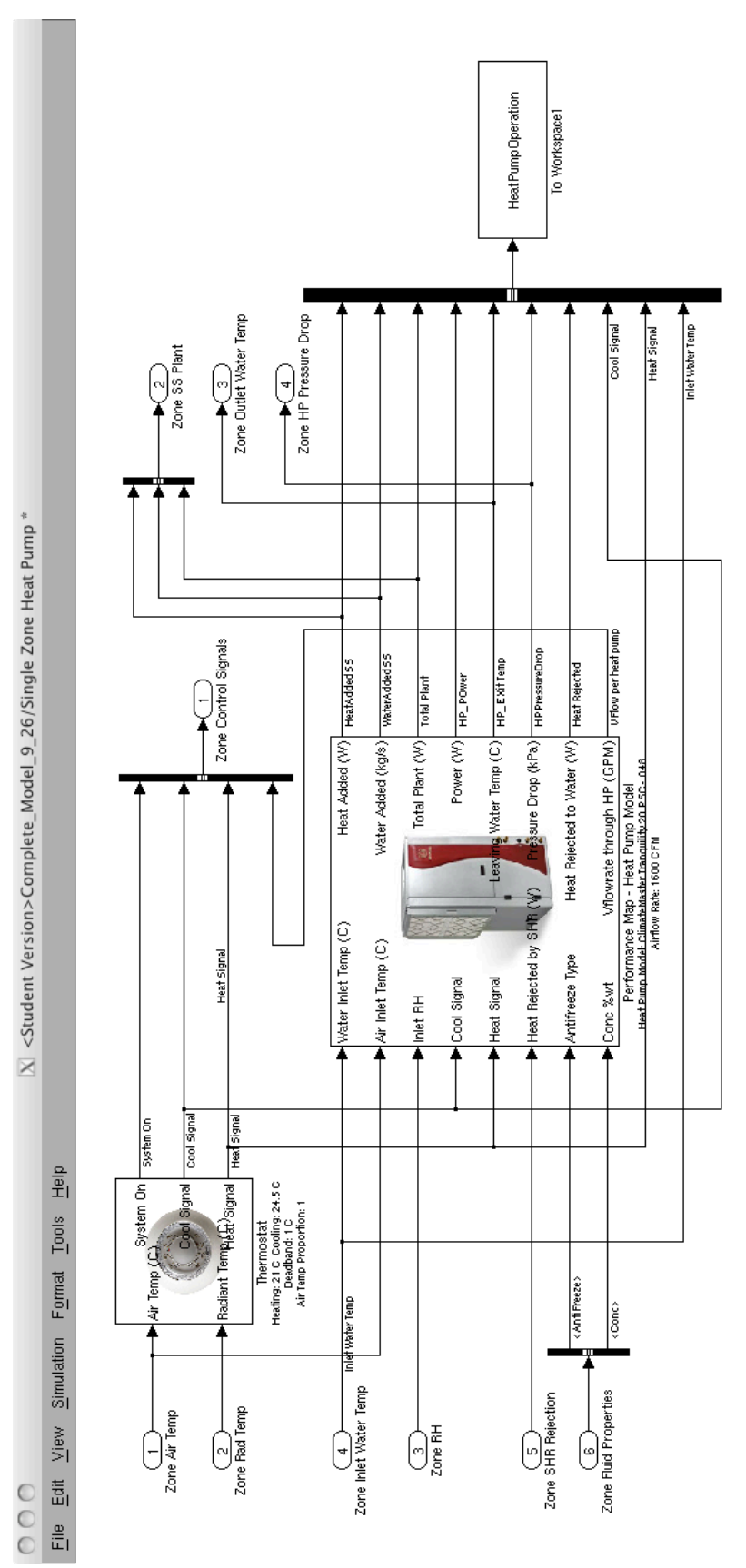

Figure 5.2: Heat pump sub-model 


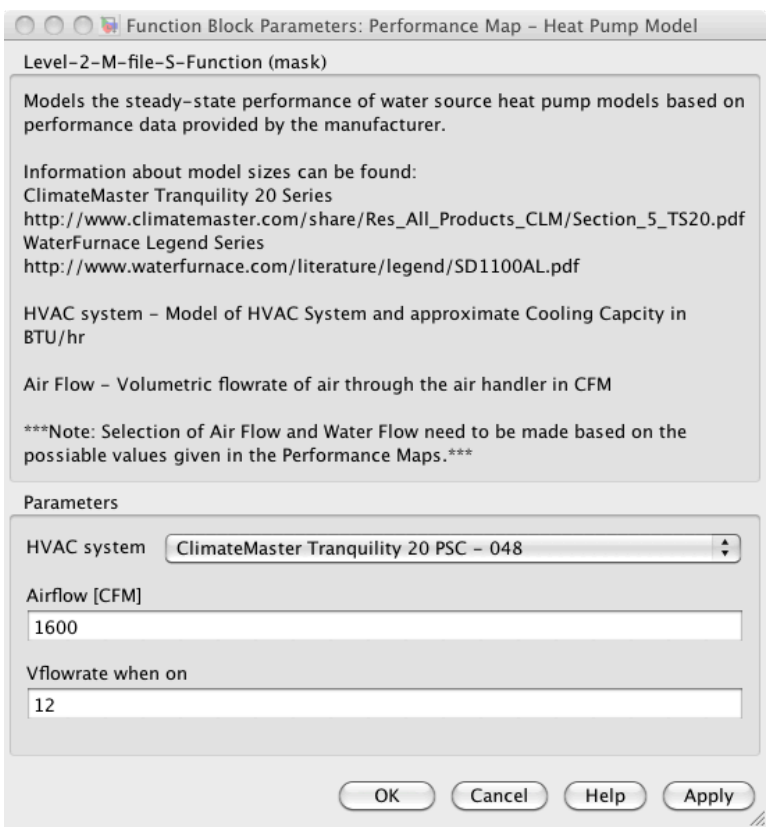

Figure 5.3: Performance map options menu

radiant wall temperatures are combined.

$$
T_{M}=\alpha T_{a i r}+(1-\alpha) T_{\text {rad }} \text { where } 0 \leq \alpha \leq 1
$$

This equation is implemented in Simulink ${ }^{\circledR}$ using the built-in blocks on the left hand side of the block diagram. The thermostat compares the temperature of the room to the user-defined temperature set points. This action is accomplished by the thermostat blocks on the right hand side of the block diagram. These blocks model the deadband of the thermostats. The deadband keeps the heat pump on after the temperature has passed back through the set point until the temperature reaches a predefined value. For example, with the cooling set point at $25^{\circ} \mathrm{C}$ and a $1^{\circ} \mathrm{C}$ deadband the heat pump will turn on when the room temperature goes above $25^{\circ} \mathrm{C}$ and will stay on until the tem- 
perature reaches $24^{\circ} \mathrm{C}$. The thermostat also contains a menu that allows the user to modify the set points, deadband and $\alpha$. The thermostat outputs a ' 1 ' for the proper signal when the thermostat determines that cooling or heating is needed. This signal is read by the performance map heat pump model to determine the proper state of operation, - cooling, off ('0' signal), or heating. The thermostat was modeled separately from the heat pump so that the control system could be modified separately from the heat pump model. The far

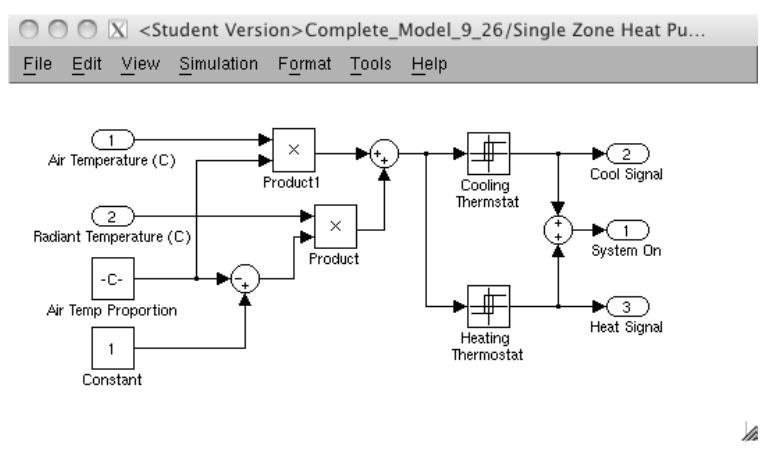

Figure 5.4: Thermostat sub-model

right side of Figure 5.2 shows a large, square box labeled "HeatPumpOperation". This block saves all the data that is connected to it. In the case of the heat pump sub-model the block saves all the outputs of the model as well as some selected inputs that are not saved in other sub-models. All sub-models have blocks like this to save the data.

\subsubsection{Building Load Model Implementation}

The Simulink ${ }^{\circledR}$ implementation of the building load model, shown in Figure 5.5, takes the output of the heat pump model and simulates the response 
of the building. The HAMBASE model block takes in the sensible and latent loads from the heat pump and a ventilation rate. Each of these variables becomes an input to each zone. The model shown in Figure 5.5 has six total inputs, since there are two zones. The inputs to zone two are all zero since that zone is unconditioned. The block outputs the air temperature, radiant temperature and relative humidity for each zone as well as some additional building values that are not used, such as the wind pressure and external temperature. The building is defined in a text file that is read by the model. The text file controls the building structure, internal loads, basic ventilation, and building location. The text file referenced by the model can be changed under the menu associated with the building model block. All data is saved for the length of each simulation.

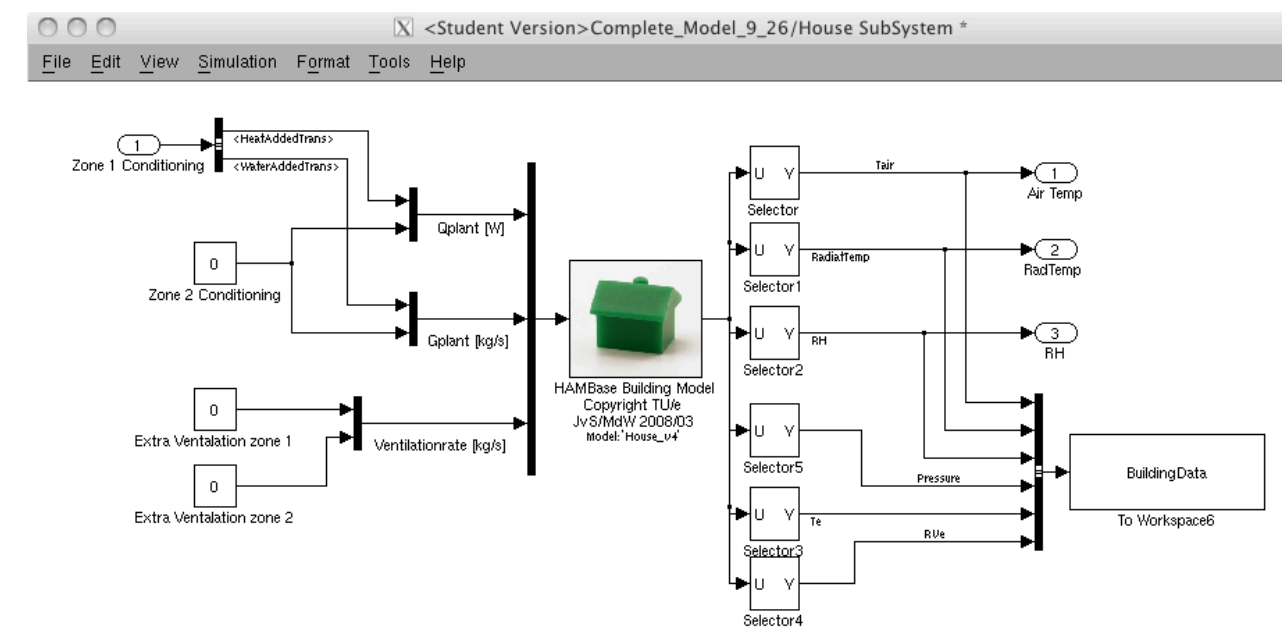

Figure 5.5: Building load sub-model 


\subsubsection{Ground Loop Model Implementation}

The implementation of Xu's ground loop model is the most complex. The ground temperatures have a significantly slower response time than the building and the heat pump system, so the ground loop is simulated at larger time step intervals, every five minutes, than the rest of the model, which is simulated every 30 seconds. This multi-rate simulation capability increases the speed of the model as well as solving the issue with oscillating ground loop temperatures due to the way the outlet and inlet water temperatures are de-

fined, as discussed in Section 4.2.1. The model takes advantage of Simulink's ${ }^{\circledR}$ built-in ability to model systems with different time steps. The rate transition blocks shown in Figure 5.6 handle the timing and data transfer between the two time steps. The model assumes that the input water temperature and flow rate to the ground loop are the average value over the previous five minutes. The averaging is accomplished using the sub-system shown on left of the ground loop model. This sub-system calculates the ground loop water flow rate over a set interval, L. To ensure that the energy content of the water represents the proper values based on the previous five minutes a weighted average of the short time step water temperatures is performed to calculate the long time step temperatures. The temperatures are weighed based on the flow rate for that time step, as shown in Equation 5.2 where $T_{\text {long }}$ is the long time step water temperature, $V_{i}$ is a short time step water flow rate and $T_{i}$ is a short time step water temperature, and $L$ is a function of the differences in 


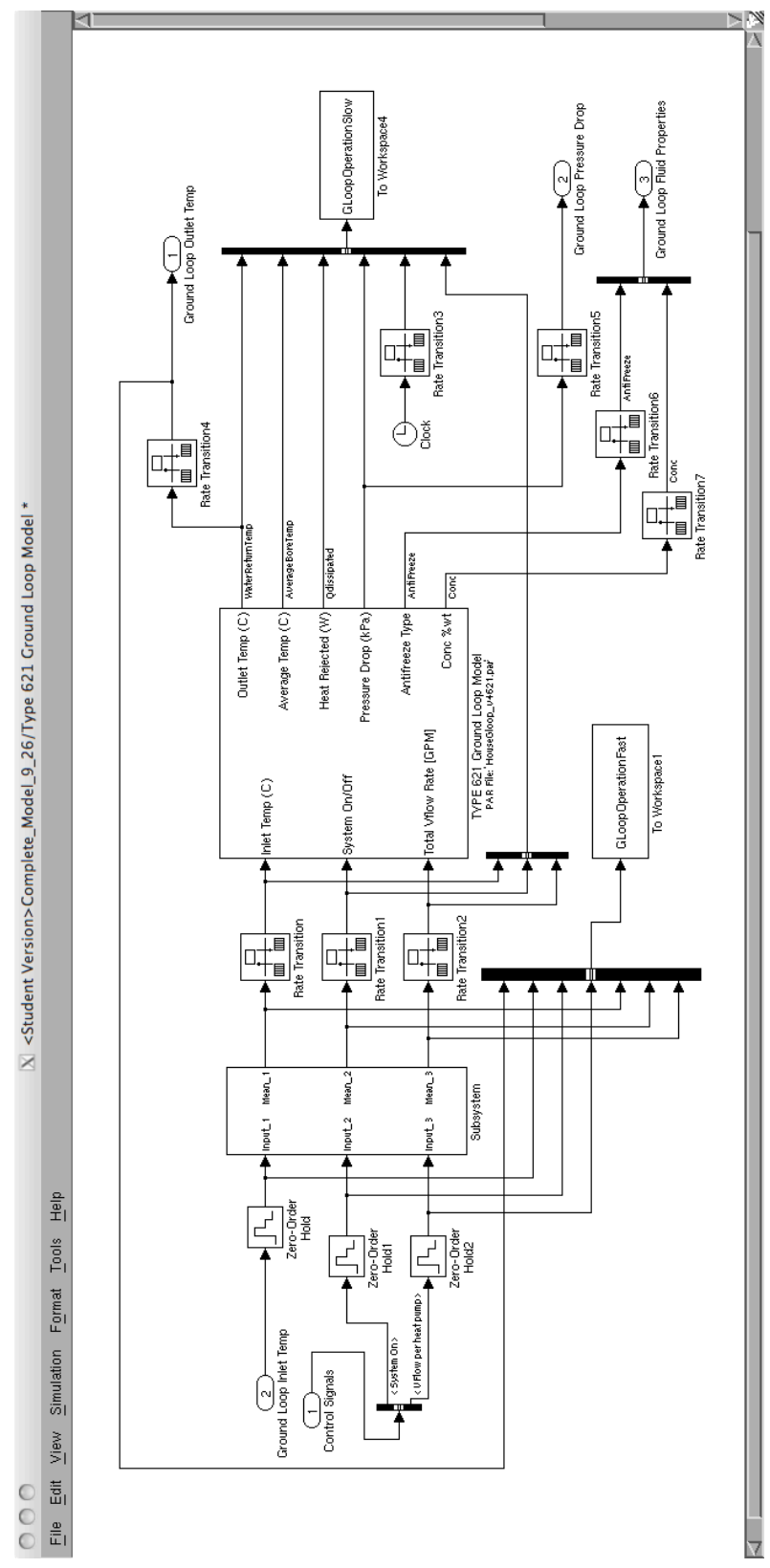

Figure 5.6: Ground loop sub-model 
the time steps.

$$
T_{\text {long }}=\frac{\sum_{i=1}^{L} V_{i} T_{i}}{\sum_{i=1}^{L} V_{i}}
$$

where $L$ is a function of the differences in the time steps. The longer ground loop time step must be an integer multiple, $L$, of the shorter time step. For this case the long time step is equal to five minutes (300 seconds) and the short time step is equal to 30 seconds, so $L$ is 10 . The outputs of the ground loop model are only updated every five minutes so the rate transitions on the right side of the ground loop model act like zero-order holds. Due to the use of the multi-rate simulation there are two blocks that save the data from the ground loop model at the two different rates.

The ground loop parameters are specified in a text file that is created using GLHEPRO [Spitler, 2000]. GLHEPRO is a software package available from Oklahoma State University. The user must input the ground and borehole parameters into GLHEPRO to create the parameter file for the ground loop. In addition to creating the parameter files, GLHEPRO can be used to size the ground loop based on the building load and type of heat pump. See Appendix C for a description of how GLHEPRO is used with the Simulink ${ }^{\circledR}$ model.

\subsubsection{Additional Model Notes}

A variety of data is shared between the different component models of the Simulink ${ }^{\circledR}$ model. For example, the heat pump specifies the water flow rate through the ground loop. This was done so that when the model is expanded to include multiple heat pumps, the flow rate through the ground 
loop depends on the number of heat pumps that are operating. The ground loop model specifies if antifreeze has been added to the ground loop water since GLHEPRO uses this information to calculate various ground loop parameters. To calculate the power needed to pump the water through the ground loop the total pressure drops for the specified flow rates are calculated in each of the component models. These pressure drops are then sent to the pump submodel, shown in Figure 5.7 where the energy required to pump the fluid is calculated. The pumping power is calculated using Equation 5.3, where $v_{w}$ is

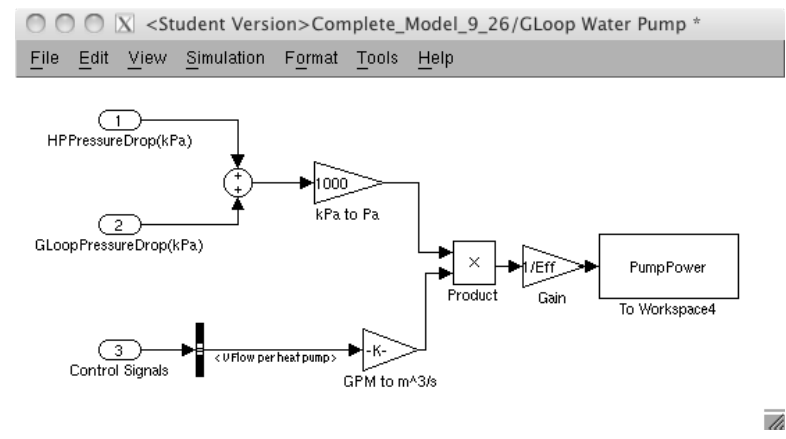

Figure 5.7: Ground loop pump sub-model

the specific volume of water, $\Delta P$ is the pressure drop across the system, and $\eta$ is the pump efficiency.

$$
W=\frac{v_{w} \Delta P}{\eta}
$$

The model is solved using a 1st order, fixed time step solver. Due to the manner in which the ground loop model was implemented, the model could not take advantage of the variable time step solvers or higher order, fixed time step solvers. Simulating the model for a single year, with a single heat pump model and a two zone building, takes approximately $1.5 \mathrm{hrs}$ on a $2.4 \mathrm{GHz}$ Intel 
processor. Solving for 15 years takes approximately $13 \mathrm{hrs}$ to solve on a 3.73 $\mathrm{GHz}$ Xeon processor.

\subsection{Model Details}

The next three sections outline the base model that was used for the validation studies as well as for the long term simulations presented in the later chapters.

\subsubsection{Residential Building Load Model}

To begin the validation process, a research team member's residential house was selected due to the availability of detailed building plans and the possibility of comparing the actual cooling and heating costs to the calculated costs. The house, shown in Figure 5.8, is a 2100 sq. ft., single-story (second story dormers are decorative only), single family dwelling. The house was assumed to be located in Austin, Texas. The house has a significant amount of shading over the windows due to warp-around porch on front side of the house which also runs along a portion of the back. During the modeling process some simplifying assumptions were made. It was assumed that the roof did not have gables or the dormers that are on the original house. These changes are represented in Figure 5.9, which is a graphical rendering of the modeled house in eQuest. It was also assumed that the roof was a traditional, asphalt single roof instead of metal. The exterior walls are covered with Austin stone and Hardy Board (a concrete based siding material), but to reduce the number of 


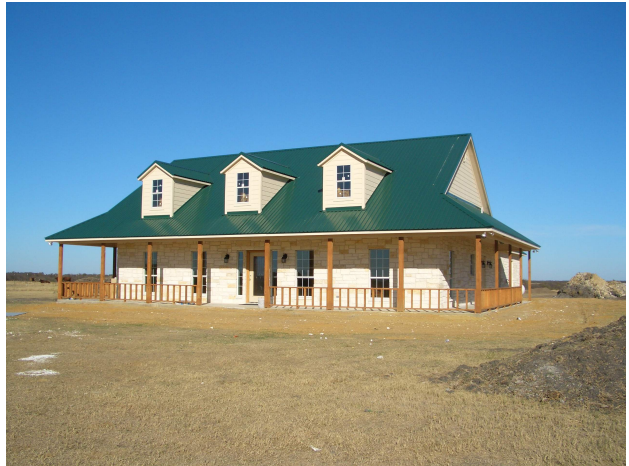

(a) Front view

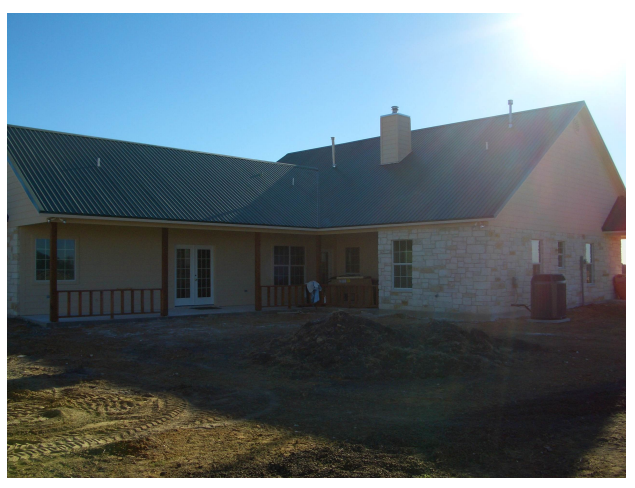

(b) Back view

Figure 5.8: Images of the modeled house

defined materials and allow for easier parameter studies the external walls were all assumed to be constructed of a single material. For the base case this was chosen as $4 \mathrm{in}$ brick. The house was modeled with a single interior zone, with a single heat pump that is controlled by a single thermostat. A breakdown of the building material envelope is given in Table 5.1. The final design included four different envelope constructions, the Exterior Walls, Roof, Ceiling, and Foundation. The Exterior Walls are green in Figure 5.9 and the Roof is purple. Each of these constructions are made up of individual materials as shown in Table 5.1. For example, the External Wall is constructed out of four different materials with define thicknesses and material properties plus two convection resistance values for the internal and external surfaces of the wall. All material properties used in the model were taken from eQuest/DOE2.2, which provides a large database of material properties that made it easy to look up properties for specific materials [Law, 2004]. 


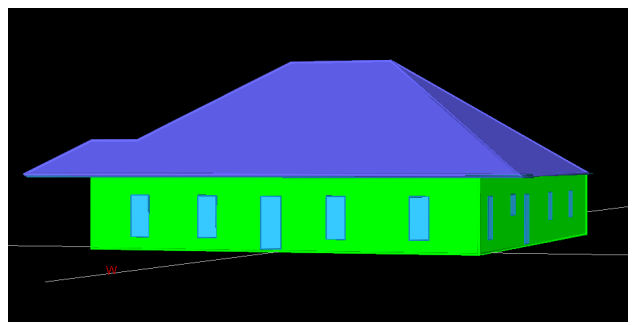

(a) Front view

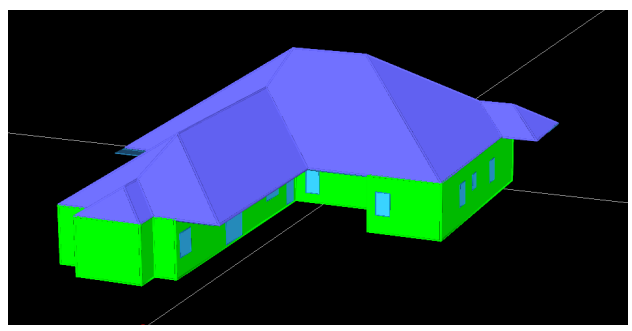

(b) Back view

Figure 5.9: eQuest rendering of the house 


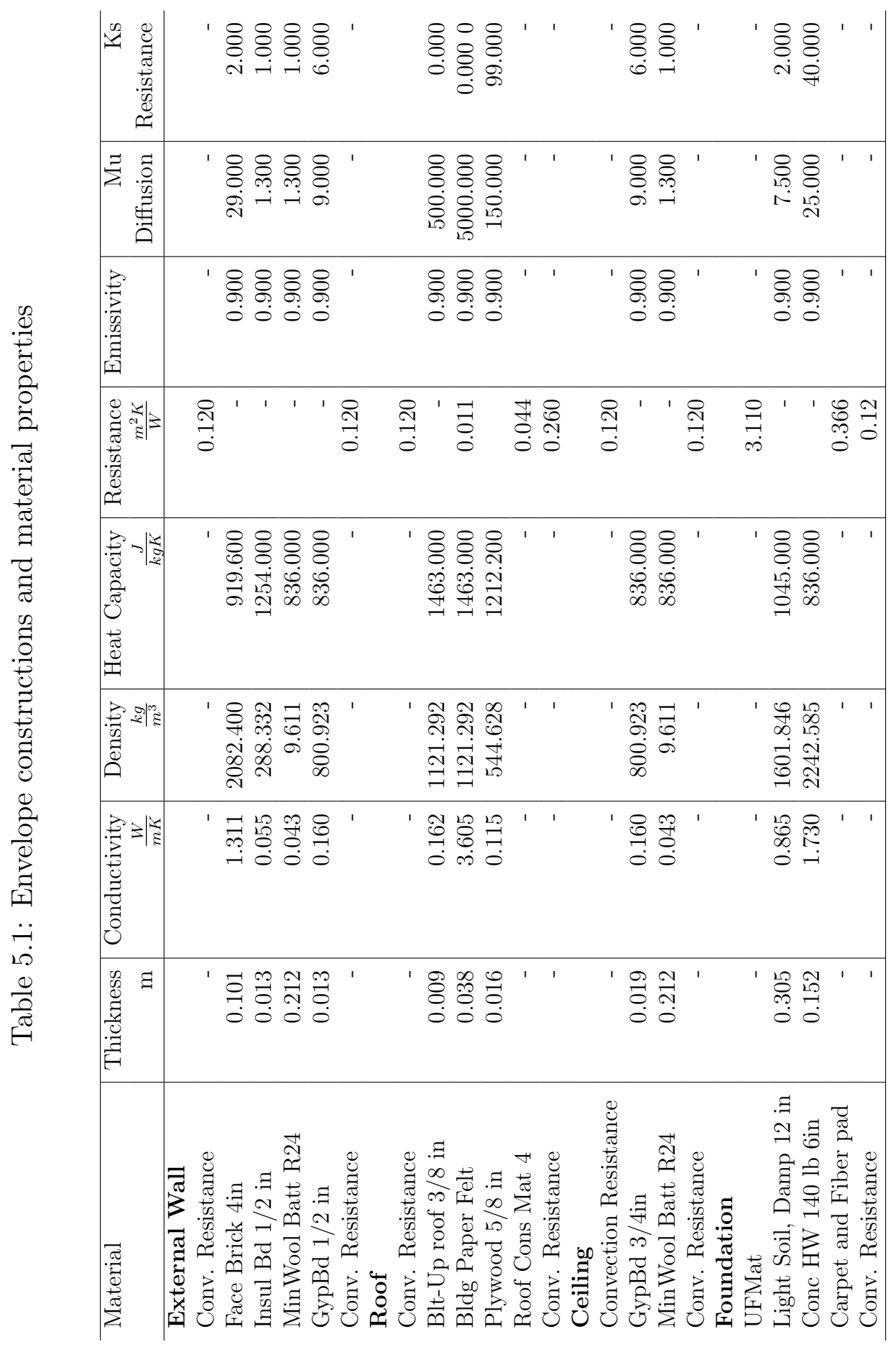


The model has two types of glazing; low-e, double-paned glazing for the 20 windows and regular double-paned glazing for the four doors that have built-in windows. As a simplifying assumption the windows were assumed to be uncovered, with no blinds or solar screens. The window properties are listed in Table 5.2. The building has a total of $24.5 \mathrm{~m}^{2}$ of glazing including both the windows and the doors. Each window that has shading over the window on the actual house also has the shading modeled using various rectangular prisms.

Table 5.2: Glazing properties used in HAMBASE model

\begin{tabular}{lrrrrr}
\hline Type & eQuest ID & Gap Thickness (in) & Gap Fill & U-Value & SHGC \\
\hline Double Clear & 2000 & 0.25 & Air & 0.68 & 0.76 \\
Double Low-E Clear & 2610 & 0.25 & Air & 0.60 & 0.72 \\
\hline
\end{tabular}

The building load model includes the internal loads that are typically found in a house. The internal loads are specified by determining a maximum value for each type of load: occupancy, lighting and equipment, and then using a schedule of scaling factors to determine the hourly building load for each hour of the day. Figure 5.10 shows the hourly internal sensible load broken down into each component of the load. The loads where compiled from a variety of sources. The per person occupancy load is $245 \mathrm{~W} /$ person sensible and $155 \mathrm{~W} /$ person latent, which was taken from eQuest [Law, 2004]. ASHRAE defines the number of occupants as the number of bedrooms plus one, which give four total occupants for the modeled house [ASH, 2009]. The lighting 
loads were taken from the Energy Plus Reference Building Models, and in particular the lighting load for the mid-rise apartments was used, which is $3.87 \mathrm{~W} / \mathrm{m}^{2}$ [Michael Deru et al., 2011]. The equipment load was also based on the data given by the Energy Plus Reference Building Models, which specifies $5.4 \mathrm{~W} / \mathrm{m}^{2}$. This load was scaled down based on occupancy density. The Reference Buildings specifies a density of $35.30 \mathrm{~m}^{2} /$ person for the apartment while ASHRAE's values for the house is $49.3 \mathrm{~m}^{2} /$ person. The ratio of these values was used to scale down the equipment load to $3.86 \mathrm{~W} / \mathrm{m}^{2}$ [ASH, 2009, Michael Deru et al., 2011].

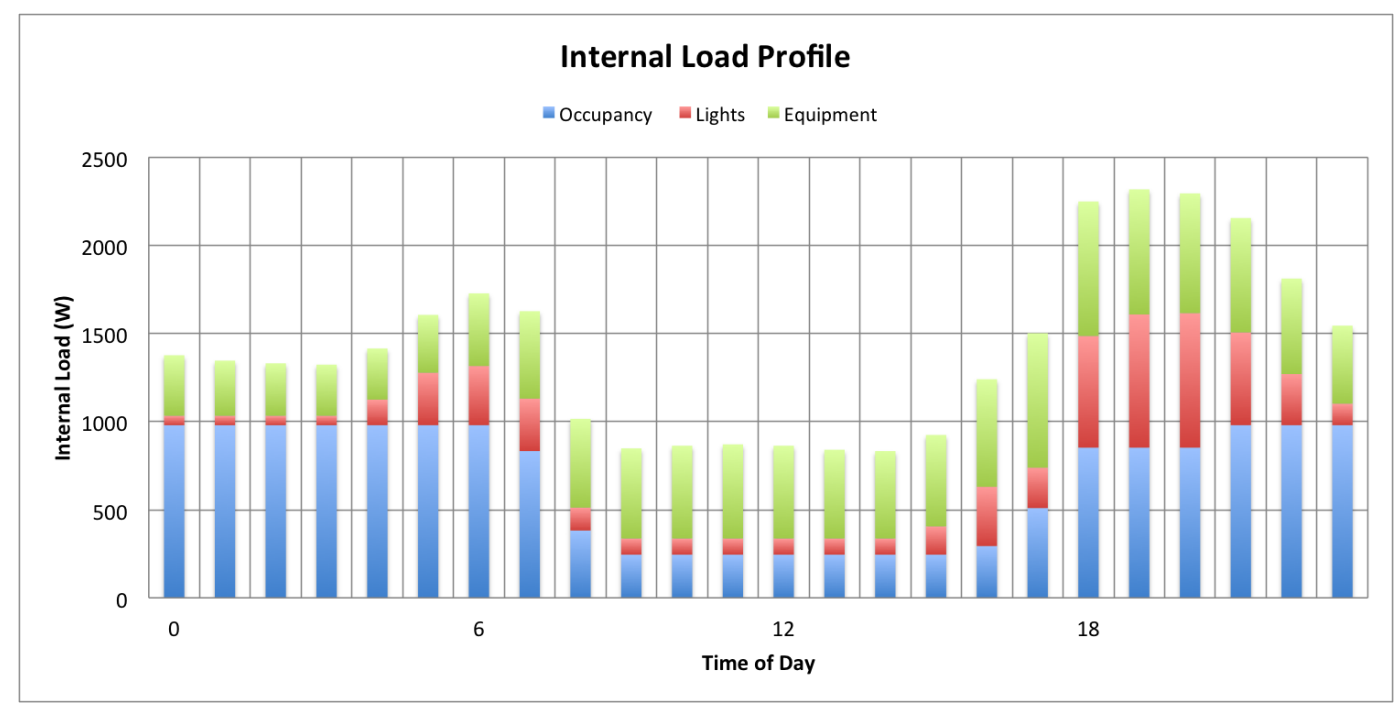

Figure 5.10: Internal load profiles

The hourly schedule was taken from the Energy Plus Reference Building Models for the mid-rise apartment building. The schedule defines a multiplier for each type of load, for each hour of the day. This scales down the base values listed earlier to represent the hourly occupancy, lighting and equipment 
loads. For example, the full occupant load was determined to be $980 \mathrm{~W}$ for four people, which is assumed to be the load after 9 p.m. (21:00) and before 7 a.m. This is indicated by the constant loads for the occupancy loads during this time frame in Figure 5.10. After 7 a.m., the load decreases to $25 \%$ of the full occupancy load to represent occupants leaving the house for the day. At 4 p.m. (16:00) the occupancy loads begin to increase back to the full load as occupants begin to arrive home for the evening. The lighting and equipment loads are also scaled in an similar manner [Michael Deru et al., 2011].

The infiltration rate is set at $0.5 \mathrm{ACH}$ (Air Changes per Hour) for both zones which was determined from ASHRAE's values for a tight house [ASH, 2009]. The house does not include any forced ventilation in either the attic zone or the main floor. The air flow between the zones was assumed to be zero as well.

\subsubsection{Ground Source Heat Pump}

The ground source heat pump parameters consist of the parameters defining the water-source heat pump operation and the ground loop operation. The water-source heat pump model parameters that needed to be specified were the type and size of heat pump to be used as well as the air and water flow rates and temperature set points. The heat pumps from ClimateMaster, Inc., the largest GSHP manufacturer in the U.S., were used for all simulations. In particular, the Tranquility 20 series of single stage heat pumps with single speed fans were used. This unit was chosen as the test base case so that two- 
stage heat pumps and variable speed fans could be simulated later to assess improvements to heat pump performance [ClimateMaster, 2010].

To determine the proper sized heat pump, a series of trials where conducted. For each trial the model was outfitted with a different capacity heat pump and simulated for a single year. To determine which heat pump was the proper size the number of hours that the average building temperature was above or below the set point temperatures were compared. The capacity of the heat pump was increased until the these values did not decrease anymore. This method was used because changing the capacity of the heat pump was affecting the peak loads that would have otherwise been used to size the heat pump. Based on this approach, the TS 048 heat pump was chosen. The unit features a peak cooling capacity of 14,625 W(49,900 Btu/h) and peak heating capacity of $11,430 W(39,000 \mathrm{Btu} / \mathrm{h})$ with an energy efficiency rating of 5.2 $W / W(17.6 \mathrm{Btu} / W)$ for cooling and a COP of 3.7. The set points where set at $21^{\circ} \mathrm{C}$ and $25^{\circ} \mathrm{C}$ with a $1^{\circ} \mathrm{C}$ deadband. These values were taken from the eQuest default set points. The water flow and air flow rates were assumed to be the maximum rated values for the heat pump unit. For the TS 048 unit these values are $0.75 \mathrm{~L} / \mathrm{s}(12 \mathrm{GPM})$ and $0.76 \mathrm{~m}^{3} / \mathrm{s}(1600 \mathrm{CFM})$, respectively.

The ground parameters used were taken from a couple of different sources. A map of the Texas ground temperatures are shown in Figure 5.11. The temperatures shown are for depths greater than $9.1 \mathrm{~m}(30 \mathrm{ft})$. Based on the maps an undisturbed ground temperature of $21.7^{\circ} \mathrm{C}\left(71^{\circ} \mathrm{F}\right)$ was chosen and bulk ground conductivity was chosen as $0.3895 \mathrm{~W} / \mathrm{m} / \mathrm{K}\left(0.77 \mathrm{Btu} \mathrm{ft} / \mathrm{hr} / \mathrm{ft}^{2} /{ }^{\circ} \mathrm{F}\right)$ 
[American Society of Petroleum Geologists, 1974]. The density of the bulk ground for Austin was chosen to be $2475 \mathrm{~kg} / \mathrm{m}^{3}$ (155 lb/ $\mathrm{ft}^{3}$ ) [O'Neal et al., 1994]. The model assumes that the borehole is $127 \mathrm{~mm}$ ( 5 inches) in diameter

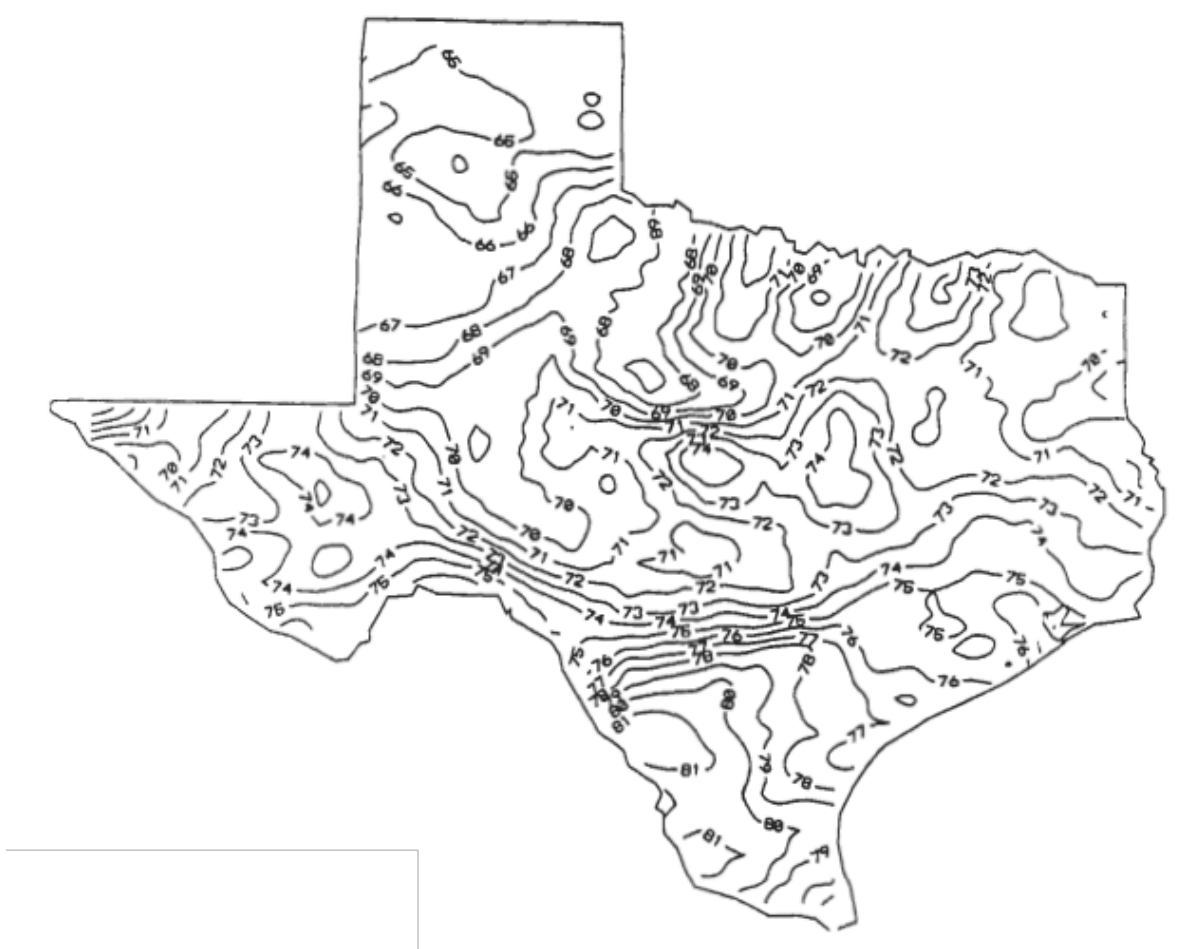

Figure 5.11: Undisturbed ground temperatures $\left({ }^{\circ} F\right)$ at depths greater than $9.1 \mathrm{~m}(30 \mathrm{ft})$ [American Society of Petroleum Geologists, 1974]

with SDR-11 tubing with a nominal diameter of $25 \mathrm{~mm}(1 \mathrm{in})$. The model assumed that regular (as opposed to thermally enhanced) bentonite grout was used to fill the borehole. The boreholes were arranged in a $1 \times 4$ line spaced $4.6 m(15 \mathrm{ft})$ apart. Based on the ground parameters, building load, and chosen heat pump, GLHEPRO sized the ground loops to be $68.5 \mathrm{~m}(225 \mathrm{ft})$. All the input values are available in Table C.1 in Appendix C. The building 


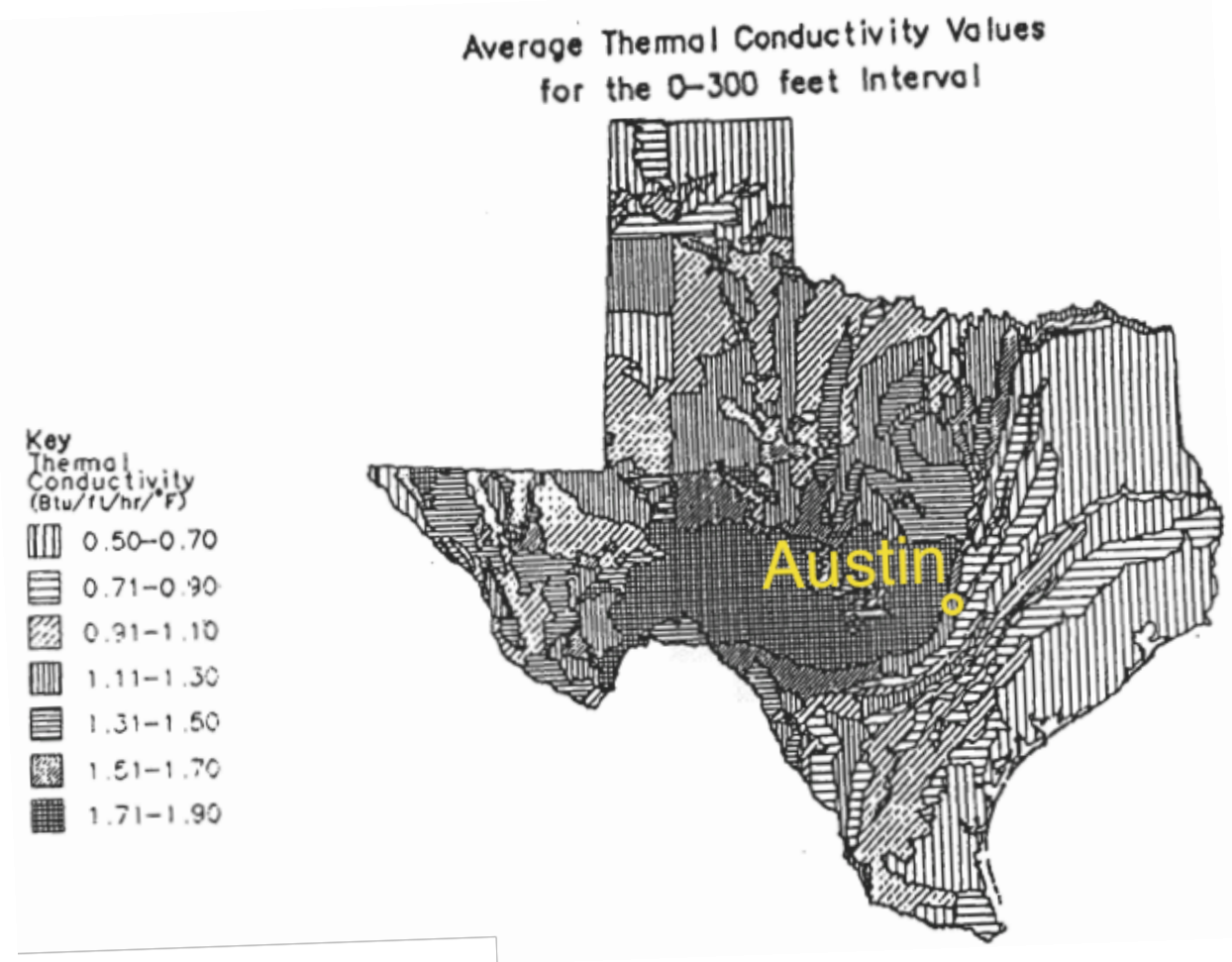

Figure 5.12: Average ground conductivity from 0-300 ft [American Society of Petroleum Geologists, 1974]

loads used to size the heat pump are shown in Table 5.3.

\subsection{Model Validation}

In addition to the validation of the HAMBASE building model presented in Chapter 2 the integrated building load-GSHP model needed to be validated. The validation of the integrated model consisted of using two additional simulation programs. First, eQuest was used to validate the building loads that were calculated by the HAMBASE model. Additionally the 
Table 5.3: Building loads used to size ground loop using GLHEPRO

\begin{tabular}{lrrrr}
\hline Month & $\begin{array}{r}\text { Heating Total } \\
\mathrm{kWh}\end{array}$ & $\begin{array}{r}\text { Cooling Total } \\
\mathrm{kWh}\end{array}$ & $\begin{array}{r}\text { Heating Peak } \\
\mathrm{kW}\end{array}$ & $\begin{array}{r}\text { Cooling Peak } \\
\mathrm{kW}\end{array}$ \\
\hline Jan & 1743.79 & 24.33 & 10.37 & 2.29 \\
Feb & 1012.57 & 91.79 & 5.24 & 3.20 \\
Mar & 416.03 & 655.39 & 5.02 & 4.57 \\
Apr & 0.00 & 1601.99 & 0.00 & 5.70 \\
May & 0.00 & 2750.56 & 0.00 & 7.75 \\
Jun & 0.00 & 3708.09 & 0.00 & 8.39 \\
Jul & 0.00 & 4362.54 & 0.00 & 8.63 \\
Aug & 0.00 & 4266.12 & 0.00 & 8.43 \\
Sep & 0.00 & 2793.82 & 0.00 & 7.11 \\
Oct & 0.00 & 1545.87 & 0.00 & 6.10 \\
Nov & 247.57 & 470.52 & 3.02 & 4.48 \\
Dec & 1455.74 & 22.74 & 6.12 & 3.01 \\
\hline
\end{tabular}

total heat rejected into the ground was compared between eQuest and the Simulink ${ }^{\circledR}$ model. Then, GLHEPRO was used to verify the heat pump-ground loop model combination.

\subsubsection{Building Load Model Validation}

The building load portion of the Simulink ${ }^{\circledR}$ model was validated by comparing the results of annual heating and cooling values to the results from eQuest. The validation criteria was taken from the ASHRAE 140-2007 model validation that was completed for the HAMBASE building model. The annual total loads reported by the 140-2007 standard for the six reference models for Case 600 vary from each other as much as $28 \%$ and $54 \%$ for Case 900 (see 
Chapter 2 for more information). Table 5.4 showa the range of the reported values from the eight reference models for the annual heating and cooling for both cases 600 and 900. Based on these values the the criteria for agreement was set to be less that $25 \%$. An eQuest building model of the residential model Table 5.4: Range of the reported values for annual building loads for ASHRAE 140-2007, cases 600 and 900

\begin{tabular}{llrrr}
\hline Case & & $\begin{array}{r}\text { Minimum } \\
\text { MWh }\end{array}$ & $\begin{array}{r}\text { Maximum } \\
\text { MWh }\end{array}$ & Difference \\
\hline \multirow{2}{*}{600} & Cooling & 6.137 & 7.964 & $25.91 \%$ \\
& Heating & 4.296 & 5.709 & $28.25 \%$ \\
900 & Cooling & 2.132 & 3.415 & $46.26 \%$ \\
& Heating & 1.170 & 2.041 & $54.25 \%$ \\
\hline
\end{tabular}

presented in Section 5.2.1 was created to provide a comparison for validation. The eQuest building creation wizard suggested values for the internal loads based on occupancy and typical equipment and lighting loads. The loads were given assuming seven occupants, with $5.4 \mathrm{~W} / \mathrm{m}^{2}$ for both lighting and equipment loads. This gave a total of $3839 \mathrm{~W}$ of sensible load and $1085 \mathrm{~W}$ of latent loads, which were assumed to be on at all times. The validation was performed using these loads as well as a case with no internal loads. These two tests were done to give a range of internal load values at which the model had been validated, which allow for sensitivity studies regarding the magnitude and schedule of the internal loads to be completed.

Table 5.5 shows the annual and monthly cooling and heating loads for both eQuest and the integrated Simulink ${ }^{\circledR}$ model. The total yearly cooling 
Table 5.5: Comparison between Simulink ${ }^{\circledR}$ model and eQuest building load results

\begin{tabular}{lrrrr}
\hline & eQuest & Simulink ${ }^{\circledR}$ & Difference & $\%$ Difference \\
\hline Full eQuest Internal Loads & & & \\
Total Cooling (kBtu) & 131801.02 & 127553.16 & -4247.86 & $-3.2 \%$ \\
Total Heating (kBtu) & 0.19 & 4644.79 & 4644.61 & $2508436.3 \%$ \\
\hline No Internal Loads & & & & \\
Total Cooling (kBtu) & 62892.85 & 50190.02 & -12702.83 & $-20.2 \%$ \\
Total Heating (kBtu) & 761.88 & 27163.32 & 26401.43 & $3465.3 \%$ \\
\hline
\end{tabular}

values have good agreement between the models for both the full eQuest internal loads and the no load case with $3.2 \%$ and $20.2 \%$ differences, respectively. The total heating values have large differences relative to each other because eQuest predicts a very small amount of heating for both cases. For the full load case eQuest predicts a negligible amount of heating while the Simulink ${ }^{\circledR}$ model predicts $4644 \mathrm{kBtu}$ of heating. Even though the percent difference for the full load annual heating values is large, these total heating values are still very small $(\approx 3 \%)$ compared to the total amount of cooling provided. For the no load case the Simulink ${ }^{\circledR}$ model predicts $27163 \mathrm{kBtu}$ of heating while eQuest predicts $762 \mathrm{kBtu}$.

The total monthly cooling load values for the full internal load case, shown in Appendix B, Table B.1, have an differences as high as $39.9 \%$ for the months without any heating in the Simulink ${ }^{\circledR}$ model. The no load case shown in Table B.2 has a high value of $19.5 \%$ for month without any heating. For both cases, the total monthly cooling loads in the months with heating (months 
that have both heating and cooling) have significant differences. Simulink ${ }^{\circledR}$ predicts no cooling for the no load case in January and December, while eQuest predicts some cooling. The full internal load case has differences as high as $81 \%$ for the total monthly cooling values.

For the purpose of studying ground heating the total yearly heat that is rejected/extracted to/from the ground is important over the life cycle of the GSHP system. Tables B.3 and B.4 show the yearly and monthly heat rejection and extraction values for both eQuest and Simulink ${ }^{\circledR}$. For the full internal load case the Simulink ${ }^{\circledR}$ model predicts 7.7\% (168 MBtu vs 156 MBtu) more heat rejected into the ground during the year than the eQuest model. The Simulink ${ }^{\circledR}$ model also predicts 41\% (43 MBtu vs $74 \mathrm{MBtu}$ ) less heat rejected for the no internal load case. This large difference is caused by the discrepancies between the yearly heating values for the no internal load case.

The validation of the model using eQuest shows that there is good agreement in the total yearly cooling values for both internal load cases. For the total yearly heating values there is not good agreement, due to the Simulink ${ }^{\circledR}$ model predicting significantly more heating load for both cases. Intuition and past experiences could lead one to question the very low total yearly heating results from eQuest, but irregardless, the higher heating values from the Simulink ${ }^{\circledR}$ model reduce the total annual heat rejected in the ground. This is shown by the difference between the total yearly heat rejected values for the no internal load case. Any long term ground heating issues that show up in the Simulink ${ }^{\circledR}$ model would be significantly worse if the building 
load values for the eQuest model where used. Therefore, for long term ground heating the Simulink ${ }^{\circledR}$ model results are the more conservative values. Based on this and the other results presented in this section the building load models agree within reason.

\subsubsection{Ground Loop Validation}

To validate the combination of the ground loop model and the heat pump model the monthly heat rejection values and loop ground temperatures from the Simulink ${ }^{\circledR}$ model were compared to results calculated by GLHEPRO. For the purposes of the validation the borehole was assumed to be $91.4 \mathrm{~m}$ (300 ft) with all other ground loop parameters the same as the discussed in Section 5.2.1. For the validation the two internal load values from the eQuest comparison were used. For the GLHEPRO simulation the monthly building cooling and heating loads are needed as well as the monthly peak heating and cooling loads. These loads were taken from the building load values calculated by the Simulink ${ }^{\circledR}$ model. GLHEPRO also requires information about the type of heat pump that is being used to calculate the heat rejected/extracted to/from the borehole based on the building loads. This was accomplished by using the same set of manufacturer data that was used to create the performance map model presented in Chapter 3.

For the comparison only a single year was simulated. The ground loop that was used $(91.4 \mathrm{~m}, 300 \mathrm{ft})$ was shorter than a properly sized borehole would be for the full internal load case. This was done to increase the magni- 
tude of the short term (less than a year) temperature response of the borehole. For simulations longer than a year the increased temperatures would cause the building load in the Simulink ${ }^{\circledR}$ model to change due to the full coupling of the Simulink ${ }^{\circledR}$ model. GLHEPRO does not have the ability to model the change in the building load over the length of the simulation. Therefore the comparison between the model is only valid for the first year. The actual data values and differences for the ground loop validation are presented in Tables B.5 and B.6, which are in Appendix B.

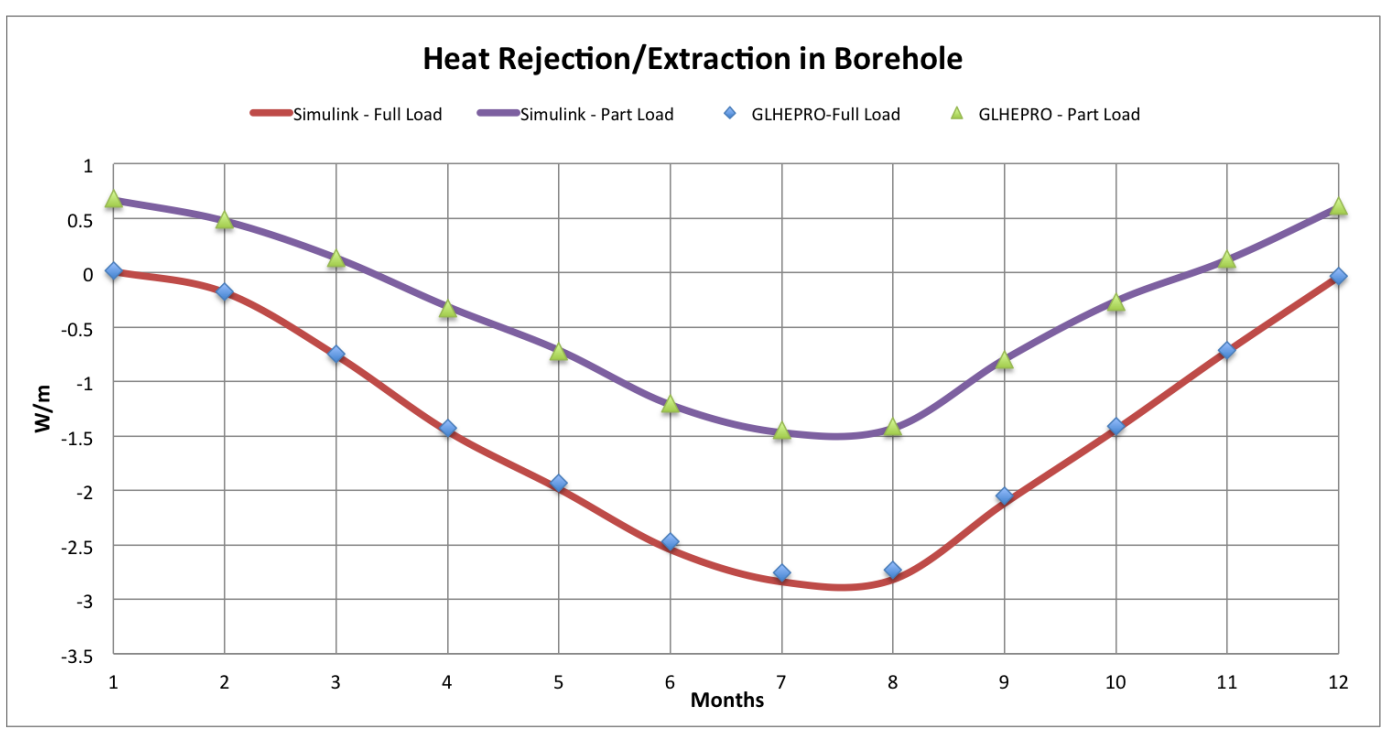

Figure 5.13: Monthly average heat rejected/extracted in the borehole, comparison between GLHEPRO and Simulink ${ }^{\circledR}$ ground loop models - Jan. to Dec., data can be found in Tables B.5 and B.6

Figure 5.13 shows the heat rejected into the ground for both internal load cases. GLHEPRO, represented by the diamonds and triangles, agrees very well with the values calculated in Simulink ${ }^{\circledR}$, represented by the lines. 
This agreement shows that based on the same building loads the heat pump performance map model is calculating the proper temperature rise across the heat pump and that the loop water temperatures entering the ground are being averaged properly across the time step transition discussed in Section 5.1.3.

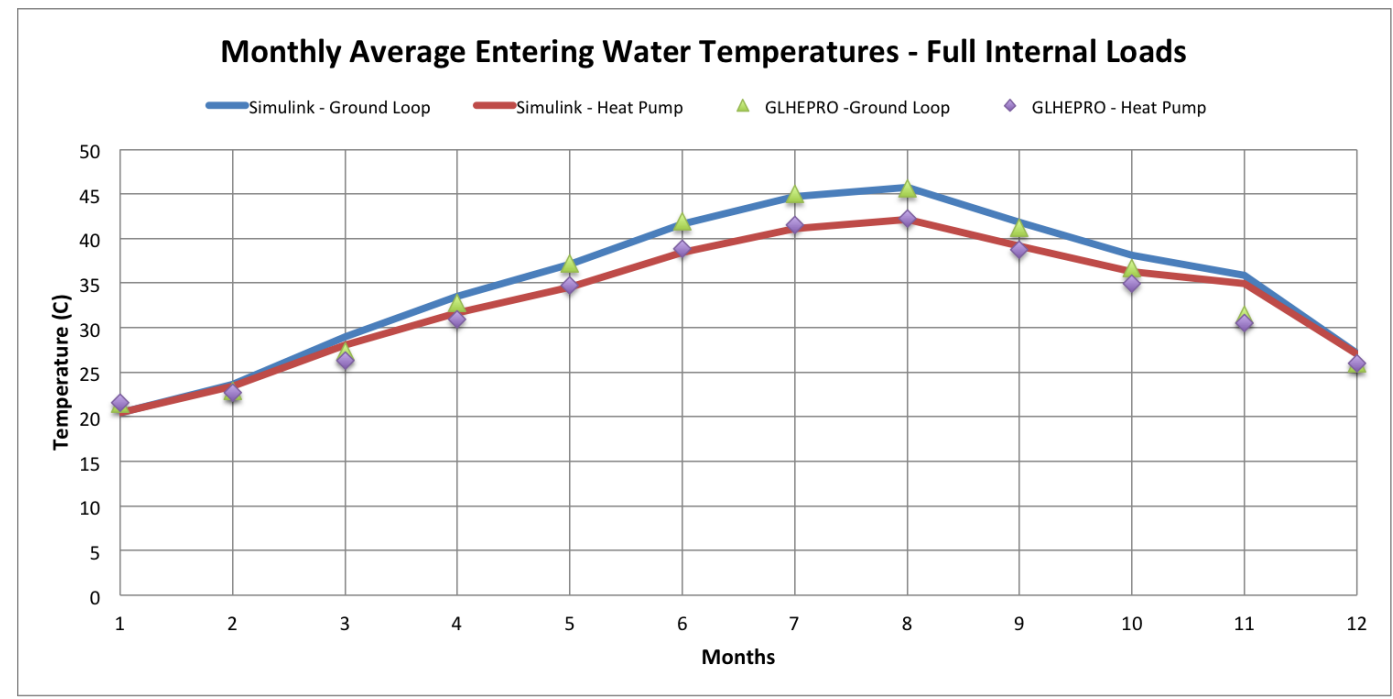

Figure 5.14: Monthly average water temperatures entering the borehole and heat pump, comparison between GLHEPRO and Simulink ${ }^{\circledR}$ ground loop models,- Jan. to Dec.- full internal load, data can be found in Tables B.5 and B.6

Figure 5.14 shows the monthly average water temperatures at the entrance of the ground loop and of the heat pump for full internal loads. Figure 5.15 shows the same temperatures but with no internal loads. Both figures show good agreement between the values generated by GLHEPRO and the Simulink ${ }^{\circledR}$ model with the only significant difference occurring in the spring and fall when the building has lower total building loads which cause the heat pump to operate less. The difference could be a result of assumptions about 


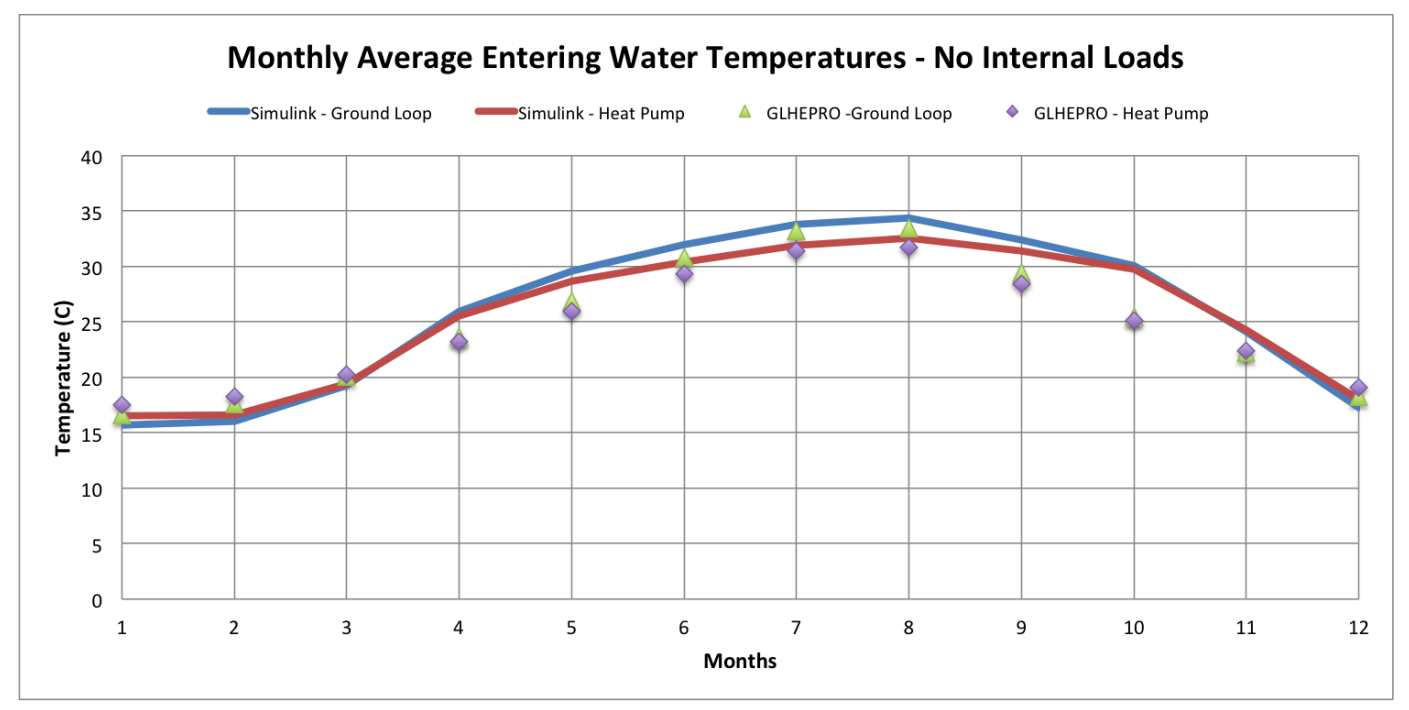

Figure 5.15: Monthly average water temperatures entering the borehole and heat pump, comparison between GLHEPRO and Simulink ${ }^{\circledR}$ ground loop models,- Jan. to Dec.- no internal load, data can be found in Tables B.5 and B.6

the temperatures or ground loop flow rates when the heat pump is not running. For example, the Simulink ${ }^{\circledR}$ model assumes that the outlet temperature is the the average borehole temperature whenever there is no flow through the ground loop. If GLHEPRO assumes a different value when the heat pump is not running, then the average monthly values would be different for months with significant amounts of time when the heat pump is not running. Table 5.6 shows the yearly maximum and minimum heat pump entering water temperatures for both the full and no internal load cases. The Simulink ${ }^{\circledR}$ model is predicting maximum temperatures for both loading cases within $2 \%(<0.6$ ${ }^{\circ} C$ ) of the values predicted by GLHEPRO. The minimum values that are calculated by the model do not agree as well as the maximum values, but show 
Table 5.6: Comparison of maximum and minimum entering water temperatures to the heat pump

\begin{tabular}{lrrrrrr}
\hline & \multicolumn{3}{c}{ Maximum } & & \multicolumn{2}{c}{ Minimum } \\
& Glhepro & Simulink $^{\circledR}$ & Diff & Glhepro & Simulink \\
& $\mathrm{C}$ & $\mathrm{C}$ & $\%$ & $\mathrm{C}$ & $\mathrm{C}$ & Diff \\
\hline Full Load & 43.98 & 44.54 & $-1.3 \%$ & 17.94 & 15.34 & $14.5 \%$ \\
No Load & 33.46 & 34.08 & $-1.9 \%$ & 14.22 & 12.93 & $9.1 \%$ \\
\hline
\end{tabular}

good agreement.

Based on the comparison of the heat rejected by the Simulink ${ }^{\circledR}$ ground loop model and GLHEPRO, it can be concluded that the heat pump model is correctly calculating the temperature responses across the heat pump. This also indicates that the time step transition that occurs between the heat pump and the ground loop (30 second versus 5 minute time steps) is being performed correctly. The temperature responses shown indicated that the ground loop is properly calculating the temperature rise of the ground loop water when the heat pump unit is operating. For the months with less cooling and heat loads there are slight differences between the two models, but this can be attributed to differences in the assumptions about the loop temperatures and flow rates when the heat pump is not operating.

\subsubsection{Validation Conclusions}

In the previous sections, it was shown that the Simulink ${ }^{\circledR}$ building load model gives results that are in good agreement with a widely used build 
load modeling program (eQuest). The results of the building load comparison show that when considering the net effect of the building loads on long term ground heating the integrated model gives conservative results. The validation of the Simulink ${ }^{\circledR}$ heat pump-ground loop model using GLHEPRO showed results that indicated that both the performance map heat pump model and the ground loop model are correctly calculating the temperature change of the water in the ground loop. These validation results indicate that the integrated model is sufficiently accurate to model the long term performance of ground source heat pumps for residential applications. 


\section{Chapter 6}

\section{Base Model Results}

This chapter presents the simulation results for the base model de-

scribed in Chapter 5. The majority of the analysis presented is based on hourly averages of the output data. Hourly averages are used so that the results can be compared to other building load models, such as eQuest and Energy Plus. The chapter is divided up into four parts, each presenting the results at different time resolutions.

\subsection{Time Step Results}

This section presents model results at the model time step (30 second) level. These results highlight the truly dynamic nature of the integrated building load-GSHP model. All results presented in this section are from 12:00 to 15:00 (noon - 3:00 p.m.) on June $30^{\text {th }}$ during the first year of operation. These results show the model during the cooling mode of operation, but similar results could be shown for times of the year when heating is required.

Figure 6.1 shows the building air and radiant wall temperatures for both zones of the building model. In this and all subsequent figures, zone 1 is the conditioned living space and zone 2 is the unconditioned attic. For the 
times shown in the figures the building requires periodic cooling to keep the temperature below the set point temperature, so the zone 1 air temperature (solid blue line) oscillates. The zone 1 radiant wall temperature (blue dashed line) also oscillates due to the provided cooling. The zone 2 temperatures (red lines) are significantly higher than the zone 1 temperatures since zone 2 is unconditioned. The jumps in the zone 2 wall temperature are due to changes in the weather. The weather files contain data for every hour and the model assumes that the data is constant for each hour. Figure 6.2 shows the thermostat response due to the zone 1 air temperatures. The cooling limits shown (red and green dashed lines) represent the combination of the thermostat cooling set point of $25^{\circ} \mathrm{C}\left(77^{\circ} \mathrm{F}\right)$ and included deadband of $1^{\circ} \mathrm{C}\left(1.8^{\circ} \mathrm{F}\right)$. When the air temperature increases past the set point the thermostat cooling signal changes to "1" (solid green line), which starts the heat pump. Once the temperature reaches the $24^{\circ} \mathrm{C}\left(75.2^{\circ} \mathrm{F}\right)$, which is set point temperature minus the deadband, the thermostat cooling signal changes to " 0 " to shut the heat pump off. The air temperature does go above and below the range defined by the set point and deadband because of the fixed time step solver that was used. With smaller/larger time steps this deviation would decrease/increase.

Figure 6.3 shows the relative humidity in both building model zones. The relative humidity in zone 1 is oscillates due to the changes in the air temperature as well as the condensation of water from the air caused by the heat pump. The calculated relative humidity could be used to control the dehumidification capabilities of a multi-stage heat pump system. Figure 6.4 


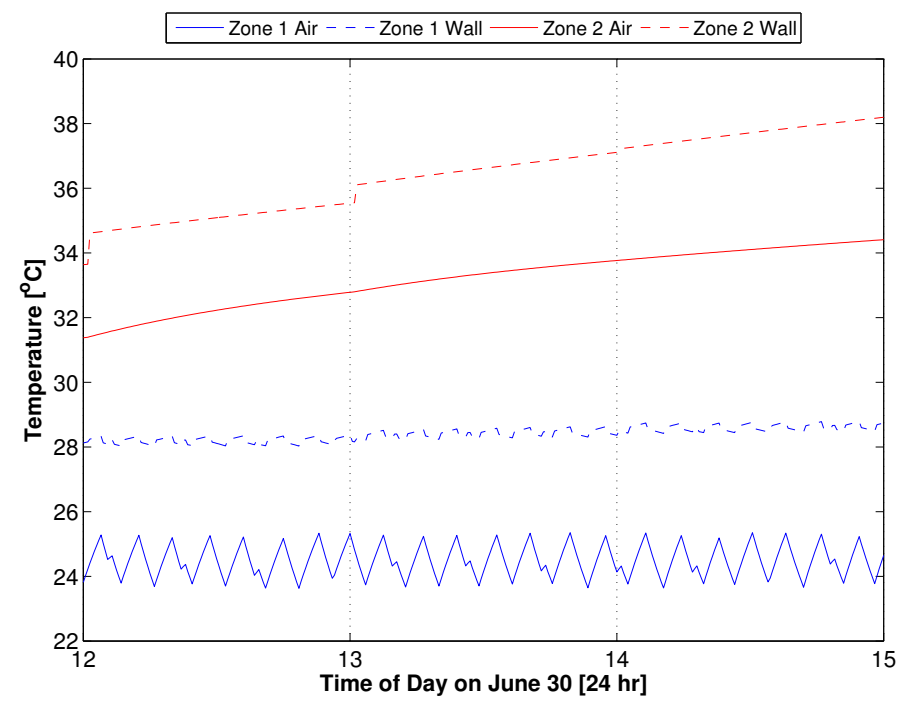

Figure 6.1: Building air and wall temperatures by zone for June 30, 12:00-15:00

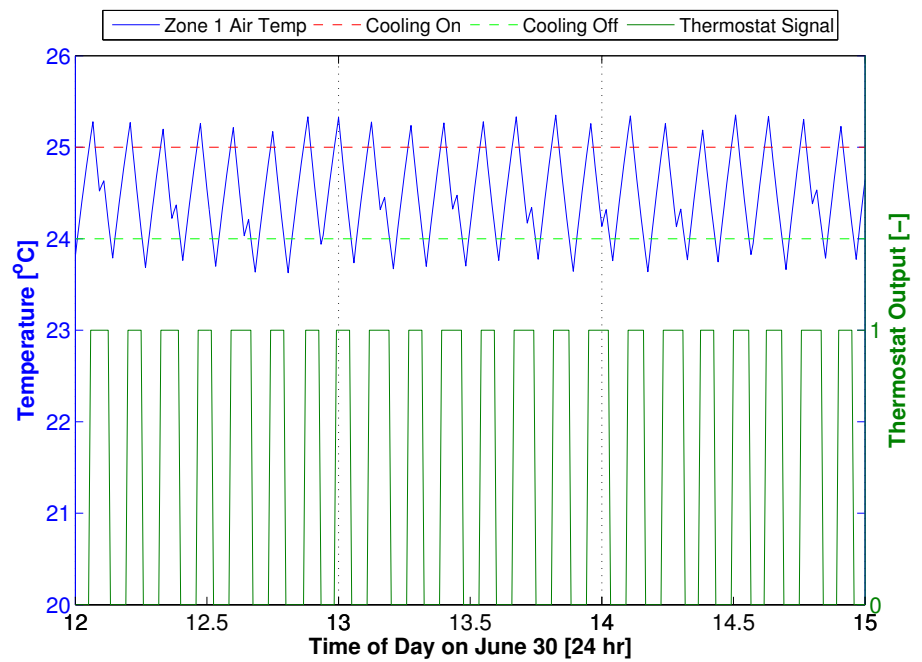

Figure 6.2: Zone 1 air temperature, thermostat limits, and thermostat response for June 30, 12:00-15:00 


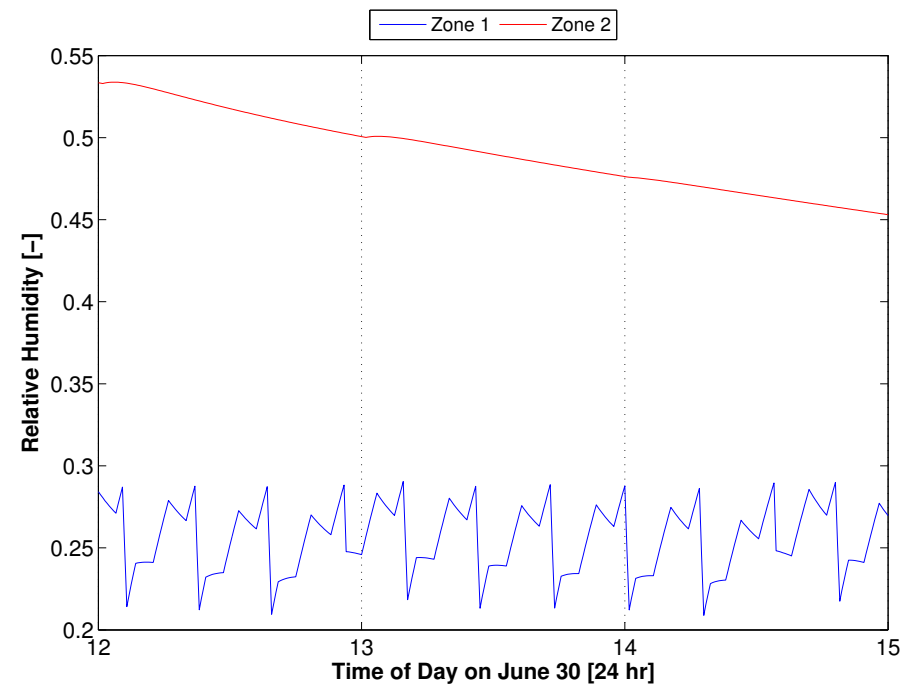

Figure 6.3: Building air relative humidity by zone for June 30, 12:00-15:00

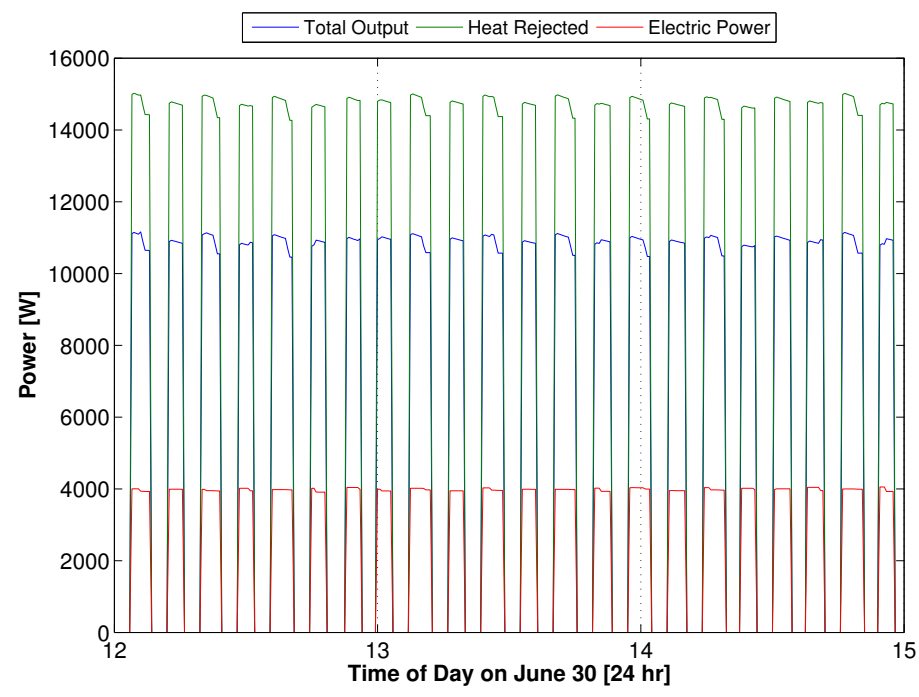

Figure 6.4: Heat extracted from the conditioned space, heat rejected to the ground loop water, and electricity used by the heat pump for June 30, 12:0015:00 
shows the conditioning provided to the building (blue line), the heat rejected to the ground loop water (green line), and the electric power needed for operation (red line). The heat pump model output varies while the unit is operating due to changes in the air temperature, relative humidity, and ground loop water temperature. These variations also affect the heat rejected and the electric power required. The sum of the conditioning provided and the electrical power consumed is approximately equal to total amount of heat rejected into the ground loop water.

Figure 6.5 shows the ground loop water temperatures at the entrance (EWT) of the heat pump (blue line) and the entrance of the ground loop (green line). The heat pump entrance temperature, which is used for the 30 second time steps, jumps when the output temperature of the ground loop model is updated, which occurs every five minutes. The heat pump entrance temperature has a great effect on the output and efficiency of the unit. On this short time scale it is not evident, but for longer time scales (on the order of months/years) this effect becomes more pronounced. The ground loop entrance temperature changes as the heat pump is switched on and off. When the heat pump is off no heat is rejected to the water by the heat pump so both temperatures are the same. During cooling the heat pump is rejecting heat to the water causing the water temperature to rise. 


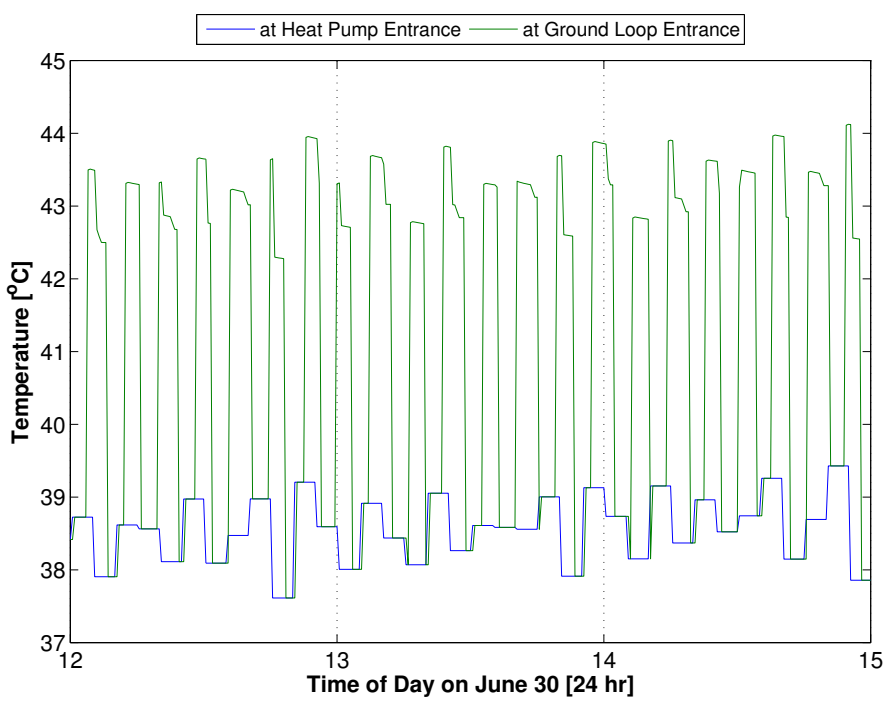

Figure 6.5: Ground loop water temperatures at the entrance to the heat pump and ground loop

\subsection{Hourly Results}

The majority of the results and analysis presented are based on hourly averages of the model outputs. The primary reason why hourly averages are used is so that results and analysis from this model can be directly compared to results calculated by common building load models, such as eQuest and Energy Plus, which typically report hourly values. In addition, the data files that contain the results based on the 30 second time steps are approximately 78 MB per year simulated. For a 15 year simulation 1.15 GB of data is generated. Using the hourly averaged data brings this down to $1.4 \mathrm{MB}$ per year simulated or $21 \mathrm{MB}$ for a 15 year simulation.

The results presented in this section are based on hourly averages of 


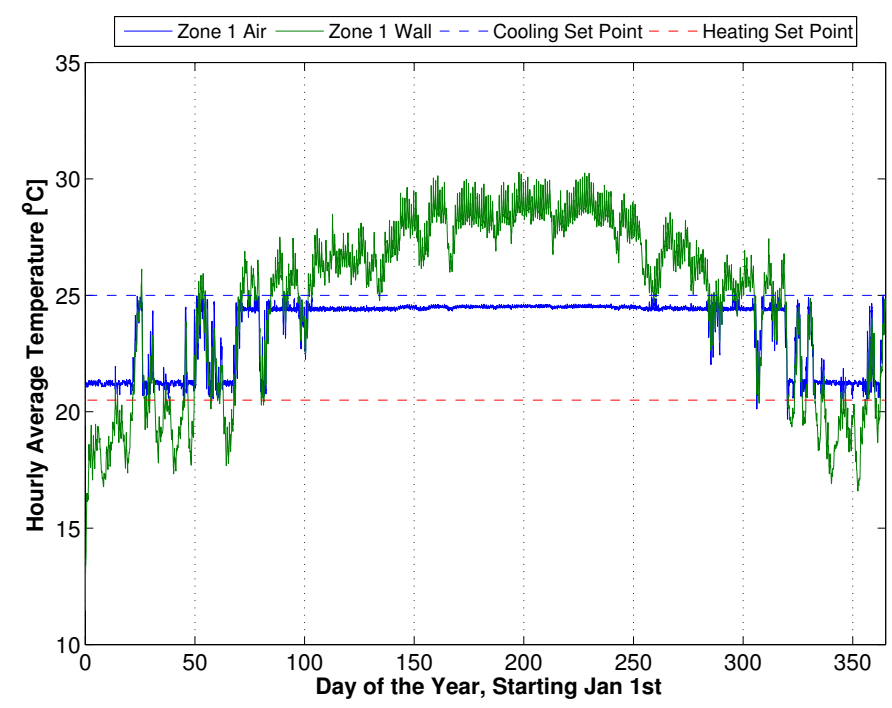

Figure 6.6: Hourly mean values of conditioned zone 1 temperatures and thermostat set points for the first year of simulation, Jan.-Dec.

the simulated values for the first year of the operation, which runs from January 1st to December 31st. Figure 6.6 shows the hourly average air and wall temperatures of zone 1 and the thermostat set point temperatures. During the first year of operation the conditioned air temperature of zone 1 (blue line) remains with in the thermostat set point ranges (blue and red dashed lines). The wall temperature (green line) varies significantly throughout the year based on the outside weather conditions. Figure 6.7 shows the conditioning provided by the heat pump for each hour of the year. In the figure heating is positive and cooling is negative. The data shows significantly more total cooling during the year than heating, but the peak cooling and heating values are similar in magnitude. Figure 6.8 shows the heat rejected into the ground loop water. 


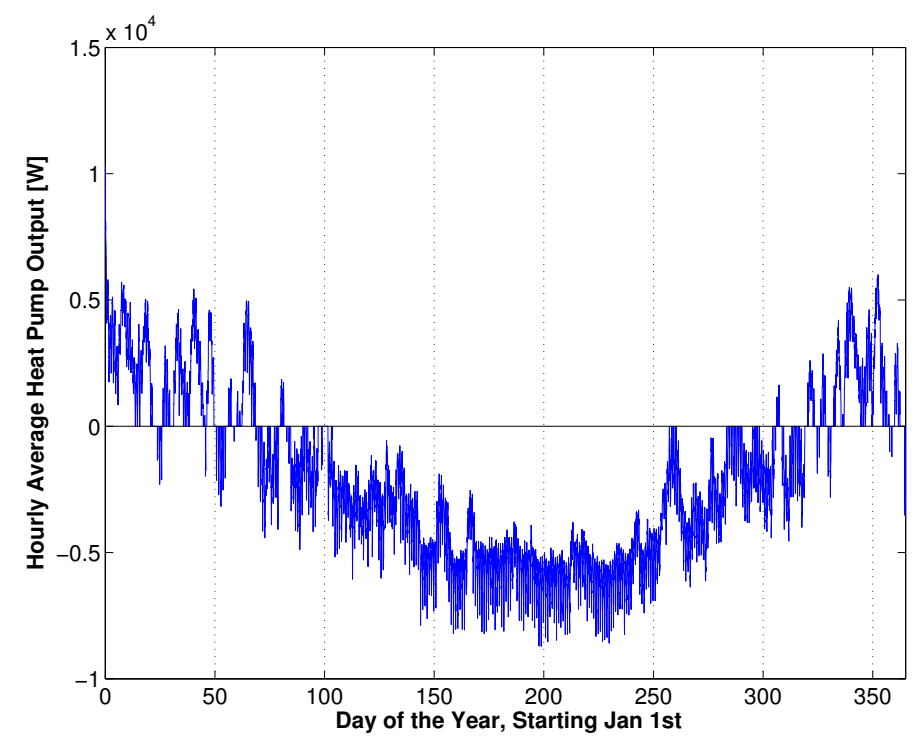

Figure 6.7: Hourly mean values of heat pump output to the conditioned zone (heating is positive), Jan.-Dec.

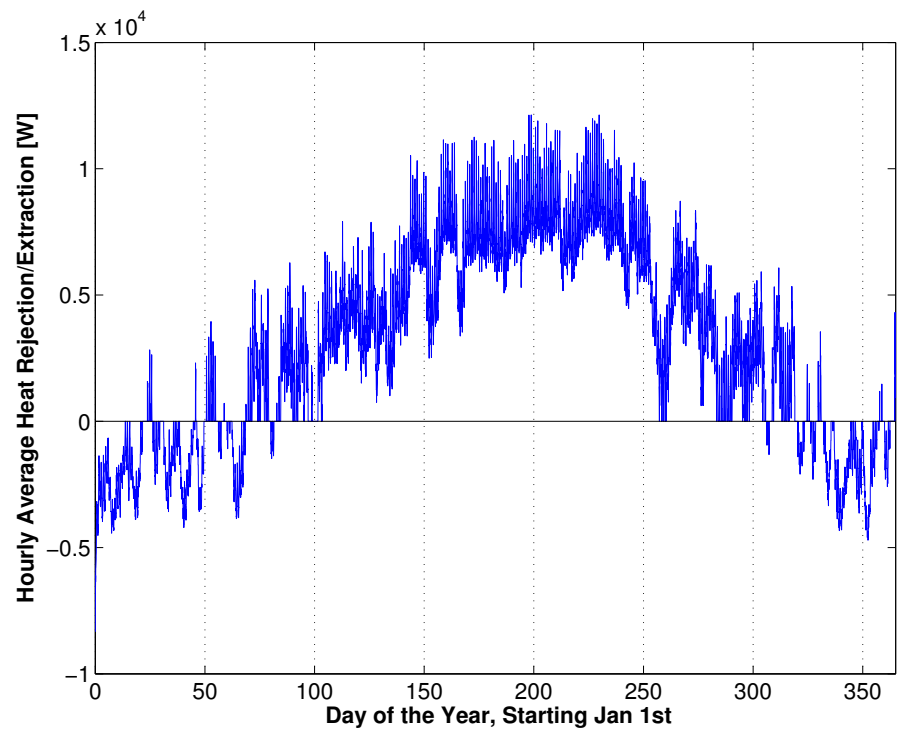

Figure 6.8: Hourly mean values of heat rejected to ground loop water by the heat pump (positive heat rejection is associated with cooling) Jan.-Dec. 
The positive values are associated with the heat pump adding energy to the ground loop water, which occurs when the heat pump is providing cooling to (removing heat from) the conditioned air.

Comparison of Figure 6.7 to Figure 6.8 shows that the heat pump rejects more heat to the ground loop water than it removes from the conditioned air when cooling and that the heat pump extracts less heat from the ground loop water than it adds to the conditioned air when heating. This result occurs because the energy added to the refrigerant by the compressor must be rejected into the high temperature heat sink when the refrigerant is condensing. When the heat pump is cooling the high temperature sink is the ground loop water and when the unit is heating it is the conditioned air. This means that even if the annual heating and cooling building loads are the same there will still be an unbalanced heating load on the ground.

Figure 6.9 shows the ground loop water temperature at the heat pump entrance (blue line) and the change in the water temperature across the heat pump. The water temperature at the heat pump entrance has a large affect on the operation of the heat pump. During cooling, high water temperatures reduce in operational efficiency. The heat pump also has built-in safe guards that shut the heat pump off if the inlet water temperature ever goes above $48.9^{\circ} \mathrm{C}\left(120^{\circ} \mathrm{F}\right)$ during cooling. The combination of both of these conditions can result in loss of the ability of the heat pump to provided adequate cooling. These results show that the temperatures remain below $45^{\circ} \mathrm{C}\left(113^{\circ} \mathrm{F}\right)$ during the first year of the simulation. 


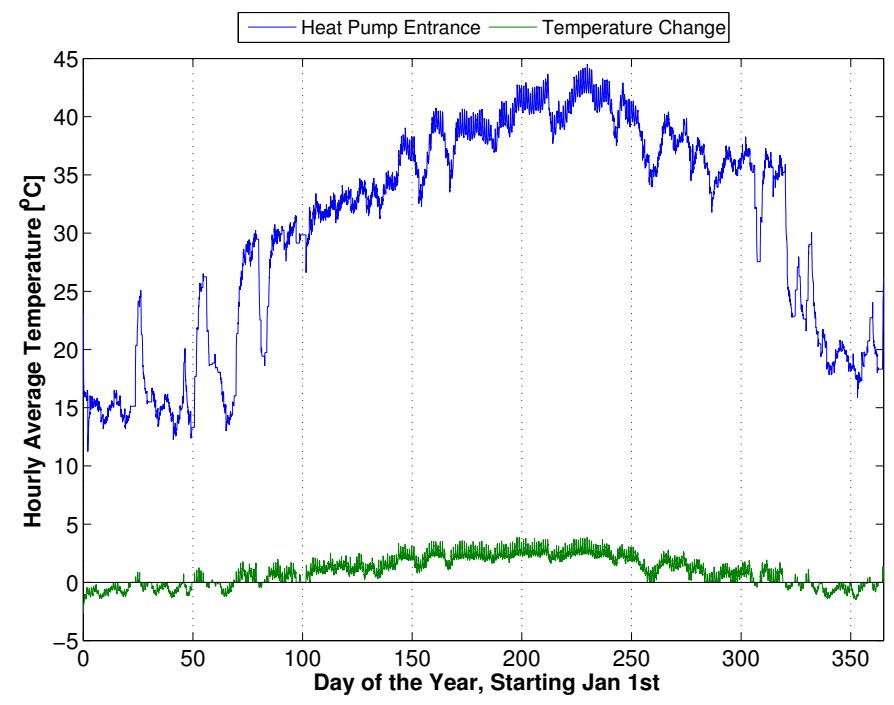

Figure 6.9: Hourly mean values of heat pump entrance temperature and temperature change, Jan.-Dec.

Figure 6.10 shows the water temperature at the entrance to the ground loop (blue line), the change in the temperatures across the ground loop (green line) and the undisturbed ground temperature (red dashed line). This location is also the exit of the heat pump. The temperatures shown here are higher/lower than the temperatures entering the heat pump shown in Figure 6.9 depending on the cooling/heating operating mode of the heat pump. It is also evident that the higher rates of heat rejection during cooling that are shown in Figure 6.8 cause higher temperature deviations from the undisturbed ground temperature. 


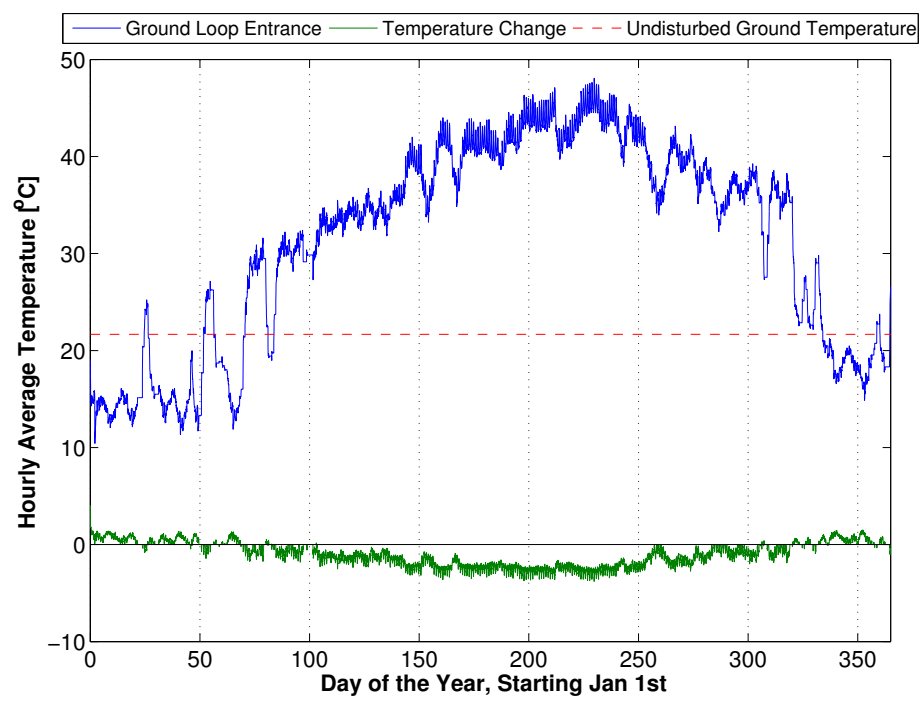

Figure 6.10: Hourly mean values of ground loop entrance temperature and temperature change, Jan.-Dec.

\subsection{Monthly Results}

Monthly and yearly values are used to examine long term trends in the results. The monthly values presented in this section show total energy values instead of the rates that were shown in the time step and hourly results. For example, Figure 6.11 shows the monthly total delivered conditioning in $M W h$, whereas previous plots showed the delivered rate (power) in $W$. This figure shows that over the 15 years that were simulated the delivered cooling (blue line) was constant for each month from year to year. The delivered heating (red line) show the same results except for the first month of the simulation. The first month of simulation shows that the house will require more heating than any other January of the simulation, which is caused by the initial temperature 
conditions of the building model being set at $10^{\circ} \mathrm{C}\left(50^{\circ} \mathrm{F}\right)$ (set point at $25^{\circ} \mathrm{C}$ $\left.\left(77^{\circ} F\right)\right)$. This deviation causes the heat pump to run extensively in the first part of January to bring the building model temperatures up to the set point values.

Figure 6.12 shows the monthly heat pump operation time for heating (red line) and cooling (blue line) over the 15 years of the simulation. The heating operation time does not change over the 15 years, but during the summer the operation time increases every year. The maximum monthly operation time over the 15 years increases by $15 \%$. The previous figure shows that there is not a significant change in the delivered cooling during these months, therefore the the cooling rate of the heat pump is reducing.

The increased operation time shown in Figure 6.12 is reflected in the power consumed by the heat pump, shown in Figure 6.13. During the first seven years of operation the peak electricity use for cooling (blue line) changes from $1693 \mathrm{kWh}$ to $1954 \mathrm{kWh}$, an increase of $15.4 \%$. After year seven, the peak values remain approximately the same. In comparison the peak electricity usage for heating (red line) is only $284 \mathrm{kWh}$ for all 15 years.

The increase operation time due to the reduction in cooling capacity and the associated increase in peak electricity use can be attributed to the increasing ground loop water temperature at the entrance of the heat pump. Figure 6.14 shows the monthly mean, maximum, and minimum water temperatures at the entrance of the heat pump. The yearly peak mean temperature (blue line) increases significantly over the first seven years with a first order 


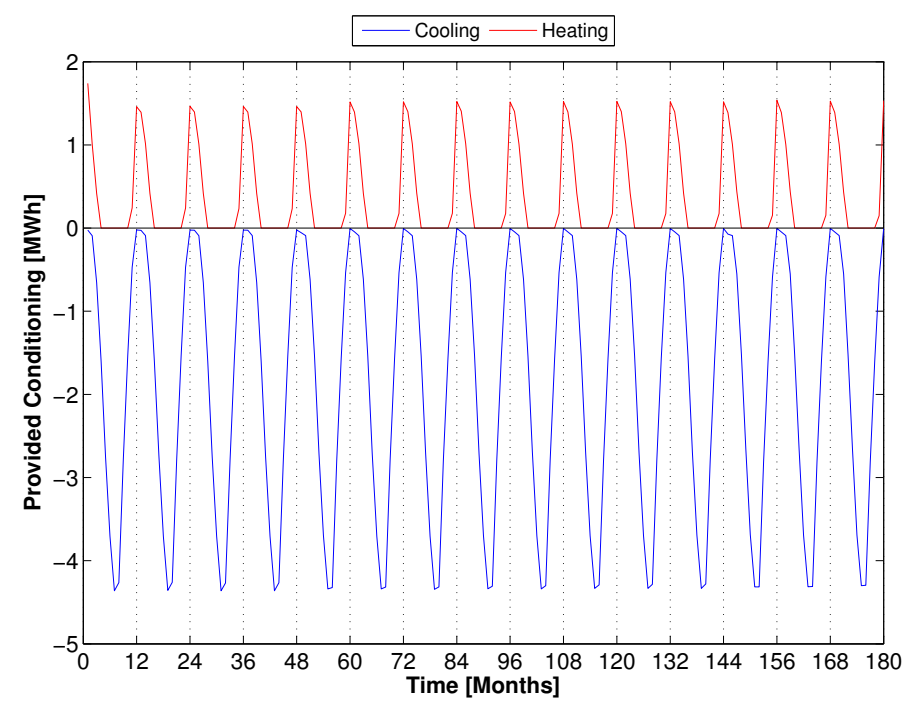

Figure 6.11: Monthly total values of heat pump output to the conditioned zone 1,15 years

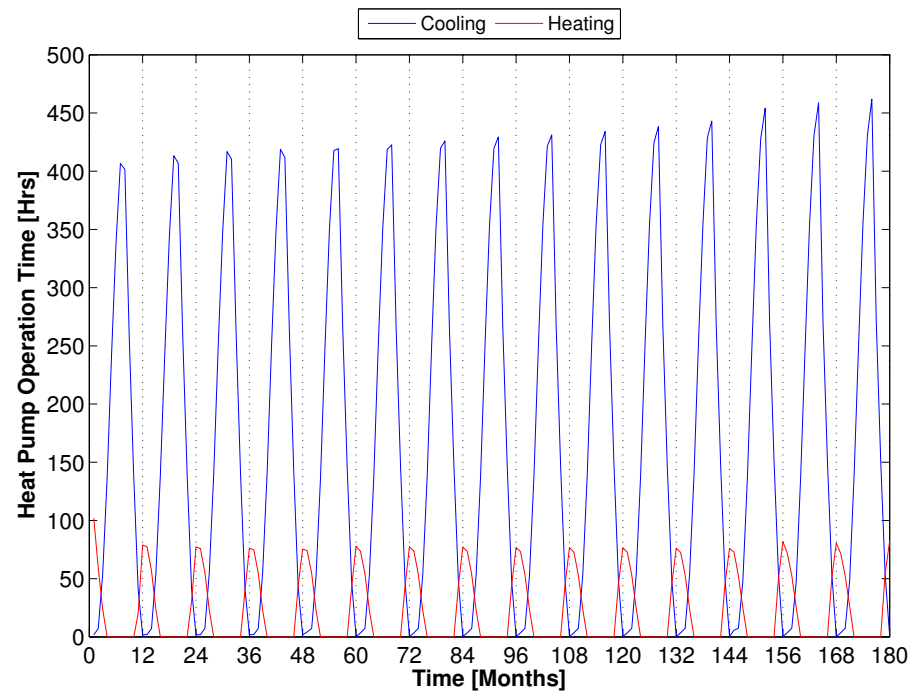

Figure 6.12: Monthly total values of heat pump operation time, 15 years 


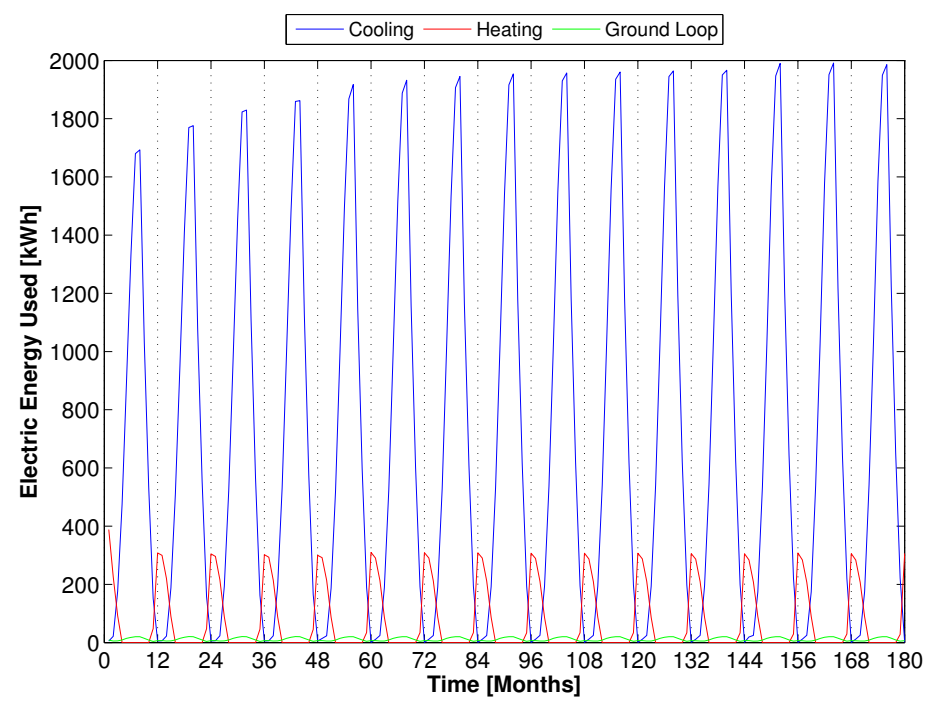

Figure 6.13: Monthly total values of electricity used to provide cooling and heating, and to operate the ground loop water pump, 15 years

type response, then begins to increase in a linear fashion for the remainder of the simulation. During a single year the monthly mean value has a range in excess of $20^{\circ} \mathrm{C}\left(36^{\circ} \mathrm{F}\right)$.

The increased operating temperatures result in a decrease in cooling efficiency and an increase in the heating efficiency. Figure 6.15 shows the monthly average EER (Energy Efficiency Ration, used for cooling) and the COP (Coefficient of Performance, used for heating). The EER is defined as the heat removed from the building in Btu $(W h)$ divided the electricity used in $W h$ and the COP is defined as the heat added to the building in $W h$ divided the electricity used in $W h$. The EER (blue line) varies significantly throughout the year, with peaks in the winter of at least $14 \mathrm{Btu} / \mathrm{Wh}(4.1 \mathrm{Wh} / \mathrm{Wh})$ and 


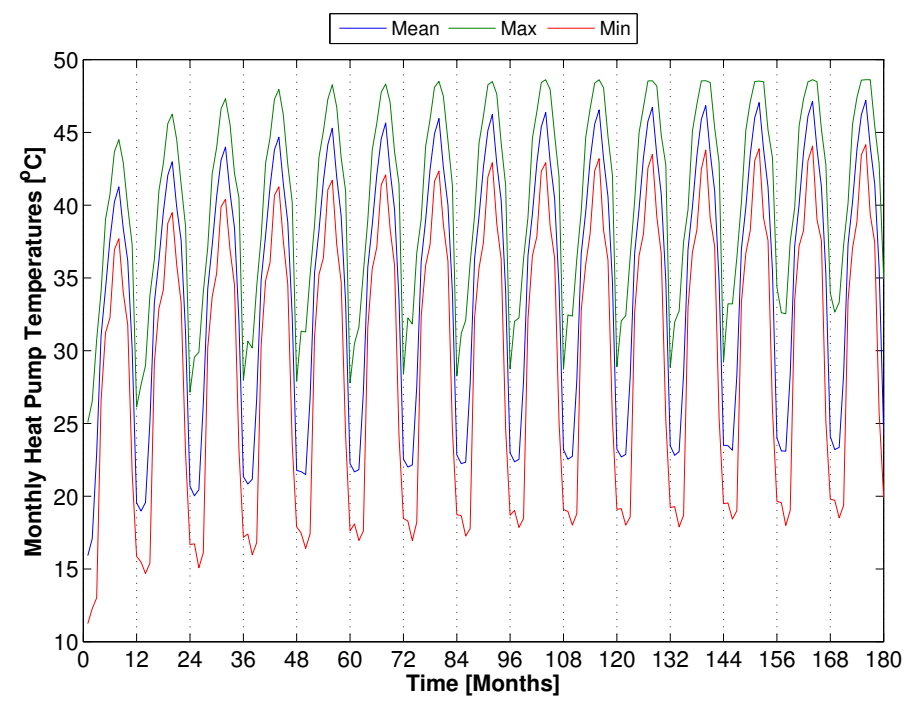

Figure 6.14: Monthly values of mean, maximum and minimum heat pump entering water temperatures (maximum and minimum based on hourly averages), 15 years

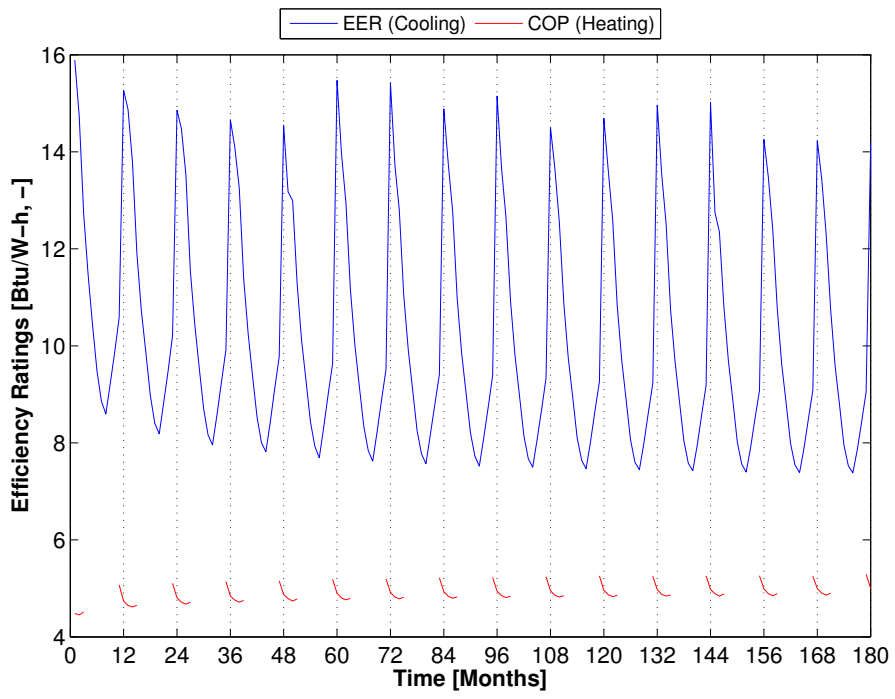

Figure 6.15: Monthly values for efficiency ratings for the heat pump operation, 15 years 
minimum values in the summer months of $7.4 \mathrm{Btu} / \mathrm{Wh}(2.2 \mathrm{Wh} / \mathrm{Wh})$ after seven years. Every year the COP reduces from approximately 5.15 to 4.78 , a decrease of $7 \%$, as the water temperatures reduce due to the heat extracted from the ground. This change also causes the ERR to increase in the winter.

\subsection{Yearly Results}

This section shows yearly values for the simulation. The yearly values are used to calculate operation costs and long term changes in the heat pump operation. All plots presented in this section have an associated table in Appendix D. Table 6.1 and Figure 6.16 show that the total delivered heating and cooling do not change over the 15 years of operation. If these values decreased it would mean that the heat pump lost its ability to cool or heat the building. The annual buildings load of $22.3 \mathrm{MWh}(75,700 \mathrm{kBtu})$ and 4.52 $M W h(15,400 \mathrm{kBtu})$ for cooling and heating, respectively, falls into the range of the validation values that were tested in Chapter 5 .

Table 6.1 also shows the total annual heat pump operation time for both heating and cooling, and yearly values are shown in Figure 6.17. The total annual heating times vary very little compared to the total cooling times. Over the 15 years the cooling times increase by $7.3 \%$ from 2022 to 2169 hours. Over the same time the mean heat pump entering water temperature increases by $5.9^{\circ} \mathrm{C}\left(10.6^{\circ} \mathrm{F}\right)$ from $30.4^{\circ} \mathrm{C}\left(86.7^{\circ} \mathrm{F}\right)$ to $36.3^{\circ} \mathrm{C}\left(97.3^{\circ} \mathrm{F}\right)$, as shown Table 6.2 and Figure 6.18. The yearly maximum temperature increase during the first seven years and level off at $48.5^{\circ} \mathrm{C}\left(119.3^{\circ} \mathrm{F}\right)$. This corresponds to the 


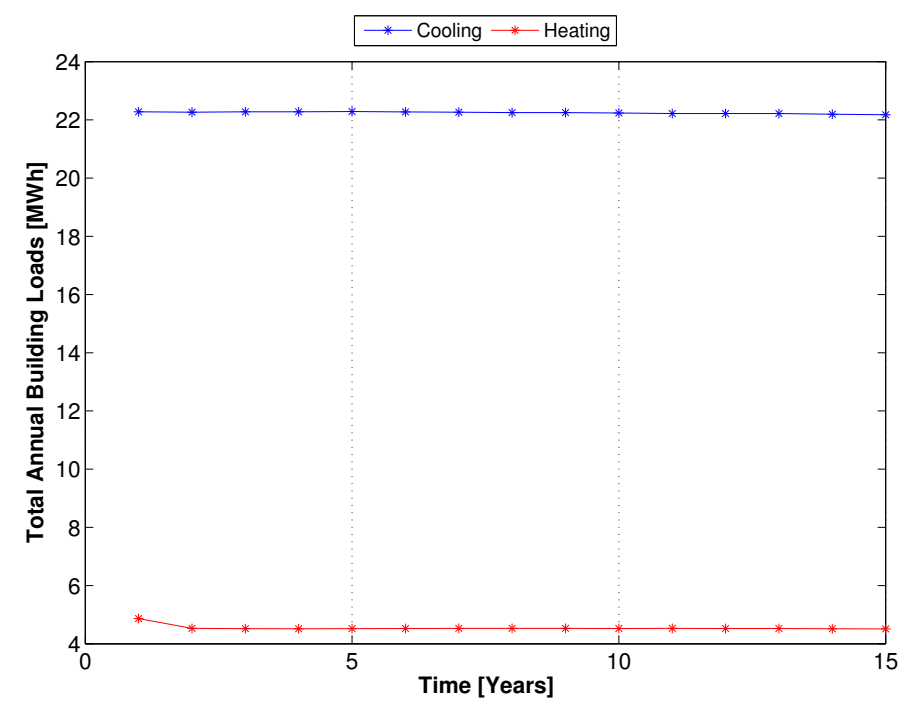

Figure 6.16: Annual total building loads for heating and cooling, 15 years, data can be found in Table D.1

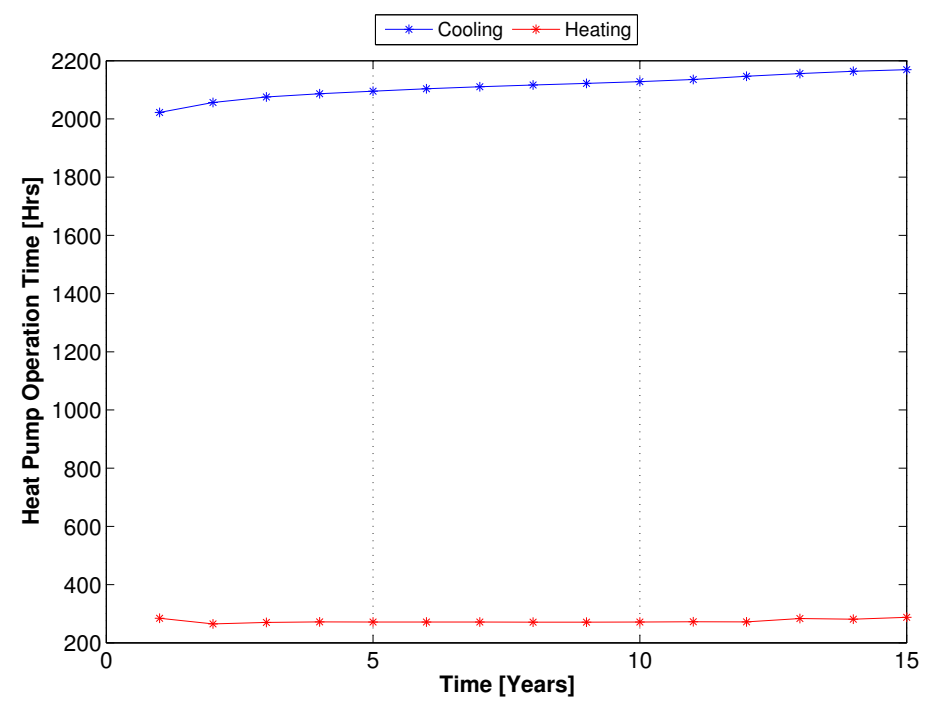

Figure 6.17: Annual total heat pump operation time for heating and cooling, 15 years, data can be found in Table D.1 
Table 6.1: Summary building loads and heat pump operation time over 15 years

\begin{tabular}{lrrrr}
\hline Year & Annual Cooling & Annual Heating & Cooling Time & Heating Time \\
& $M W h$ & $M W h$ & Hrs & Hrs \\
\hline 1 & 22.28 & 4.87 & 2022 & 284 \\
5 & 22.29 & 4.52 & 2095 & 271 \\
10 & 22.24 & 4.53 & 2128 & 271 \\
15 & 22.18 & 4.51 & 2169 & 287 \\
\hline
\end{tabular}

Table 6.2: Summary total energy use, ground loop temperatures and heat pump efficiencies over 15 years

\begin{tabular}{lrrrrr}
\hline Year & $\begin{array}{r}\text { Total Energy } \\
k W h\end{array}$ & $\begin{array}{r}\text { Mean HP Temp } \\
{ }^{o} \mathrm{C}\end{array}$ & $\begin{array}{r}\text { Peak HP Temp } \\
{ }^{\circ} C\end{array}$ & $\begin{array}{r}\text { EER } \\
\text { Btu/Wh }\end{array}$ & \\
\hline 1 & 9068 & 30.4 & 44.5 & 9.56 & 4.59 \\
5 & 9890 & 34.3 & 48.3 & 8.55 & 4.84 \\
10 & 10183 & 35.5 & 48.6 & 8.25 & 4.91 \\
15 & 10317 & 36.3 & 48.6 & 8.11 & 4.95 \\
\hline
\end{tabular}

temperature limits that are imposed on the heat pump. If the entering water exceeds $48.9{ }^{\circ} \mathrm{C}\left(120^{\circ} \mathrm{F}\right)$ the heat pump will shut off to prevent excessive pressures in the system.

Figure 6.19 shows that the yearly average EER decreases by $15 \%$ from $9.56 \mathrm{Btu} / \mathrm{Wh}(2.80 \mathrm{Wh} / \mathrm{Wh})$ to $8.11 \mathrm{Btu} / \mathrm{Wh}(2.37 \mathrm{Wh} / \mathrm{Wh})$ during the simulation. It is important to note that these yearly values are on the lower side of the range given by the monthly values $(7.5-16 B t u / W h)$ since there is significantly more cooling provided in the summer when the EER is low. The yearly COP also increases by $8 \%$ from 4.59 to 4.95 during the simulation. 


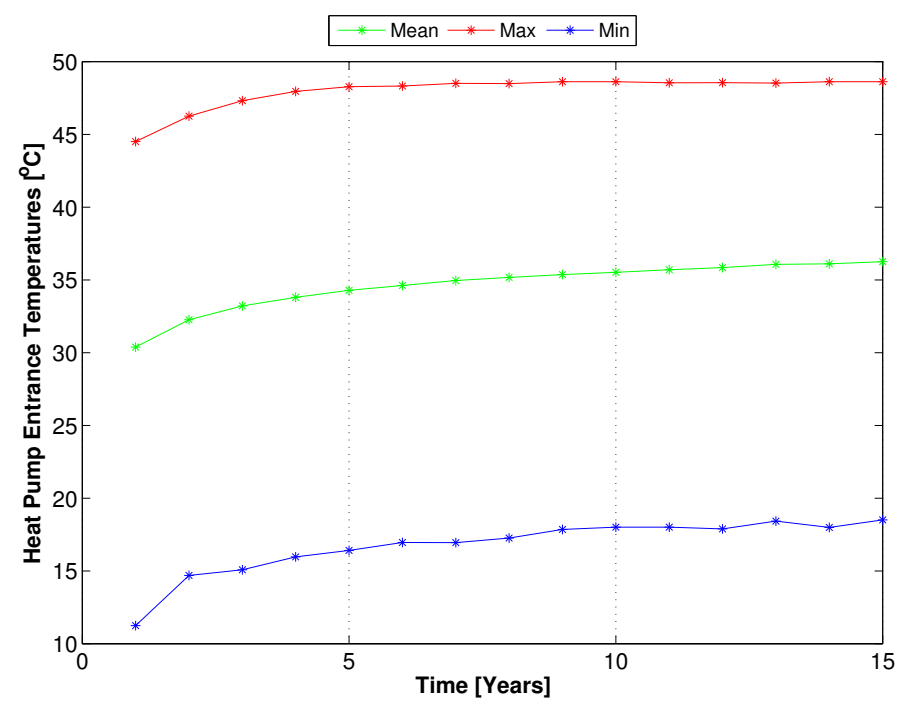

Figure 6.18: Annual mean, maximum, and minimum ground loop water temperatures at the entrance of the heat pump (maximum and minimum based on hourly averages) 15 years, data can be found in Table D.3

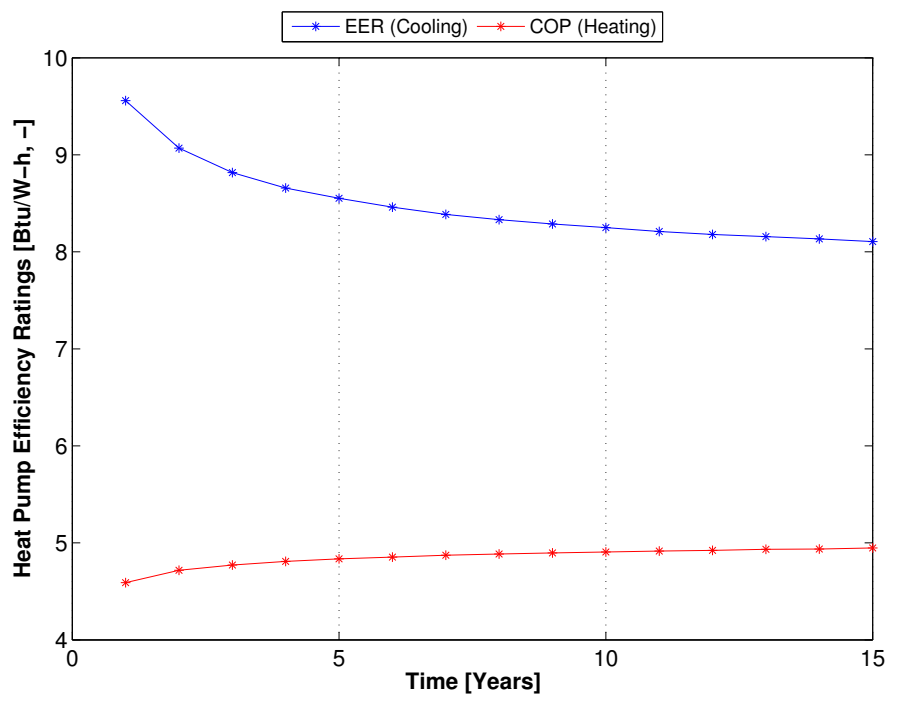

Figure 6.19: Annual mean efficiency ratings for the heat pump, 15 years, data can be found in Table D.3 
Figure 6.20 shows the yearly electricity used in total, for cooling, for heating and during the peak month. Due to the decreased cooling efficiency (15\% over 15 years) and the increased operation time ( $7.3 \%$ over 15 years) the annual electricity used to provided cooling increases by $15.8 \%$. The increasing COP ( $8 \%$ over 15 years) causes the annual electricity used to provide heating to decreases by $4.8 \%$. The net effect of these changes results in a $13.7 \%$ increase, from 9,068 to $10,317 \mathrm{kWh}$, in the total electricity used to operate the heat pump. A concern for many homeowners in cooling dominated climates are the high summer electricity bills associated with peak cooling during the summer. Over the first seven years of operation the peak monthly usage increased by $14.8 \%$ from 1693 to $1945 \mathrm{kWh}$ and remains fairly constant over the remainder of the simulation at about $1960 \mathrm{kWh}$, increasing by only $2.1 \%$. It can also be noted that the total electricity required for heating is less than the electricity required during the peak month of cooling. 


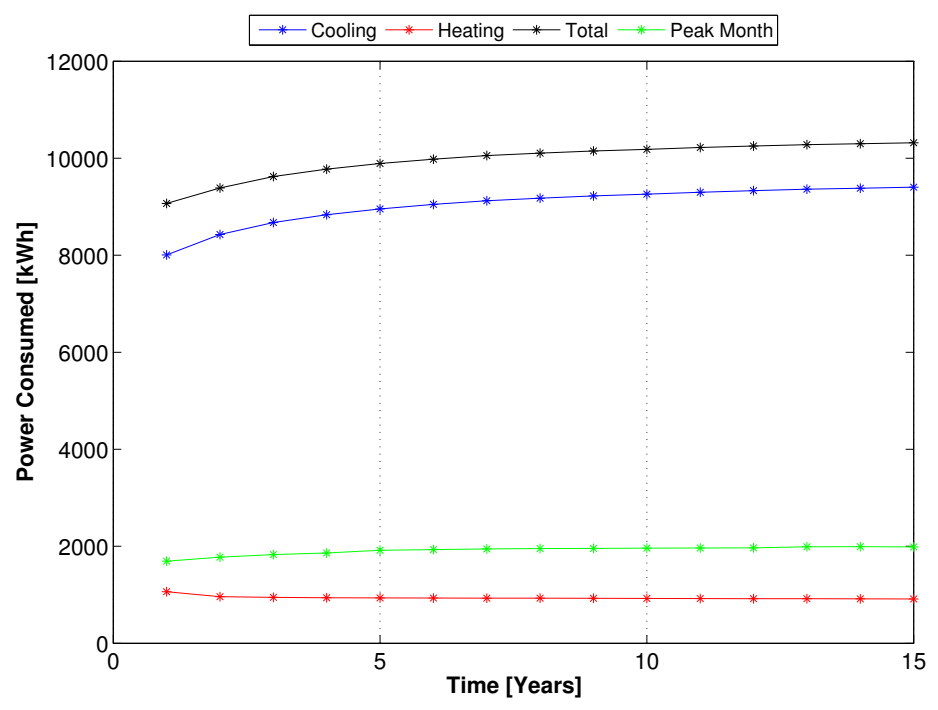

Figure 6.20: Annual and peak electricity used by the heat pump, 15 years, data can be found in Table D.2 


\section{Chapter 7}

\section{Sensitivity Studies}

This chapter presents a series of sensitivity studies varying the ground loop parameters. The list of parameters varied are by no means an exhaustive list of possible parameters and parameter combinations. The total length of the ground loop was varied to determine the effect of changes and to determine if the size computed by GLHEPRO was correct. The configuration and spacing of the borehole were changed to determine the effects the thermal interaction among the boreholes. The ground temperature was varied over the range of ground temperatures found in Texas. Finally, the effect of varying the conductivity of the grout was studied. During the studies the price of electricity was assumed to be $0.1133 \$ / k W h$, which is the residential average

price for Texas in August 2011 [U.S. Dept. of Energy, 2011a]. In addition, the costs were calculated for the first ten years of operation even though the simulations were run for 15 years. All plots presented have corresponding tables in the Appendix E. 


\subsection{Borehole Length}

To verify the length of the borehole that was determined by GLHEPRO and to determine the effects of oversizing the borehole, which is common in the industry, a borehole length sensitivity study was completed. The only difference between the models simulated was the length of the borehole, the all other parameters are identical to the base model described in Chapter 5 . The borehole was sized by GLHEPRO to be four boreholes in a line at $68.6 \mathrm{~m}$ (225.7 ft) each, for a total length of $274 \mathrm{~m}$ (903 ft). The tested lengths were chosen to be $\pm 5 \%, \pm 10 \%$, and $\pm 20 \%$ of the original length. A summary of the lengths and installation costs are shown in Table 7.1. In Texas, boreholes are typically priced on a per/ $f t$ basis and for the Austin area this value is $10 \$ / f t$ [Hammond, 2011]. This price drilling the boreholes, installing the u-tube, and back filling the borehole with grout to enhance the heat transfer.

Table 7.1: Borehole length sensitivity study summary and installation cost

\begin{tabular}{lrrr}
\hline Test & $\begin{array}{r}\text { Bore Length } \\
m(f t)\end{array}$ & $\begin{array}{r}\text { Total Length } \\
m(f t)\end{array}$ & $\begin{array}{r}\text { Installation Cost } \\
\$\end{array}$ \\
\hline $80 \%$ & $55.0(180.6)$ & $220.1(722.2)$ & $\$ 7,222$ \\
$90 \%$ & $61.9(203.1)$ & $247.6(812.5)$ & $\$ 8,125$ \\
$95 \%$ & $65.4(214.4)$ & $261.4(857.6)$ & $\$ 8,576$ \\
Base Case & $68.8(225.7)$ & $275.2(902.8)$ & $\$ 9,028$ \\
$105 \%$ & $72.2(237.0)$ & $288.9(947.9)$ & $\$ 9,479$ \\
$110 \%$ & $75.7(248.3)$ & $302.7(993.0)$ & $\$ 9,930$ \\
$120 \%$ & $82.5(270.8)$ & $330.2(1083.3)$ & $\$ 10,833$ \\
\hline
\end{tabular}

For the range of lengths simulated there were two important results; 


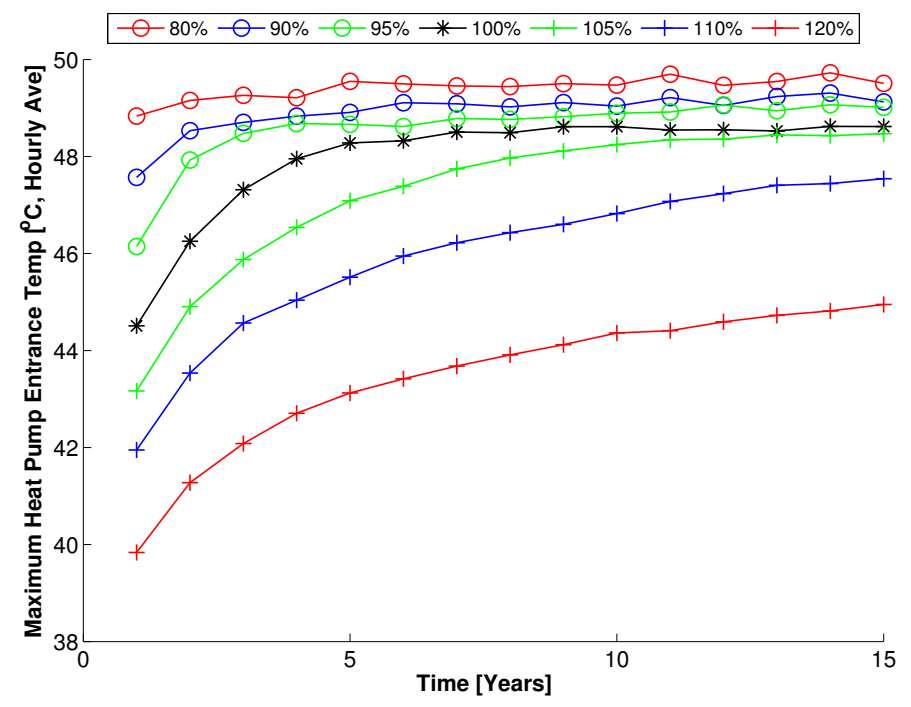

Figure 7.1: Maximum yearly heat pump entrance temperatures for different borehole lenghts, based on hourly averages, data can be found in Table E.1

either premature failure or the heat pump operating with increased efficiency. Both of these results are caused by the temperature of the water entering the heat pump. The yearly maximum temperatures, shown in Figure 7.1, are reaching their lifetime maximum temperatures within three years for all lengths shorter than the base case. The base case takes seven years and the longer boreholes take at least eleven years to reach their lifetime maximum temperatures. It is important to remember that when the water entering the heat pump exceeds $48.9^{\circ} \mathrm{C}\left(120^{\circ} \mathrm{F}\right)$ the heat pump is designed to shut off to prevent excessive pressures in the system.

Figure 7.2 shows the annual cooling provided by the heat pump. The base case sees a slight reduction $(0.15 \%)$ in the provided cooling by year 
10 compared to the longer boreholes. The shorter boreholes have a greater reduction in the provided cooling with $0.85 \%, 2.5 \%$, and $7.4 \%$ reductions for the $95 \%, 90 \%$ and $80 \%$ cases, respectively. This reduction in cooling indicates that the heat pump lost the ability to cool the house due to its built-in thermal protections (e.g. the heat pump did not operate even though the temperature in the conditioned zone exceeded the set point temperature).

This result is confirmed by Figure 7.3, which shows the number of hours that the conditioned zone 1 temperature exceeded the set point temperature. For the base case this value reaches 167 hours in year 15, but is only 63 hours in year ten. The latter is less than $1 \%$ of the year and represents $3 \%$ of the total cooling time (2128 hours), which is an acceptable value considering the borehole was sized for 10 years of operation. For the $105 \%$ case, the temperature exceeds the set point for only 33 hours in year 15, and the other two longer cases do not exceed the set point temperature at all during the simulations. For the shorter boreholes, the number of hours that the conditioned temperature exceeds the set point become significant very quickly. Those cases begin to exceed the set point temperature by at least 200 hours, which corresponds to approximately $10 \%$ of the total cooling time, in years 8 , 4, and 1 for the 95\%, 90\% and 80\% cases, respectively. These results represents a significant failure of the system. The failure of the systems shorter than the GLHEPRO sized base case indicate that the ground loop was properly sized.

Examining the results for the oversized boreholes shows an increase in the EER (energy efficiency ratio) over the base case borehole, as shown in 


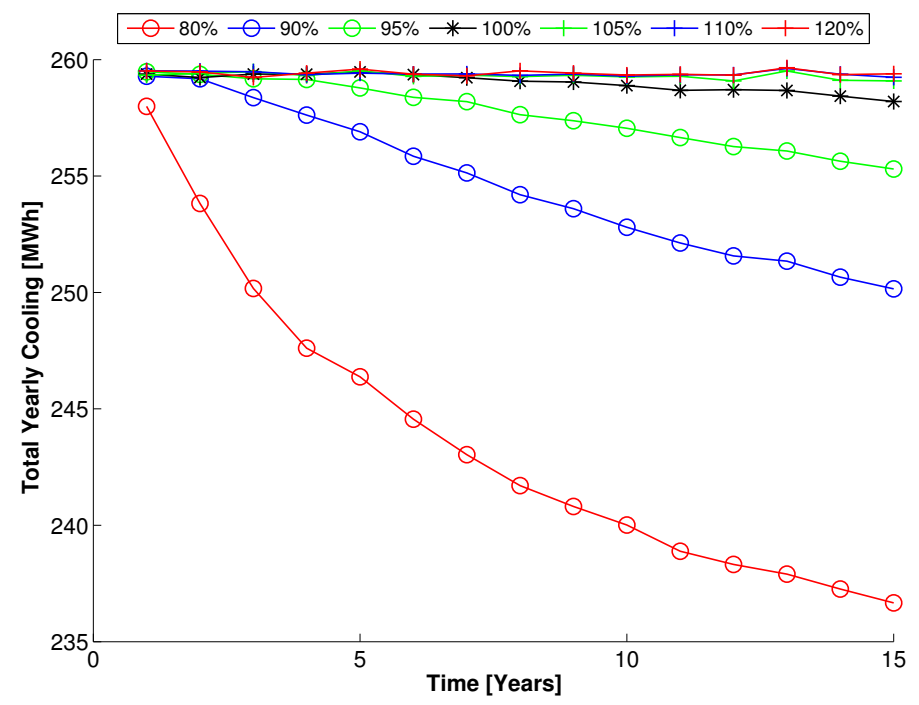

Figure 7.2: Total annual cooling for the different borehole lengths tested, data can be found in Table E.2

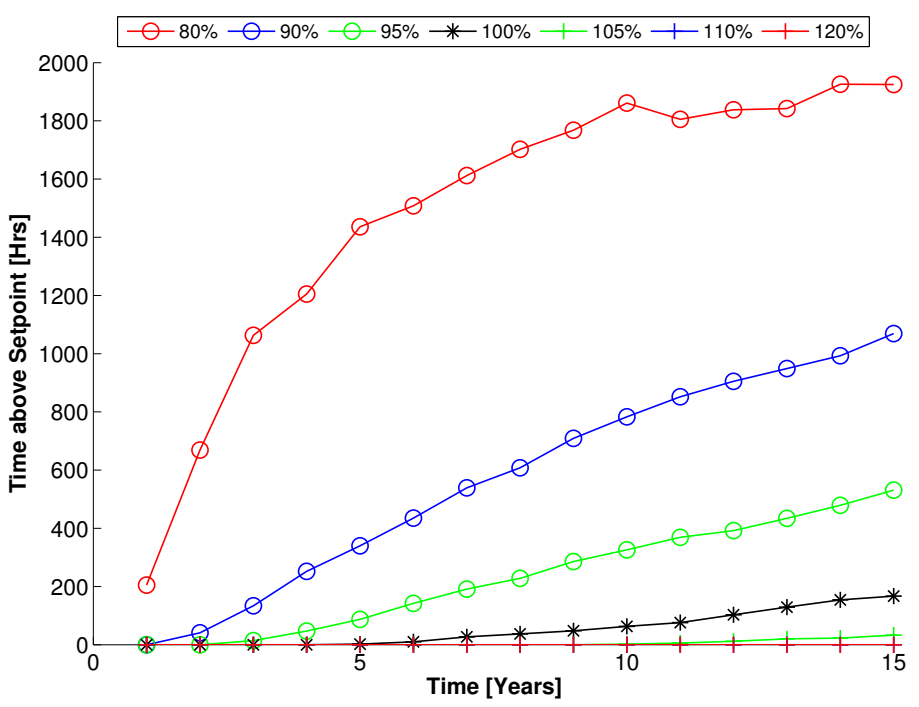

Figure 7.3: Total annual time that zone 1 air temperature exceeded the cooling set point for different borehole lengths tested, based on hourly averages, data can be found in Table E.3 
Figure 7.4. For the longer boreholes, the EER still decreases over the 15 year duration of the simulation but it starts at a higher value for longer boreholes. In year five, the EER is $1.8 \%, 3.9 \%$, and $7.8 \%$ higher than the base case EER for the $105 \%, 110 \%$ and $120 \%$ cases, respectively.

The increased EER values result in less annual energy consumed by the heat pump to provided the same amount of cooling. Figure 7.5 shows the electricity consumption for each of the lengths simulated. The shortest two boreholes actually show a reduction in the amount of energy used after two and seven years due to the high water temperatures shutting down the heat pump. For the longer boreholes, the higher EERs translate into lower annual energy consumption. In year five the total electricity consumed is $2.6 \%$, $5.4 \%$, and $9,7 \%$ lower than the base case for the $105 \%, 110 \%$ and $120 \%$ cases, respectively.

Table 7.2: Comparison of initial borehole costs for different borehole lengths and the resulting energy costs over ten years, assuming $0.1133 \$ / k W h$ (Texas residential price August 2011) [U.S. Dept. of Energy, 2011a]

\begin{tabular}{lrrrrr}
\hline Length & \multicolumn{2}{c}{ Borehole Cost } & \multicolumn{2}{c}{ Energy Costs } \\
$\%$ & Cost & Increase & Cost & Reduction & Net Cost \\
\hline Base Case & $\$ 9,028$ & - & $\$ 11,127.87$ & - & - \\
$105 \%$ & $\$ 9,479$ & $\$ 451$ & $\$ 10,845.30$ & $\$ 282.57$ & $\$ 168.81$ \\
$110 \%$ & $\$ 9,930$ & $\$ 903$ & $\$ 10,546.08$ & $\$ 581.80$ & $\$ 320.96$ \\
$120 \%$ & $\$ 10,833$ & $\$ 1,806$ & $\$ 10,063.19$ & $\$ 1,064.68$ & $\$ 740.83$ \\
\hline
\end{tabular}

Table 7.2 compares the increase cost of the longer boreholes to the energy costs over ten years of operation. The casesof the shorter borehole 


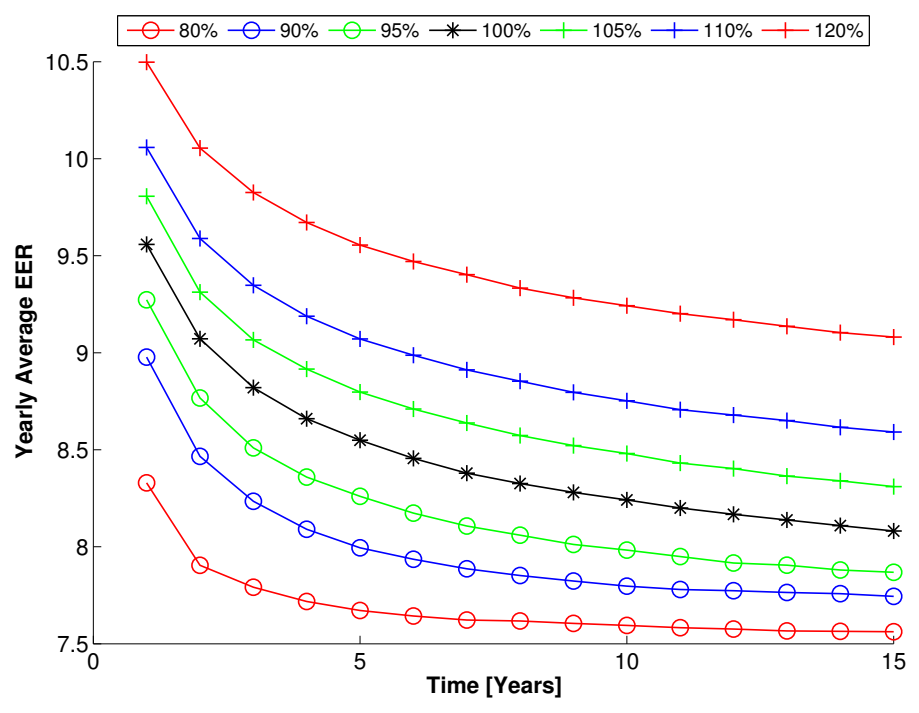

Figure 7.4: Average annual energy efficiency ratio (EER) for the different borehole lengths tested, data can be found in Table E.4

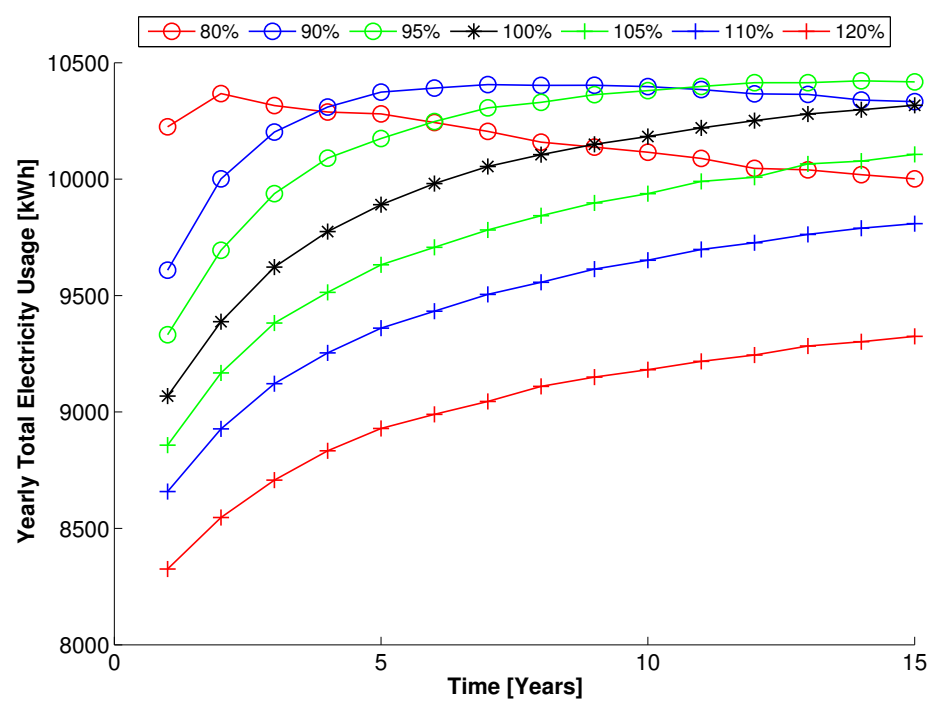

Figure 7.5: Total annual electricity use for the different borehole lengths tested, data can be found in Table E.5 
lengths that failed prematurely were not considered for this analysis. A ten years comparison was used since this was the lifetime used to size the borehole originally. For all cases the additional initial cost is more than the savings achieved in reducing electricity cost. For this calculation the average residential retail price of electricity for Texas was used to calculate the energy costs. For all cases to break even for the ten year period the energy rate needs to be at least $0.1921 \$ / k W h$. This rate corresponds to the average price of electricity in New York state, which is the second highest in the United States [U.S. Dept. of Energy, 2011a]. From a strictly cost perspective, oversized boreholes could be a good investment, depending on the additional installation costs and the local electricity rate.

\subsection{Borehole Configuration and Spacing}

The placement of the vertical boreholes in a residential setting is typically dictated by the lot size and available open space. Fitting the required total length of borehole on a particular property can possibly lead to less than optimal configuration and spacing. This sensitivity study looks at how the configuration and spacing affect the long term operation of the borehole. The study looks at two possible configurations; a line of four boreholes and a 2-by-2 square of boreholes, as shown in Figure 7.6. For these two configuration the 2-by-2 orientation is the less optimal case due the increased borehole thermal interaction and the corresponding higher ground temperatures that would occur over time. For each configuration the borehole spacing, $S$, was also varied. 


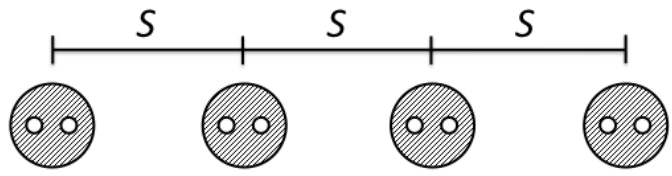

(a) Line of four - $1 \times 4 \times S$

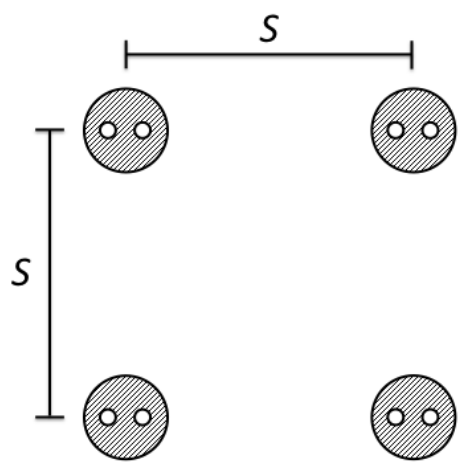

(b) 2-by-2 square - $2 \times 2 \times S$

Figure 7.6: Borehole configurations tested, figure not to scale

The tested spacings were $10 \mathrm{ft}(3.0 \mathrm{~m}), 15 \mathrm{ft}(4.6 \mathrm{~m}), 20 \mathrm{ft}(6.1 \mathrm{~m})$, and $25 \mathrm{ft}$ $(7.6 \mathrm{~m})$. The base case described in Chapter 5 assumes that the boreholes are in a line of four with a spacing of $15 \mathrm{ft}(4.6 \mathrm{~m})$. The length of each borehole that was determined for the base case, $68.6 \mathrm{~m}(225.7 \mathrm{ft})$, was held constant for the simulations. The remainder of the model parameters are identical to the base case model.

The study showed that if the borehole spacing is decreased from the the base case value or the boreholes are placed in a less optimal configuration, premature failure will occur. Figure 7.7 shows a reduction in the annual provided cooling for the both configurations with the closest spacing $(1 \times 4 \times 10$ and $2 \times 2 \times 10)$ and the square configuration for the base case spacing $(2 \times 2 \times 15)^{1}$. In

\footnotetext{
${ }^{1}$ In all of the plots in this section, the spacing is denoted by the color of the lines and configuration is denoted by the data marker, a square for the square configuration and a plus sign for the line of four configuration. In the plot legend the spacing, $S$, is given in feet.
} 
year 10 the provided cooling is reduced by $0.7 \%$ for the square configuration with $15 \mathrm{ft}$ spacing, $1.4 \%$ for the line configuration with $10 \mathrm{ft}$ spacing, and $3.3 \%$ or the square configuration with $10 \mathrm{ft}$ spacing. An interesting feature of the plot is the how the result for the square configuration with a spacing of 20 $f t$ is very close to the result of the base case configuration and spacing.

Figure 7.8 shows the annual time that the building temperature exceeded the set point temperature. From the figure it is obvious that the cases with the smallest spacing and the square configuration with $15 \mathrm{ft}$ spacing are experience premature failure. These cases begin to exceed the set point temperature by at least 200 hours, which corresponds to approximately $10 \%$ of the total cooling time; in year 4 for the square configuration with $10 \mathrm{ft}$ spacing, year 6 for the line configuration with $10 \mathrm{ft}$ spacing, and year 9 for the square configuration with $15 \mathrm{ft}$ spacing. For the remainder of the analysis in this section, the cases that experienced failure will be not be considered. As with the previous plot, the results for the square configuration with $20 \mathrm{ft}$ spacing are very similar to the base case.

As expected the cases with less borehole interaction have lower ground loop water temperatures, resulting in an increase operating efficiency as shown in Figure 7.9. All cases that did not result in a premature failure have the same or an increased efficiency compared to the base case. Table 7.3 shows the increase in the EER for years five and ten for all of the cases that did not experience premature failure. Increasing the spacing from the base case by an additional $5 \mathrm{ft}$ increased the EER by approximately $2.7 \%$ for all years 


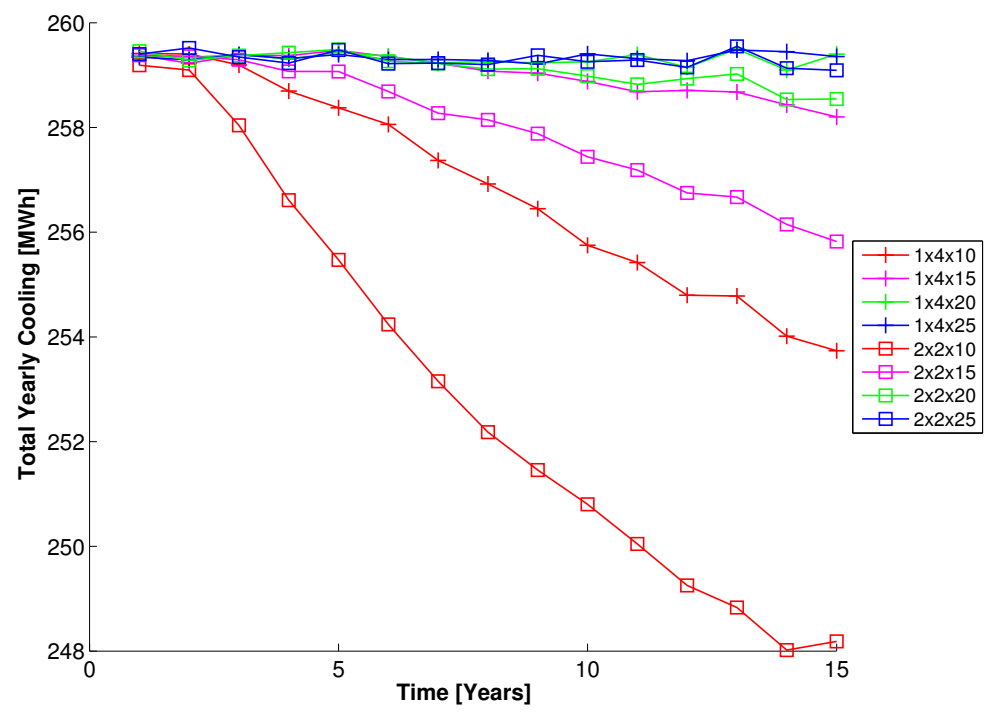

Figure 7.7: Total annual cooling for the different borehole configurations tested, data can be found in Table E.6

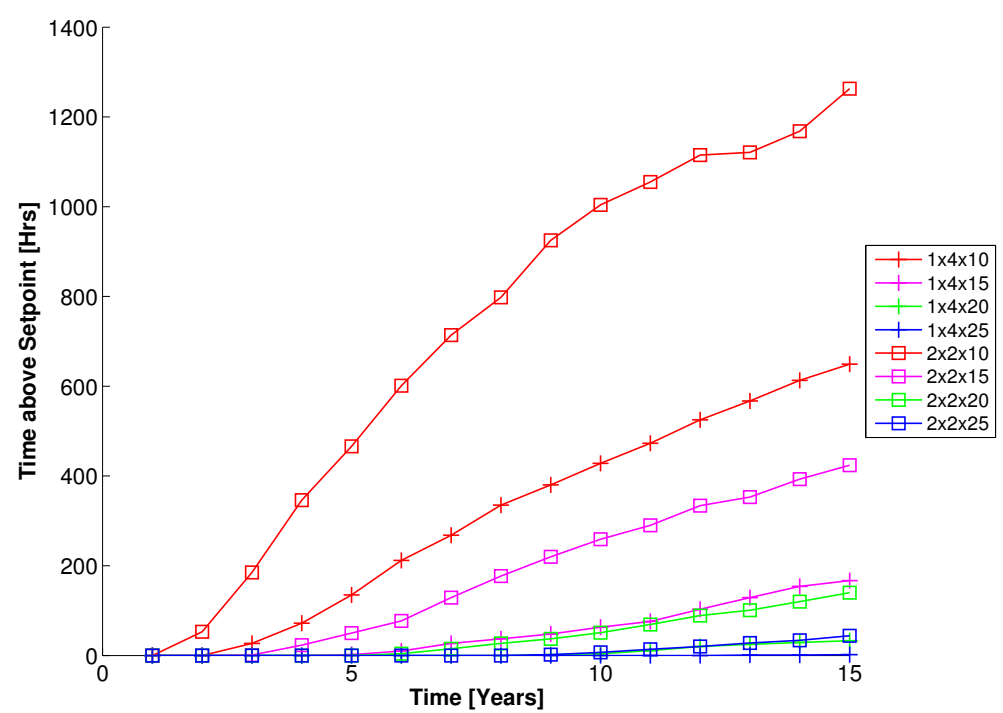

Figure 7.8: Total annual time that zone 1 air temperature exceeded the cooling set point for the different borehole configurations tested, based on hourly averages, data can be found in Table E.7 
simulated. If the spacing was increased by an additional $10 \mathrm{ft}$ the EER is increased by approximately $4.5 \%$ for all years. Figure 7.10 shows the annual Table 7.3: Comparison of EER for years five and ten based on the different configurations and spacing simulated

\begin{tabular}{lrrrrr}
\hline & Base Case & $1 \times 4 \times 20$ & $1 \times 4 \times 25$ & $2 \times 2 \times 20$ & $2 \times 2 \times 25$ \\
\hline Year 5 EER & 8.55 & 8.78 & 8.93 & 8.57 & 8.75 \\
Increase & - & $2.65 \%$ & $4.51 \%$ & $0.27 \%$ & $2.41 \%$ \\
\hline Year 10 EER & 8.24 & 8.46 & 8.63 & 8.24 & 8.42 \\
Increase & - & $2.71 \%$ & $4.73 \%$ & $-0.04 \%$ & $2.18 \%$ \\
\hline
\end{tabular}

energy consumption for each of the configurations and spacings simulated. As shown in the previous study the energy consumption actually decreases after a certain period of time for the cases that experience premature failure when the heat pump is shut down due to excessive inlet water temperatures. For the rest of the cases the configurations with less borehole interactions have lower annual energy usage. Table 7.4 shows the energy consumption for years five and ten and the reduction in energy consumption compared to the base case. As expected increasing the spacing for any of these cases results in lower energy consumption. The energy used for the line of four configuration with 15 $f t$ spacing is almost identical to the energy used for the square configuration with $20 \mathrm{ft}$ spacing.

When comparing these results it is important to remember that all cases have the same initial investment, the boreholes have the same depth and the same heat pump is used. The only difference is the placement of 


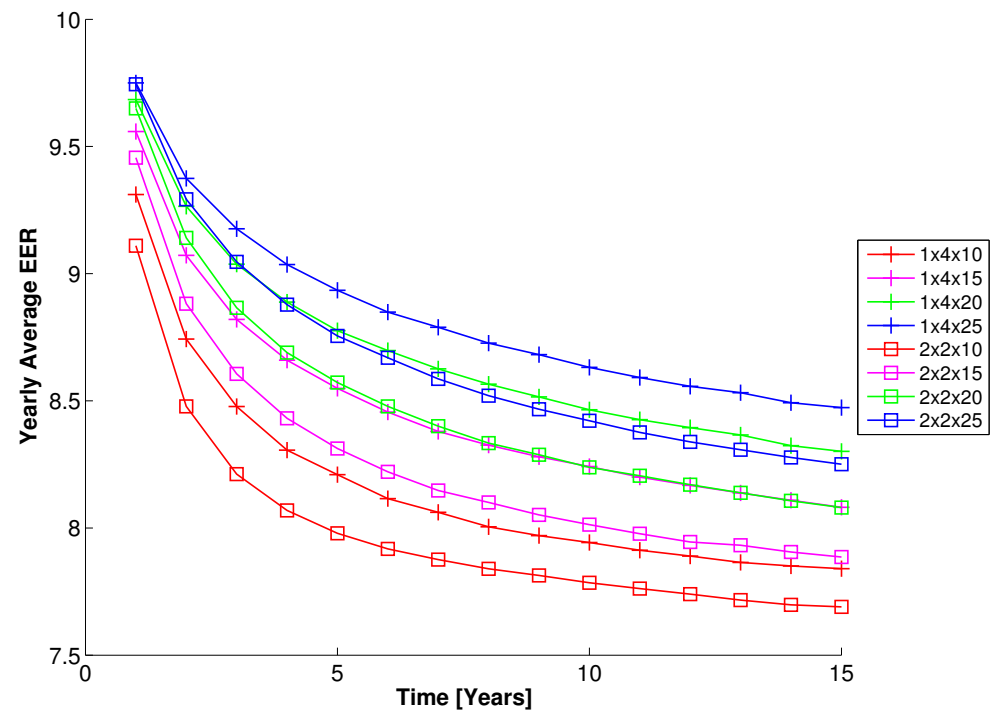

Figure 7.9: Average annual energy efficiency ratio (EER) for the different borehole configurations tested, data can be found in Table E. 8

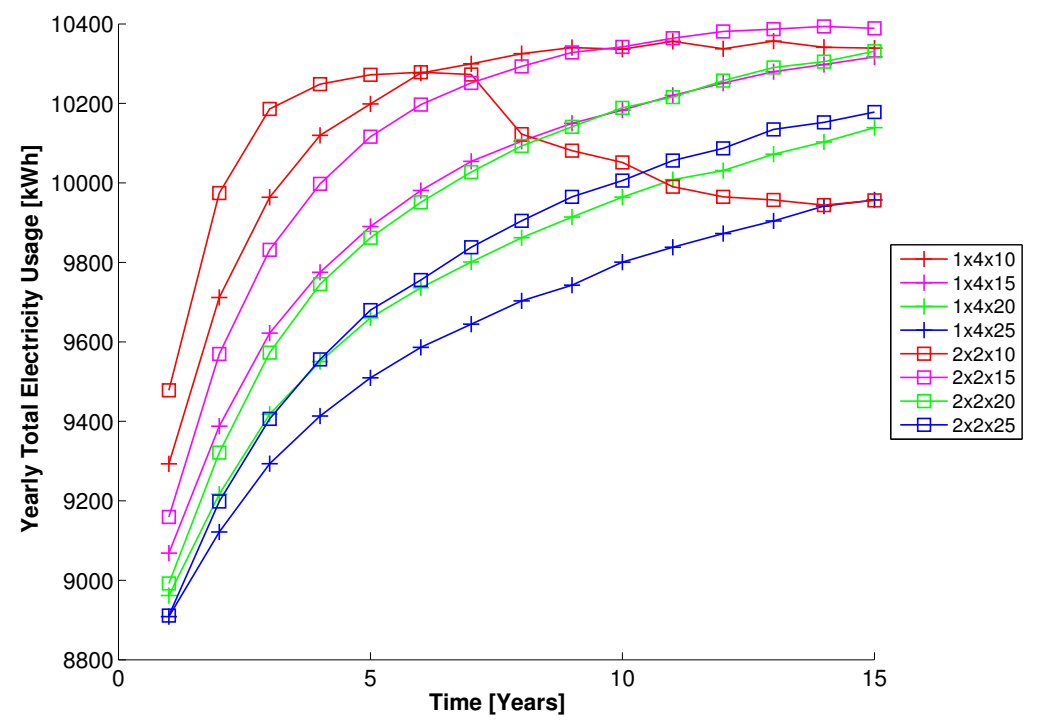

Figure 7.10: Total annual electricity use for the different borehole configurations tested, data can be found in Table E.9 
Table 7.4: Comparison of EER for years five and ten based on the different configurations and spacing simulated

\begin{tabular}{lrrrrr}
\hline & Base Case & $1 \times 4 \times 20$ & $1 \times 4 \times 25$ & $2 \times 2 \times 20$ & $2 \times 2 \times 25$ \\
\hline Year 5 Energy $(\mathrm{kWh})$ & 9890 & 9661 & 9510 & 9862 & 9680 \\
Decrease & - & $-2.32 \%$ & $-3.85 \%$ & $-0.28 \%$ & $-2.12 \%$ \\
\hline Year 10 Energy $(\mathrm{kWh})$ & 10183 & 9964 & 9801 & 10189 & 10006 \\
Decrease & - & $-2.15 \%$ & $-3.76 \%$ & $0.06 \%$ & $-1.74 \%$ \\
\hline
\end{tabular}

the boreholes, and this improvement in operation is free, other than possibly additional trenching to bury the surface runs of pipe. Table 7.5 shows the total energy used and the associated cost over ten years of operation. Increasing the spacing between boreholes by an additional $5 \mathrm{ft}$ saved $\$ 200$ over the ten year period. If the spacing was increased by an additional $10 \mathrm{ft} \$ 328$ was saved. The square configuration with $20 \mathrm{ft}$ spacing ends up costing about the same over the ten years of operation as the base case. Increasing this spacing to 25 $f t$ saved $\$ 187$.

Table 7.5: Comparison of operating costs and savings over ten years for the different configurations tested, assuming $0.1133 \$ / k W h$ (Texas residential price August 2011) [U.S. Dept. of Energy, 2011a]

\begin{tabular}{lrrrrr}
\hline & Base & $1 \times 4 \times 20$ & $1 \times 4 \times 25$ & $2 \times 2 \times 20$ & $2 \times 2 \times 25$ \\
\hline Total Energy $(\mathrm{kWh})$ & 98217 & 96084 & 94724 & 97896 & 96220 \\
Total Energy Cost $\$$ & $\$ 9,213$ & $\$ 9,013$ & $\$ 8,885$ & $\$ 9,183$ & $\$ 9,025$ \\
Energy Savings $(\mathrm{kWh})$ & - & 2132 & 3493 & 321 & 1996 \\
Cost Savings $\$$ & - & $\$ 200$ & $\$ 328$ & $\$ 30$ & $\$ 187$ \\
\hline
\end{tabular}

So far it has been shown that by increasing the borehole spacing be- 


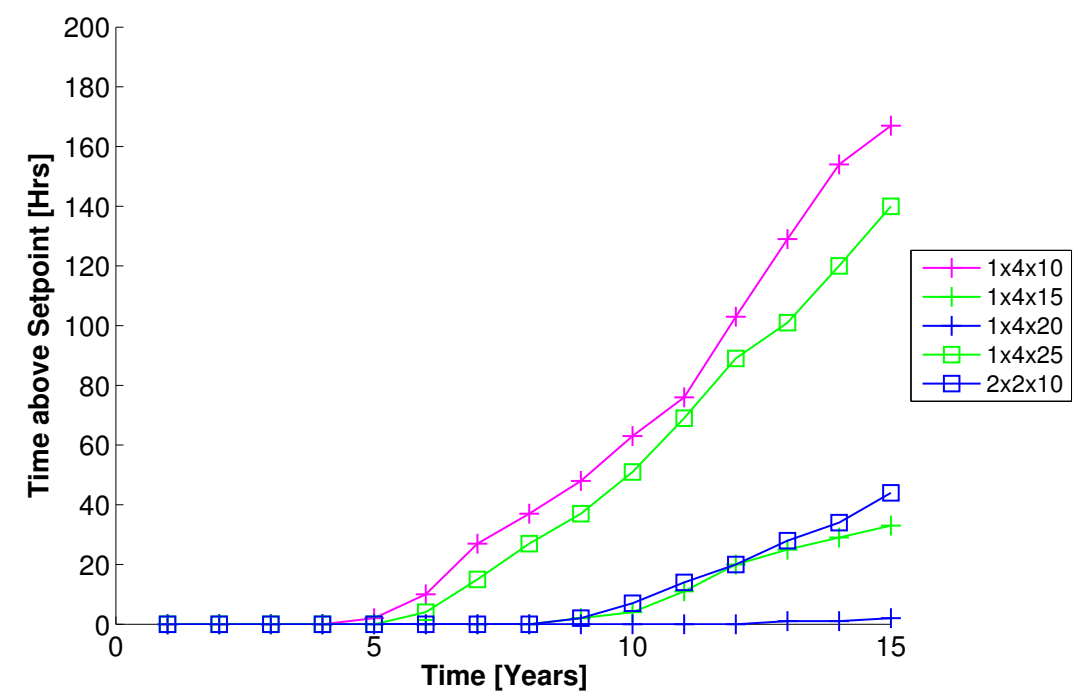

Figure 7.11: Total annual time that zone 1 air temperature exceeded cooling set point for the improved borehole configurations tested, based on hourly averages, data can be found in Table E.7

tween the boreholes the operating cost can be reduced. Moreover, by increasing the borehole spacing the lifetime of the boreholes is also extended. Figure 7.11 shows the number of hours each year that the air temperature in the building exceeds the set point temperature for only the improved cases. In year 10 the base case is over the set point temperature by 63 hours. An additional $5 \mathrm{ft}$ between the boreholes reduces this time to four hours. In year 15 the base case has reached a situation where the boreholes have lost the ability to provided sufficient cooling, but by adding an additional $5 \mathrm{ft}$ the conditioned temperature exceeds the set point temperature 33 hours and for the case with an additional $10 \mathrm{ft}$ the temperature exceeds the set point for only 2 hours. This indicates that increasing the spacing between boreholes will result in a 
significantly longer borehole lifetime.

Based on the results presented, the configuration and spacing of the boreholes can reduce the annual energy costs, but more importantly, it can increase the life of the borehole. By providing the maximum amount of space between the boreholes and using configurations that reduce borehole interactions the lifetime of the borehole could be substantially increased without a significant increase in installation costs.

\subsection{Ground Temperature}

One of the factors that sets Texas and the southwest U.S. apart from areas where ground source heat pumps are common, such as the midwest and northeast parts of the United States, is higher ground temperatures and lower ground conductivities. Figure 7.12 shows the ground temperatures in Texas at $9.1 \mathrm{~m}(30 \mathrm{ft})$ below the surface of the ground. The figure shows that the temperatures range from $60^{\circ} \mathrm{F}\left(15.5^{\circ} \mathrm{C}\right)$ in the panhandle to $81^{\circ} \mathrm{F}\left(27.2^{\circ} \mathrm{C}\right)$ in the most southern parts. To determine the effects of the ground temperatures

Table 7.6: Simulated ground temperatures

\begin{tabular}{llllllll}
\hline Celsius & 17.3 & 18.8 & 20.3 & 21.7 & 23.3 & 24.8 & $25.3{ }^{\circ} \mathrm{C}$ \\
Fahrenheit & 63.1 & 65.8 & 68.5 & 71.2 & 73.9 & 76.6 & $79.3{ }^{\circ} \mathrm{F}$ \\
\hline
\end{tabular}

on ground source heat pumps a sensitivity study was performed. Seven different temperatures were simulated, using Austin's ground temperature, $21.7^{\circ} \mathrm{C}$ 


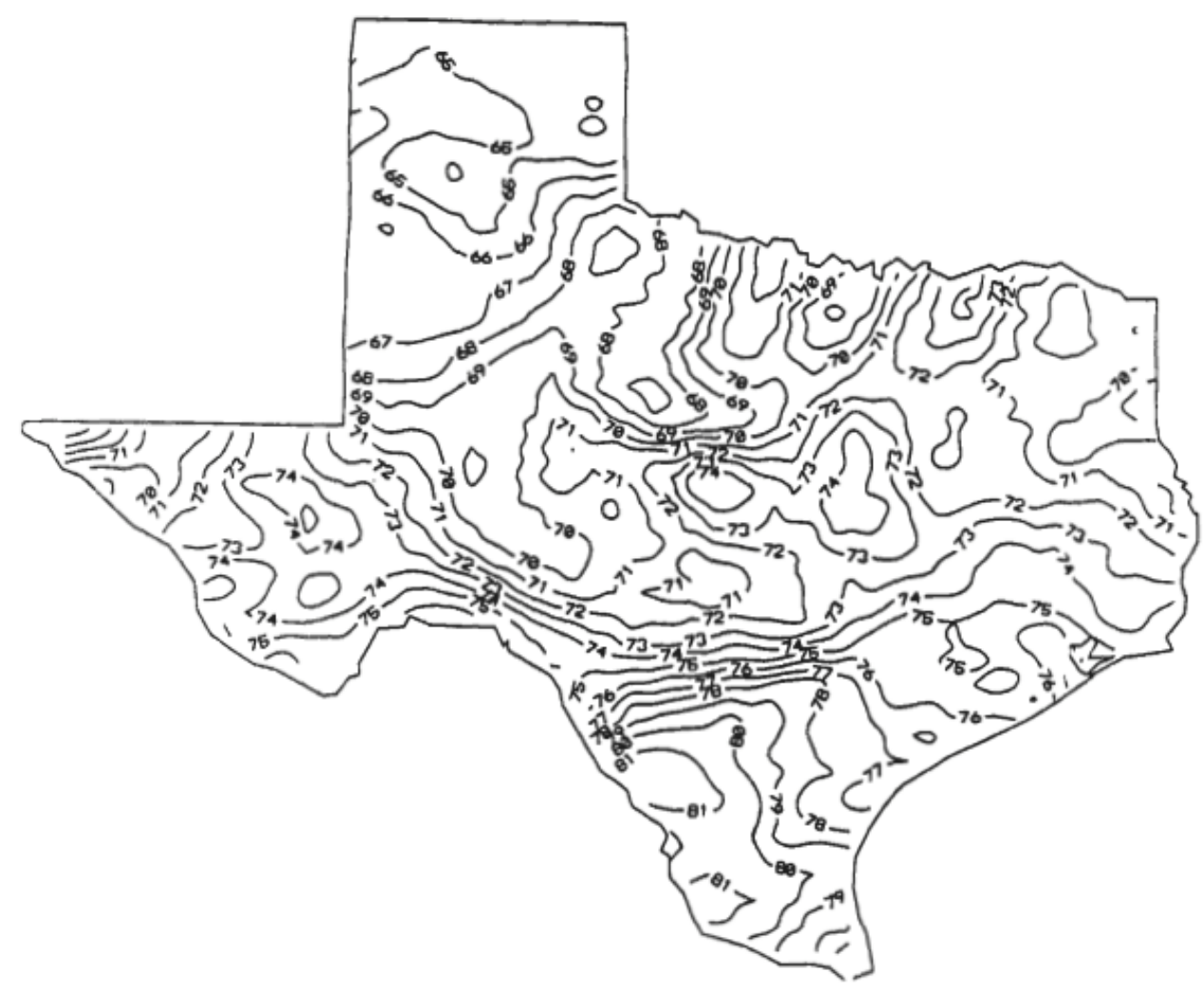

Figure 7.12: Undisturbed ground temperatures $\left({ }^{\circ} F\right)$ at depths greater than $9.1 \mathrm{~m}(30 \mathrm{ft})$ [American Society of Petroleum Geologists, 1974]

$\left(71.2^{\circ} \mathrm{F}\right)$ as the base case and the temperature was increased and decreased in $1.5^{\circ} \mathrm{C}\left(2.7^{\circ} \mathrm{F}\right)$ increments. The simulated temperatures are shown in Table 7.6.

As expected, the starting ground temperature affects the ground loop temperatures. As the starting ground temperatures increases across the tested range the average heat pump entering water temperatures increased by the same amounts, as shown is Figure 7.13. An interesting phenomenon occurs in 
year eight of the highest temperature tested. There is a significant increase in the average temperature between year seven and eight which is caused by high water temperatures during the winter that causes the heat pump to shut down. The heat pump will stop operating while it is in the heating mode if the entering water temperatures exceeds $32.2^{\circ} \mathrm{C}\left(90^{\circ} \mathrm{F}\right)$.

The ground temperature results were very similar to the results from the length analysis; the ground temperatures higher than Austin's ground temperature resulted in premature failure of the ground loop. In Figure 7.15 the total annual cooling for each year of operation is given. By year ten the annual delivered cooling is reduced by $1.3 \%, 3.8 \%$, and $7.3 \%$ for the $22.3^{\circ} \mathrm{C}, 24.8^{\circ} \mathrm{C}$, and $25.3^{\circ} \mathrm{C}$ cases, respectively. Figure 7.16 shows the number of hours each year that the building air temperature exceeded the set point temperature. The cases exceeded 200 hours of time above the set point, which corresponds to approximately $10 \%$ of the total annual cooling time, in years 7,3 , and 2 for the $22.3^{\circ} \mathrm{C}, 24.8^{\circ} \mathrm{C}$, and $25.3^{\circ} \mathrm{C}$ cases, respectively, which represents a significant failure in the system. The lower ground temperatures prevent the building temperature from exceeding the set point temperatures. In year fifteen, there are only 20 hours where the building temperature exceeded set point temperature for the $20.3^{\circ} \mathrm{C}$ case and no hours for the two lower temperatures.

The lower water temperatures associated with the reduced ground temperatures shown in Figures 7.13 and 7.14 translate into more efficient heat pump operation, as shown in Figure 7.17. In year five the EER is increased 


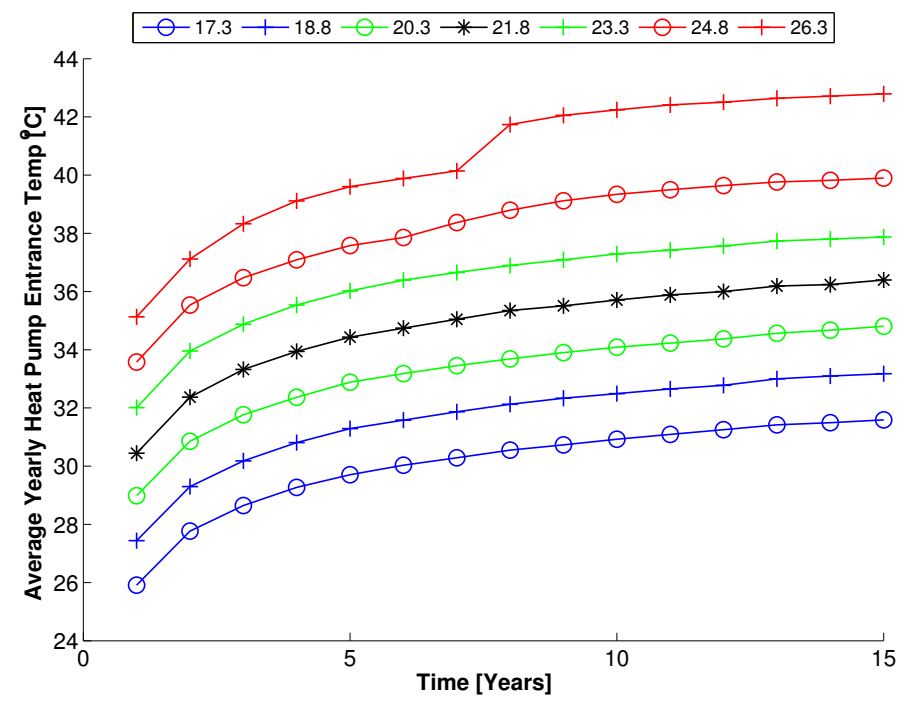

Figure 7.13: Yearly mean water temperature entering the heat pump for the different ground temperatures tested, data can be found in Table E.10

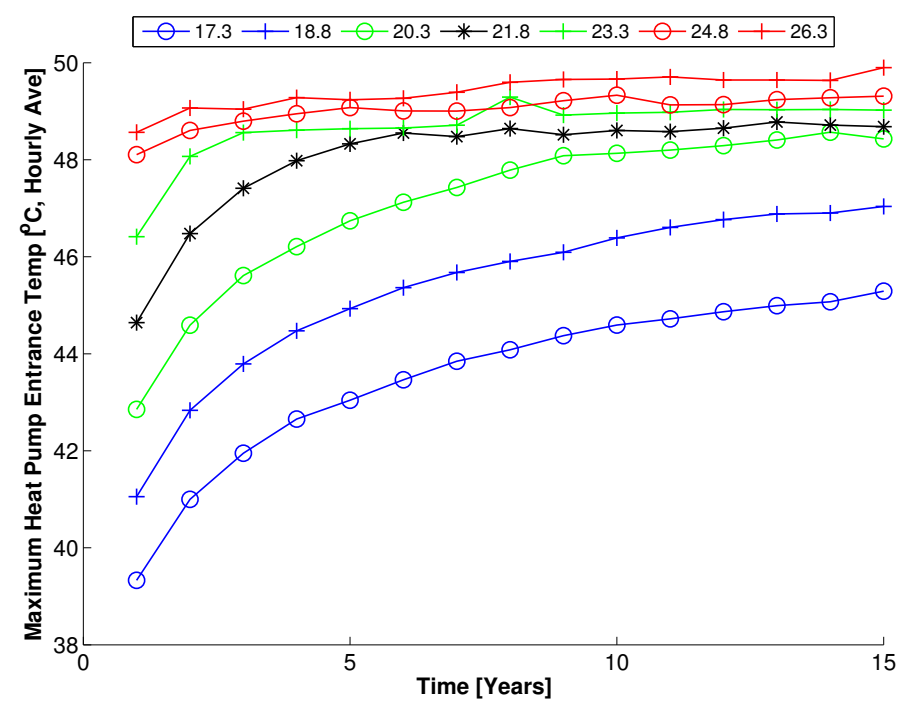

Figure 7.14: Yearly maximum water temperature entering the heat pump for the different ground temperatures tested, data can be found in Table E.11 


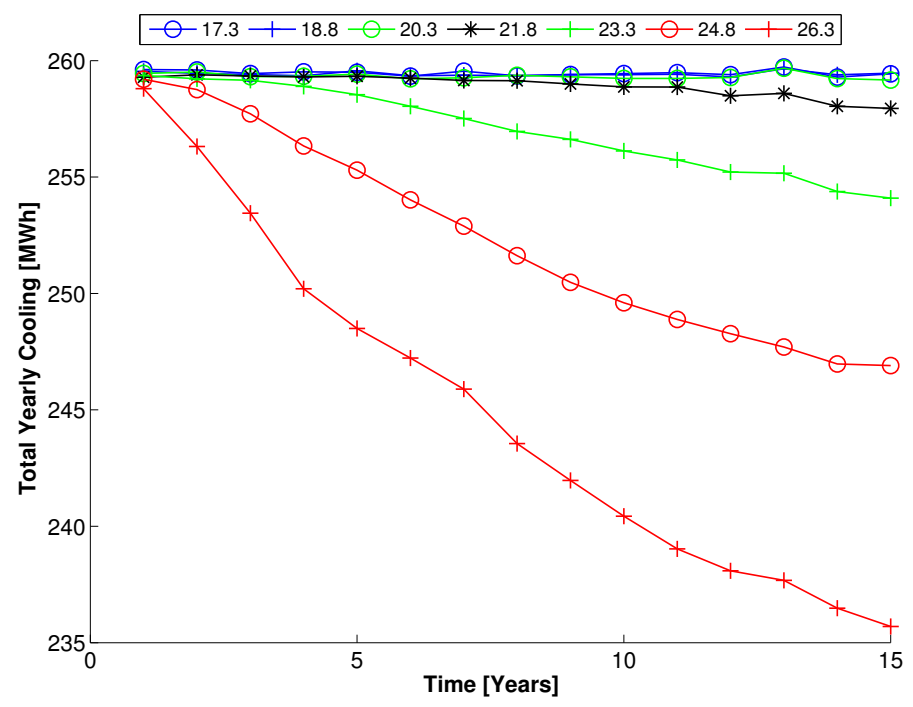

Figure 7.15: Total annual cooling for the different ground temperatures tested, data can be found in Table E.12

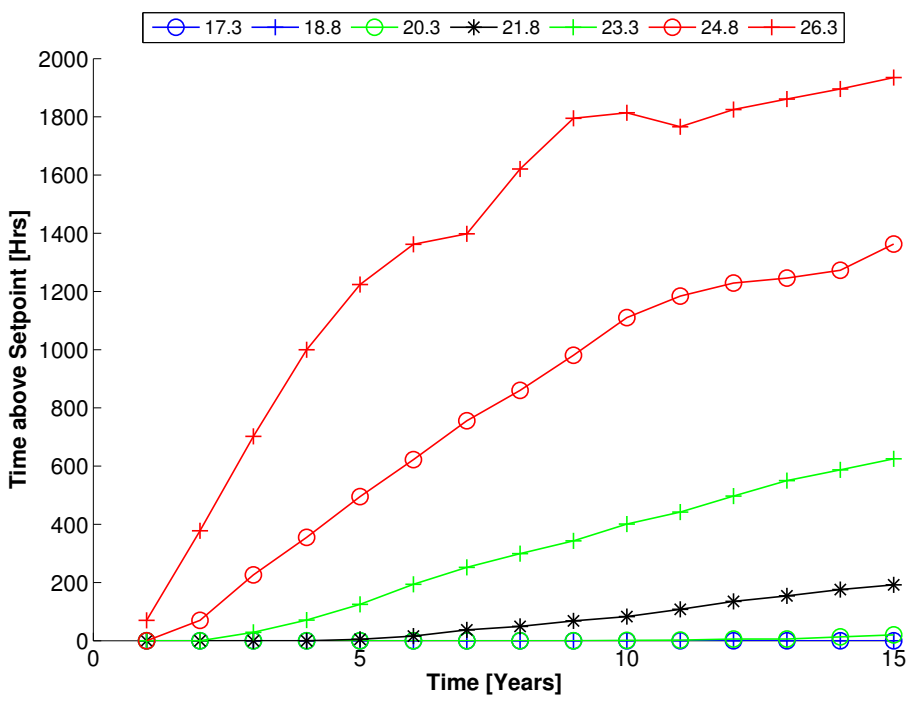

Figure 7.16: Total annual time that zone 1 air temperature exceeds cooling set point for the different ground temperatures tested, based on hourly averages, data can be found in Table E.13 
from the base case by $4.8 \%, 10.0 \%$ and $15.6 \%$ for the successively lower ground temperatures. Similar values are seen in year ten as well. Of all of the results presented, ground temperature had the greatest effect on the EER. The lowest ground temperature tested produced the highest EER for any of the sensitivity tests completed.

Figure 7.18 shows the total annual electricity use over the 15 years of the simulation. As shown previously, the cases that experience premature failure actually see a reduction in the annual electricity used. For the cases without premature failure there is a $2.5 \%$ reduction in the annual energy use for every $1^{\circ} \mathrm{C}\left(1.8^{\circ} \mathrm{F}\right)$ reduction in ground temperature over the range tested in years five and ten. The lowest temperature tested consumes $11.5 \%$ less energy in years five and ten than the base case.

Table 7.7: Comparison of operating costs and savings over ten years for the different ground temperatures tested, assuming $0.1133 \$ / k W h$ (Texas residential price August 2011) [U.S. Dept. of Energy, 2011a]

\begin{tabular}{lrrrr}
\hline Ground Temperature $\left[{ }^{\circ} \mathrm{C}\right]$ & Base - 21.7 & 20.3 & 18.8 & 17.3 \\
\hline Total Energy $(\mathrm{kWh})$ & 98217 & 94609 & 90788 & 87137 \\
Total Operating Cost $\$$ & $\$ 11,128$ & $\$ 10,719$ & $\$ 10,286$ & $\$ 9,873$ \\
Energy Savings $(\mathrm{kWh})$ & - & 3608 & 7428 & 11080 \\
Cost Savings $\$$ & - & $\$ 409$ & $\$ 842$ & $\$ 1,255$ \\
\hline
\end{tabular}

Table 7.7 shows the total energy used and cost over ten years for the ground temperatures that did not cause premature failure. There are significant reductions in the total operating cost of the ground loop as the ground temperatures decrease. For these simulations the total operating costs were 


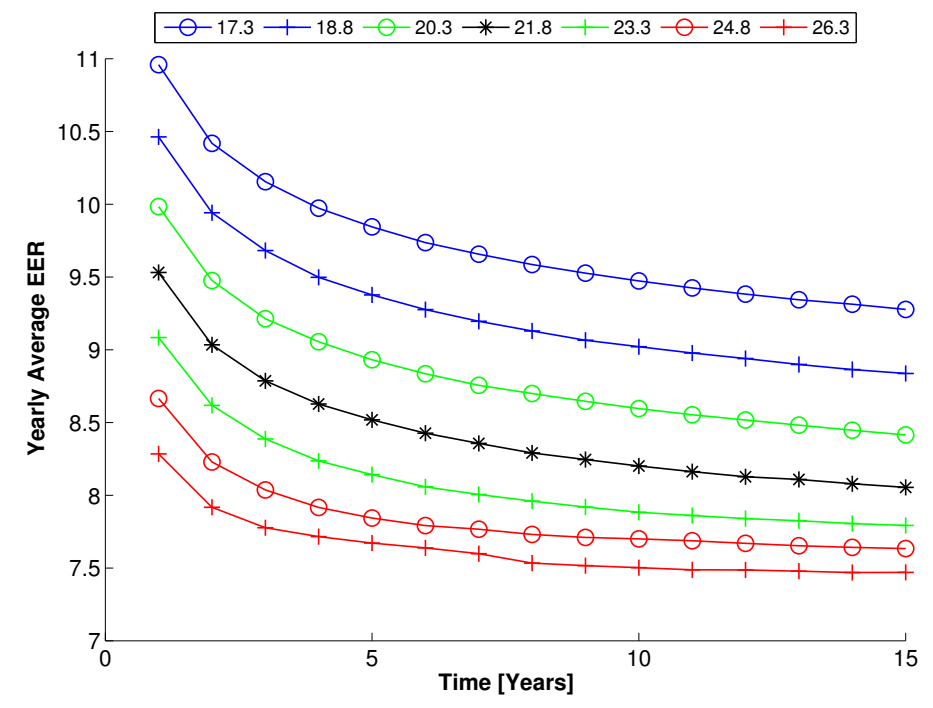

Figure 7.17: Average annual energy efficiency ratio (EER) for the different ground temperatures tested, data can be found in Table E.14

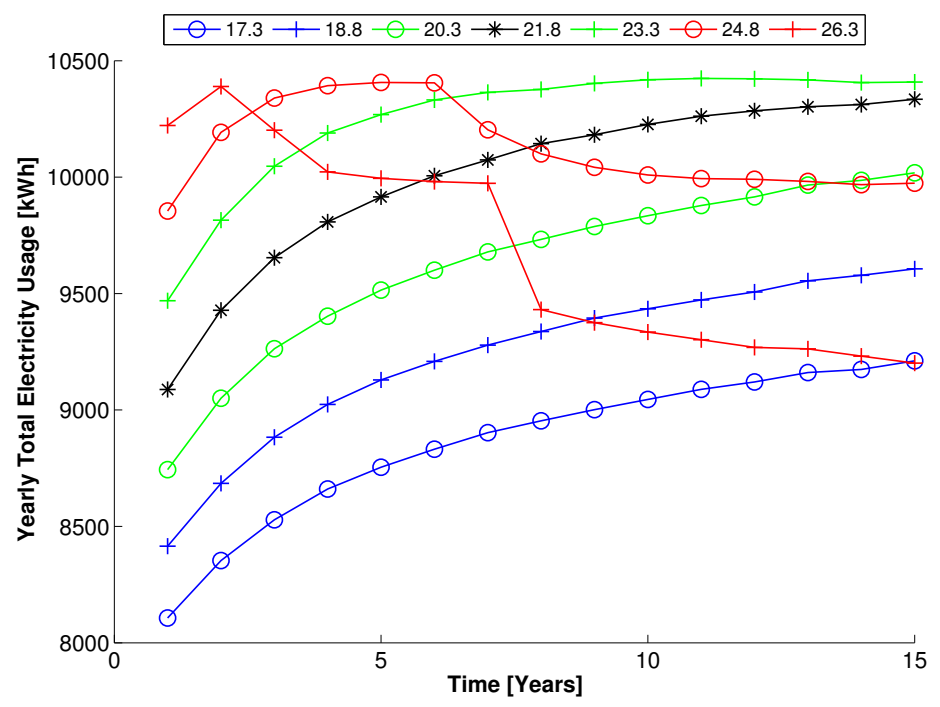

Figure 7.18: Total annual electricity use for the different ground temperatures tested, data can be found in Table E.15 
reduced by $\$ 285$ per ${ }^{\circ} C\left(\$ 155\right.$ per $\left.{ }^{\circ} F\right)$. Based on the results, ground temperature has a large effect on the operation of the heat pump. Higher ground temperatures result in lower operating efficiencies and shorter borehole life times.

\subsection{Grout Conductivity}

A common method to increase borehole performance is to increase the conductivity of the grout used to back fill the borehole. This is accomplished by using a thermally enhanced grout. Normal grout is typically made with bentonite, a type of clay, which has a thermal conductivity of $0.744 \mathrm{~W} / \mathrm{m} \mathrm{K}$ $\left(0.43 \mathrm{Btu} / \mathrm{hr} f t^{\circ} \mathrm{F}\right)$. The grout is packaged in bags and is mixed with water on site and pumped down the boreholes. To create thermally enhanced grout, silica sand is added to the base bentonite grout in varying ratios to increase conductivity up to $2.06 \mathrm{~W} / \mathrm{m} \mathrm{K}\left(1.20 \mathrm{Btu} / \mathrm{hr} \mathrm{ft}^{\circ} \mathrm{F}\right)$. If the boreholes are improperly backfilled with grout, pockets of air can be left behind resulting in a reduced effective borehole conductivity.

To determine the effects of changes in grout conductivity five different grout conductivities were tested. The conductivity of standard bentonite grout, $0.744 \mathrm{~W} / \mathrm{m} K\left(0.43 \mathrm{Btu} / \mathrm{hr} f t^{\circ} \mathrm{F}\right)$, and a conductivity equal of the local soil $1.333 \mathrm{~W} / \mathrm{m} \mathrm{K}\left(0.78 \mathrm{Btu} / \mathrm{hr} f t^{\circ} \mathrm{F}\right)$ were simulated. In addition, the grouts with $0.5 \mathrm{~W} / \mathrm{m} \mathrm{K}\left(0.29 \mathrm{Btu} / \mathrm{hr} f t^{o} \mathrm{~F}\right), 1.0 \mathrm{~W} / \mathrm{m} \mathrm{K}\left(0.58 \mathrm{Btu} / \mathrm{hr} f t^{o} \mathrm{~F}\right)$, and $1.5 \mathrm{~W} / \mathrm{m} K\left(0.87 \mathrm{Btu} / \mathrm{hr} f t^{\circ} \mathrm{F}\right)$ were used. All other model parameter where left identical to the base model. 
Figure 7.19 shows that increasing the conductivity decreases the average water loop temperatures up to the point when the conductivity of the grout is equal to the ground conductivity. The change in the mean temperature between $0.744 \mathrm{~W} / \mathrm{m} \mathrm{K}$ and $1.333 \mathrm{~W} / \mathrm{m} \mathrm{K}$ is $1{ }^{\circ} \mathrm{C}\left(1.8^{\circ} \mathrm{F}\right)$ for years five and ten. For $1.333 \mathrm{~W} / \mathrm{m} \mathrm{K}$ and $1.500 \mathrm{~W} / \mathrm{m} \mathrm{K}$ it is only $0.17{ }^{\circ} \mathrm{C}(0.3$ $\left.{ }^{\circ} \mathrm{F}\right)$ and $0.10^{\circ} \mathrm{C}\left(0.18^{\circ} \mathrm{F}\right)$ for years five and ten, respectively. The figure also shows that a reduction in the conductivity has a larger effect on the mean temperatures than an increase of a similar amount. In year five, the mean temperature increases by $1.1^{\circ} \mathrm{C}\left(2.0^{\circ} \mathrm{F}\right)$ when decreasing the conductivity by $0.244 \mathrm{~W} / \mathrm{m} \mathrm{K}$, but only decreases by $0.6{ }^{\circ} \mathrm{C}\left(1.1^{\circ} \mathrm{F}\right)$ when the conductivity is increased by a similar amount. Similar values are seen in year ten.

Figure 7.20 shows the effects of the grout conductivity on the annual maximum temperatures. The grouts with lower conductivities reach their lifetime maximum values significantly quicker that the those with higher conductivities. Here the reduced effect of increasing the grout conductivity past the ground conductivity is seen as well. Comparing this figure with the previous figure the effect of increasing the grout conductivity is more pronounced on the maximum temperatures than it is on the mean temperatures. Table 7.8 shows the change in the temperatures compared to the base case grout conductivity values. Using a grout with a conductivity of $1.333 \mathrm{~W} / \mathrm{m} \mathrm{K}$ reduces the maximum temperature by $5.7 \%$ and $3.4 \%$ in years five and ten, when compared to the base case grout. The mean temperature is only reduced by $3.4 \%$ and $2.8 \%$ in years five and ten. 


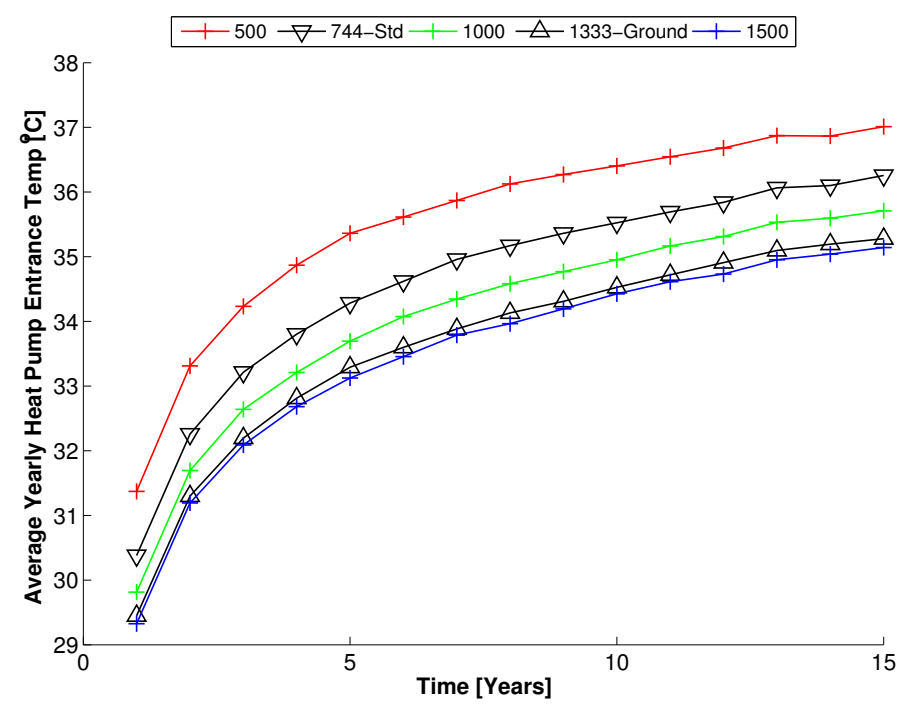

Figure 7.19: Yearly mean water temperature at the heat pump entrance for the different grout conductivities tested, data can be found in Table E.16

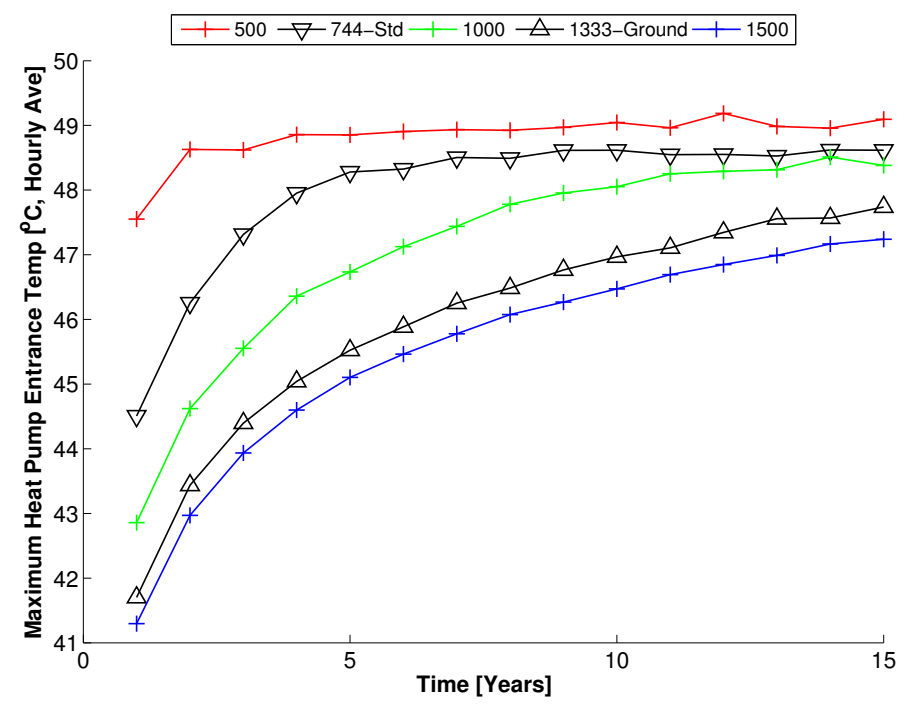

Figure 7.20: Yearly maximum water temperature at the heat pump entrance for the different grout conductivities tested, data can be found in Table E.17 
Table 7.8: Comparison of maximum and mean heat pump water temperatures in ${ }^{\circ} \mathrm{C}$ for years five and ten

\begin{tabular}{lrrrrr}
\hline Conductivity $[W / m K]$ & 0.500 & 0.744 & 1.000 & 1.333 & 1.500 \\
\hline Year 5 & & & & & \\
Maximum Temperature & 48.85 & 48.28 & 46.74 & 45.52 & 45.10 \\
Change & $1.19 \%$ & - & $-3.20 \%$ & $-5.71 \%$ & $-6.58 \%$ \\
Mean Temperature & 35.36 & 34.28 & 33.69 & 33.29 & 33.13 \\
Change & $3.15 \%$ & - & $-1.71 \%$ & $-2.89 \%$ & $-3.38 \%$ \\
\hline Year 10 & & & & & \\
Maximum Temperature & 49.04 & 48.62 & 48.05 & 46.97 & 46.47 \\
Change & $0.88 \%$ & - & $-1.16 \%$ & $-3.39 \%$ & $-4.41 \%$ \\
Mean Temperature & 36.40 & 35.52 & 34.95 & 34.53 & 34.43 \\
Change & $2.47 \%$ & - & $-1.61 \%$ & $-2.81 \%$ & $-3.09 \%$ \\
\hline
\end{tabular}

The total annual cooling provided by the heat pump, shown in Figure 7.21, reduces for the lowest conductivity case while the rest of the values remain constant. The lowest conductivity case has a reduction of $1.6 \%$ in the provided annual cooling in year ten. Comparing this with Figure 7.22, which shows the total time above the set point it become clear that a grout conductivity of $0.5 \mathrm{~W} / \mathrm{m} K$ causes premature failure of the boreholes. This demonstrates the importance of properly back filling the borehole when they are installed to ensure that the proper borehole conductivity has been reached along the length of the borehole.

For the cases with an increased grout conductivity the time above the set point temperature is significantly reduced. For the highest two values there are no hours above the set point temperature by the end of the 15 year 


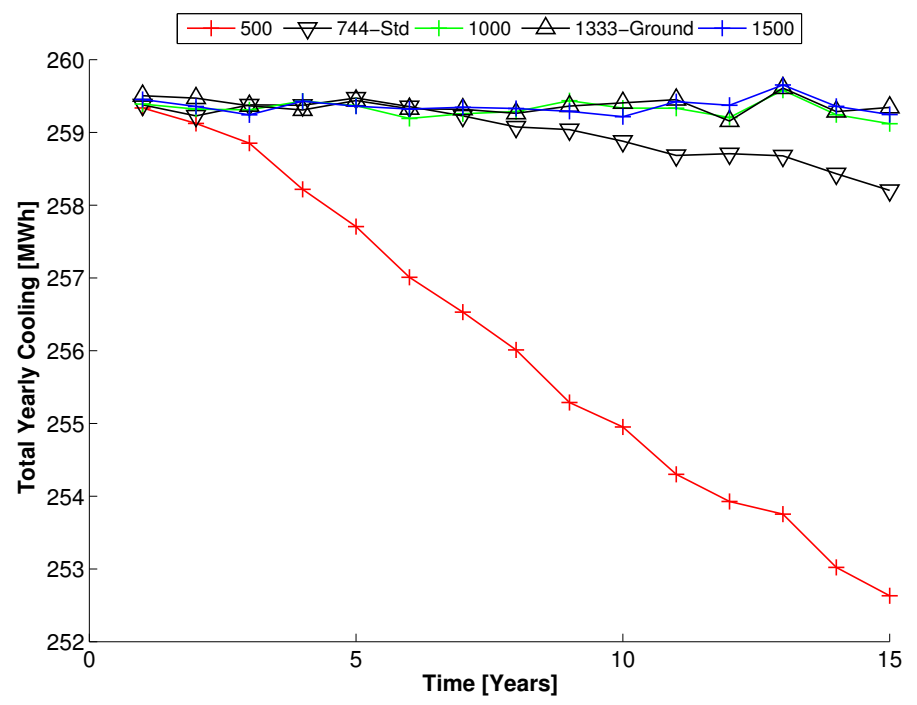

Figure 7.21: Total annual cooling for the different grout conductivities tested, data can be found in Table E.18

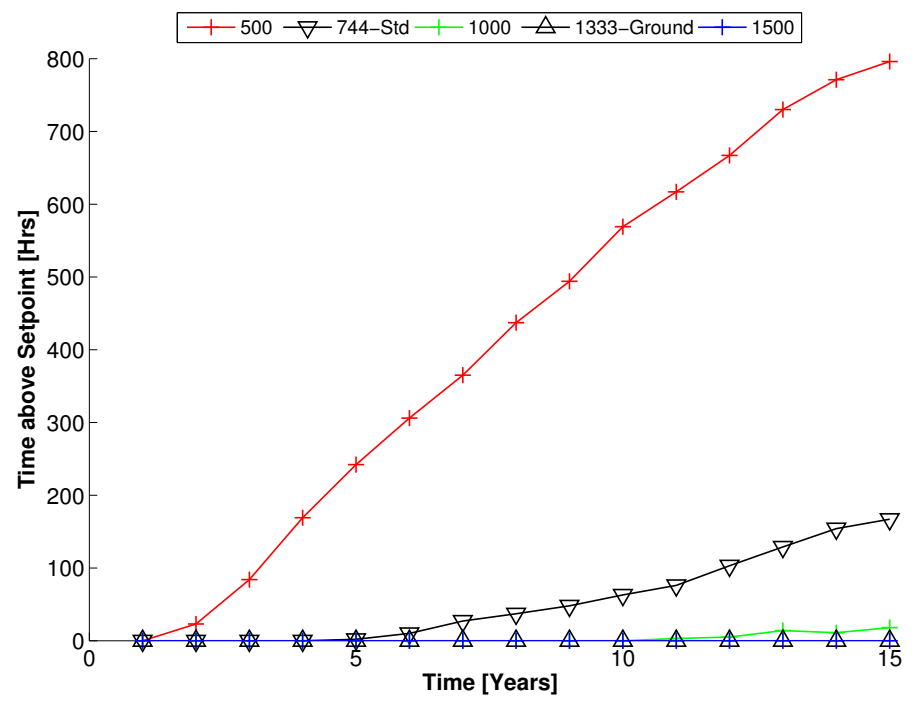

Figure 7.22: Total annual time that zone 1 air temperature exceeds cooling set point for the different grout conductivities tested, based on hourly averages, data can be found in Table E.19 
simulation. The case with a conductivity of $1.0 \mathrm{~W} / \mathrm{m} \mathrm{K}$ shows no hours above the set point in year ten compared to 63 hours for the base case and only 18 hours in year 15 compared to 167 hours. This indicates that increasing the conductivity of the grout will extend the lifetime of the boreholes.

Due to the lower water temperatures in the ground loop the heat pump operates more efficiently with higher conductivity grouts. Figure 7.23 shows the EER for each year of operation for all of the conductivities simulated. In year five the EER increases by $3.2 \%, 5.7 \%$ and $6.5 \%$ for each successively higher conductivity above the base case. Similar increases are also seen in year ten. The lower ERRs cause the annual electricity use to decrease as shown in Figure 7.24. The total energy used over ten years of operation is shown in Table 7.9. Increasing the conductivity of the grout to $1.0 \mathrm{~W} / \mathrm{m} \mathrm{K}, 1.333$ $W / m K$, and $1.5 W / m K$ reduces the total energy consumption over the ten year period by $2.9 \%, 5.0 \%$, and $5.6 \%$, respectively, when compared to the base case of $0.744 \mathrm{~W} / \mathrm{m} \mathrm{K}$.

Table 7.9: Comparison of operating costs and savings over ten years for the different grout conductivities tested, assuming $0.1133 \$ / k W h$ (Texas residential price August 2011) [U.S. Dept. of Energy, 2011a]

\begin{tabular}{lrrrr}
\hline Conductivity $[W / m K]$ & Base -0.744 & 1.000 & 1.333 & 1.500 \\
\hline Total Energy $(\mathrm{kWh})$ & 98217 & 95422 & 93361 & 92675 \\
Total Energy Cost $\$$ & $\$ 11,128$ & $\$ 10,811$ & $\$ 10,578$ & $\$ 10,500$ \\
Energy Savings $(\mathrm{kWh})$ & - & 2795 & 4856 & 5542 \\
Cost Savings $\$$ & - & $\$ 317$ & $\$ 550$ & $\$ 628$ \\
\hline
\end{tabular}

Based on the results of this study, increasing the conductivity of the 


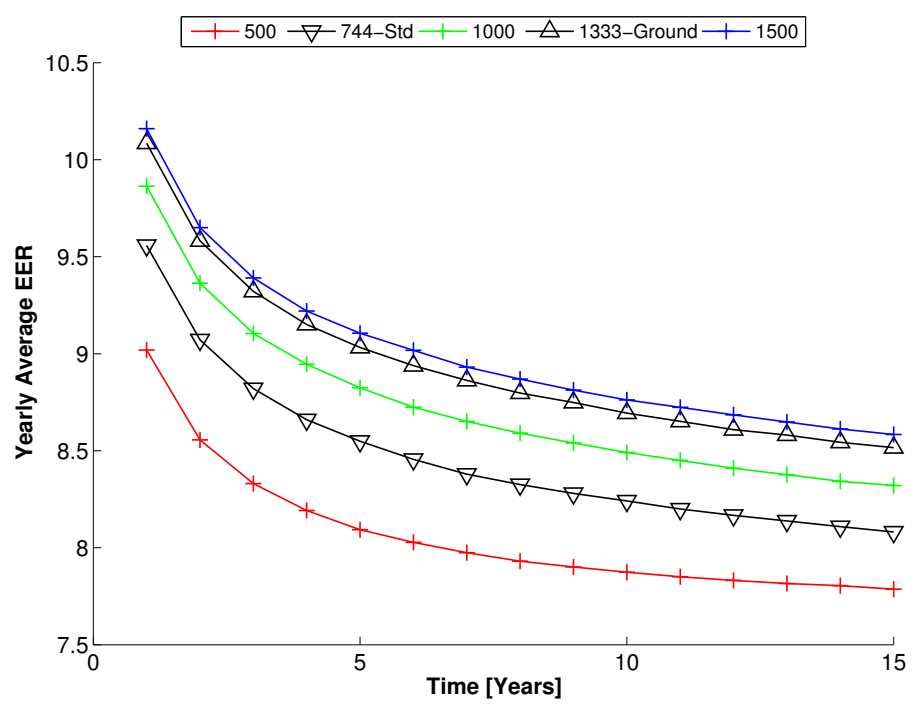

Figure 7.23: Average annual energy efficiency ratio (EER) for the different grout conductivities tested, data can be found in Table E.20

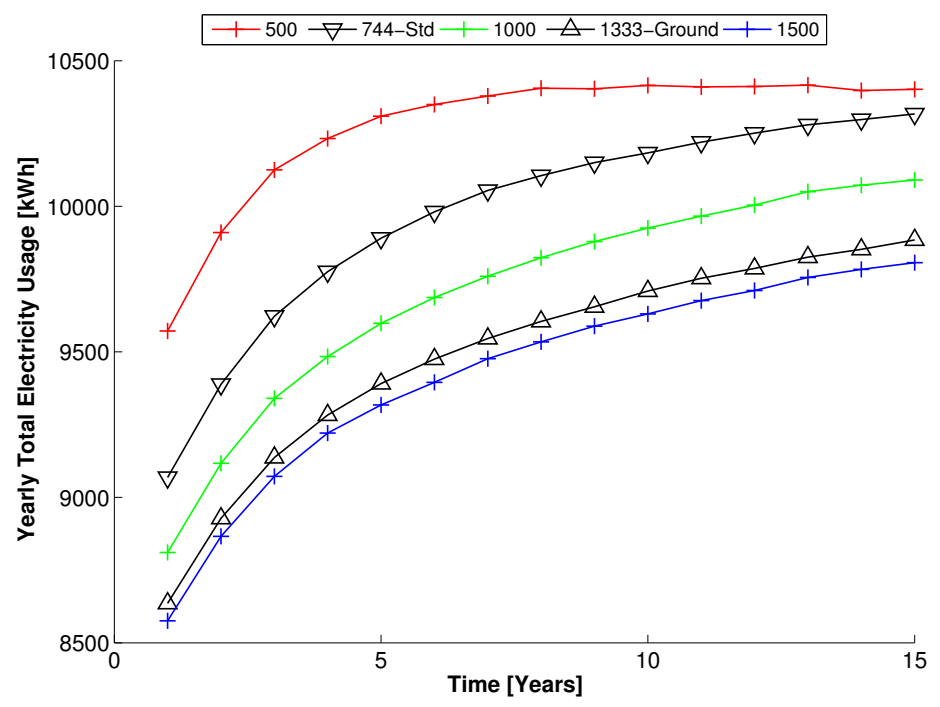

Figure 7.24: Total annual electricity use for the different grout conductivities tested, data can be found in Table E.21 
grout used to backfill the borehole not only reduces the annual energy costs associated with the operation of the heat pump, it also increases the life of the borehole by reducing the annual maximum temperatures of the water. This lower temperature water prevents the unit from shutting down due to built-in thermal protections.

\subsection{Conclusions}

The parameters varied in this chapter illustrated only a few possible parameters that could be varied by the model. All results show that the borehole operation is very sensitive to these parameters. For a perfectly sized borehole, such as the one used in the base case, any parameter changes that would reduce the effectiveness of the borehole indicated that the ground loop will prematurely fail. This potential highlights the need to add extra borehole length to account for parameter variations since ground parameters are not typically known to precise values for residential installations. Of the individual sensitivity studies performed, the most cost effective measure that can be addressed by the designer is the configuration and spacing of the boreholes. The configuration and spacing study indicated that spacing the boreholes as far apart as possible will lead to a significantly longer borehole lifetimes, for almost no additional cost. Also, avoiding configurations that result in excessive borehole thermal interaction will also increase the lifetime of the borehole. 


\section{Chapter 8}

\section{Conclusions}

With the goal of investigating new technologies and methods to increase the deployment and long term viability of GSHPs in Texas and the

Southwest portion of the United States, a integrated building load-ground source heat pump model was developed for use as a test bed to assess shortand long-term GSHP performance. The integrated model combines individual component models in a user-friendly modeling environment. The building load model, HAMBASE, simulates the dynamic response of the building temperatures. HAMBASE was validated using the ASHRAE 140-2007 standard for validating building load models. A ground source heat pump model was created based on performance data that is readily available from manufacturers. Using this data allows for a wide range of ground source heat pump models to be accurately simulated. The chosen ground loop model can accurately model the thermal response of vertical borehole including thermal interactions among neighboring boreholes over many years as well as calculate the ground loop water temperatures for short time steps. Using GLHEPRO to perform the required ground loop sizing proved to be an accurate method for sizing the boreholes. 
The component models were combined using the Simulink ${ }^{\circledR}$ modeling environment, which gives this integrated model many unique advantages over other building load-ground source heat pump models. The Simulink ${ }^{\circledR}$ environment allows for individual component models, such as SHRs, to be developed and tested independently of the integrated model while utilizing the builtin functionality of Matlab ${ }^{\circledR}$. The addition of custom component models to the integrated model is very easy with Simulink's ${ }^{\circledR}$ graphical programming environment and the graphical interface allows the model to be run by inexperienced users.

The integrated model can compute building temperature responses with small time steps on the order of tens of seconds, while computing the longterm response of the ground loop over many years. The model fully couples the building load model, ground source heat pump model, and the ground loop model to illustrate the effects of ground loop temperatures on the temperatures in the building. The integrated model results were compared, with good agreement to results produced by eQuest for a single-family house with a GSHP. The model does require a significant amount of time to run simulations. It takes approximately 1.5 hours to simulate a single year on a $2.4 \mathrm{GHz}$ Intel processor, and approximately 13 hours to simulate a 15 year period on a $3.73 \mathrm{GHz}$ Xeon processor with at least $6 \mathrm{~GB}$ of RAM.

A 15 year simulation of a single family home illustrated the models ability to simulate dynamic responses of the building while also calculating the long term effects of the ground source heat pump. The simulation revealed 
that over the lifetime of a GSHP, the effectiveness and efficiencies of the system will decrease over its lifetime. This performance degradation causes the yearly operating costs to increase while also increasing the amount of time that the conditioned air exceeds the set point temperature.

The sensitivity study determined cost effective measures to increase the long-term viability of GSHPs in Texas and the southwest portion of the United States. The results illustrated the need to account for local variations in the ground properties when sizing ground loops. Slight reductions in the effectiveness of the boreholes resulted in premature failure of the boreholes and the resulting inability of the heat pumps to provide the necessary energy loads. Of the studies reported in this work, the most cost effective measure to extend the lifetime of the boreholes was the design of the borehole configuration and spacing. Optimizing borehole configuration and maximizing spacing increase the total available capacitance for each borehole and reduced the thermal interactions among boreholes, which results in longer borehole lifetimes.

Throughout Texas and the Southwest regions of the United States, doubt about the long-term technical viability of GSHPs has arisen due inadequate designs to the unfavorable environmental and geological conditions presented by the region. The unbalanced ground heating loads due to these cooling dominated climates, mild winter temperatures, and unfavorable soil conditions, including soils with low conductivities, the lack of moisture and ground water flow to remove heat, and higher annual ground temperatures all effect the performance of GSHPs. Despite these challenges, proper de- 
sign (with or without SHR) will allow GSHPs to perform as designed in these regions. 
Appendices 


\section{Appendix A}

\section{HAMBASE Validation}

Table A.1: Summary of sensitivity study cases

\begin{tabular}{|c|c|c|c|}
\hline Case & Base Case & Changes & Relevant Figure(s) \\
\hline 600 & none & Base case, described in Section 2.3.1 & A. $1-$ A. 6 \\
\hline 610 & 600 & Addition of shading over south facing windows & A.7 \\
\hline 620 & 600 & $\begin{array}{l}\text { Removes the } 12 \mathrm{~m}^{2} \text { of windows from the south wall } \\
\text { and adds } 6 \mathrm{~m}^{2} \text { of shading to the east and west walls }\end{array}$ & A. 8 \\
\hline 630 & 620 & $\begin{array}{r}\text { Addition of shading above and around the widows on } \\
\text { the east and west walls }\end{array}$ & A. 9 \\
\hline 640 & 600 & $\begin{array}{r}\text { The heater thermostat is setback to } 10^{\circ} \mathrm{C} \\
\text { between the } 2300 \text { and } 0700 \text { hours and left at } 20^{\circ} \mathrm{C} \\
\text { between } 0700 \text { and } 2300 \text { hours }\end{array}$ & A. 10 \\
\hline 650 & 600 & $\begin{array}{r}\text { Night time ventilation is added between } 1800 \\
\text { and } 0700 \text { hours, the heat is always off and cooling is } \\
\text { only provided between } 0700 \text { and } 1800 .\end{array}$ & A. 11 \\
\hline 900 & 600 & $\begin{array}{r}\text { Construction materials changed to materials } \\
\text { with higher heat capacities }\end{array}$ & A.12 - A.14 \\
\hline 910 & 610 & Same as 900 & A. 15 \\
\hline 920 & 620 & Same as 900 & A.16 \\
\hline 930 & 630 & Same as 900 & A. 17 \\
\hline 940 & 640 & Same as 900 & A. 18 \\
\hline 950 & 650 & Same as 900 & A.19 \\
\hline 960 & 900 & $\begin{array}{r}\text { Addition of unconditioned sunspace on the } \\
\text { south side of the house }\end{array}$ & A. 20 \\
\hline $600 \mathrm{FF}$ & 600 & No heating or cooling provided to the building & A. 21 \\
\hline $650 \mathrm{FF}$ & 650 & Same as $600 \mathrm{FF}$, still has night time ventilation & A. 22 \\
\hline $900 \mathrm{FF}$ & 900 & Same as $600 \mathrm{FF}$ & A. $23 \&$ A. 24 \\
\hline $950 \mathrm{FF}$ & 950 & Same as $600 \mathrm{FF}$, still has night time ventilation & A. 25 \\
\hline
\end{tabular}




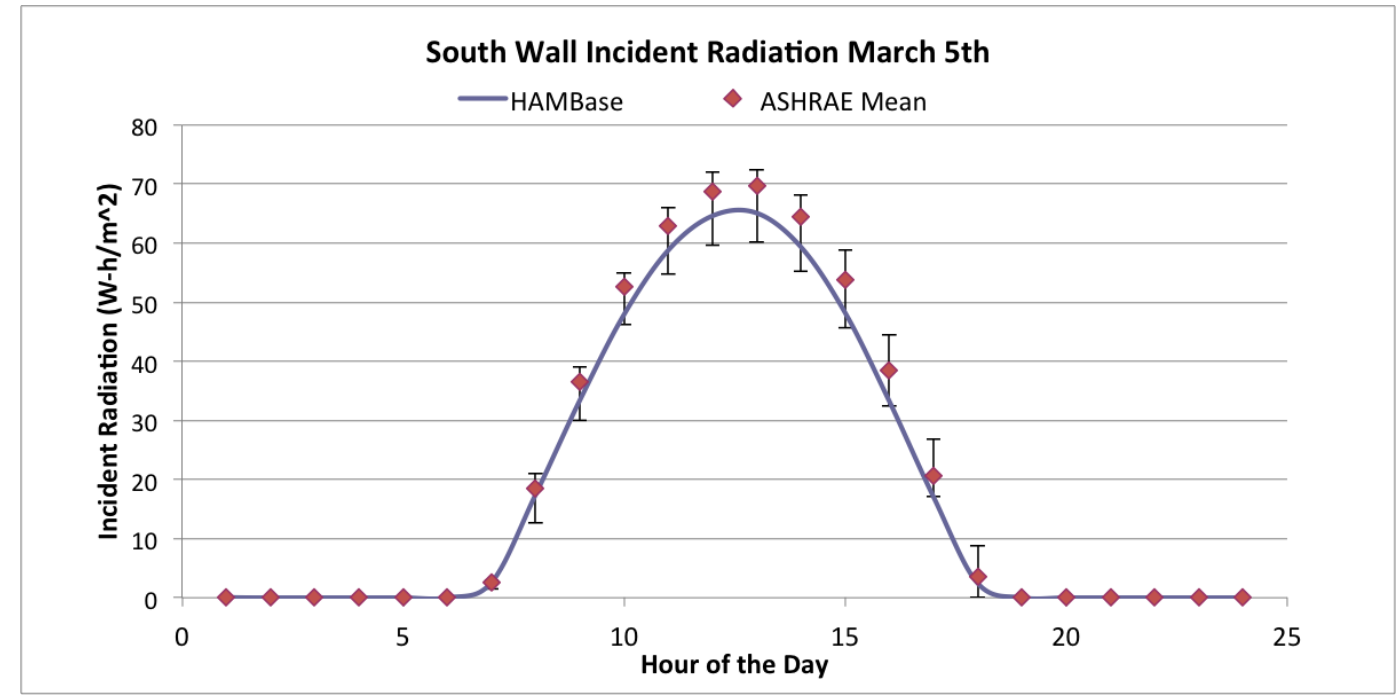

Figure A.1: Comparison of hourly incident radiation on the south wall for March 5th

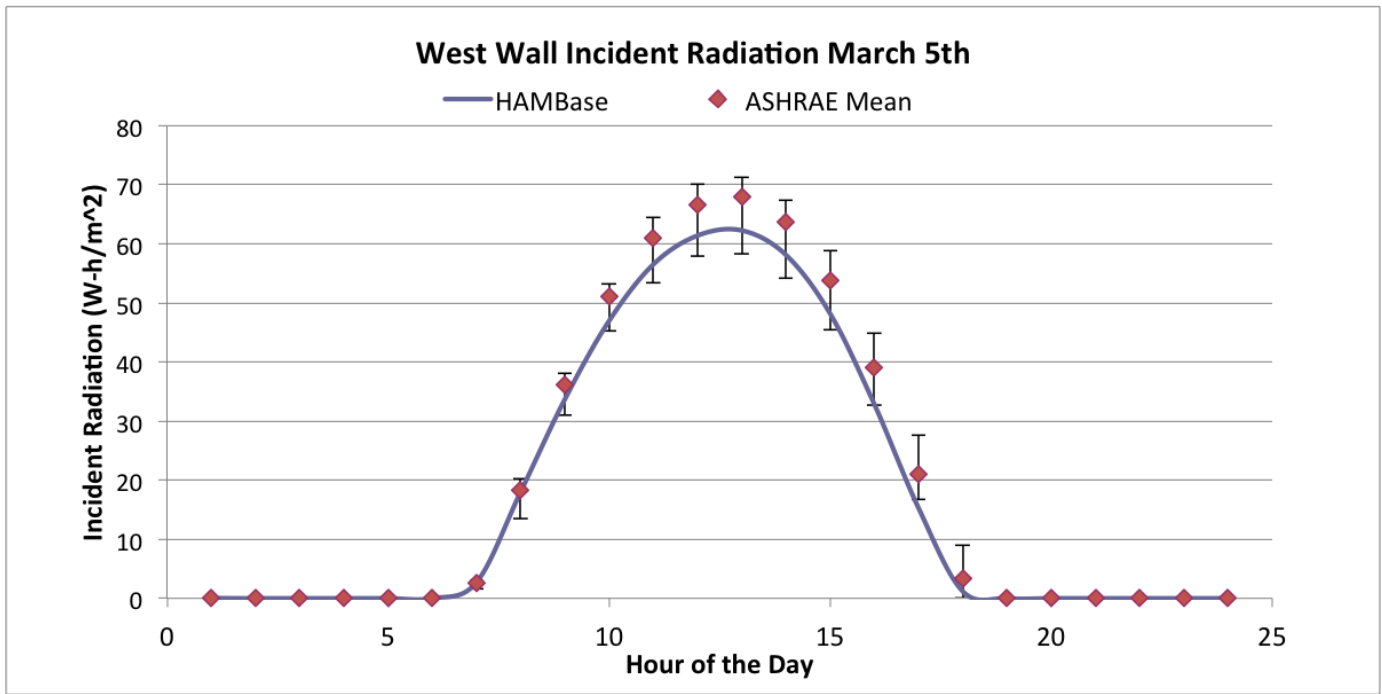

Figure A.2: Comparison of hourly incident radiation on the west wall for March 5th 


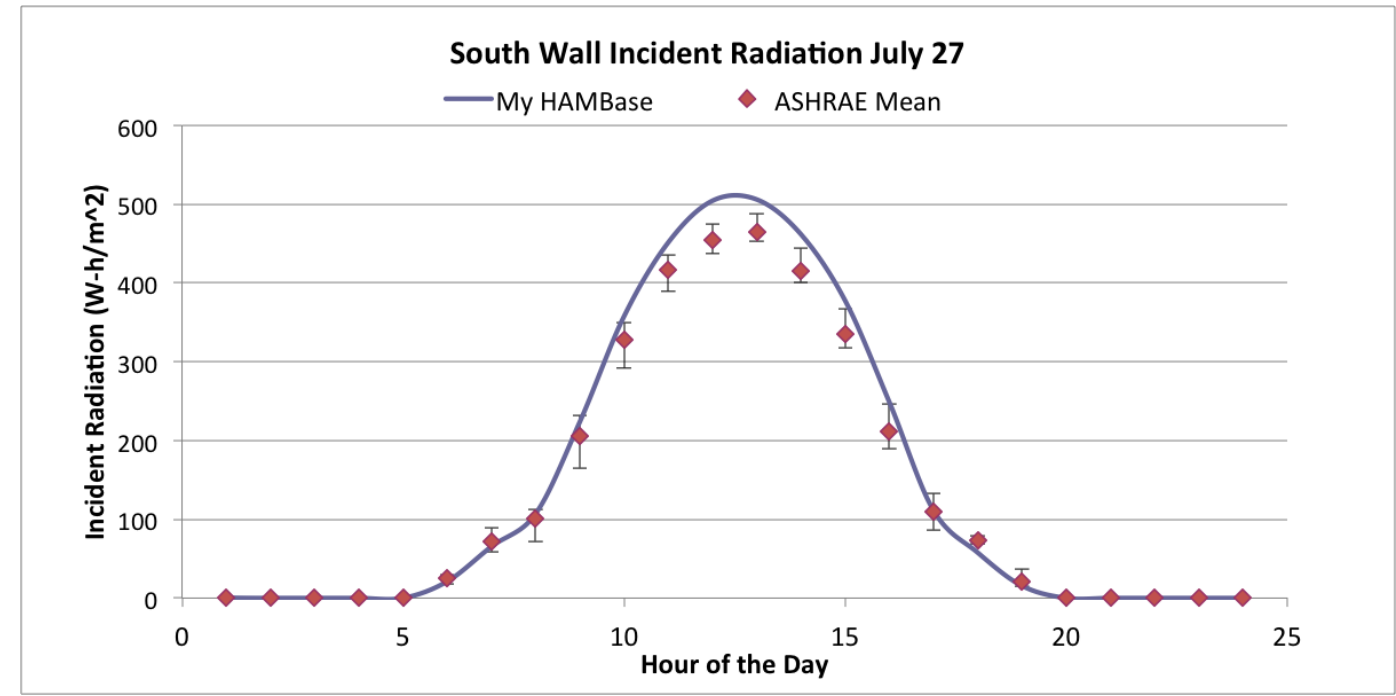

Figure A.3: Comparison of hourly incident radiation on the south wall for July 27th

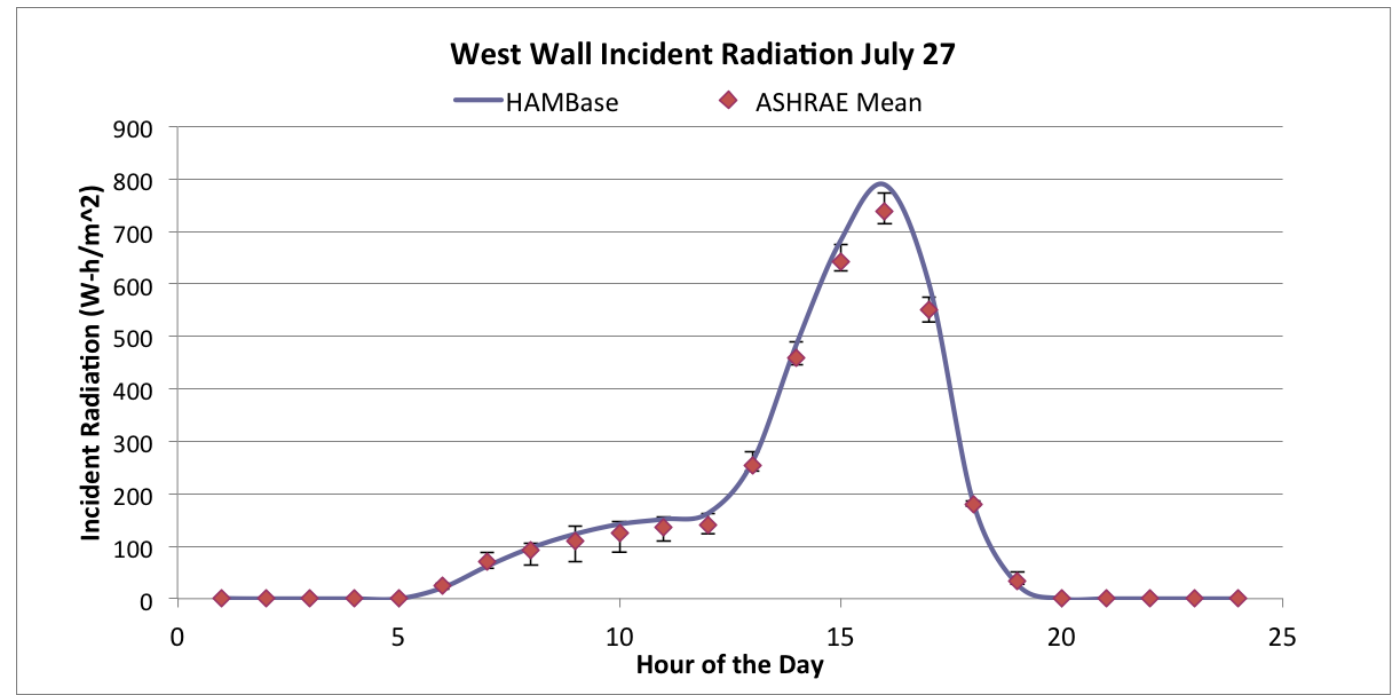

Figure A.4: Comparison of hourly incident radiation on the west wall for July 27th 


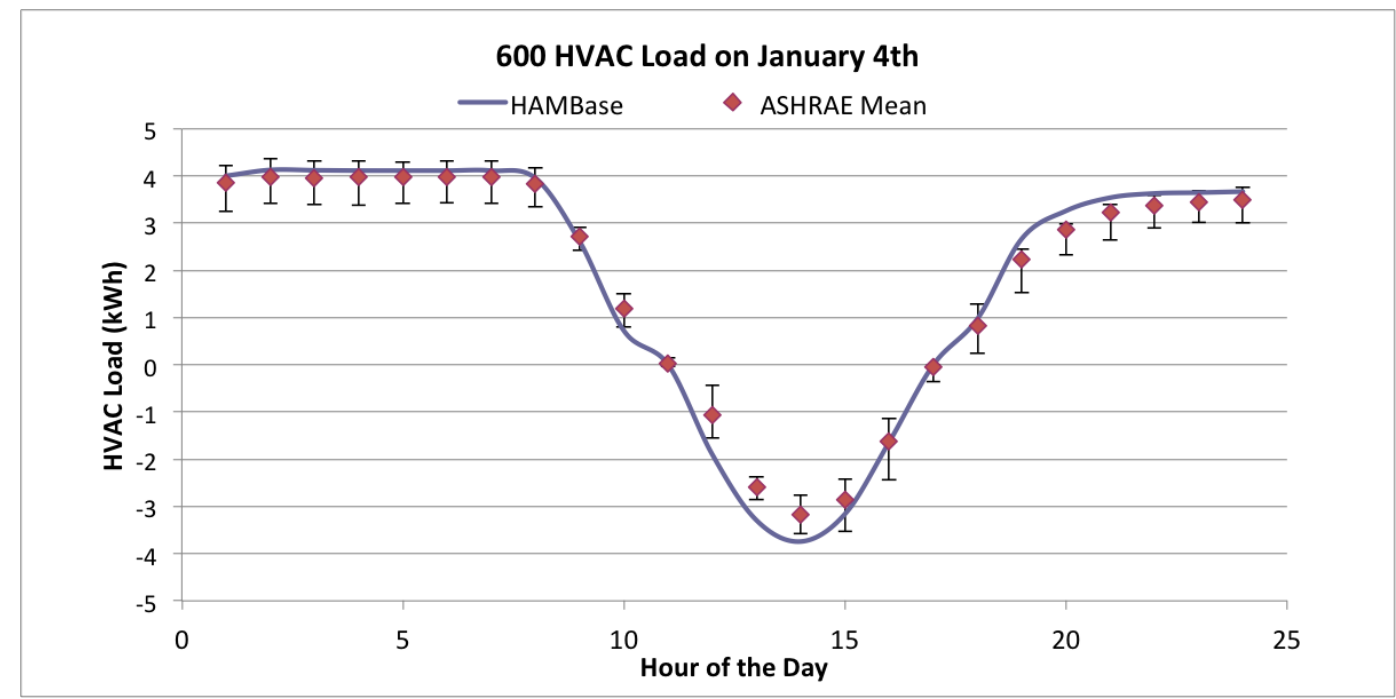

Figure A.5: Comparison of hourly HVAC system loads for case 600 on January 4 th

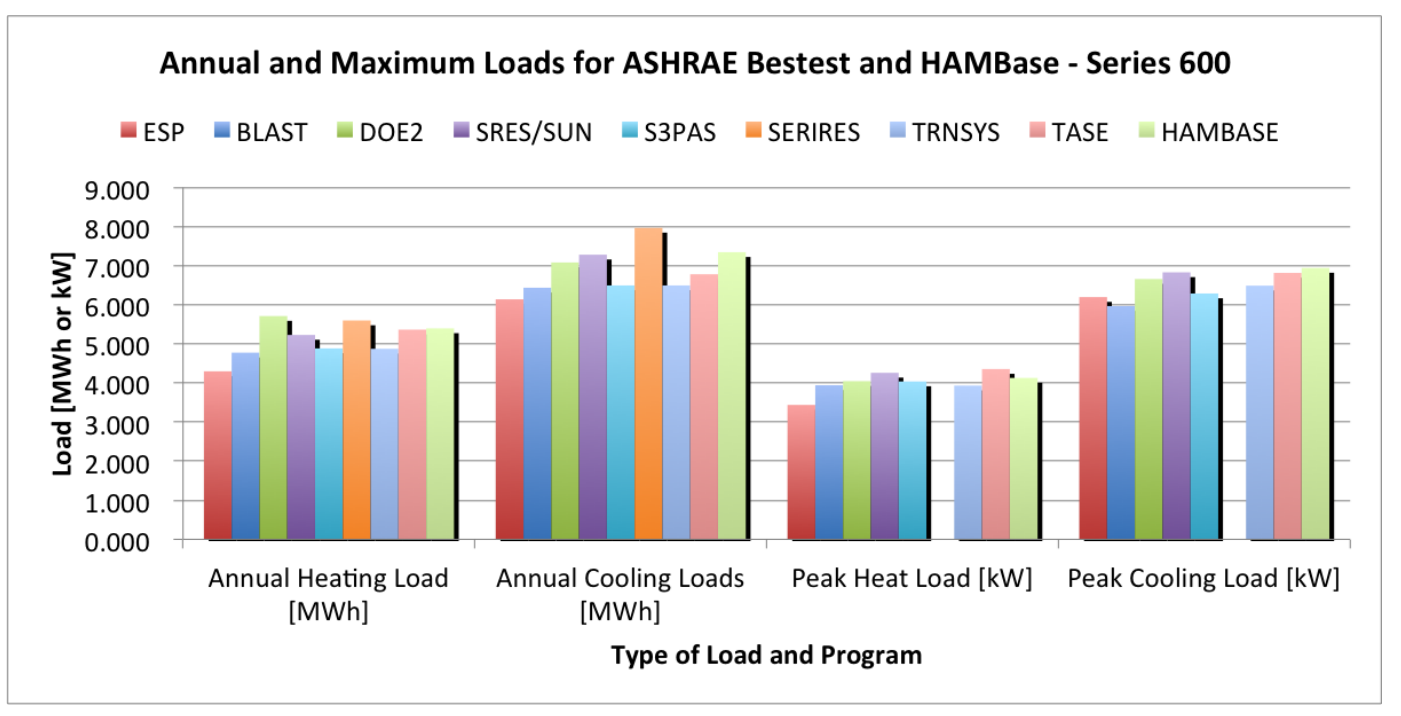

Figure A.6: Comparison of total annual and peak load for case 600 


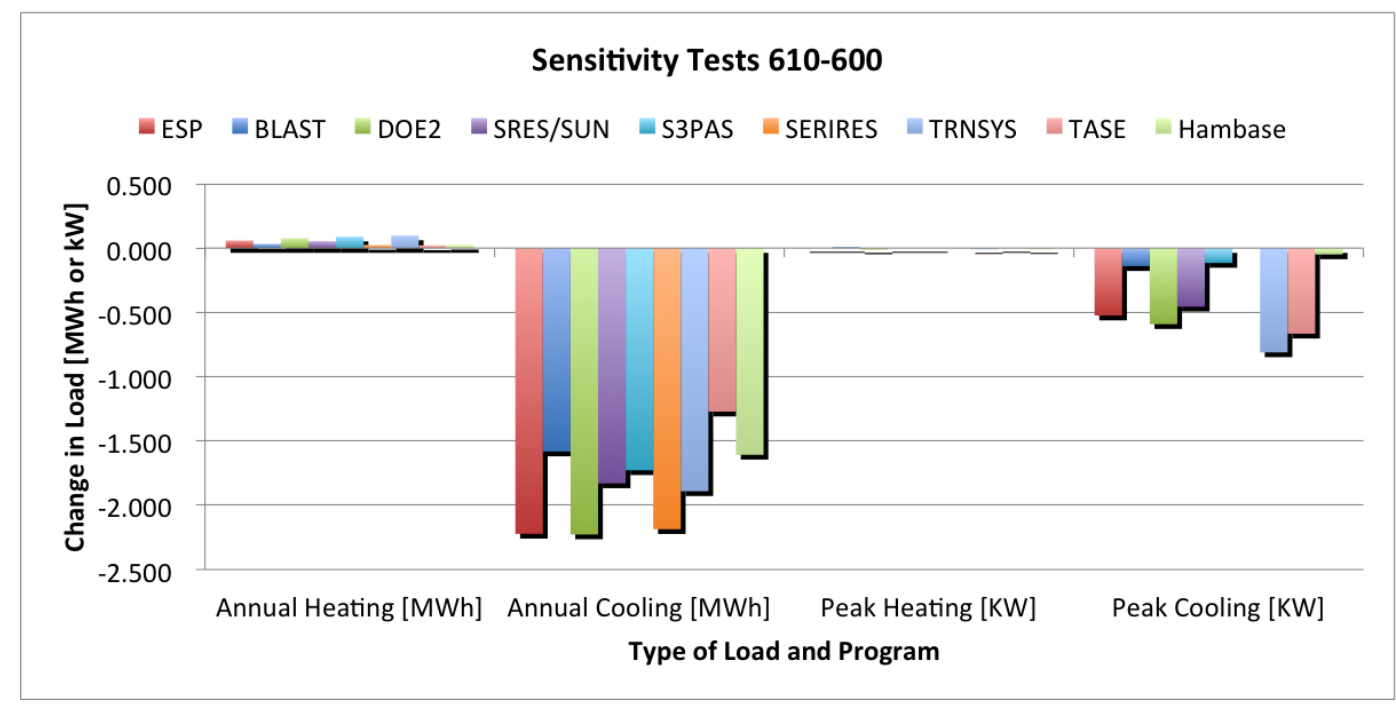

Figure A.7: Comparison of total annual and peak load differences between case 610 and 600 . Includes the addition of shading over the south windows

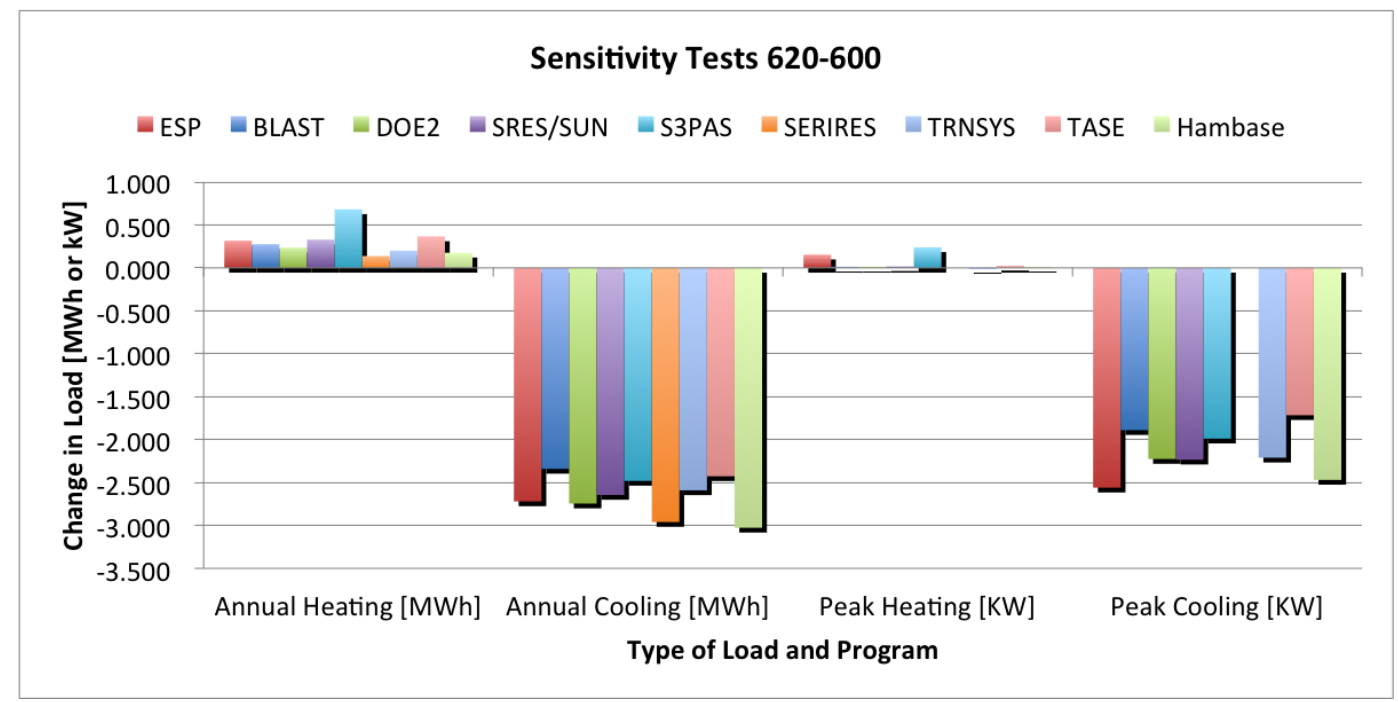

Figure A.8: Comparison of total annual and peak load differences between case 620 and 600 . Moves the windows from the south wall to the east and west walls. 


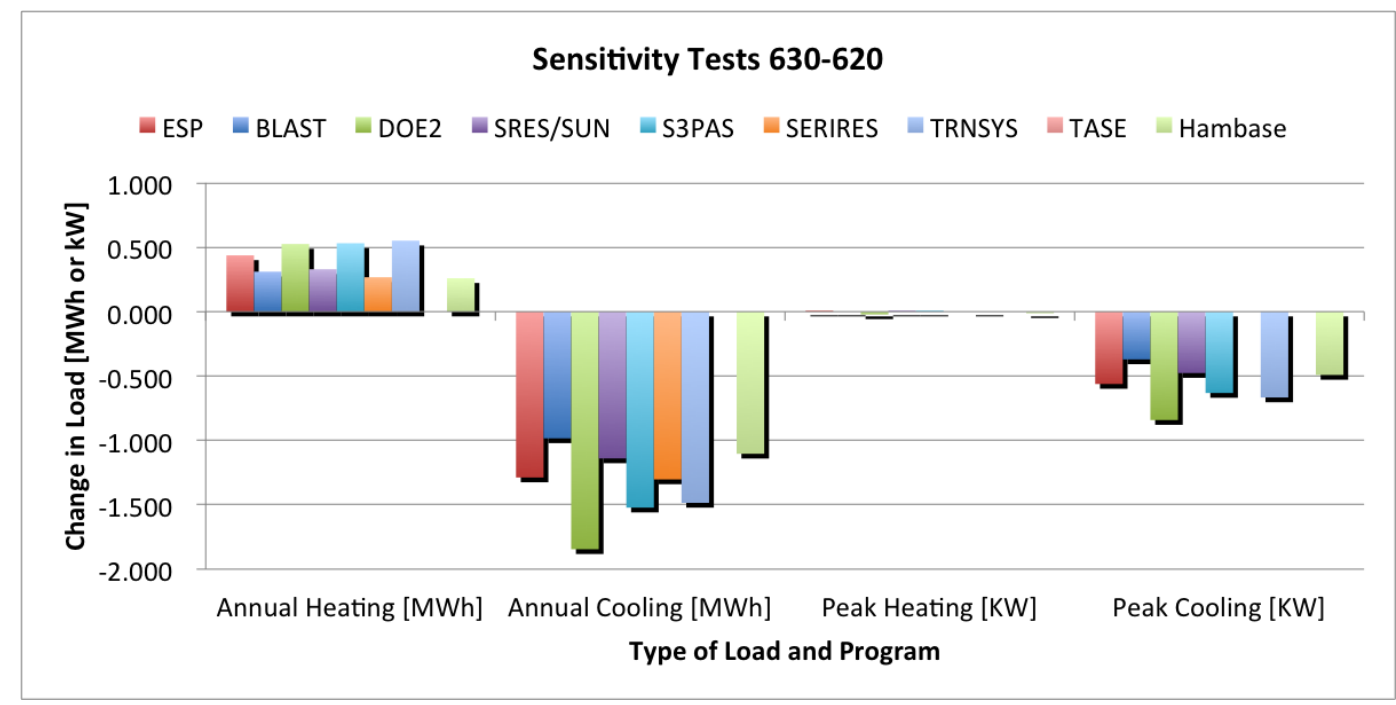

Figure A.9: Comparison of total annual and peak load differences between case 630 and 620 . Includes the addition of shading around the windows on the east and west walls

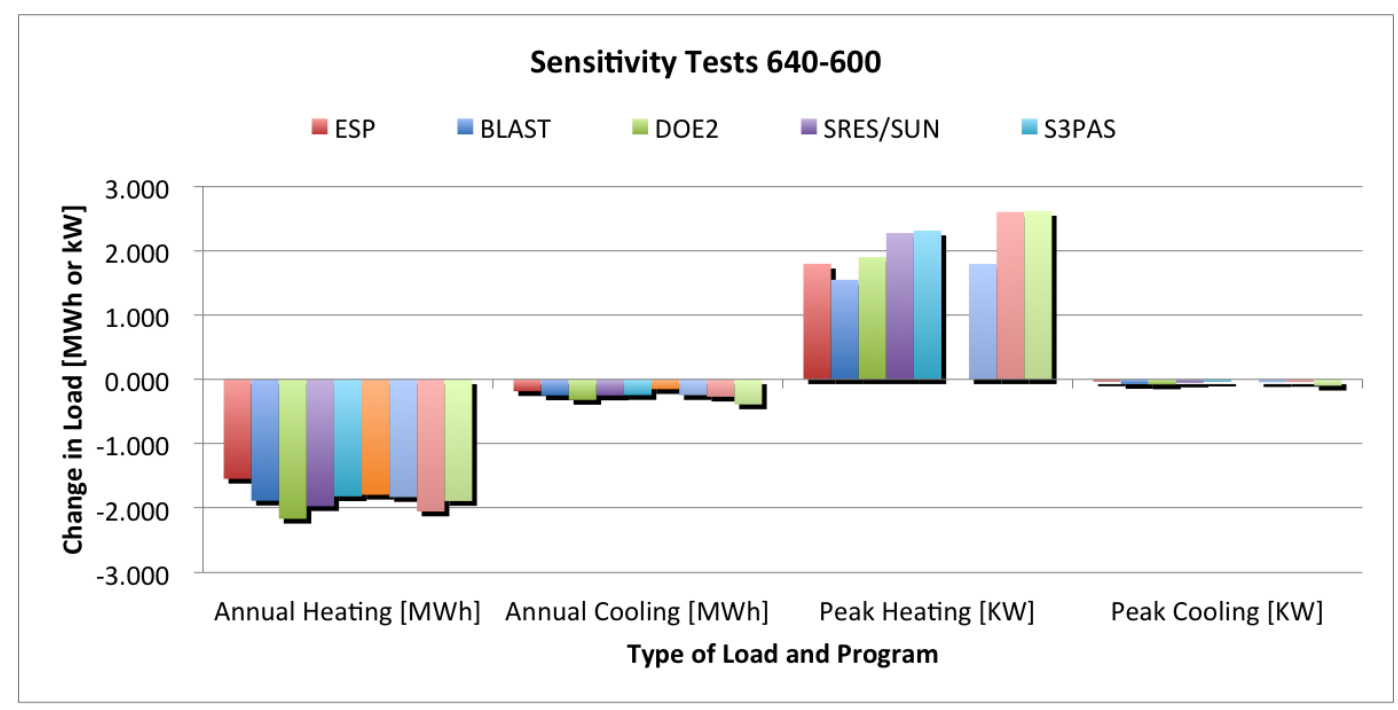

Figure A.10: Comparison of total annual and peak load differences between case 640 and 600 . Heater thermostat is setback to $10^{\circ} \mathrm{C}$ at night 


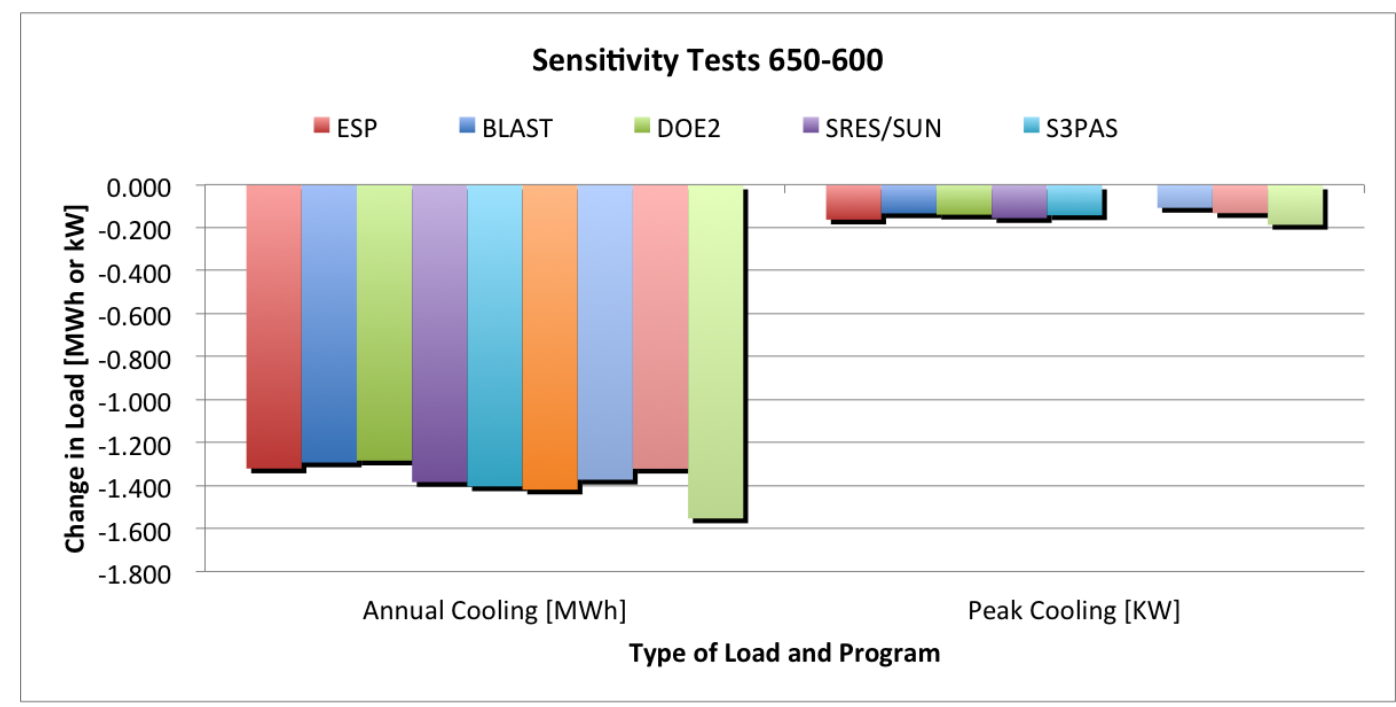

Figure A.11: Comparison of total annual and peak load differences between case 650 and 600. Adds night time ventilation

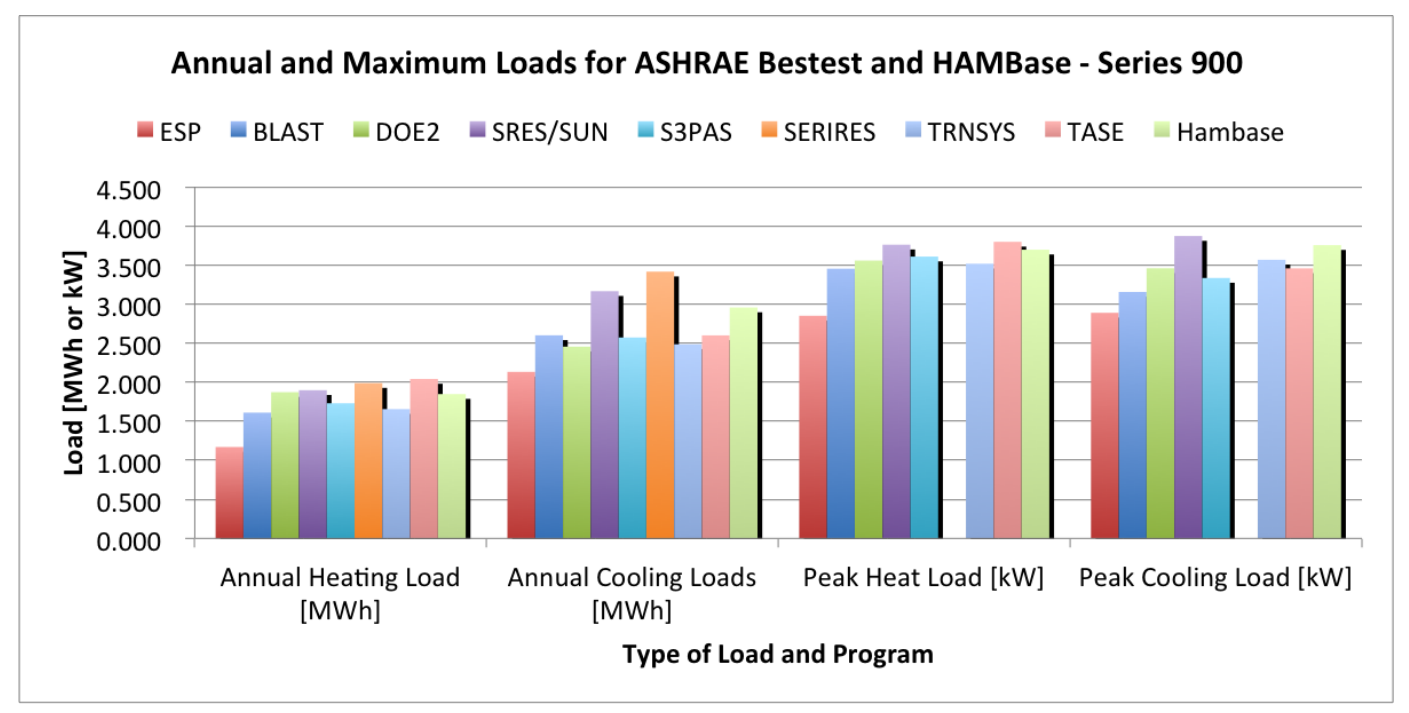

Figure A.12: Comparison of total annual and peak load for case 900 


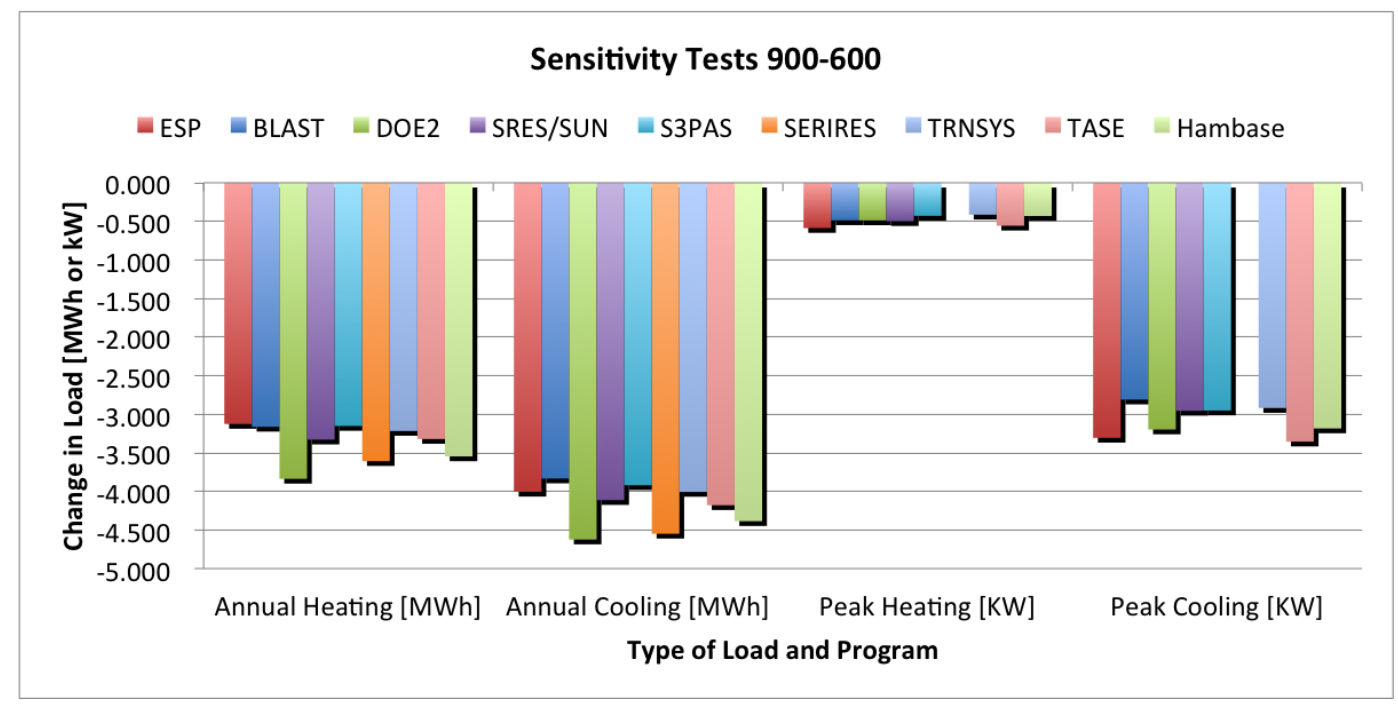

Figure A.13: Comparison of total annual and peak load differences between case 900 and 600 . The construction materials properties are changed to have higher volumetric heat capacities

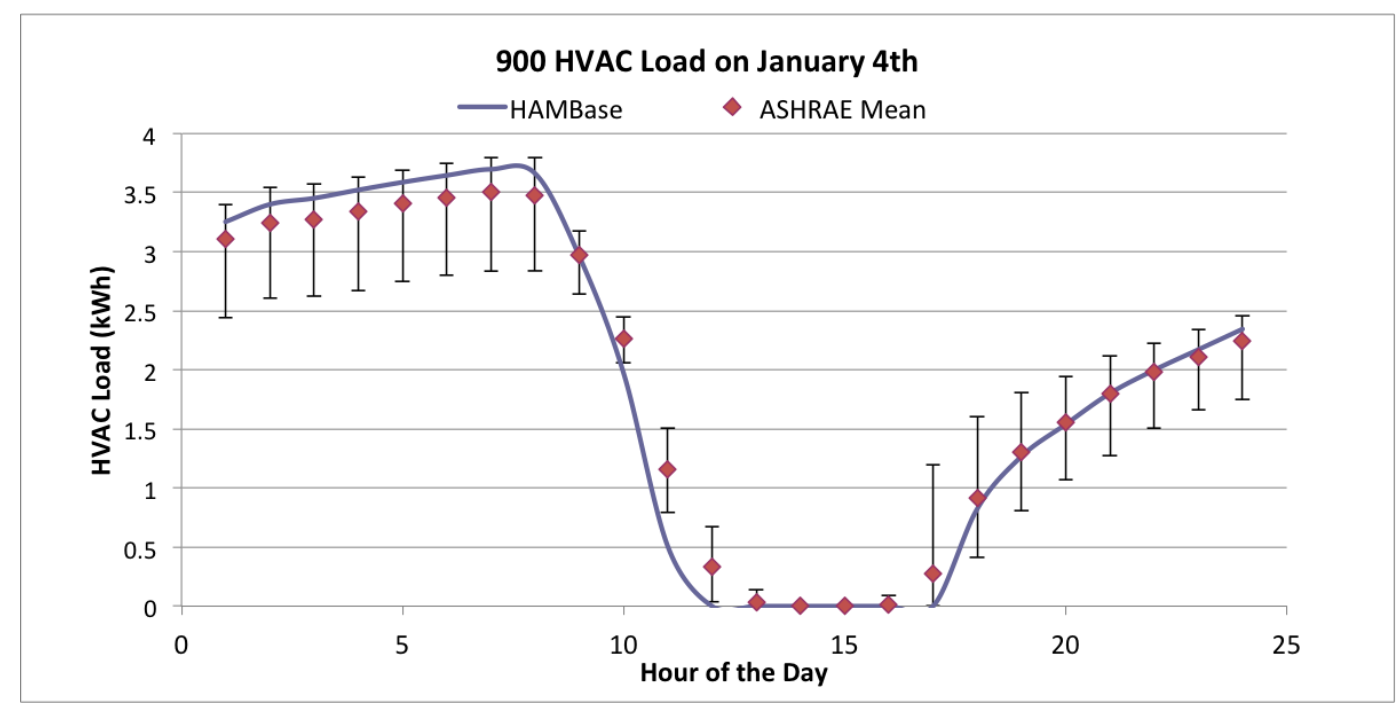

Figure A.14: Comparison of hourly HVAC system loads for case 900 on January 4 th 


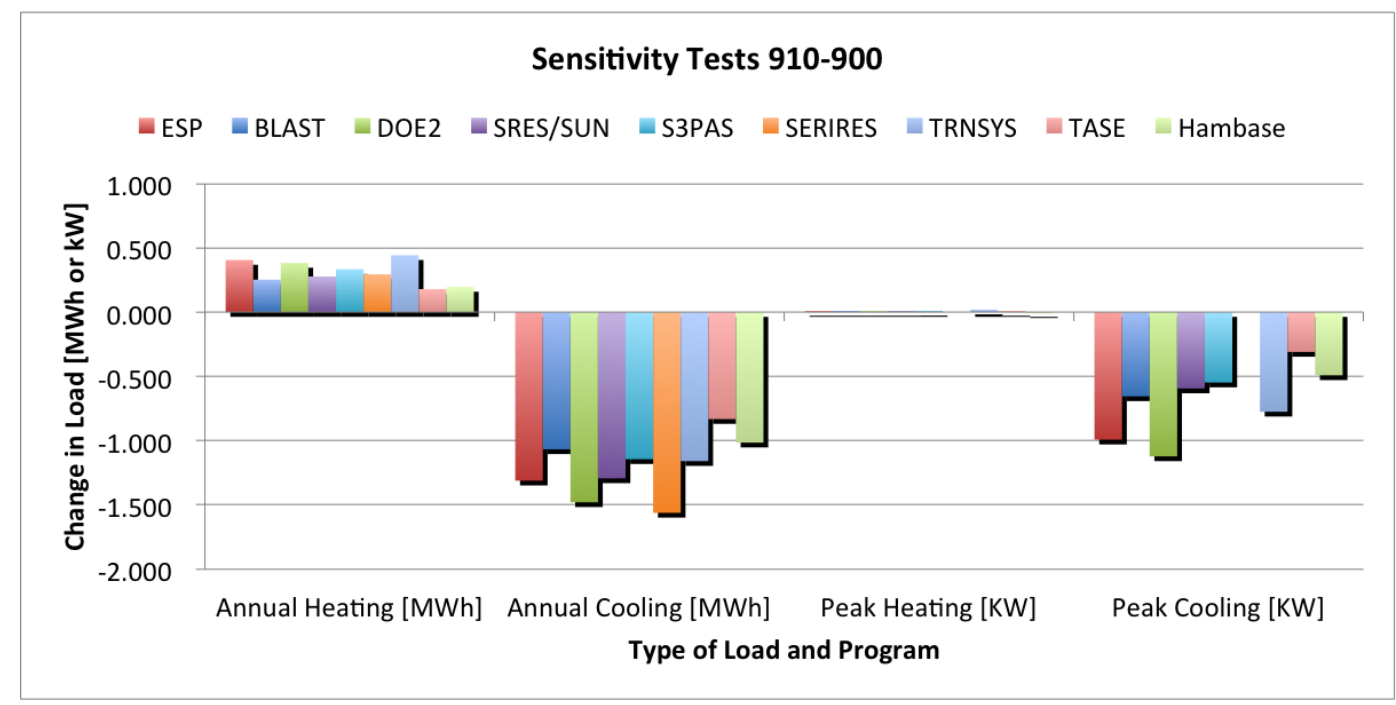

Figure A.15: Comparison of total annual and peak load differences between case 910 and 900 . Includes the addition of shading over the south windows

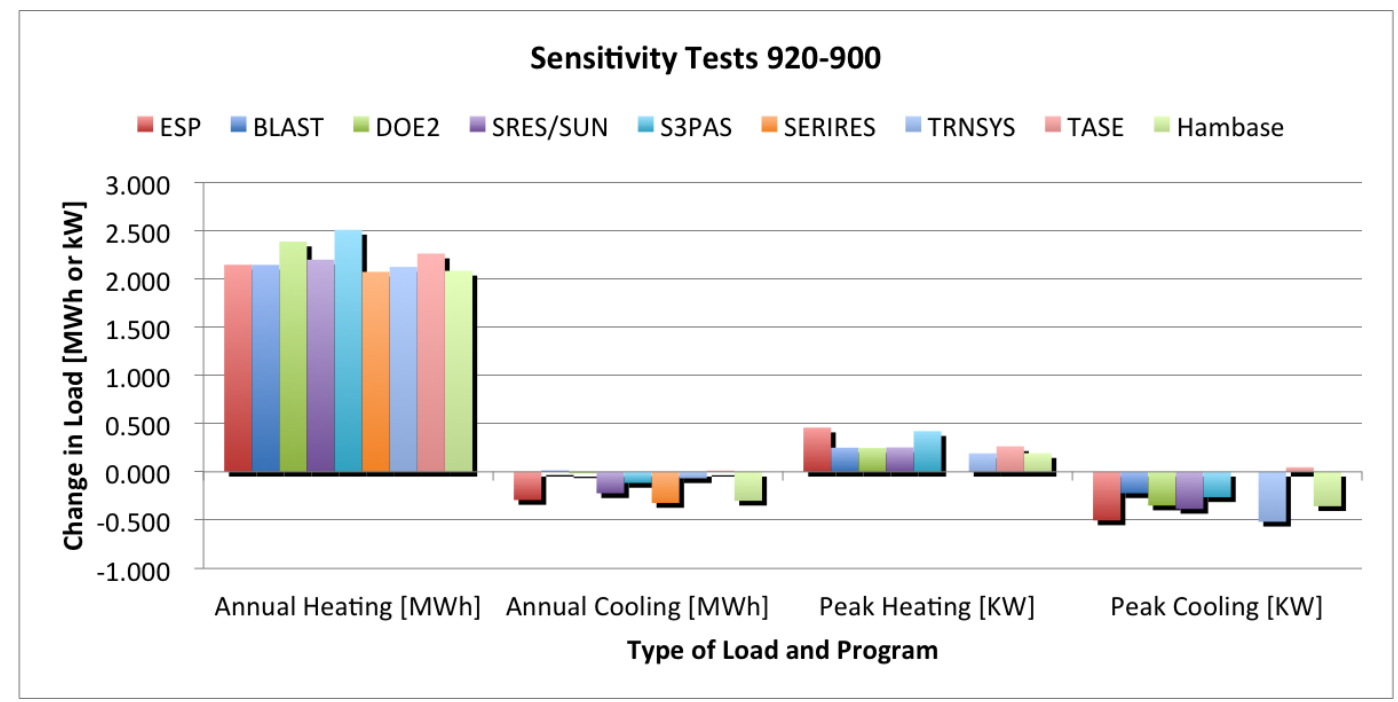

Figure A.16: Comparison of total annual and peak load differences between case 920 and 900 . Moves the windows from the south wall to the east and west walls. 


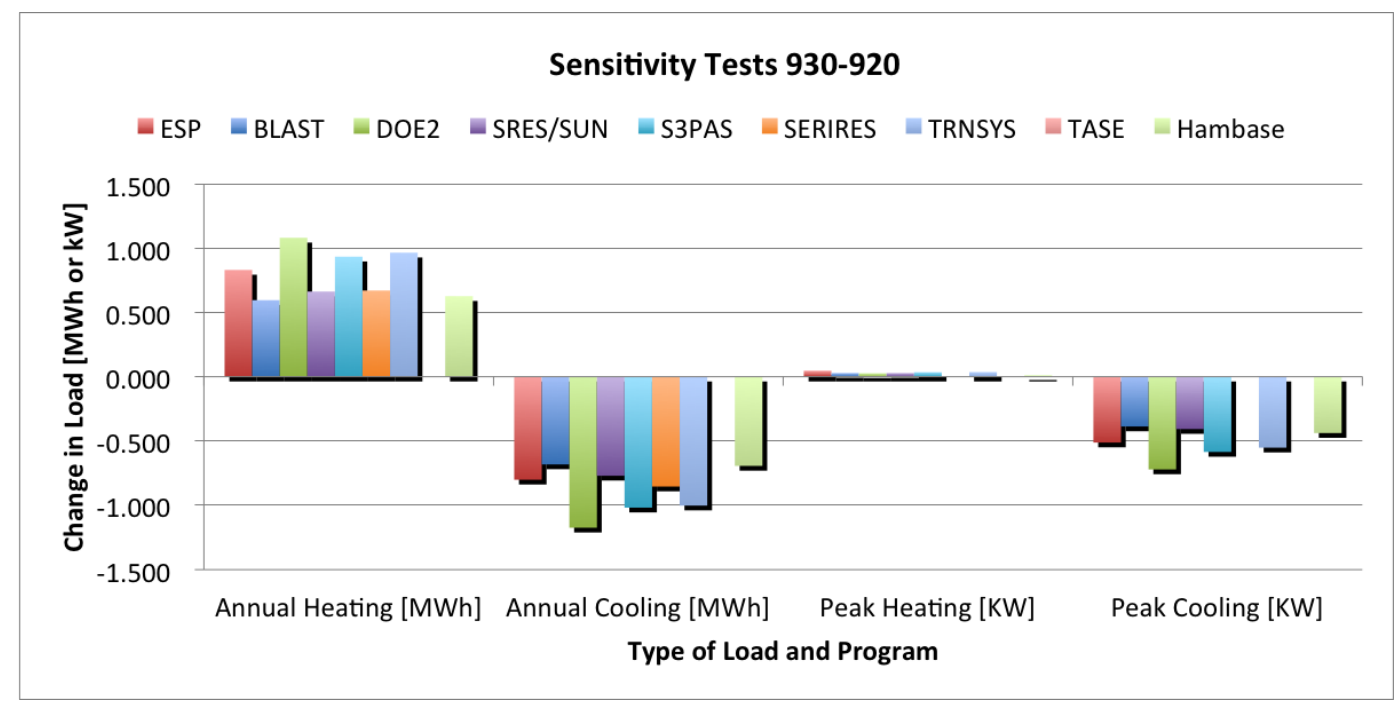

Figure A.17: Comparison of total annual and peak load differences between case 930 and 920 . Includes the addition of shading around the windows on the east and west walls

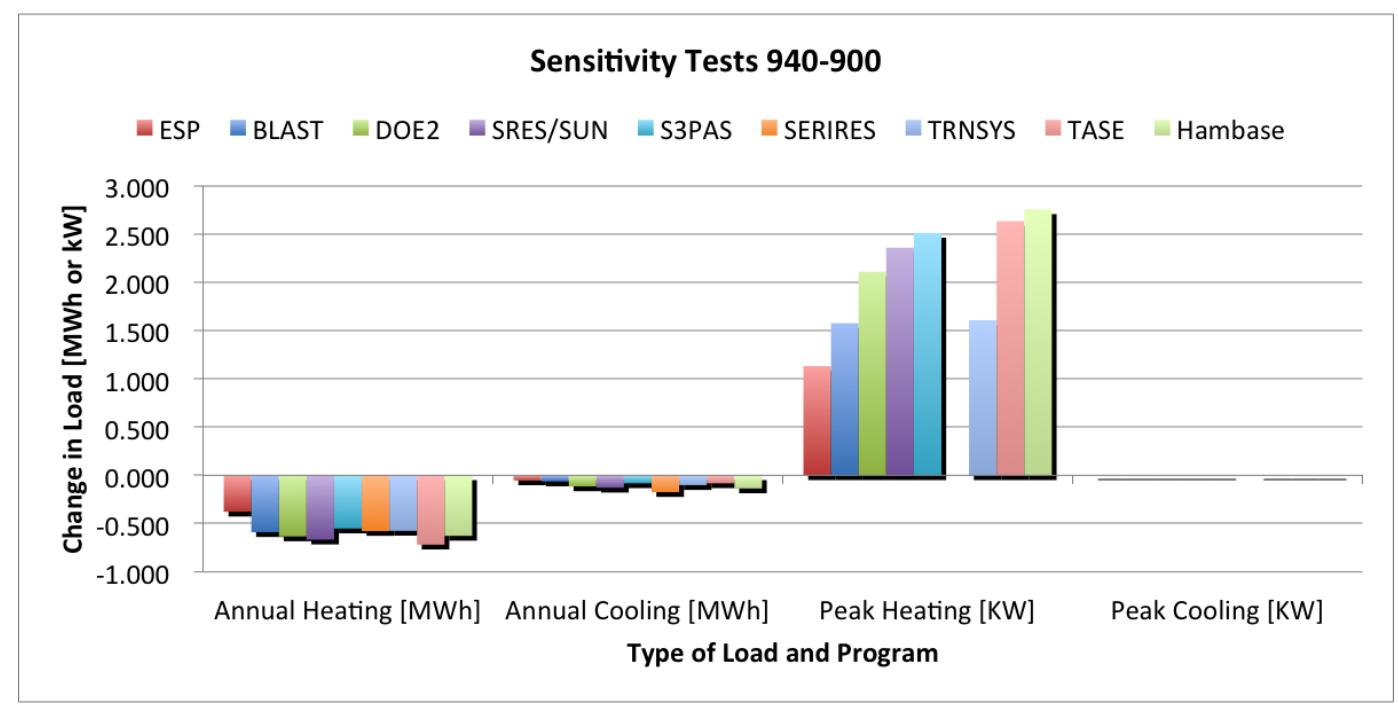

Figure A.18: Comparison of total annual and peak load differences between case 940 and 900 . Heater thermostat is setback to $10^{\circ} \mathrm{C}$ at night 


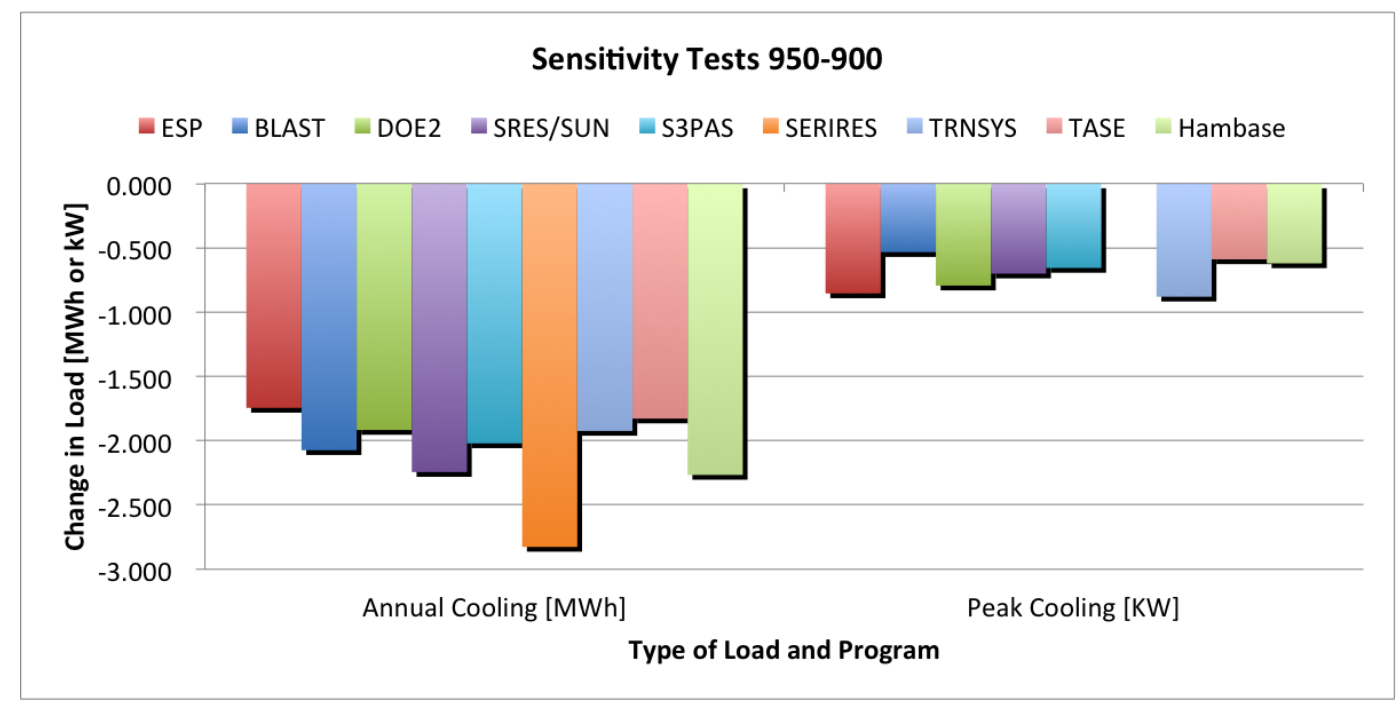

Figure A.19: Comparison of total annual and peak load differences between case 950 and 900. Adds night time ventilation

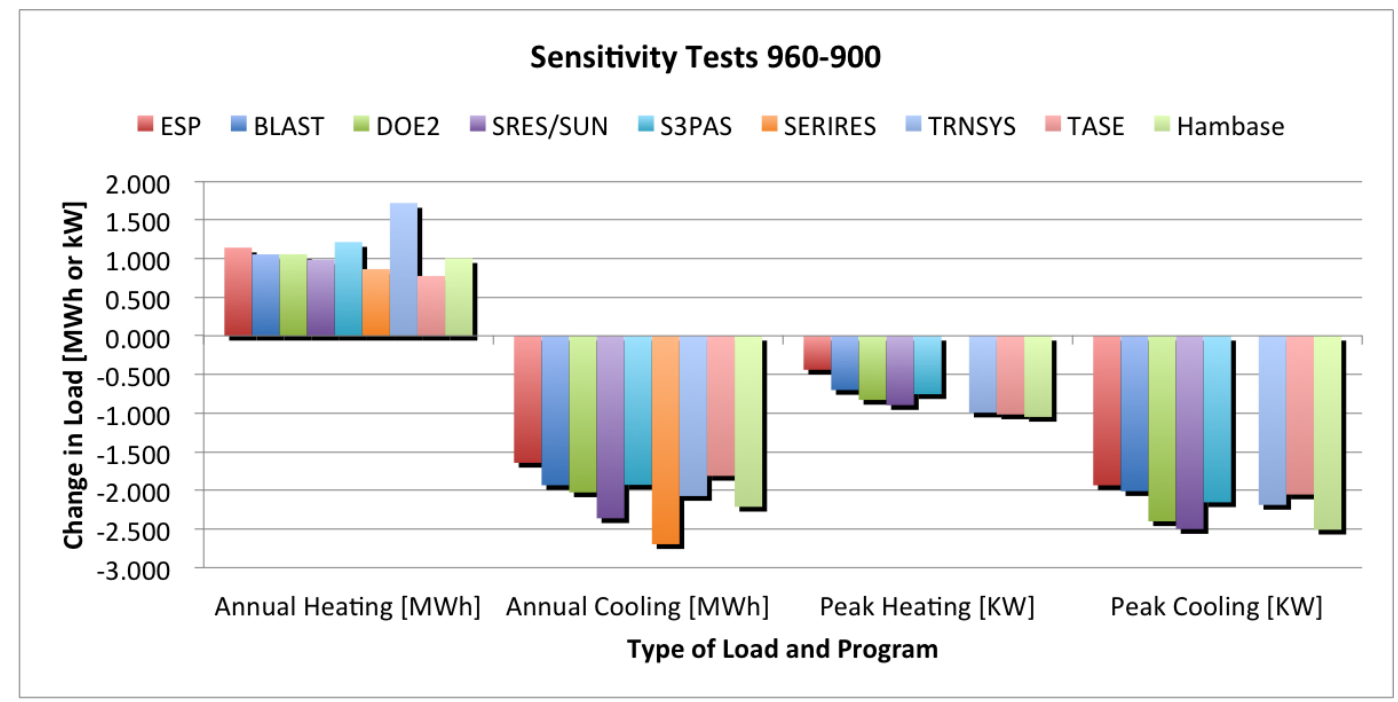

Figure A.20: Comparison of total annual and peak load differences between case 960 and 900. Addition of unconditioned solar space on the south side of the building 


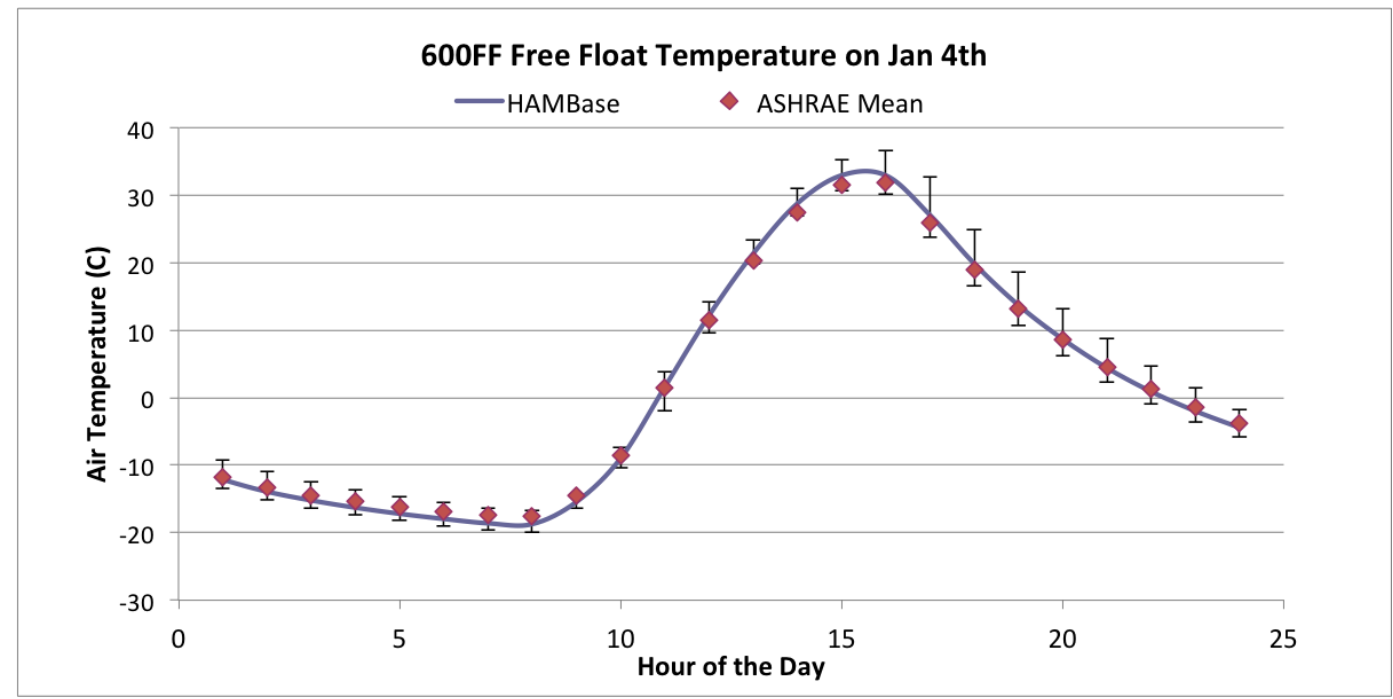

Figure A.21: Hourly temperatures on January 4th for the 600FF case

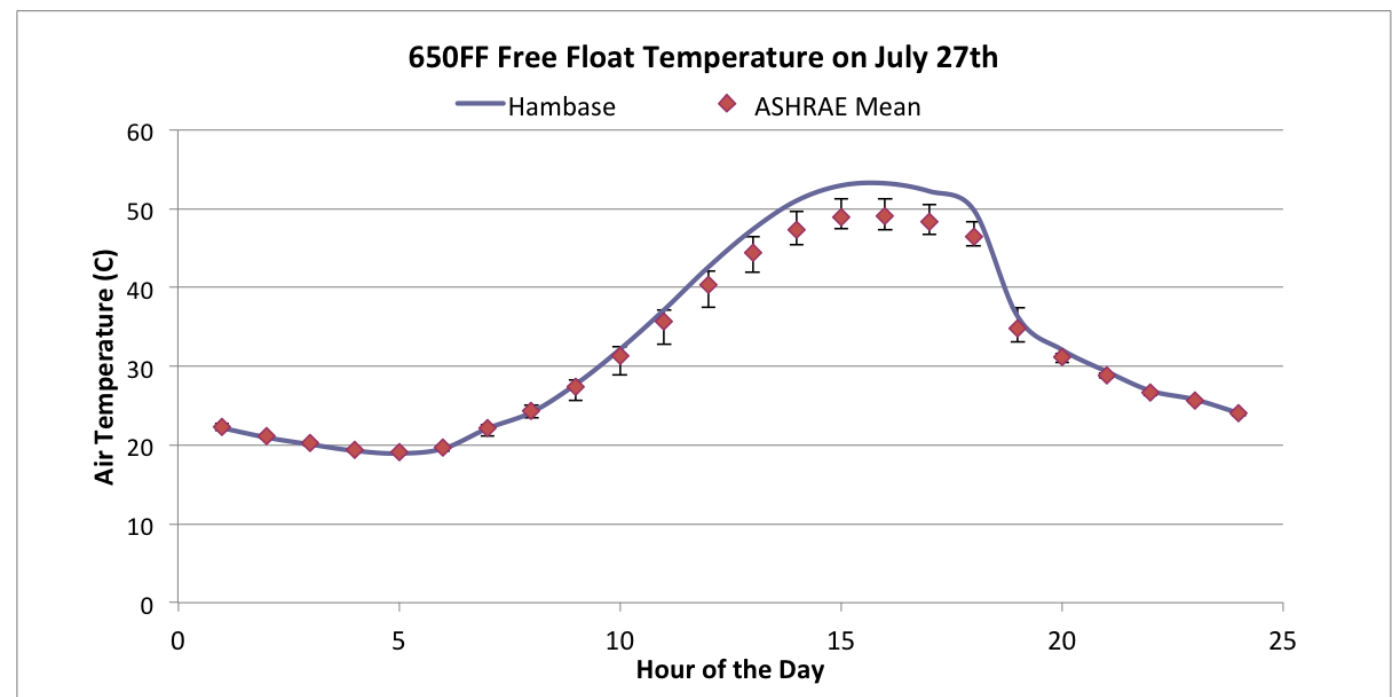

Figure A.22: Hourly temperatures on July 27th for the $650 \mathrm{FF}$ case 


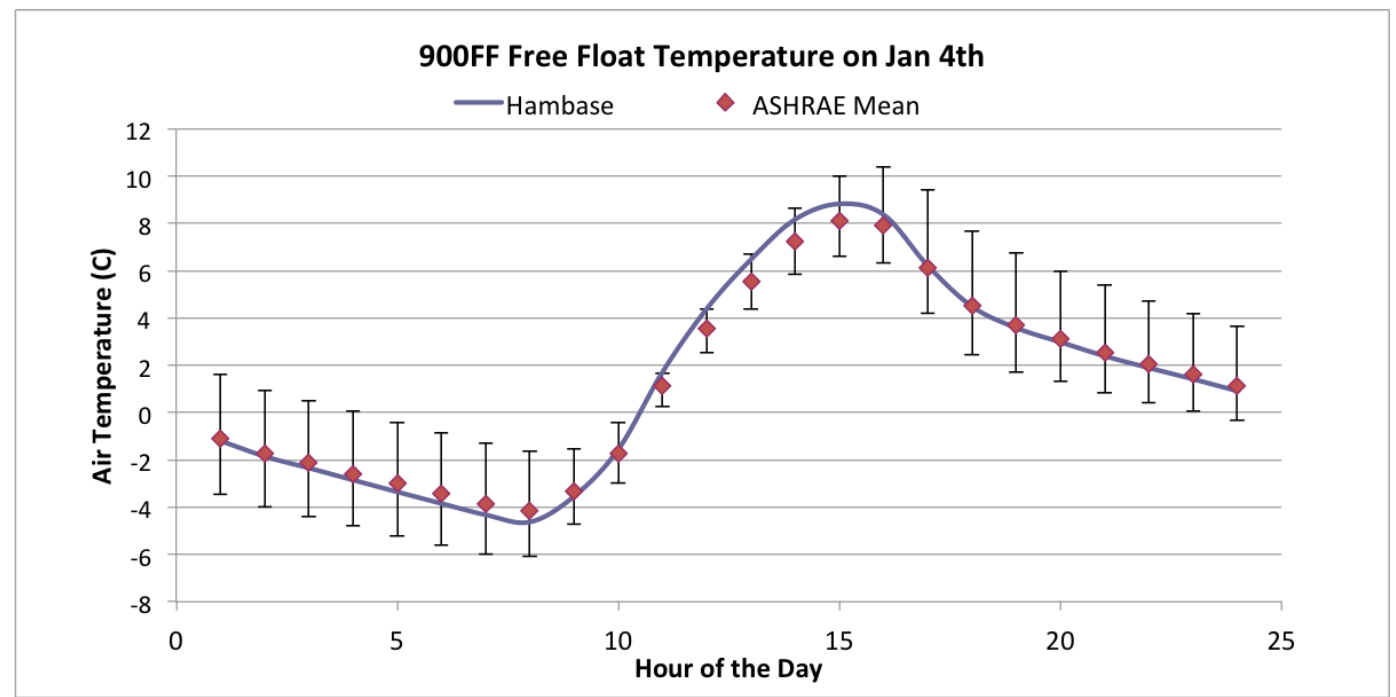

Figure A.23: Hourly temperatures on January 4th for the $900 \mathrm{FF}$ case

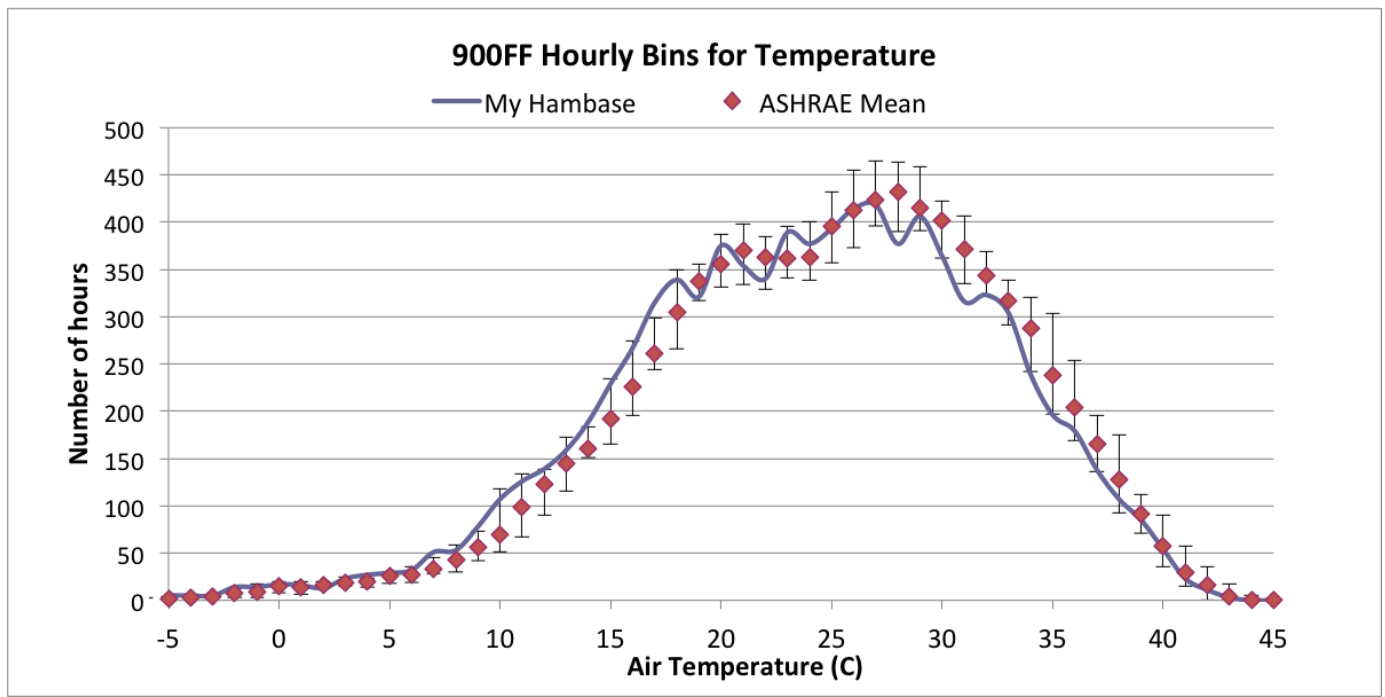

Figure A.24: Histogram of the hourly temperatures for the 900FF case 


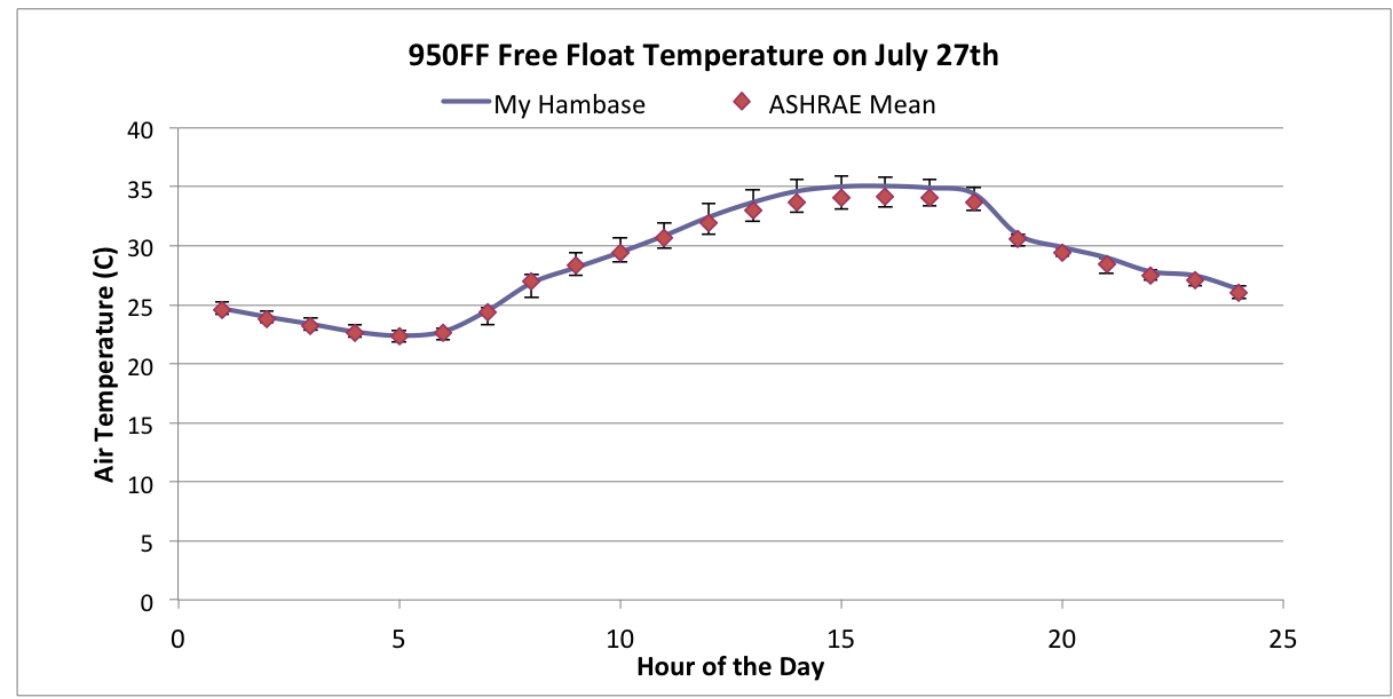

Figure A.25: Hourly temperatures on July 27th for the $950 \mathrm{FF}$ case 


\section{Appendix B}

\section{Integrated Model Validation}


Table B.1: Comparison between Simulink ${ }^{\circledR}$ model and eQuest building load results for full internal load case

\begin{tabular}{l|rrrr} 
& eQuest & Simulink ${ }^{\circledR}$ & Difference & \% Difference \\
\hline Total Cooling (kBtu) & 131801.02 & 127553.16 & -4247.86 & $-3.2 \%$ \\
Total Heating (kBtu) & 0.19 & 4644.79 & 4644.61 & $2508436.3 \%$ \\
\hline Monthly Cooling (kBtu) & & & & \\
January & 5830.78 & 1247.35 & -4583.43 & $-78.6 \%$ \\
February & 5528.83 & 1840.98 & -3687.86 & $-66.7 \%$ \\
March & 8127.50 & 6332.78 & -1794.73 & $-22.1 \%$ \\
April & 10718.38 & 11052.40 & 334.02 & $3.1 \%$ \\
May & 12979.23 & 15129.03 & 2149.80 & $16.6 \%$ \\
June & 14524.40 & 18185.60 & 3661.20 & $25.2 \%$ \\
July & 16225.85 & 20613.06 & 4387.21 & $27.0 \%$ \\
August & 16167.55 & 20295.00 & 4127.45 & $25.5 \%$ \\
September & 13794.97 & 15102.13 & 1307.16 & $9.5 \%$ \\
October & 12423.88 & 11017.86 & -1406.01 & $-11.3 \%$ \\
November & 9194.27 & 5527.95 & -3666.32 & $-39.9 \%$ \\
December & 6285.38 & 1209.03 & -5076.35 & $-80.8 \%$ \\
\hline Monthly Heating (kBtu) & & & & \\
January & 0.16 & 2112.91 & 2112.75 & $1362073.2 \%$ \\
February & 0.00 & 774.86 & 774.86 & \\
March & 0.00 & 337.25 & 337.25 & \\
April & 0.00 & 0.00 & 0.00 & \\
May & 0.00 & 0.00 & 0.00 & \\
June & 0.00 & 0.00 & 0.00 & \\
July & 0.00 & 0.00 & 0.00 & \\
August & 0.00 & 0.00 & 0.00 & \\
September & 0.00 & 0.00 & 0.00 & \\
October & 0.00 & 0.00 & 0.00 & \\
November & 0.00 & 0.00 & 0.00 & \\
December & 0.03 & 1419.77 & 1419.74 & $4725155.9 \%$
\end{tabular}


Table B.2: Comparison between Simulink ${ }^{\circledR}$ model and eQuest building load results for no internal load case

\begin{tabular}{l|rrrr} 
& eQuest & Simulink $^{\circledR}$ & Difference & \% Difference \\
\hline Total Cooling (kBtu) & 62892.85 & 50190.02 & -12702.83 & $-20.2 \%$ \\
Total Heating (kBtu) & 761.88 & 27163.32 & 26401.43 & $3465.3 \%$ \\
\hline Monthly Cooling (Btu) & & & & \\
January & 819.57 & 0.00 & -819.57 & $-100.0 \%$ \\
February & 1027.13 & 27.45 & -999.68 & $-97.3 \%$ \\
March & 2566.58 & 591.12 & -1975.46 & $-77.0 \%$ \\
April & 4637.24 & 2649.84 & -1987.41 & $-42.9 \%$ \\
May & 6740.74 & 5900.19 & -840.55 & $-12.5 \%$ \\
June & 8557.49 & 9395.40 & 837.91 & $9.8 \%$ \\
July & 10130.18 & 11531.14 & 1400.97 & $13.8 \%$ \\
August & 10056.82 & 11201.90 & 1145.08 & $11.4 \%$ \\
September & 7782.40 & 6264.84 & -1517.56 & $-19.5 \%$ \\
October & 6119.44 & 2227.25 & -3892.18 & $-63.6 \%$ \\
November & 3302.56 & 400.87 & -2901.69 & $-87.9 \%$ \\
December & 1152.71 & 0.00 & -1152.71 & $-100.0 \%$ \\
\hline Monthly Heating (Btu) & & & & \\
January & 130.58 & 8692.30 & 8561.73 & $6556.9 \%$ \\
February & 193.90 & 5714.18 & 5520.28 & $2847.0 \%$ \\
March & 209.14 & 2663.09 & 2453.95 & $1173.4 \%$ \\
April & 0.05 & 55.71 & 55.66 & $116820.2 \%$ \\
May & 0.00 & 0.00 & 0.00 & \\
June & 0.00 & 0.00 & 0.00 & \\
July & 0.00 & 0.00 & 0.00 & \\
August & 0.00 & 0.00 & 0.00 & \\
September & 0.00 & 0.00 & 0.00 & \\
October & 0.01 & 51.18 & 51.17 & $401615.1 \%$ \\
November & 0.07 & 2159.59 & 2159.52 & $2937452.8 \%$ \\
December & 228.14 & 7827.25 & 7599.12 & $3330.9 \%$
\end{tabular}




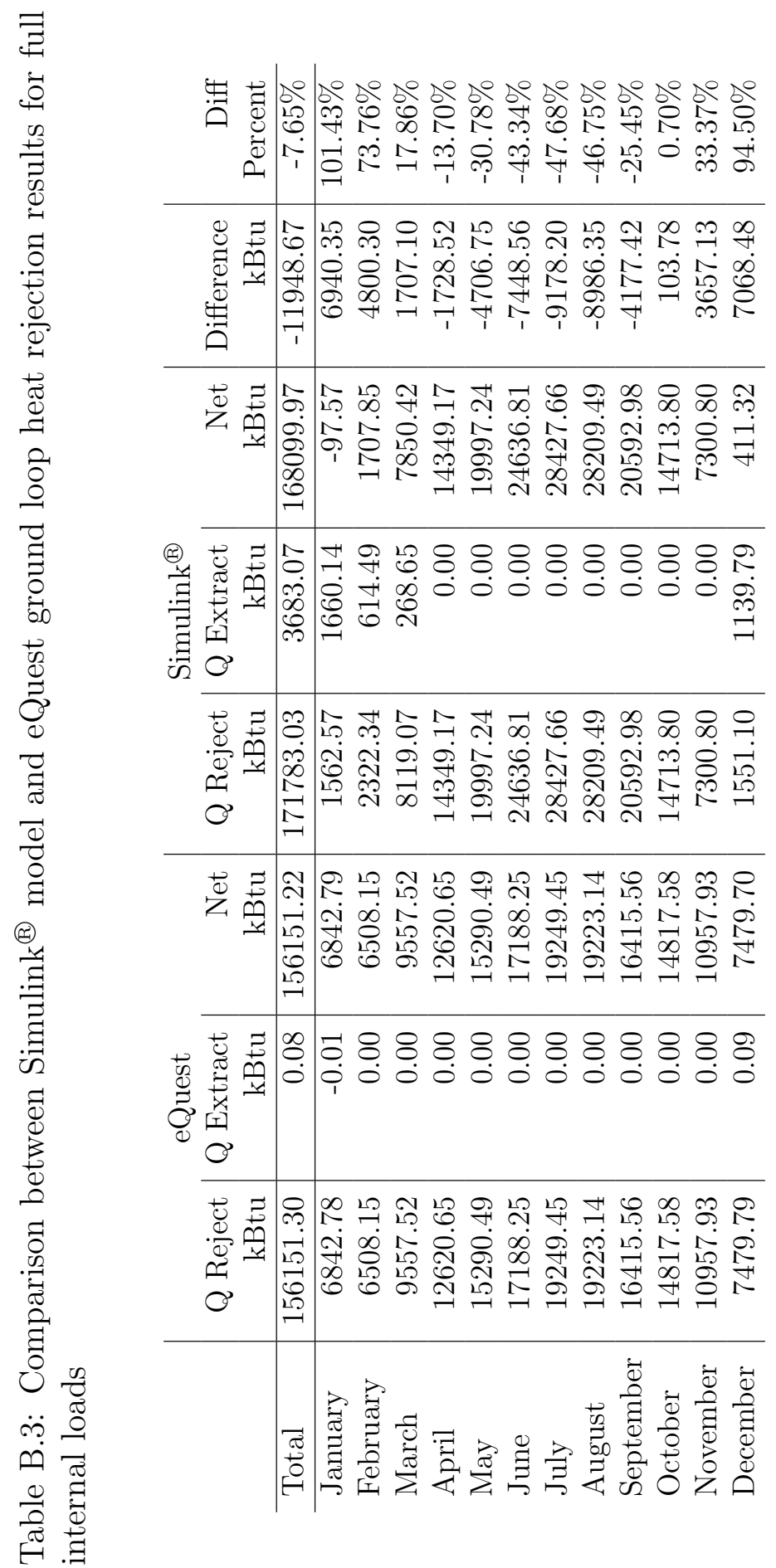




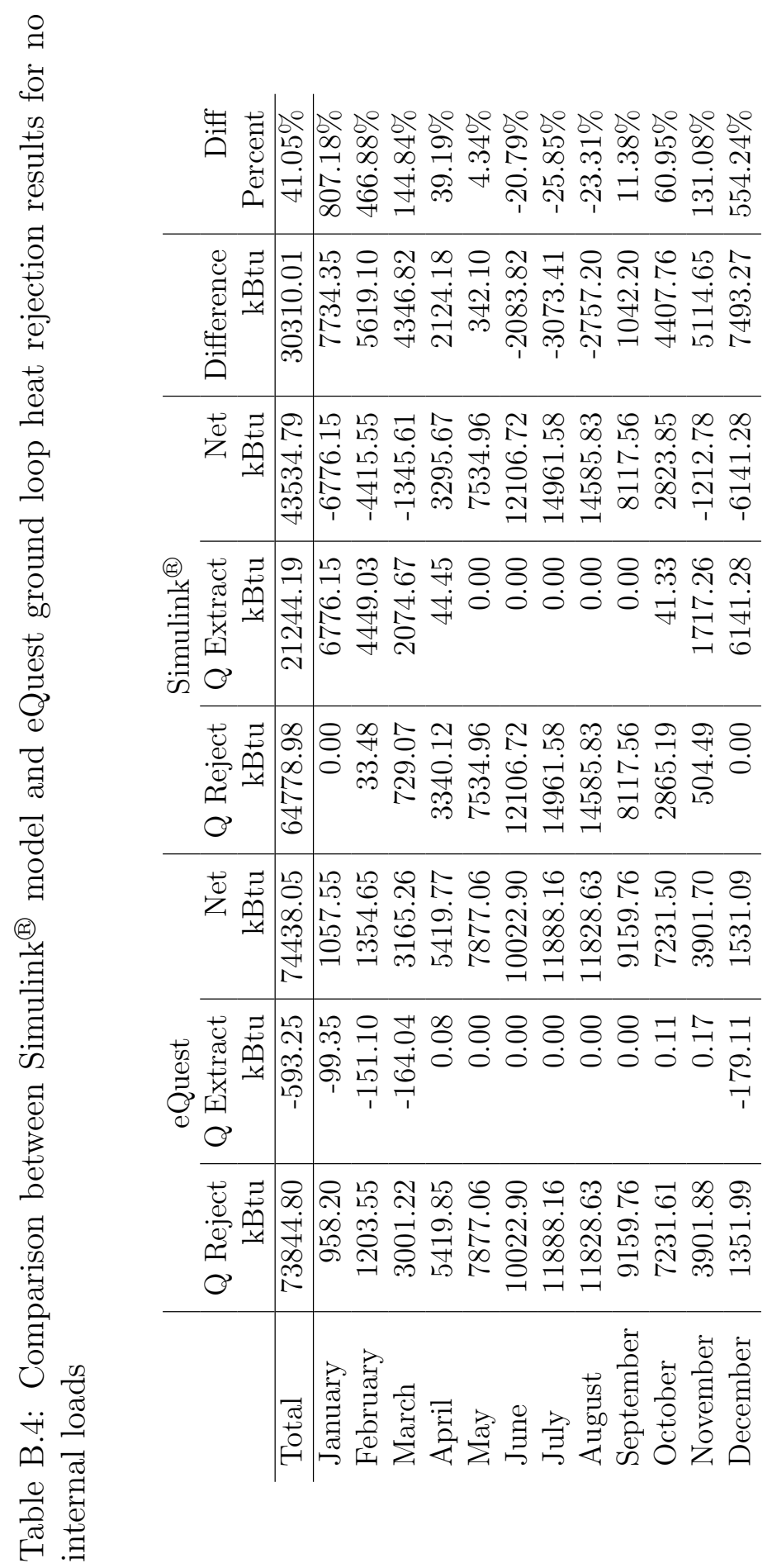




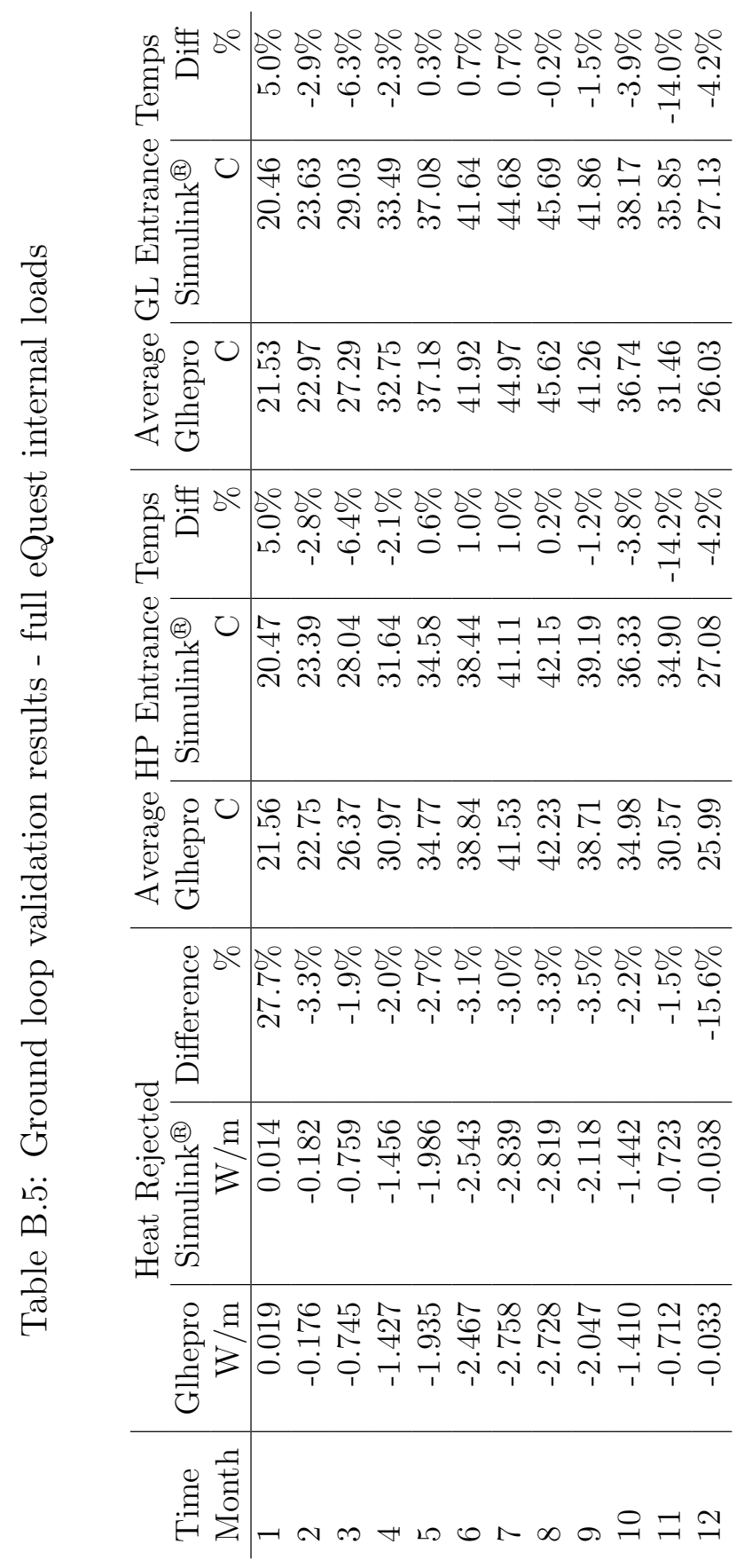




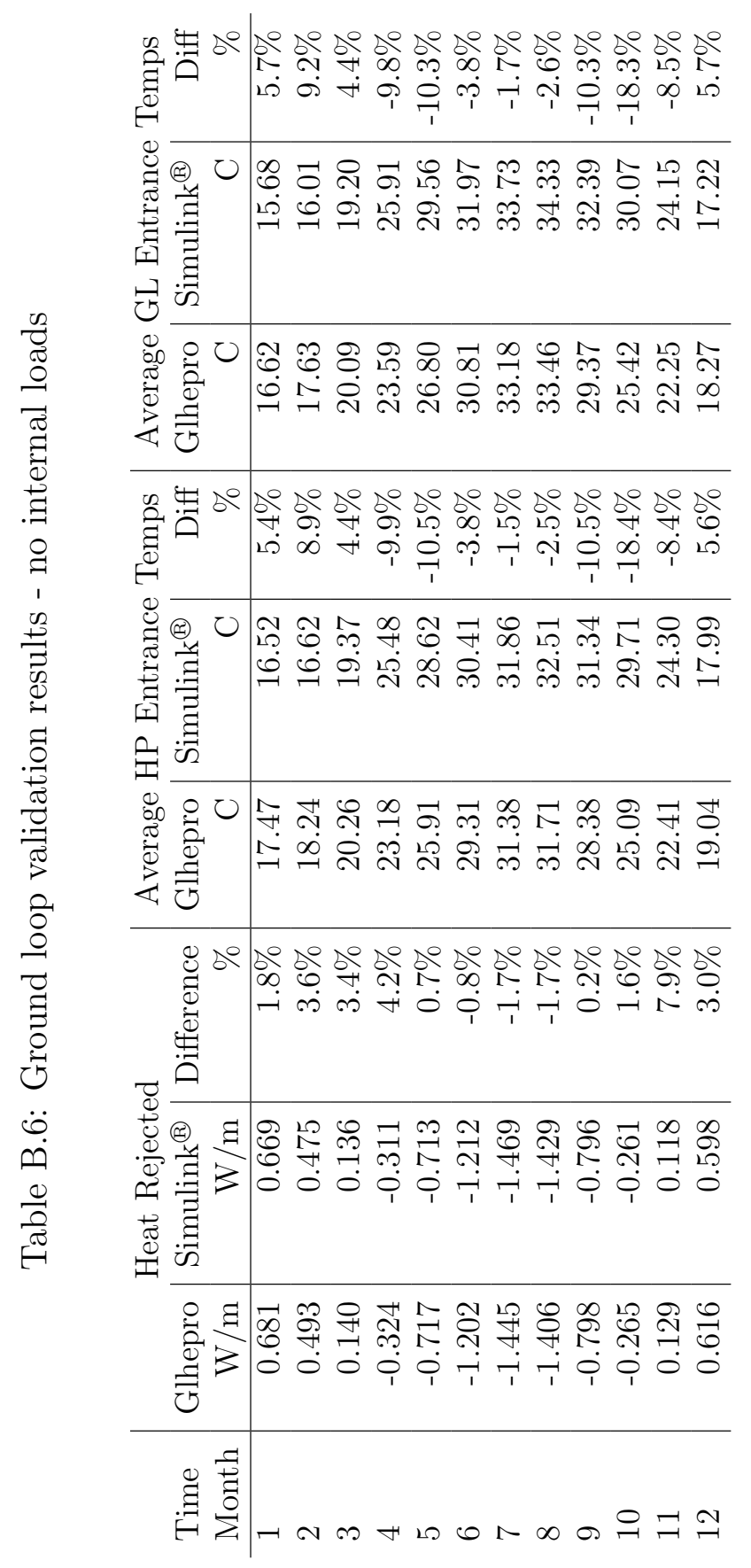




\section{Appendix $\mathrm{C}$}

\section{Ground Loop Properties and GLHEPRO Use}

\section{C.1 GLHEPRO Inputs for Base Model}

Table C.1: Ground loop properties used in GLHEPRO

\begin{tabular}{|c|c|c|c|c|}
\hline \multicolumn{5}{|c|}{ Geometry } \\
\hline Length & 68.6 & $m$ & 225 & $f t$ \\
\hline Borehole Diameter & 127 & $m m$ & 5 & in \\
\hline Shank Spacing & 25.4 & $m m$ & 1 & in \\
\hline Borehole Spacing & 4.572 & $m$ & 15 & ft \\
\hline Geometry & Line of 4 & - & & \\
\hline U -Tube ID & 27.33 & $m m$ & 1.076 & in \\
\hline U-Tube OD & 33.4 & $m m$ & 1.315 & in \\
\hline \multirow{2}{*}{\multicolumn{5}{|c|}{ Thermal Properties }} \\
\hline U-Tube & & & & \\
\hline Conductivity & 1.333 & $W / m / K$ & 0.225 & Btu/hr/ft/ $/{ }^{\circ} F$ \\
\hline Capacitance & 1767 & $k J / m^{3} / K$ & 22.99 & $\mathrm{Btu} / \mathrm{ft} t^{3} /{ }^{\circ} \mathrm{F}$ \\
\hline \multicolumn{5}{|l|}{ Grout } \\
\hline Conductivity & 0.7443 & $W / m / K$ & 0.43 & $B t u / h r / f t /{ }^{\circ} F$ \\
\hline Capacitance & 3901 & $k J / m^{3} / K$ & 58.17 & $B t u / f t^{3} /{ }^{o} F$ \\
\hline \multicolumn{5}{|l|}{ Ground } \\
\hline Conductivity & 0.3895 & $W / m / K$ & 0.77 & $B t u / h r / f t /{ }^{o} F$ \\
\hline Capacitance & 1542 & $k J / m^{3} / K$ & 26.35 & $B t u / f t^{3} /{ }^{o} F$ \\
\hline Undisturbed Temperature & 21.67 & ${ }^{\circ} \mathrm{C}$ & 71.01 & ${ }^{o} \mathrm{~F}$ \\
\hline \multicolumn{5}{|c|}{ Fluid Properties } \\
\hline Antifreeze & None & - & & \\
\hline Convection Coefficient & 1534 & $W / m^{2} / K$ & 270.2 & $B t u / h r / f t^{2} /{ }^{o} F$ \\
\hline Fluid Factor & 1 & - & & \\
\hline Flow Rate per Borehole & 0.1893 & $L / s$ & 3 & $G P M$ \\
\hline Borehole Resistance & 0.2097 & $K m / W$ & 0.3629 & ${ }^{o} \mathrm{Fhrft} / \mathrm{Btu}$ \\
\hline
\end{tabular}




\section{C.2 Use of GLHEPRO}

GLHEPRO is used to size the ground loop based on total heat load on the ground as well as to create the parameter files for the Simulink ${ }^{\circledR}$ model. The values shown in the following screen-shots are those used for the base model which uses Austin ground properties and energy loads computed for the modeled house.

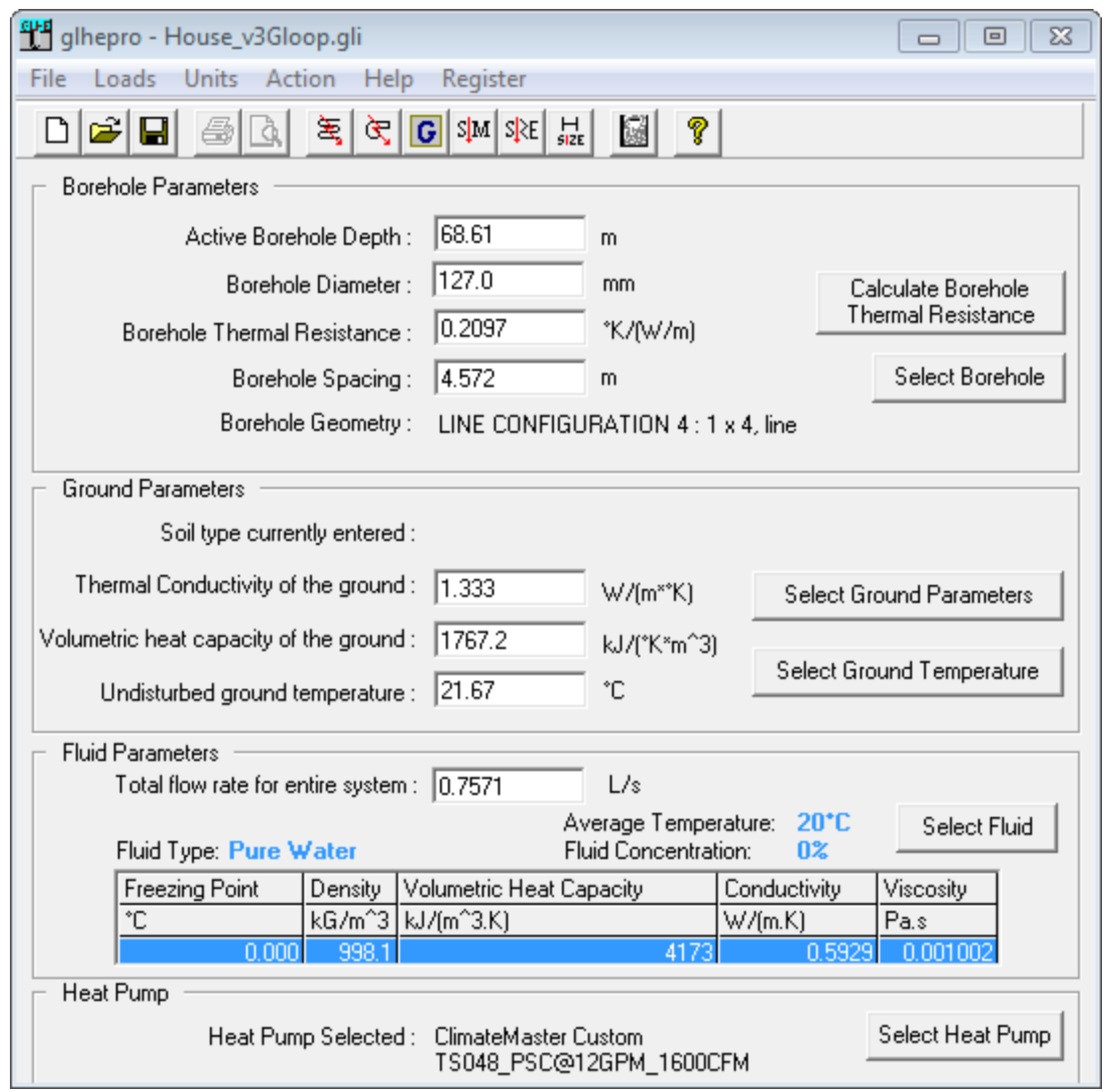

Figure C.1: Main screen of GLHEPRO

Figure C.1 shows the main input screen of the GLHEPRO software. On 
this screen the borehole field parameters such as borehole length, spacing, and geometry are entered. The borehole geometry defines how multiple borehole interact with one another. For example, the base model uses a single line of four boreholes. Other options include single boreholes and rectangular, Lshaped and U-shaped borehole fields. The undisturbed ground temperature is also entered on this screen. There is an option to pull up a map that shows the ground temperatures of the United States. The ground thermal properties can be entered on this screen as well.

The borehole thermal resistance and the g-functions for the model are calculated using the screen shown in Figure C.2. It is accessed by clicking on the "Calculate Borehole Thermal Resistance" button on the main page. At this point the user can choose to model a single u-tube, double u-tube, or concentric tube borehole by clicking on the proper tab at the top of the screen. After selecting this, the detailed borehole geometry is entered. For the single u-tube configuration this includes the shank spacing (distance between the legs of the $\mathrm{u}$-tube), the diameters of the $\mathrm{u}$-tube and the volumetric flow rate in each borehole. Next the ground, grout, and pipe thermal properties are entered. Finally, the user has the option to enter a specific convection coefficient or use the built-in calculator to determine one. After entering all the data the user can calculate the borehole resistance and create the g-functions for the borehole. If the borehole has been properly sized the user can create the parameter file for the Simulink ${ }^{\circledR}$ model by clicking on "Select G-function Print Format" and choosing to create an HVACSIM+ parameter file. 


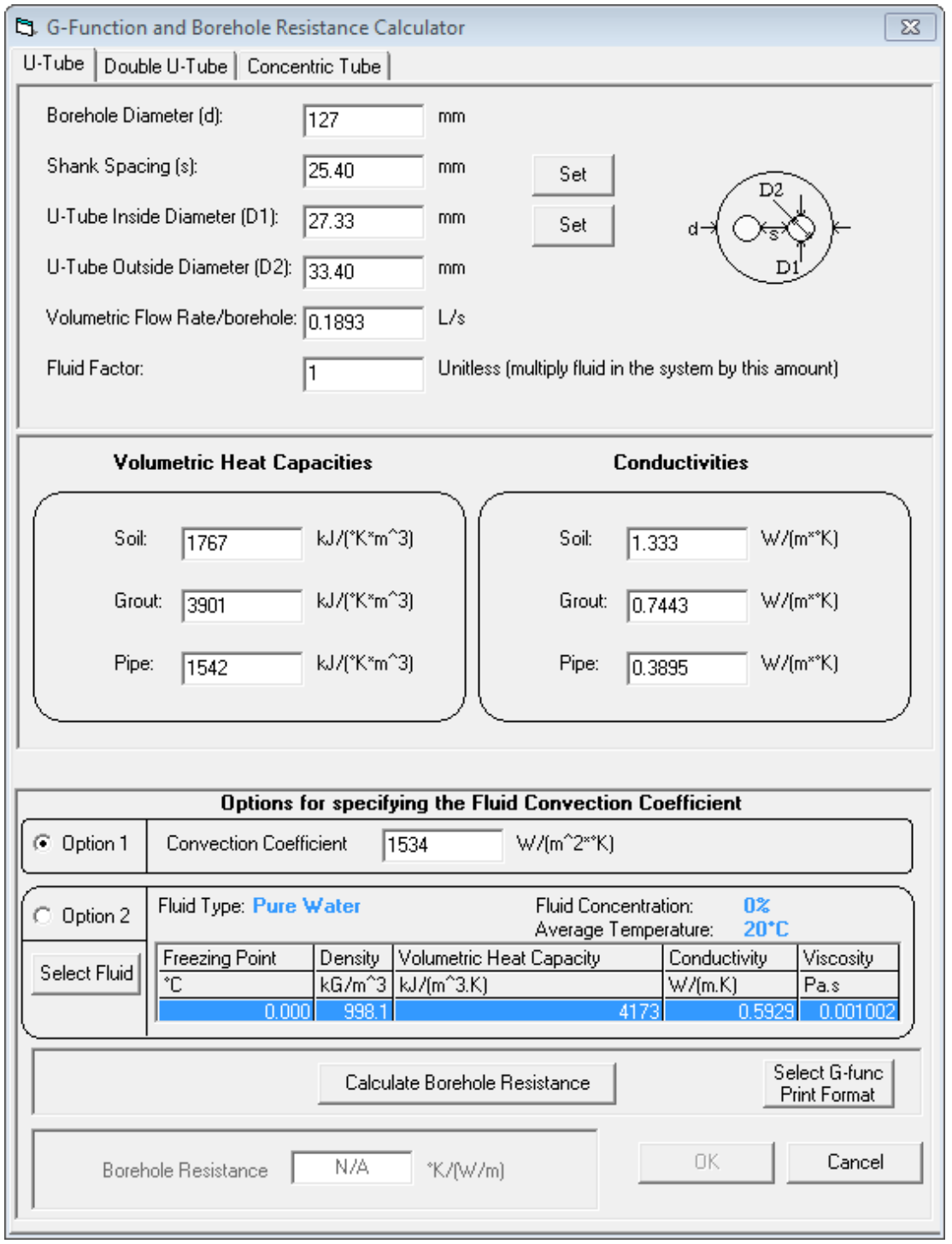

Figure C.2: G-function and borehole resistance calculation screen 
Once the borehole properties have been entered into GLHEPRO, the user can proceed to perform long term simulations or determine the proper borehole length. This requires that the monthly building loads be entered into the program. This is accomplished under the Loads>Edit Heat Pump Loads menu. Once the loads are entered the user can perform a long term simulation using the specified borehole length by selecting Action $>$ Perform Simulation from the menu. After a simulation the monthly average, maximum, and minimum loop temperatures are reported in a csv file.

If the users only need to determine the proper length of the borehole, they can choose to perform a standard sizing or a hybrid sizing. The standard sizing is used for sizing the loop when there is not a supplemental heat rejector available. To perform the standard sizing the user selects Action>Perform Sizing from the menu. The user then selects the desired maximum and minimum loop temperatures as well as the life time of the ground loop. Based on the inputs GLHEPRO runs multiple simulations with different borehole lengths until the maximum or minimum loop temperatures are reached in the last year of the specified life time. The resulting length is then properly sized length for the ground loop based on the provided loads.

The hybrid sizing procedure assumes that there is a supplementary device which can add or remove heat from the ground loop. To determine the loop length GLHEPRO determines loop lengths that will give the userspecified maximum and minimum temperatures at the end of its lifetime. The shorter of the two lengths is chosen and the additional heat that needs to be 
rejected/extracted from the borehole is then calculated and reported as the proper size for the supplementary device. 


\section{Appendix D}

\section{Base Results}

Table D.1: Heat pump operation time and output for base case, basis for Figures 6.16 and 6.17

\begin{tabular}{lrrrr}
\hline Year & $\begin{array}{r}\text { Cool Time } \\
\text { Hrs }\end{array}$ & $\begin{array}{r}\text { Heat time } \\
\text { Hrs }\end{array}$ & $\begin{array}{r}\text { Cooling Provided } \\
\text { MWh }\end{array}$ & $\begin{array}{r}\text { Heating Provided } \\
\text { MWh }\end{array}$ \\
\hline 1 & 2022 & 284 & -22.28 & 4.87 \\
2 & 2056 & 265 & -22.27 & 4.53 \\
3 & 2075 & 270 & -22.28 & 4.52 \\
4 & 2087 & 272 & -22.28 & 4.51 \\
5 & 2095 & 271 & -22.29 & 4.52 \\
6 & 2104 & 271 & -22.28 & 4.52 \\
7 & 2111 & 272 & -22.27 & 4.53 \\
8 & 2116 & 271 & -22.25 & 4.53 \\
9 & 2122 & 271 & -22.25 & 4.53 \\
10 & 2128 & 271 & -22.24 & 4.53 \\
11 & 2135 & 272 & -22.22 & 4.53 \\
12 & 2147 & 272 & -22.22 & 4.52 \\
13 & 2156 & 283 & -22.22 & 4.52 \\
14 & 2164 & 281 & -22.20 & 4.51 \\
15 & 2169 & 287 & -22.18 & 4.51 \\
\hline
\end{tabular}


Table D.2: Annual and monthly peak electricity usage of the heat pump, basis for Figure 6.20

\begin{tabular}{lrrrr}
\hline Year & $\begin{array}{r}\text { Cooling Elect } \\
\mathrm{kWh}\end{array}$ & $\begin{array}{r}\text { Heating Elect } \\
\mathrm{kWh}\end{array}$ & $\begin{array}{r}\text { Total Elect } \\
\mathrm{kWh}\end{array}$ & $\begin{array}{r}\text { Peak Elect } \\
\mathrm{kWh}\end{array}$ \\
\hline 1 & 8005 & 1063 & 9068 & 1693 \\
2 & 8427 & 961 & 9388 & 1776 \\
3 & 8674 & 948 & 9622 & 1830 \\
4 & 8835 & 940 & 9775 & 1862 \\
5 & 8954 & 937 & 9890 & 1918 \\
6 & 9047 & 933 & 9981 & 1932 \\
7 & 9123 & 931 & 10054 & 1945 \\
8 & 9176 & 929 & 10105 & 1954 \\
9 & 9223 & 927 & 10150 & 1957 \\
10 & 9259 & 924 & 10183 & 1961 \\
11 & 9297 & 923 & 10220 & 1964 \\
12 & 9331 & 920 & 10251 & 1967 \\
13 & 9361 & 918 & 10280 & 1990 \\
14 & 9382 & 916 & 10298 & 1991 \\
15 & 9403 & 914 & 10317 & 1986 \\
\hline
\end{tabular}


Table D.3: Annual heat pump temperatures and efficiency ratings, basis for Figures 6.18 and 6.19

\begin{tabular}{lrrrrr}
\hline Year & $\begin{array}{r}\text { Mean } \\
\text { C }\end{array}$ & $\begin{array}{r}\text { Max } \\
\text { C }\end{array}$ & $\begin{array}{r}\text { Min } \\
\text { C }\end{array}$ & & \\
\hline 1 & 30.38 & 44.51 & 11.25 & 9.56 & 4.59 \\
2 & 32.26 & 46.25 & 14.69 & 9.07 & 4.72 \\
3 & 33.21 & 47.31 & 15.08 & 8.82 & 4.77 \\
4 & 33.80 & 47.95 & 15.97 & 8.66 & 4.81 \\
5 & 34.28 & 48.28 & 16.41 & 8.55 & 4.84 \\
6 & 34.62 & 48.32 & 16.96 & 8.46 & 4.85 \\
7 & 34.96 & 48.50 & 16.95 & 8.39 & 4.87 \\
8 & 35.17 & 48.49 & 17.26 & 8.33 & 4.88 \\
9 & 35.36 & 48.61 & 17.86 & 8.29 & 4.90 \\
10 & 35.52 & 48.62 & 18.01 & 8.25 & 4.91 \\
11 & 35.69 & 48.55 & 18.01 & 8.21 & 4.92 \\
12 & 35.84 & 48.55 & 17.89 & 8.18 & 4.92 \\
13 & 36.07 & 48.53 & 18.42 & 8.16 & 4.93 \\
14 & 36.10 & 48.62 & 17.99 & 8.13 & 4.94 \\
15 & 36.26 & 48.62 & 18.51 & 8.11 & 4.95 \\
\hline
\end{tabular}




\section{Appendix E}

\section{Sensitivity Study Data}

\section{E.1 Borehole Length}

Table E.1: Maximum yearly heat pump entrance temperature in ${ }^{\circ} C$, based on hourly averages, basis for Figure 7.1

\begin{tabular}{lrrrrrrr}
\hline Year & $80 \%$ & $90 \%$ & $95 \%$ & $100 \%$ & $105 \%$ & $110 \%$ & $120 \%$ \\
\hline 1 & 48.84 & 47.57 & 46.15 & 44.51 & 43.17 & 41.95 & 39.84 \\
2 & 49.16 & 48.53 & 47.93 & 46.25 & 44.91 & 43.54 & 41.28 \\
3 & 49.26 & 48.70 & 48.48 & 47.31 & 45.88 & 44.57 & 42.08 \\
4 & 49.21 & 48.83 & 48.68 & 47.95 & 46.54 & 45.04 & 42.71 \\
5 & 49.55 & 48.91 & 48.66 & 48.28 & 47.09 & 45.51 & 43.12 \\
6 & 49.50 & 49.11 & 48.62 & 48.32 & 47.39 & 45.95 & 43.42 \\
7 & 49.46 & 49.09 & 48.78 & 48.50 & 47.74 & 46.22 & 43.68 \\
8 & 49.44 & 49.02 & 48.77 & 48.49 & 47.97 & 46.43 & 43.91 \\
9 & 49.50 & 49.11 & 48.82 & 48.61 & 48.12 & 46.60 & 44.12 \\
10 & 49.47 & 49.04 & 48.89 & 48.62 & 48.25 & 46.82 & 44.36 \\
11 & 49.70 & 49.21 & 48.92 & 48.55 & 48.35 & 47.07 & 44.41 \\
12 & 49.47 & 49.05 & 49.06 & 48.55 & 48.36 & 47.24 & 44.59 \\
13 & 49.55 & 49.24 & 48.94 & 48.53 & 48.45 & 47.41 & 44.72 \\
14 & 49.72 & 49.31 & 49.07 & 48.62 & 48.43 & 47.44 & 44.82 \\
15 & 49.51 & 49.13 & 49.01 & 48.62 & 48.47 & 47.54 & 44.95 \\
\hline
\end{tabular}


Table E.2: Total annual cooling in $M W h$ for borehole lengths tested over 15 years, basis for Figure 7.2

\begin{tabular}{lrrrrrrr}
\hline Year & $80 \%$ & $90 \%$ & $95 \%$ & $100 \%$ & $105 \%$ & $110 \%$ & $120 \%$ \\
\hline 1 & 258.0 & 259.3 & 259.5 & 259.4 & 259.3 & 259.5 & 259.5 \\
2 & 253.8 & 259.2 & 259.4 & 259.2 & 259.4 & 259.5 & 259.5 \\
3 & 250.2 & 258.4 & 259.2 & 259.4 & 259.5 & 259.5 & 259.2 \\
4 & 247.6 & 257.6 & 259.1 & 259.4 & 259.3 & 259.4 & 259.4 \\
5 & 246.4 & 256.9 & 258.8 & 259.5 & 259.5 & 259.4 & 259.6 \\
6 & 244.6 & 255.8 & 258.4 & 259.4 & 259.3 & 259.4 & 259.4 \\
7 & 243.0 & 255.1 & 258.2 & 259.2 & 259.3 & 259.4 & 259.3 \\
8 & 241.7 & 254.2 & 257.6 & 259.1 & 259.3 & 259.3 & 259.5 \\
9 & 240.8 & 253.6 & 257.4 & 259.0 & 259.3 & 259.4 & 259.4 \\
10 & 240.0 & 252.8 & 257.1 & 258.9 & 259.3 & 259.3 & 259.3 \\
11 & 238.9 & 252.1 & 256.7 & 258.7 & 259.3 & 259.3 & 259.4 \\
12 & 238.3 & 251.6 & 256.3 & 258.7 & 259.1 & 259.3 & 259.3 \\
13 & 237.9 & 251.3 & 256.1 & 258.7 & 259.5 & 259.6 & 259.7 \\
14 & 237.3 & 250.7 & 255.6 & 258.4 & 259.1 & 259.4 & 259.4 \\
15 & 236.7 & 250.2 & 255.3 & 258.2 & 259.1 & 259.2 & 259.4 \\
\hline
\end{tabular}

Table E.3: Total annual time in hours that zone 1 air temperature is above cooling set point for the bore lengths tested, basis for Figure 7.3

\begin{tabular}{lrrrrrrr}
\hline Year & $80 \%$ & $90 \%$ & $95 \%$ & $100 \%$ & $105 \%$ & $110 \%$ & $120 \%$ \\
\hline 1 & 205 & 0 & 0 & 0 & 0 & 0 & 0 \\
2 & 669 & 41 & 0 & 0 & 0 & 0 & 0 \\
3 & 1063 & 134 & 14 & 0 & 0 & 0 & 0 \\
4 & 1205 & 252 & 47 & 0 & 0 & 0 & 0 \\
5 & 1436 & 340 & 87 & 2 & 0 & 0 & 0 \\
6 & 1508 & 435 & 142 & 10 & 0 & 0 & 0 \\
7 & 1612 & 539 & 191 & 27 & 0 & 0 & 0 \\
8 & 1702 & 608 & 228 & 37 & 0 & 0 & 0 \\
9 & 1768 & 709 & 286 & 48 & 0 & 0 & 0 \\
10 & 1861 & 783 & 326 & 63 & 2 & 0 & 0 \\
11 & 1805 & 852 & 369 & 76 & 6 & 0 & 0 \\
12 & 1838 & 905 & 392 & 103 & 12 & 0 & 0 \\
13 & 1842 & 949 & 434 & 129 & 20 & 0 & 0 \\
14 & 1926 & 993 & 479 & 154 & 23 & 0 & 0 \\
15 & 1925 & 1069 & 531 & 167 & 33 & 0 & 0 \\
\hline
\end{tabular}


Table E.4: Average annual energy efficiency ratio (EER) in Btu/Wh for the bore lengths tested, basis for Figure 7.4

\begin{tabular}{lrrrrrrr}
\hline Year & $80 \%$ & $90 \%$ & $95 \%$ & $100 \%$ & $105 \%$ & $110 \%$ & $120 \%$ \\
\hline 1 & 10.52 & 11.01 & 11.22 & 11.43 & 11.61 & 11.79 & 12.11 \\
2 & 9.90 & 10.36 & 10.62 & 10.84 & 11.03 & 11.24 & 11.61 \\
3 & 9.67 & 10.07 & 10.31 & 10.57 & 10.75 & 10.98 & 11.35 \\
4 & 9.56 & 9.93 & 10.13 & 10.38 & 10.61 & 10.81 & 11.20 \\
5 & 9.44 & 9.74 & 10.02 & 10.28 & 10.47 & 10.68 & 11.09 \\
6 & 9.51 & 9.83 & 9.96 & 10.26 & 10.47 & 10.68 & 11.05 \\
7 & 9.41 & 9.74 & 9.95 & 10.12 & 10.34 & 10.62 & 10.93 \\
8 & 9.42 & 9.71 & 9.83 & 10.10 & 10.31 & 10.49 & 10.90 \\
9 & 9.37 & 9.63 & 9.83 & 10.00 & 10.25 & 10.47 & 10.86 \\
10 & 9.36 & 9.58 & 9.79 & 9.97 & 10.16 & 10.42 & 10.82 \\
11 & 9.27 & 9.56 & 9.74 & 9.96 & 10.11 & 10.33 & 10.73 \\
12 & 9.30 & 9.53 & 9.71 & 9.92 & 10.12 & 10.31 & 10.74 \\
13 & 9.18 & 9.43 & 9.59 & 9.77 & 9.96 & 10.20 & 10.60 \\
14 & 9.23 & 9.47 & 9.61 & 9.81 & 9.99 & 10.22 & 10.63 \\
15 & 9.22 & 9.47 & 9.60 & 9.77 & 9.97 & 10.20 & 10.59 \\
\hline
\end{tabular}

Table E.5: Total annual electricity use in $k W h$ for the bore lengths tested, basis for Figure 7.5

\begin{tabular}{lrrrrrrr}
\hline Year & $80 \%$ & $90 \%$ & $95 \%$ & $100 \%$ & $105 \%$ & $110 \%$ & $120 \%$ \\
\hline 1 & 10225 & 9609 & 9331 & 9068 & 8858 & 8658 & 8325 \\
2 & 10368 & 10001 & 9695 & 9388 & 9168 & 8927 & 8547 \\
3 & 10316 & 10202 & 9938 & 9622 & 9382 & 9121 & 8707 \\
4 & 10288 & 10310 & 10090 & 9775 & 9514 & 9254 & 8834 \\
5 & 10280 & 10374 & 10175 & 9890 & 9632 & 9360 & 8929 \\
6 & 10243 & 10391 & 10247 & 9981 & 9707 & 9433 & 8990 \\
7 & 10205 & 10406 & 10306 & 10054 & 9782 & 9505 & 9045 \\
8 & 10159 & 10403 & 10330 & 10105 & 9843 & 9557 & 9110 \\
9 & 10138 & 10404 & 10363 & 10150 & 9898 & 9614 & 9150 \\
10 & 10115 & 10398 & 10380 & 10183 & 9938 & 9652 & 9182 \\
11 & 10089 & 10385 & 10398 & 10220 & 9991 & 9698 & 9217 \\
12 & 10046 & 10366 & 10414 & 10251 & 10008 & 9727 & 9244 \\
13 & 10040 & 10364 & 10414 & 10280 & 10065 & 9763 & 9283 \\
14 & 10019 & 10340 & 10423 & 10298 & 10078 & 9789 & 9302 \\
15 & 10001 & 10333 & 10418 & 10317 & 10106 & 9809 & 9325 \\
\hline
\end{tabular}




\section{E.2 Borehole Layout and Spacing}

Table E.6: Total annual cooling in $M W h$ for the borehole configurations tested over 15 years, basis for Figure 7.7

\begin{tabular}{lrrrrrrrr}
\hline Year & $1 \times 4 \times 10$ & $1 \times 4 \times 15$ & $1 \times 4 \times 20$ & $1 \times 4 \times 25$ & $2 \times 2 \times 10$ & $2 \times 2 \times 15$ & $2 \times 2 \times 20$ & $2 \times 2 \times 25$ \\
\hline 1 & 259.4 & 259.4 & 259.4 & 259.3 & 259.2 & 259.4 & 259.5 & 259.4 \\
2 & 259.4 & 259.2 & 259.3 & 259.3 & 259.1 & 259.4 & 259.3 & 259.5 \\
3 & 259.2 & 259.4 & 259.4 & 259.4 & 258.0 & 259.3 & 259.4 & 259.3 \\
4 & 258.7 & 259.4 & 259.3 & 259.3 & 256.6 & 259.1 & 259.4 & 259.2 \\
5 & 258.4 & 259.5 & 259.4 & 259.4 & 255.5 & 259.1 & 259.5 & 259.5 \\
6 & 258.1 & 259.4 & 259.4 & 259.3 & 254.2 & 258.7 & 259.3 & 259.2 \\
7 & 257.4 & 259.2 & 259.2 & 259.3 & 253.2 & 258.3 & 259.2 & 259.2 \\
8 & 256.9 & 259.1 & 259.3 & 259.3 & 252.2 & 258.1 & 259.1 & 259.2 \\
9 & 256.4 & 259.0 & 259.2 & 259.2 & 251.5 & 257.9 & 259.1 & 259.4 \\
10 & 255.7 & 258.9 & 259.3 & 259.4 & 250.8 & 257.4 & 259.0 & 259.3 \\
11 & 255.4 & 258.7 & 259.4 & 259.3 & 250.0 & 257.2 & 258.8 & 259.3 \\
12 & 254.8 & 258.7 & 259.1 & 259.3 & 249.3 & 256.8 & 258.9 & 259.1 \\
13 & 254.8 & 258.7 & 259.5 & 259.5 & 248.8 & 256.7 & 259.0 & 259.5 \\
14 & 254.0 & 258.4 & 259.1 & 259.4 & 248.0 & 256.1 & 258.5 & 259.1 \\
15 & 253.7 & 258.2 & 259.4 & 259.4 & 248.2 & 255.8 & 258.5 & 259.1 \\
\hline
\end{tabular}


Table E.7: Total annual time in hours that zone 1 air temperature is above cooling set point for the borehole configurations tested, basis for Figure 7.8

\begin{tabular}{lrrrrrrrr}
\hline Year & $1 \times 4 \times 10$ & $1 \times 4 \times 15$ & $1 \times 4 \times 20$ & $1 \times 4 \times 25$ & $2 \times 2 \times 10$ & $2 \times 2 \times 15$ & $2 \times 2 \times 20$ & $2 \times 2 \times 25$ \\
\hline 1 & 0 & 0 & 0 & 0 & 0 & 0 & 0 & 0 \\
2 & 0 & 0 & 0 & 0 & 53 & 0 & 0 & 0 \\
3 & 27 & 0 & 0 & 0 & 185 & 1 & 0 & 0 \\
4 & 72 & 0 & 0 & 0 & 346 & 23 & 0 & 0 \\
5 & 135 & 2 & 0 & 0 & 466 & 50 & 0 & 0 \\
6 & 212 & 10 & 0 & 0 & 601 & 77 & 4 & 0 \\
7 & 268 & 27 & 0 & 0 & 714 & 129 & 15 & 0 \\
8 & 335 & 37 & 0 & 0 & 798 & 177 & 27 & 0 \\
9 & 380 & 48 & 2 & 0 & 925 & 220 & 37 & 2 \\
10 & 428 & 63 & 4 & 0 & 1004 & 259 & 51 & 7 \\
11 & 473 & 76 & 11 & 0 & 1055 & 290 & 69 & 14 \\
12 & 525 & 103 & 20 & 0 & 1115 & 334 & 89 & 20 \\
13 & 567 & 129 & 25 & 1 & 1121 & 353 & 101 & 28 \\
14 & 613 & 154 & 29 & 1 & 1168 & 393 & 120 & 34 \\
15 & 649 & 167 & 33 & 2 & 1263 & 424 & 140 & 44 \\
\hline
\end{tabular}

Table E.8: Average annual energy efficiency ratio (EER) in Btu/Wh for the borehole configurations tested, basis for Figure 7.9

\begin{tabular}{lrrrrrrrr}
\hline Year & $1 \times 4 \times 10$ & $1 \times 4 \times 15$ & $1 \times 4 \times 20$ & $1 \times 4 \times 25$ & $2 \times 2 \times 10$ & $2 \times 2 \times 15$ & $2 \times 2 \times 20$ & $2 \times 2 \times 25$ \\
\hline 1 & 9.31 & 9.56 & 9.68 & 9.75 & 9.11 & 9.46 & 9.65 & 9.74 \\
2 & 8.74 & 9.07 & 9.26 & 9.37 & 8.48 & 8.88 & 9.14 & 9.29 \\
3 & 8.48 & 8.82 & 9.04 & 9.18 & 8.21 & 8.61 & 8.87 & 9.05 \\
4 & 8.31 & 8.66 & 8.89 & 9.04 & 8.07 & 8.43 & 8.69 & 8.88 \\
5 & 8.21 & 8.55 & 8.78 & 8.93 & 7.98 & 8.31 & 8.57 & 8.75 \\
6 & 8.12 & 8.46 & 8.70 & 8.85 & 7.92 & 8.22 & 8.48 & 8.67 \\
7 & 8.06 & 8.38 & 8.63 & 8.79 & 7.88 & 8.15 & 8.40 & 8.59 \\
8 & 8.00 & 8.33 & 8.57 & 8.73 & 7.84 & 8.10 & 8.33 & 8.52 \\
9 & 7.97 & 8.28 & 8.52 & 8.68 & 7.81 & 8.05 & 8.29 & 8.47 \\
10 & 7.94 & 8.24 & 8.46 & 8.63 & 7.78 & 8.01 & 8.24 & 8.42 \\
11 & 7.91 & 8.20 & 8.43 & 8.59 & 7.76 & 7.98 & 8.21 & 8.38 \\
12 & 7.89 & 8.17 & 8.39 & 8.56 & 7.74 & 7.95 & 8.17 & 8.34 \\
13 & 7.86 & 8.14 & 8.37 & 8.53 & 7.72 & 7.93 & 8.14 & 8.31 \\
14 & 7.85 & 8.11 & 8.32 & 8.49 & 7.70 & 7.91 & 8.11 & 8.28 \\
15 & 7.84 & 8.08 & 8.30 & 8.47 & 7.69 & 7.89 & 8.08 & 8.25 \\
\hline
\end{tabular}


Table E.9: Total annual electricity use in $k W h$ for the borehole configurations tested, basis for Figure 7.10

\begin{tabular}{lrrrrrrrr}
\hline Year & $1 \times 4 \times 10$ & $1 \times 4 \times 15$ & $1 \times 4 \times 20$ & $1 \times 4 \times 25$ & $2 \times 2 \times 10$ & $2 \times 2 \times 15$ & $2 \times 2 \times 20$ & $2 \times 2 \times 25$ \\
\hline 1 & 9293 & 9068 & 8962 & 8909 & 9478 & 9159 & 8992 & 8911 \\
2 & 9712 & 9388 & 9217 & 9122 & 9975 & 9570 & 9321 & 9198 \\
3 & 9964 & 9622 & 9418 & 9293 & 10186 & 9832 & 9573 & 9406 \\
4 & 10119 & 9775 & 9551 & 9413 & 10248 & 9998 & 9746 & 9556 \\
5 & 10199 & 9890 & 9661 & 9510 & 10272 & 10116 & 9862 & 9680 \\
6 & 10276 & 9981 & 9736 & 9586 & 10278 & 10197 & 9951 & 9756 \\
7 & 10300 & 10054 & 9801 & 9644 & 10273 & 10252 & 10027 & 9838 \\
8 & 10325 & 10105 & 9862 & 9703 & 10123 & 10293 & 10093 & 9905 \\
9 & 10341 & 10150 & 9914 & 9743 & 10081 & 10328 & 10141 & 9965 \\
10 & 10337 & 10183 & 9964 & 9801 & 10051 & 10342 & 10189 & 10006 \\
11 & 10356 & 10220 & 10008 & 9838 & 9990 & 10364 & 10216 & 10056 \\
12 & 10337 & 10251 & 10031 & 9873 & 9965 & 10381 & 10257 & 10087 \\
13 & 10357 & 10280 & 10072 & 9904 & 9957 & 10387 & 10290 & 10135 \\
14 & 10341 & 10298 & 10103 & 9942 & 9944 & 10394 & 10305 & 10152 \\
15 & 10339 & 10317 & 10139 & 9957 & 9956 & 10389 & 10331 & 10178 \\
\hline
\end{tabular}




\section{E.3 Ground Temperature}

Table E.10: Mean yearly heat pump entrance temperature in ${ }^{\circ} C$, based on hourly averages, basis for Figure 7.13

\begin{tabular}{lrrrrrrr}
\hline Year & 17.3 & 18.8 & 20.3 & 21.8 & 23.3 & 24.8 & 25.3 \\
\hline 1 & 25.91 & 27.44 & 28.98 & 30.45 & 32.01 & 33.58 & 35.13 \\
2 & 27.77 & 29.30 & 30.86 & 32.37 & 33.95 & 35.54 & 37.12 \\
3 & 28.65 & 30.18 & 31.77 & 33.32 & 34.88 & 36.47 & 38.33 \\
4 & 29.27 & 30.81 & 32.36 & 33.94 & 35.53 & 37.09 & 39.12 \\
5 & 29.71 & 31.29 & 32.88 & 34.43 & 36.02 & 37.58 & 39.60 \\
6 & 30.03 & 31.58 & 33.18 & 34.74 & 36.39 & 37.86 & 39.89 \\
7 & 30.29 & 31.87 & 33.45 & 35.05 & 36.65 & 38.37 & 40.14 \\
8 & 30.55 & 32.12 & 33.68 & 35.35 & 36.89 & 38.79 & 41.74 \\
9 & 30.73 & 32.33 & 33.90 & 35.51 & 37.09 & 39.12 & 42.05 \\
10 & 30.92 & 32.49 & 34.08 & 35.71 & 37.29 & 39.34 & 42.24 \\
11 & 31.09 & 32.65 & 34.23 & 35.88 & 37.42 & 39.50 & 42.41 \\
12 & 31.25 & 32.78 & 34.37 & 36.00 & 37.57 & 39.64 & 42.51 \\
13 & 31.42 & 33.00 & 34.57 & 36.19 & 37.74 & 39.76 & 42.64 \\
14 & 31.49 & 33.10 & 34.67 & 36.24 & 37.80 & 39.82 & 42.71 \\
15 & 31.59 & 33.17 & 34.80 & 36.40 & 37.87 & 39.90 & 42.79 \\
\hline
\end{tabular}


Table E.11: Maximum yearly heat pump entrance temperature in ${ }^{\circ} C$, based on hourly averages, basis for Figure 7.14

\begin{tabular}{lrrrrrrr}
\hline Year & 17.3 & 18.8 & 20.3 & 21.8 & 23.3 & 24.8 & 25.3 \\
\hline 1 & 39.33 & 41.05 & 42.85 & 44.64 & 46.41 & 48.11 & 48.56 \\
2 & 41.00 & 42.84 & 44.59 & 46.48 & 48.07 & 48.60 & 49.07 \\
3 & 41.95 & 43.79 & 45.61 & 47.41 & 48.56 & 48.79 & 49.04 \\
4 & 42.65 & 44.47 & 46.21 & 47.98 & 48.61 & 48.95 & 49.28 \\
5 & 43.04 & 44.93 & 46.74 & 48.33 & 48.64 & 49.08 & 49.24 \\
6 & 43.46 & 45.36 & 47.12 & 48.55 & 48.65 & 49.01 & 49.27 \\
7 & 43.85 & 45.68 & 47.43 & 48.48 & 48.71 & 49.00 & 49.39 \\
8 & 44.08 & 45.90 & 47.79 & 48.64 & 49.29 & 49.08 & 49.60 \\
9 & 44.37 & 46.09 & 48.08 & 48.52 & 48.92 & 49.22 & 49.66 \\
10 & 44.59 & 46.39 & 48.13 & 48.61 & 48.96 & 49.33 & 49.66 \\
11 & 44.72 & 46.61 & 48.20 & 48.58 & 48.98 & 49.13 & 49.71 \\
12 & 44.87 & 46.77 & 48.29 & 48.65 & 49.04 & 49.14 & 49.65 \\
13 & 44.99 & 46.88 & 48.41 & 48.78 & 49.03 & 49.24 & 49.64 \\
14 & 45.07 & 46.90 & 48.57 & 48.72 & 49.04 & 49.28 & 49.64 \\
15 & 45.29 & 47.04 & 48.43 & 48.68 & 49.02 & 49.31 & 49.90 \\
\hline
\end{tabular}

Table E.12: Total annual cooling in $M W h$ for the ground temperatures tested over 15 years, basis for Figure 7.15

\begin{tabular}{lrrrrrrr}
\hline Year & 17.3 & 18.8 & 20.3 & 21.7 & 23.3 & 24.8 & 25.3 \\
\hline 1 & 259.6 & 259.5 & 259.5 & 259.3 & 259.4 & 259.2 & 258.8 \\
2 & 259.6 & 259.5 & 259.5 & 259.4 & 259.2 & 258.8 & 256.3 \\
3 & 259.4 & 259.4 & 259.3 & 259.3 & 259.2 & 257.7 & 253.4 \\
4 & 259.5 & 259.3 & 259.3 & 259.3 & 258.9 & 256.3 & 250.2 \\
5 & 259.5 & 259.6 & 259.4 & 259.3 & 258.5 & 255.3 & 248.5 \\
6 & 259.3 & 259.4 & 259.2 & 259.2 & 258.0 & 254.0 & 247.2 \\
7 & 259.5 & 259.4 & 259.3 & 259.1 & 257.5 & 252.9 & 245.9 \\
8 & 259.3 & 259.4 & 259.4 & 259.1 & 257.0 & 251.6 & 243.6 \\
9 & 259.4 & 259.4 & 259.3 & 259.0 & 256.6 & 250.5 & 242.0 \\
10 & 259.4 & 259.4 & 259.2 & 258.9 & 256.1 & 249.6 & 240.4 \\
11 & 259.5 & 259.4 & 259.2 & 258.9 & 255.7 & 248.9 & 239.0 \\
12 & 259.4 & 259.3 & 259.3 & 258.5 & 255.2 & 248.3 & 238.1 \\
13 & 259.7 & 259.7 & 259.7 & 258.6 & 255.2 & 247.7 & 237.7 \\
14 & 259.3 & 259.4 & 259.2 & 258.0 & 254.4 & 247.0 & 236.5 \\
15 & 259.4 & 259.5 & 259.2 & 257.9 & 254.1 & 246.9 & 235.7 \\
\hline
\end{tabular}


Table E.13: Total annual time in hours that zone 1 air temperature is above cooling set point for the ground temperatures tested, basis for Figure 7.16

\begin{tabular}{lrrrrrrr}
\hline Year & 17.3 & 18.8 & 20.3 & 21.7 & 23.3 & 24.8 & 25.3 \\
\hline 1 & 0 & 0 & 0 & 0 & 0 & 0 & 70 \\
2 & 0 & 0 & 0 & 0 & 0 & 70 & 378 \\
3 & 0 & 0 & 0 & 0 & 29 & 226 & 702 \\
4 & 0 & 0 & 0 & 0 & 71 & 355 & 1000 \\
5 & 0 & 0 & 0 & 5 & 125 & 495 & 1224 \\
6 & 0 & 0 & 0 & 16 & 194 & 622 & 1362 \\
7 & 0 & 0 & 0 & 37 & 252 & 756 & 1398 \\
8 & 0 & 0 & 0 & 49 & 299 & 860 & 1621 \\
9 & 0 & 0 & 0 & 68 & 343 & 981 & 1795 \\
10 & 0 & 0 & 1 & 83 & 401 & 1110 & 1814 \\
11 & 0 & 0 & 2 & 108 & 442 & 1184 & 1766 \\
12 & 0 & 0 & 6 & 135 & 497 & 1229 & 1825 \\
13 & 0 & 0 & 6 & 154 & 550 & 1246 & 1861 \\
14 & 0 & 0 & 13 & 176 & 587 & 1273 & 1896 \\
15 & 0 & 0 & 20 & 192 & 625 & 1363 & 1935 \\
\hline
\end{tabular}

Table E.14: Average annual energy efficiency ratio (EER) in Btu/Wh for the ground temperatures tested, basis for Figure 7.17

\begin{tabular}{lrrrrrrr}
\hline Year & 17.3 & 18.8 & 20.3 & 21.7 & 23.3 & 24.8 & 25.3 \\
\hline 1 & 10.96 & 10.46 & 9.98 & 9.53 & 9.08 & 8.67 & 8.28 \\
2 & 10.42 & 9.94 & 9.48 & 9.03 & 8.62 & 8.23 & 7.92 \\
3 & 10.16 & 9.68 & 9.21 & 8.79 & 8.39 & 8.04 & 7.78 \\
4 & 9.97 & 9.50 & 9.05 & 8.63 & 8.24 & 7.92 & 7.72 \\
5 & 9.84 & 9.38 & 8.93 & 8.52 & 8.14 & 7.84 & 7.67 \\
6 & 9.74 & 9.28 & 8.84 & 8.43 & 8.06 & 7.79 & 7.64 \\
7 & 9.66 & 9.20 & 8.76 & 8.36 & 8.01 & 7.77 & 7.60 \\
8 & 9.59 & 9.13 & 8.70 & 8.29 & 7.96 & 7.73 & 7.53 \\
9 & 9.53 & 9.06 & 8.65 & 8.25 & 7.92 & 7.71 & 7.52 \\
10 & 9.47 & 9.02 & 8.60 & 8.20 & 7.88 & 7.70 & 7.50 \\
11 & 9.42 & 8.98 & 8.55 & 8.16 & 7.86 & 7.69 & 7.49 \\
12 & 9.38 & 8.94 & 8.52 & 8.13 & 7.84 & 7.67 & 7.49 \\
13 & 9.34 & 8.90 & 8.48 & 8.11 & 7.83 & 7.65 & 7.48 \\
14 & 9.31 & 8.86 & 8.45 & 8.08 & 7.81 & 7.64 & 7.47 \\
15 & 9.28 & 8.84 & 8.41 & 8.05 & 7.79 & 7.63 & 7.47 \\
\hline
\end{tabular}


Table E.15: Total annual electricity use in $k W h$ for the ground temperatures tested, basis for Figure 7.18

\begin{tabular}{lrrrrrrr}
\hline Year & 17.3 & 18.8 & 20.3 & 21.7 & 23.3 & 24.8 & 25.3 \\
\hline 1 & 8106 & 8415 & 8744 & 9088 & 9469 & 9855 & 10222 \\
2 & 8353 & 8685 & 9051 & 9428 & 9815 & 10192 & 10389 \\
3 & 8528 & 8883 & 9263 & 9654 & 10047 & 10340 & 10202 \\
4 & 8661 & 9024 & 9403 & 9808 & 10189 & 10393 & 10023 \\
5 & 8754 & 9129 & 9515 & 9915 & 10269 & 10407 & 9995 \\
6 & 8831 & 9208 & 9600 & 10006 & 10331 & 10405 & 9981 \\
7 & 8902 & 9279 & 9679 & 10074 & 10364 & 10203 & 9973 \\
8 & 8953 & 9337 & 9733 & 10144 & 10377 & 10100 & 9431 \\
9 & 9001 & 9395 & 9788 & 10182 & 10402 & 10042 & 9375 \\
10 & 9045 & 9434 & 9835 & 10227 & 10418 & 10009 & 9335 \\
11 & 9088 & 9473 & 9878 & 10262 & 10424 & 9994 & 9302 \\
12 & 9120 & 9507 & 9915 & 10285 & 10423 & 9991 & 9269 \\
13 & 9161 & 9555 & 9966 & 10302 & 10418 & 9982 & 9263 \\
14 & 9174 & 9578 & 9986 & 10312 & 10406 & 9968 & 9231 \\
15 & 9211 & 9606 & 10018 & 10334 & 10408 & 9974 & 9201 \\
\hline
\end{tabular}




\section{E.4 Grout Conductivity}

Table E.16: Mean yearly heat pump entrance temperature in ${ }^{\circ} C$, based on hourly averages, basis for Figure 7.19

\begin{tabular}{llllll}
\hline Year & 0.500 & 0.744 & 1.000 & 1.333 & 1.500 \\
\hline 1 & 31.37 & 30.38 & 29.81 & 29.45 & 29.32 \\
2 & 33.31 & 32.26 & 31.69 & 31.30 & 31.19 \\
3 & 34.23 & 33.21 & 32.64 & 32.19 & 32.09 \\
4 & 34.87 & 33.80 & 33.21 & 32.81 & 32.68 \\
5 & 35.36 & 34.28 & 33.69 & 33.29 & 33.13 \\
6 & 35.61 & 34.62 & 34.08 & 33.60 & 33.46 \\
7 & 35.87 & 34.96 & 34.35 & 33.88 & 33.79 \\
8 & 36.13 & 35.17 & 34.58 & 34.13 & 33.96 \\
9 & 36.27 & 35.36 & 34.77 & 34.31 & 34.19 \\
10 & 36.40 & 35.52 & 34.95 & 34.53 & 34.43 \\
11 & 36.55 & 35.69 & 35.17 & 34.72 & 34.61 \\
12 & 36.68 & 35.84 & 35.31 & 34.91 & 34.73 \\
13 & 36.87 & 36.07 & 35.53 & 35.10 & 34.95 \\
14 & 36.87 & 36.10 & 35.59 & 35.19 & 35.04 \\
15 & 37.01 & 36.26 & 35.71 & 35.28 & 35.14 \\
\hline
\end{tabular}


Table E.17: Maximum yearly heat pump entrance temperature in ${ }^{\circ} C$, based on hourly averages, basis for Figure 7.20

\begin{tabular}{llllll}
\hline Year & 0.500 & 0.744 & 1.000 & 1.333 & 1.500 \\
\hline 1 & 47.55 & 44.51 & 42.86 & 41.70 & 41.30 \\
2 & 48.63 & 46.25 & 44.62 & 43.44 & 42.97 \\
3 & 48.62 & 47.31 & 45.55 & 44.40 & 43.94 \\
4 & 48.86 & 47.95 & 46.36 & 45.04 & 44.60 \\
5 & 48.85 & 48.28 & 46.74 & 45.52 & 45.10 \\
6 & 48.91 & 48.32 & 47.13 & 45.89 & 45.46 \\
7 & 48.94 & 48.50 & 47.44 & 46.25 & 45.78 \\
8 & 48.92 & 48.49 & 47.78 & 46.49 & 46.08 \\
9 & 48.97 & 48.61 & 47.95 & 46.77 & 46.27 \\
10 & 49.04 & 48.62 & 48.05 & 46.97 & 46.47 \\
11 & 48.96 & 48.55 & 48.25 & 47.11 & 46.69 \\
12 & 49.19 & 48.55 & 48.29 & 47.35 & 46.85 \\
13 & 48.99 & 48.53 & 48.31 & 47.56 & 46.99 \\
14 & 48.96 & 48.62 & 48.51 & 47.57 & 47.17 \\
15 & 49.10 & 48.62 & 48.38 & 47.74 & 47.24 \\
\hline
\end{tabular}

Table E.18: Total annual cooling in $M W h$ for the grout conductivities tested over 15 years, basis for Figure 7.21

\begin{tabular}{llllll}
\hline Year & 0.500 & 0.744 & 1.000 & 1.333 & 1.500 \\
\hline 1 & 259.3 & 259.4 & 259.4 & 259.5 & 259.5 \\
2 & 259.1 & 259.2 & 259.3 & 259.5 & 259.4 \\
3 & 258.9 & 259.4 & 259.3 & 259.4 & 259.2 \\
4 & 258.2 & 259.4 & 259.4 & 259.3 & 259.4 \\
5 & 257.7 & 259.5 & 259.4 & 259.4 & 259.4 \\
6 & 257.0 & 259.4 & 259.2 & 259.3 & 259.3 \\
7 & 256.5 & 259.2 & 259.3 & 259.3 & 259.3 \\
8 & 256.0 & 259.1 & 259.3 & 259.3 & 259.3 \\
9 & 255.3 & 259.0 & 259.4 & 259.4 & 259.3 \\
10 & 255.0 & 258.9 & 259.3 & 259.4 & 259.2 \\
11 & 254.3 & 258.7 & 259.3 & 259.4 & 259.4 \\
12 & 253.9 & 258.7 & 259.2 & 259.2 & 259.4 \\
13 & 253.8 & 258.7 & 259.6 & 259.6 & 259.7 \\
14 & 253.0 & 258.4 & 259.2 & 259.3 & 259.4 \\
15 & 252.6 & 258.2 & 259.1 & 259.3 & 259.2 \\
\hline
\end{tabular}


Table E.19: Total annual time in hours that zone 1 air temperature is above cooling set point for the grout conductivities tested, basis for Figure 7.22

\begin{tabular}{lrrrrr}
\hline Year & 0.500 & 0.744 & 1.000 & 1.333 & 1.500 \\
\hline 1 & 0 & 0 & 0 & 0 & 0 \\
2 & 23 & 0 & 0 & 0 & 0 \\
3 & 84 & 0 & 0 & 0 & 0 \\
4 & 169 & 0 & 0 & 0 & 0 \\
5 & 242 & 2 & 0 & 0 & 0 \\
6 & 306 & 10 & 0 & 0 & 0 \\
7 & 365 & 27 & 0 & 0 & 0 \\
8 & 437 & 37 & 0 & 0 & 0 \\
9 & 494 & 48 & 0 & 0 & 0 \\
10 & 569 & 63 & 0 & 0 & 0 \\
11 & 617 & 76 & 3 & 0 & 0 \\
12 & 667 & 103 & 5 & 0 & 0 \\
13 & 730 & 129 & 14 & 0 & 0 \\
14 & 771 & 154 & 11 & 0 & 0 \\
15 & 796 & 167 & 18 & 0 & 0 \\
\hline
\end{tabular}

Table E.20: Average annual energy efficiency ratio (EER) in Btu/Wh for the grout conductivities tested, basis for Figure 7.23

\begin{tabular}{lrrrrr}
\hline Year & 0.500 & 0.744 & 1.000 & 1.333 & 1.500 \\
\hline 1 & 9.02 & 9.56 & 9.86 & 10.08 & 10.16 \\
2 & 8.56 & 9.07 & 9.36 & 9.58 & 9.65 \\
3 & 8.33 & 8.82 & 9.10 & 9.32 & 9.39 \\
4 & 8.19 & 8.66 & 8.95 & 9.15 & 9.22 \\
5 & 8.09 & 8.55 & 8.82 & 9.03 & 9.11 \\
6 & 8.03 & 8.46 & 8.72 & 8.94 & 9.02 \\
7 & 7.97 & 8.38 & 8.65 & 8.86 & 8.93 \\
8 & 7.93 & 8.33 & 8.59 & 8.80 & 8.87 \\
9 & 7.90 & 8.28 & 8.54 & 8.75 & 8.81 \\
10 & 7.87 & 8.24 & 8.49 & 8.69 & 8.76 \\
11 & 7.85 & 8.20 & 8.45 & 8.65 & 8.72 \\
12 & 7.83 & 8.17 & 8.41 & 8.61 & 8.68 \\
13 & 7.82 & 8.14 & 8.38 & 8.58 & 8.65 \\
14 & 7.80 & 8.11 & 8.34 & 8.54 & 8.61 \\
15 & 7.79 & 8.08 & 8.32 & 8.52 & 8.58 \\
\hline
\end{tabular}


Table E.21: Total annual electricity use in $k W h$ for the grout conductivities tested, basis for Figure 7.24

\begin{tabular}{lrrrrr}
\hline Year & 0.500 & 0.744 & 1.000 & 1.333 & 1.500 \\
\hline 1 & 9571 & 9068 & 8810 & 8636 & 8576 \\
2 & 9910 & 9388 & 9117 & 8928 & 8866 \\
3 & 10125 & 9622 & 9340 & 9136 & 9072 \\
4 & 10233 & 9775 & 9484 & 9283 & 9221 \\
5 & 10310 & 9890 & 9598 & 9391 & 9317 \\
6 & 10349 & 9981 & 9687 & 9475 & 9395 \\
7 & 10379 & 10054 & 9760 & 9545 & 9476 \\
8 & 10406 & 10105 & 9823 & 9604 & 9534 \\
9 & 10404 & 10150 & 9879 & 9654 & 9588 \\
10 & 10415 & 10183 & 9925 & 9708 & 9630 \\
11 & 10410 & 10220 & 9966 & 9753 & 9676 \\
12 & 10411 & 10251 & 10004 & 9786 & 9711 \\
13 & 10416 & 10280 & 10050 & 9825 & 9755 \\
14 & 10398 & 10298 & 10072 & 9852 & 9783 \\
15 & 10402 & 10317 & 10090 & 9884 & 9806 \\
\hline
\end{tabular}




\section{Bibliography}

ANSI/ASHRAE 140-200\%: Standard method of test for the evaluation of building energy analysis computer programs. ASHRAE - American Society of Heating, Refrigerating and Air-Conditioning Engineers, 2007.

ClimateMaster. Tranquility 20 Single Stage Series Submittial Data. Climate Master, Inc., 7300 S.W. 44th Street Oklahoma City, OK 73179, June 2010.

U.S. Dept. of Energy. Residential electricity prices, August 2011 (cents/kwh), 2011a. URL http://www.eia.gov/state/state-energy-rankings.cfm? keyid=18\&orderid=1.

Cenk Yavuzturk. Modeling of Vertical Ground Loop Heat Exchangers for Ground Source Heat Pump Systems. PhD thesis, Oklahoma State University, December 1999.

U.S. Dept. of Energy. Types of geothermal heat pump systems, February 2011b. URL http://www.energysavers.gov/your_home/space_heating_ cooling/index.cfm/mytopic=12650.

ASHRAE 2009 Fundamentals HandBook. American Society of Heating, Refrigerating and Air-Conditioning Engineers, 1791 Tullie Cir, N.E., Atlanta, GA 30329, 2009. 
Long Fu, Guoliang Ding, and Chunlu Zhang. Dynamic simulation of airto-water dual-mode heat pump with screw compressor. Applied Thermal Engineering, 23:1629-1645, 2003.

Thomas Ray Young. Development, verification, and design analysis of the borehole fluid thermal mass model for approximating short term borehole thermal response. Master's thesis, Oklahoma State University, 2004.

Jeffrey D. Spitler. GLHEPRO - a design tool for commercial building ground loop heat exchangers. In Proceedings of the Fourth International Heat Pumps in Cold Climates Conference, Aylmer, Québec, August 2000.

Xiaowei Xu. Simulation and Optimal Control of Hybrid Ground Source Heat Pump Systems. PhD thesis, Oklahoma State University, December 2007.

American Society of Petroleum Geologists. Geological maps of texas. University Press, 1974.

U.S. Dept. of Energy. 2010 U.S. buildings energy end-use splits, by fuel type (quadrillion btu), March 2011c. URL http://buildingsdatabook.eren. doe.gov/TableView . aspx?table=1.1.5.

U.S. Dept. of Energy. Buildings share of U.S. primary energy consumption (percent), March 2011d. URL http://buildingsdatabook. eren.doe . gov/TableView . aspx?table=1.1.3. 
D.E. Fisher and S.J. Rees. Modeling ground source heat pump systems in a building energy simulation program (EnergyPlus). In 9th International IBPSA Conference, pages 311-318, Montreal, Canada, August 2005.

Patrick J. Hughes. Geothermal (ground-source) heat pumps: Market status, barriers to adoption, and actions to overcome barriers. Technical report, Oak Ridge National Laboratory, 2008.

Optimal Energy, Inc. Natural resources defense council and ceres, power to save: An alternative path to meet electric needs in texas, 2007. URL www. ceres.org/pub/docs/Ceres_texas_power.pdf.

U.S. Dept. of Energy. Energy consumption in texas homes, August 2008. URL apps1.eere.energy.gov/states/residential.cfm/state=TX.

John W. Lund, Derek H. Freeston, and Tonya L. Boyd. Direct utilization of geothermal energy 2010 worldwide review. Geothermics, 40:159-180, 2011.

Mike Hammond. Meeting, Nov 2011.

Siddharth Balasubramanian. Supplemental heat rejection in ground source heat pumps for residential houses in texas and other semi-arid regions. Master's thesis, The University of Texas at Austin, 2011.

Drury B. Crawley, Linda K. Lawrie, Frederick C. Winkelmann, W.F. Buhl, Y. Joe Huang, Curtis O. Pedersen, Richard K. Strand, Richard J. Liesen, Daniel E. Fisher, Michael J. Witte, and Jason Glazer. Energyplus: creating a 
new-generation building energy simulation program. Energy and Buildings, 33:319-331, 2001.

Drury B. Crawley, Jon W. Hand, Michael Kummert, and Brent T. Griffith. Contrasting the capabilities of building energy performance simulation programs. Building and Environment, 43:661-673, 2008.

Martin de Wit. Heat air and moisture model for building and systems evaluation. Technical report, Eindhoven: Technische Universiteit, Eindhoven, The Netherlands, 2006.

James J. Hirsch. equest v3 - overview. Technical report, Energy Design Resources, 2009.

Volume 1: DOE-2.2 Basics Manual. Lawrence Berkeley National Labs \& James J Hirsch \& Associates, 2004.

U.S. Dept. of Energy. Energy plus graphical user interfaces, March 2011e. URL http://apps1.eere.energy.gov/buildings/energyplus/ ep_interfaces.cfm.

Arunachalam Murugappan. Implementing ground source heat pump and ground loop heat exchanger models in EnergyPlus simulation environment. Master's thesis, Oklahoma State University, 2002.

Matthew J. Duffy, Marion Hiller, David E. Bradley, Werner Keilholz, and Jeff W. Thornton. TRNSYS - features and functionalitity for building simulation 2009 conference. In Building Simulation. IBPSA, July 2009. 
Mathworks. Simulink-simulation and model-based design, 2011. URL http: //www . mathworks. com/products/simulink/.

Yu Chen, Nils P. Halm, Eckhard A. Groll, and James E. Braun. Mathematical modeling of scroll compressors - part I: compression process modeling. International Journal of Refrigeration, 25:731-750, 2002a.

Yu Chen, Nils P. Halm, James E. Braun, and Eckhard A. Groll. Mathematical modeling of scroll compressors - part II: overall scroll compressor modeling. International Journal of Refrigeration, 25:751-764, 2002b.

Baolong Wang, Xianting Li, and Wenxing Shi. A general geometrical model of scroll compressors based on discretional initial angles of involute. International Journal of Refrigeration, 28:958-966, 2005.

John Judge and Reinhard Radermacher. A heat exchanger model for mixtures and pure refrigerant cycle simulations. International Journal of Refrigeration, 20(4):244-255, 1997.

O. Garca-Valladaresa, C.D. Perez-Segarrab, and J. Rigola. Numerical simulation of double-pipe condensers and evaporators. International Journal of Refrigeration, 27:656-670, 2004.

Eric Winandy, Claudio Saavedra O, and Jean Lebrun. Experimental analysis and simplified modelling of a hermetic scroll refrigeration compressor. Applied Thermal Engineering, 22:107-120, 2002. 
S. K. Fischer and C. K. Rice. The Oak Ridge heat pump models: I. a steadystate computer design model for air-to-air heat pumps. Technical report, Oak Ridge National Laboratory, 1983.

Alex H. W. Lee and J. W. Jones. Analytical model of a residential desuperheater. Applied Energy, 57(4):271-285, 1997.

Arturo Pacheco-Vega, Mihir Sen, K. T. Yang, and Rodney L. McClain. Neural network analysis of fin-tube refrigerating heat exchanger with limited experimental data. International Journal of Heat and Mass Transfer, 44: 763-770, 2001.

Jeffrey D Spitler and James Cullin. Misconceptions regarding design of groundsource heat pump systems. In Proceedings of the World Renewable Energy Congress, 2008.

WaterFurnace. Legend Series Specification Catalog. WaterFurnace International, Inc., 9000 Conservation Way Fort Wayne, IN 46809, June 2010.

Philip Schmidt, Derek Baker, Ofodike Ezekoye, and John Howell. Thermodynamics: An Integrated Learning System. Wiley, 2006.

U.S. Dept. of Commerce,Weather Bureau. Relative humidity and dew point table. http://www.wrh.noaa.gov/sto/rh0-500.pdf.

Man-Hoe Kim and Clark W. Bullard. Dynamic charateristics of a R-410a split air-conditioning system. International Journal of Refrigeration, 24:652-659, 2001. 
David R. Tree and Bruce W. Weiss. Two time constant modeling approach for residential heat pumps. In American Control Conference, pages 276-281, Boston, MA, USA, 1985.

G Hellström. Ground heat storage: Thermal analyses of duct storage systems. Sweden: Department of Mathematical Physics University of Lund, 1991.

S. P. Rottmayer, W. A. Beckman, and J. W. Mitchell. Simulation of a single vertical $\mathrm{u}$-tube ground heat exchanger in an infinite medium. ASHRAE Transactions, 103(3):651-659, 1997.

H Y Zeng, N R Diao, and Z H Fang. Efficiency of vertical geothermal heat exchangers in ground source heat pump systems. Thermal Science, 12(1): 77-81, 2003.

J Bennet, J Claesson, and G Hellström. Multipole method to compute the conductive heat flows to and between pipes in a composite cylinder. University of Lund, Department of Building Technology and Mathematical Physics. Lund, Sweden, 1987.

L. R. Ingersoll and H. J. Plass. Theory of the ground pipe heat source for the heat pump. Heating, Piping $\&$ Air Conditioning, pages 119-12, June 1948.

H S Carslaw and J C Jaeger. Conduction of heat in solids. Claremore Press, Oxford UK, 1946.

L. R. Ingersoll, O J Zobel, and A C Ingersoll. Heat conduction with engineering, geological, and other applications. McGraw-Hill, New York, 1954. 
S P Kavanaugh. Simulation and experimental verification of vertical groundcoupled heat pump systems. PhD thesis, Oklahoma State University, Stillwater, Oklahoma, 1985.

Y Gu and D L O'Neal. Development of equivalent diameter expression for vertical u-tubes used in ground-coupled heat pumps. ASHRAE Transactions, 104(2):347-355, 1998.

M K Dobson, D L O'Neal, and W Aldred. Modified analytical method for simulating cyclic operation of vertical u-tube ground-coupled heat pumps. In Proceedings of the 1995 ASME/JSME/JSES International Solar Energy Conference, pages 69-76, March 1995.

Per Eskillson. Thermal Analysis of Heat Extraction Boreholes. PhD thesis, University of Lund, 1987.

N. K. Muraya, D. L. O'Neal, and W. M. Heffington. Thermal interference of adjacent legs in a vertical u-tube heat exchanger for a ground-coupled heat pump. ASHRAE Transactions, 102(2):12-21, 1996.

T. Kohl and R. J. Hopkirk. "FRACTure" a simulation code for forced fluid flow and transport in fractured, porrous rock. Geothermics, 24(3), 1995.

T. Kohl, R. Brenni, and W. Eugester. System performance of a deep borehole heat exchanger. geothermics. Geothermics, 31:687-708, 2002.

Kristin Field Michael Deru, Daniel Studer, Kyle Benne, Brent Griffith, and Paul Torcellini. U.S. Department of Energy commercial reference building 
models of the national building stock. Technical report, National Renewable Energy Laboratory, February 2011.

Dennis L O'Neal, Jose Gonzalez, and William ALdred. A simplified procedure for sizing vertical ground coupled heat pump heat exchangers for residences in texas. Technical report, Energy Systems Laboratory, Texas A\&M University, 1994. 